Portland State University

PDXScholar

Spring 6-3-2013

\title{
Forming a New Art in the Pacific Northwest: Studio Glass in the Puget Sound Region, 1970-2003
}

Marianne Ryder

Portland State University

Follow this and additional works at: https://pdxscholar.library.pdx.edu/open_access_etds

Part of the Art Practice Commons, Fine Arts Commons, and the Urban Studies and Planning Commons

Let us know how access to this document benefits you.

\section{Recommended Citation}

Ryder, Marianne, "Forming a New Art in the Pacific Northwest: Studio Glass in the Puget Sound Region, 1970-2003" (2013). Dissertations and Theses. Paper 1096.

https://doi.org/10.15760/etd.1096

This Dissertation is brought to you for free and open access. It has been accepted for inclusion in Dissertations and Theses by an authorized administrator of PDXScholar. Please contact us if we can make this document more accessible: pdxscholar@pdx.edu. 
Forming a New Art in the Pacific Northwest:

Studio Glass in the Puget Sound Region, 1970-2003

\author{
by \\ Marianne Ryder \\ requirements for the degree of \\ Doctor of Philosophy \\ in \\ Urban Studies
Dissertation Committee:
Carl Abbott, Chair
Karen Gibson
Ethan Seltzer
Sue Taylor
Katrine Barber

A dissertation submitted in partial fulfillment of the

Portland State University

2013 
C 2013 Marianne Ryder 


\begin{abstract}
The studio glass movement first arose in the United States in the early 1950s, and was characterized by practitioners who wanted to divorce glass from its industrial associations and promote it as a fine arts medium. This movement began in a few cities in the eastern part of the country, and in Los Angeles, but gradually emerged as an art form strongly associated with the city of Seattle and the Puget Sound region. This research studies the emergence and growth of the studio glass movement in the Puget Sound region from 1970 to 2003. It examines how glass artists and Seattle's urban elites interacted and worked separately to build the support structures and "art world" that provided learning and mentoring opportunities, workspaces, artistic validation, audience development, critical and financial support, which helped make glass a signature Puget Sound art form, and the role that artist social networks, social capital, cultural capital and cultural policy played in sustaining this community. In particular, the research seeks to explore the factors that nourish a new art form and artist community in second-tier cities that do not have the substantial cultural and economic support structures found in the "arts super cities" such as Los Angeles, New York City, and San Francisco. This study contributes to the growing literature on artist communities, and the roles played by social capital, cultural capital, urban growth coalitions and policy at different stages of community development. Results can assist policymakers in formulating policies that incorporate the arts as a form of community development.
\end{abstract}




\section{Acknowledgements}

I would like to express my sincere thanks to and acknowledge the following people who helped me throughout this process.

My committee chair, Carl Abbott, along with Karen Gibson, and Charles Heying, for encouraging me to explore my interests in artists and art in the context of urban studies.

The friends who supported and encouraged me wholeheartedly through this long and difficult process: Mary Ratcliff, Laura Freeman, Ellen Walkley, Christy Bailey, Leslie Young, Mi Dove, Kathy Schneller, Randy King, Jane Waddell, Ed Menze, Flora Dalglish, and Tony Daniel.

The members of the writing interest group, who listened to, discussed and challenged my ideas in ways that helped me during the writing of the many drafts that went into the making of this document: Arlie Adkins, Lisa Bates, Lauren Larin, Moriah McSharry McGrath, Gretchen Luhr, and Jackie Kohon.

I would also like to acknowledge the financial support I received from the Maurie Clark family, Nancy Chapman, and the PSU Laurels program, for which I am grateful. 


\section{Table of Contents}

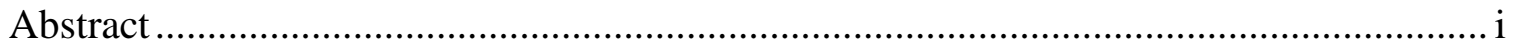

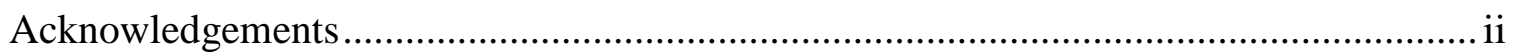

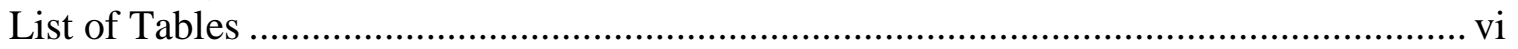

List of Figures ................................................................................................. vii

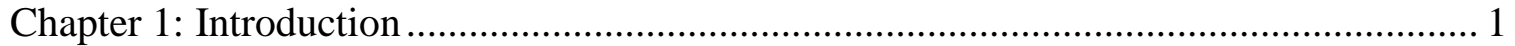

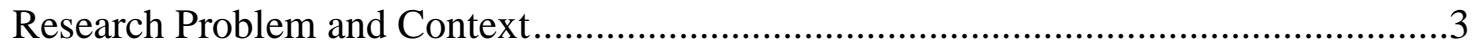

The Origins of the Studio Glass Movement in the United States ..................................5

The Case of Artists in the Puget Sound Region...........................................................

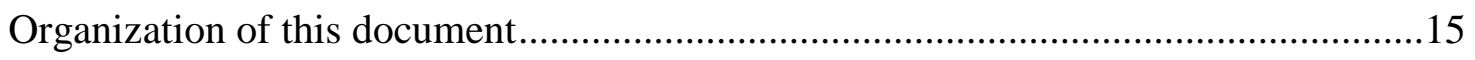

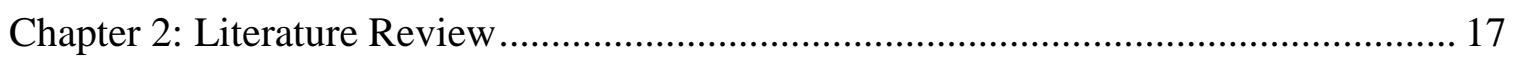

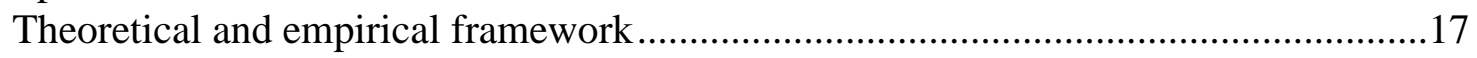

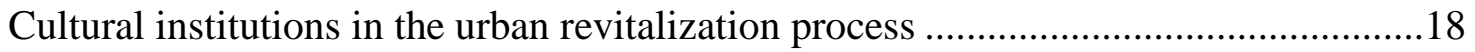

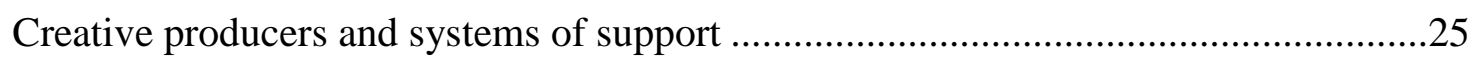

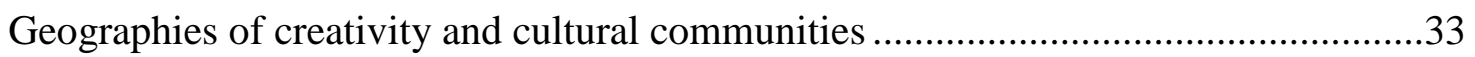

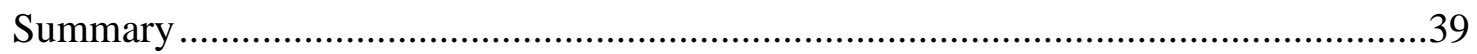

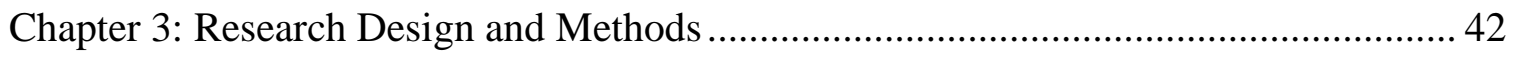

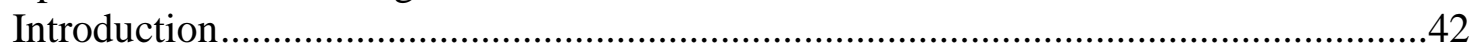

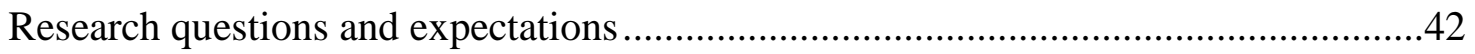

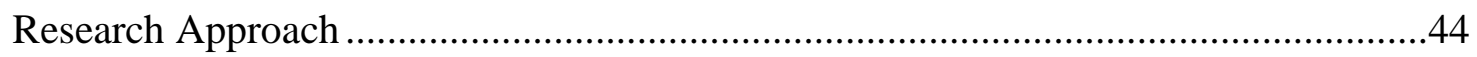

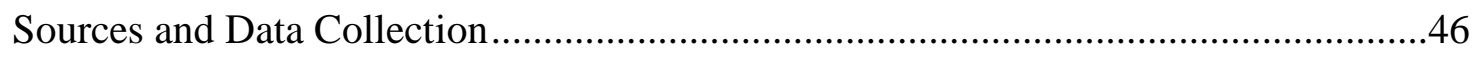

Chapter 4: Building a Cultural Infrastructure ..................................................... 50

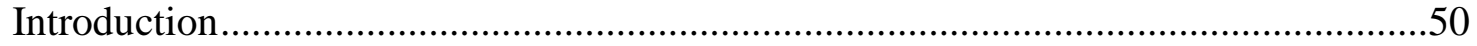

Postwar Seattle: escaping the esthetic dustbin....................................................51

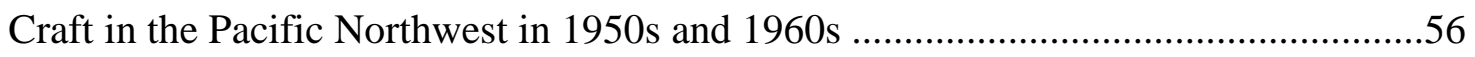

Anne Gould Hauberg and The Friends of Craft .................................................58

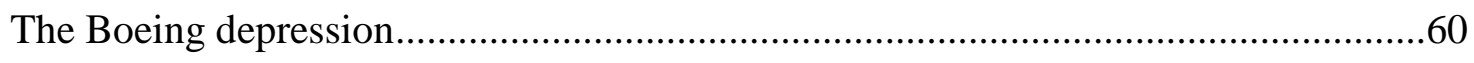

From the university to the studio, studio glass artists create places to work in Seattle.69

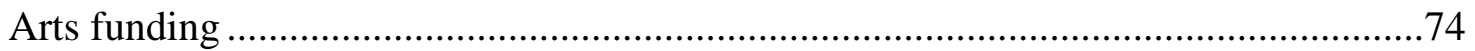

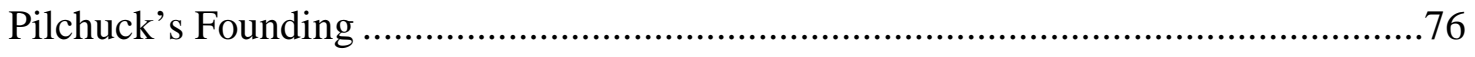

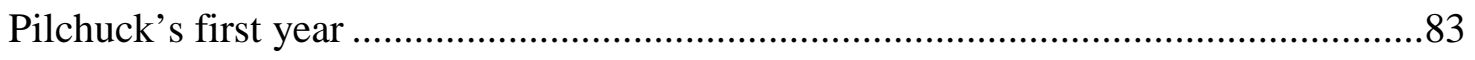

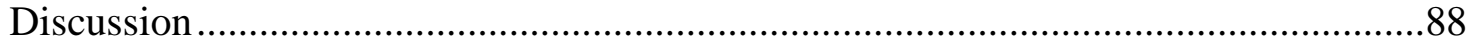

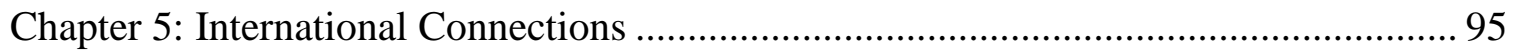

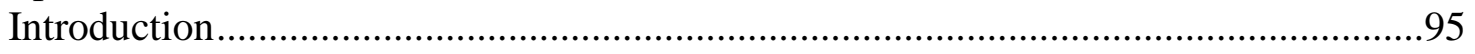


iv

The Seattle connection .....................................................................................96

Artist Exchanges - Germany, Sweden, and Italy .................................................98

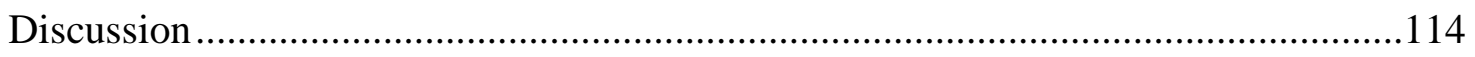

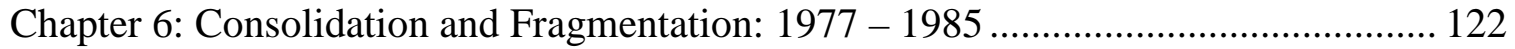

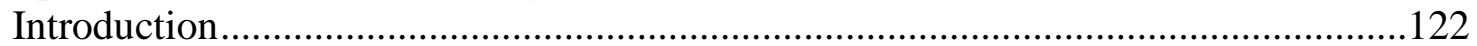

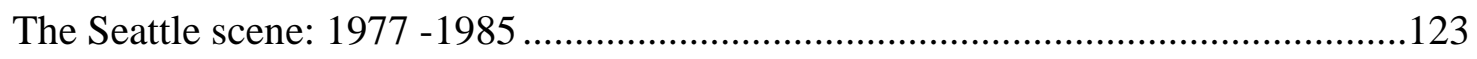

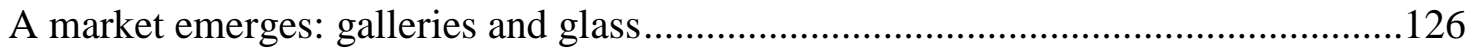

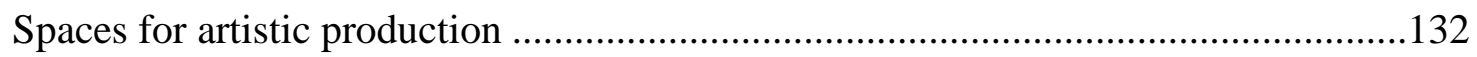

The Glass Eye and Benjamin Moore Studios .....................................................135

Pilchuck: Professionalizing the program; eliminating the "hippie elements" ............139

Pratt Fine Arts Center: A place to make art in the Central District ............................156

Glass Art Week: The 1981 Glass Art Society conference comes to Seattle................166

Chihuly's growing fame - The move to Seattle ...................................................168

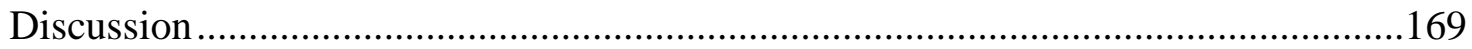

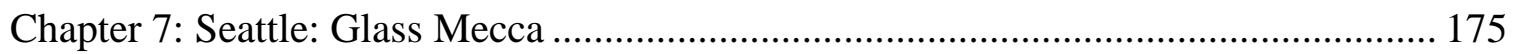

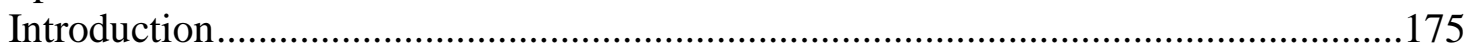

Seattle: The 1990s economy, demographics and cultural scene..............................175

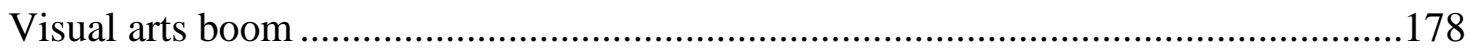

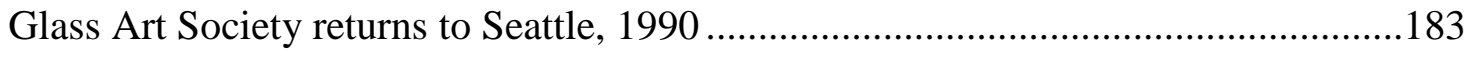

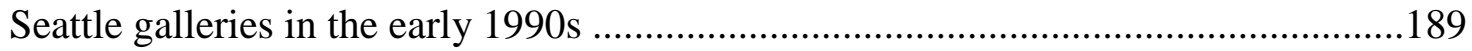

The Rise of public art - Art in Washington's public buildings, streets, and parks .....193

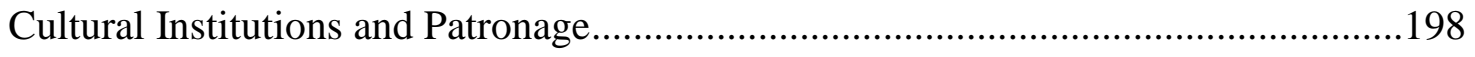

Chihuly in Seattle, Chihuly over Venice …......................................................203

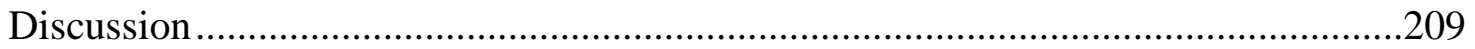

Chapter 8: Tacoma: From City of Destiny to City of Glass ....................................... 216

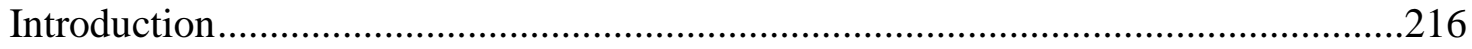

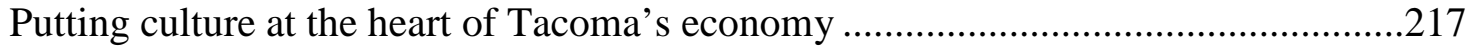

The Executive Council for a Greater Tacoma and the "Pierce County Mafia"..........220

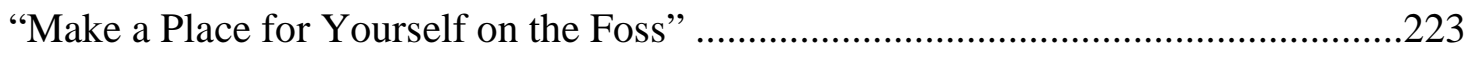

Plans for a Chihuly Glass Museum get underway ................................................227

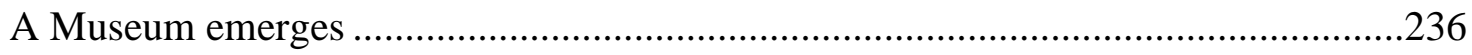




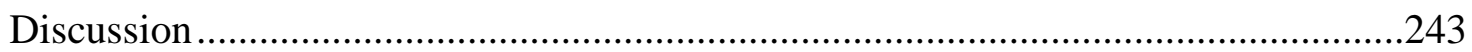

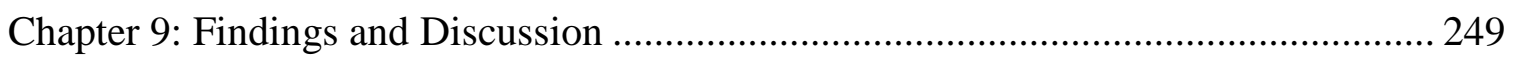

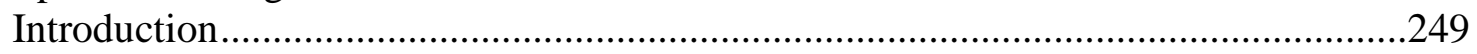

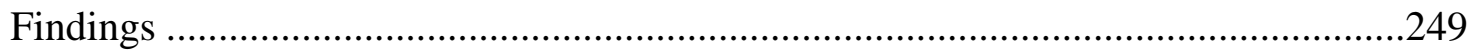

Possibilities for Future Research ......................................................................26

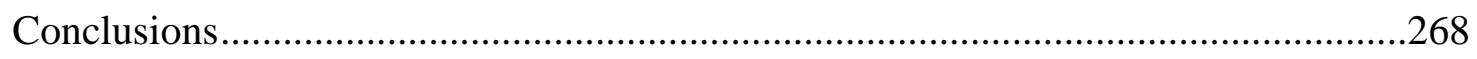

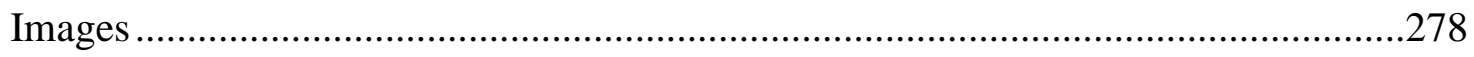

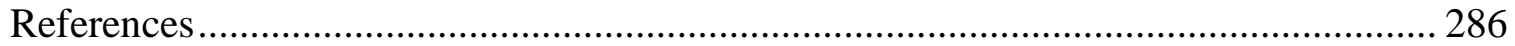

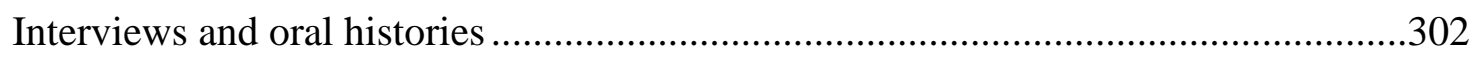

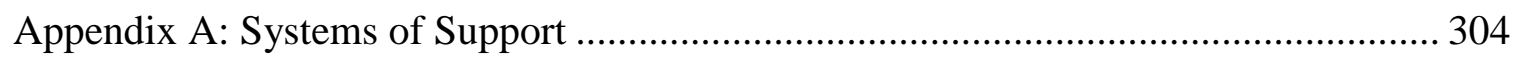

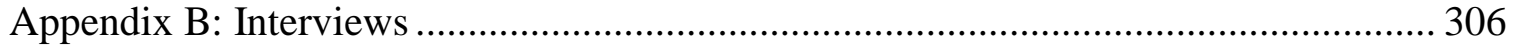

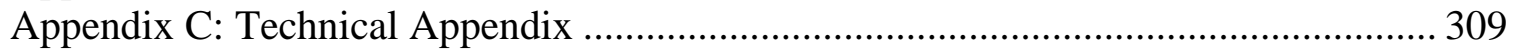




\section{List of Tables}

Table 4.1: College and university glass programs in the northwest, 1968-1978............. 67

Table 4.2. Independent glass studios and workshops - 1970s Seattle ........................... 73

Table 7.1: All artists in labor force by state of residence: 1970-1990. First five states by population, plus Washington State.

Table 8.1: Revitalization projects and strategies in Tacoma, $1985-2005$. ................... 245 


\section{List of Figures}

Figure 4.1. Cultural infrastructure of the Puget Sound region, 1971............................. 93

Figure 7.1. Cultural infrastructure of the Puget Sound region, 1980s - 1990s............... 182

Figure 9.1. Map of the Puget Sound Region Study Area........................................... 278

Figure 9.2. Downtown Seattle with selected glass studio locations ............................ 279

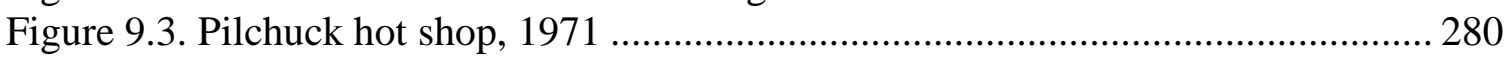

Figure 9.4. Tacoma Museum of Glass \& Chihuly Bridge of Glass, 2009 .................... 280

Figure 9.5. Pottery Booth at University District street fair, Seattle, 1971 ..................... 281

Figure 9.6. Glassblower Dale Chihuly blowing glass at Bellevue Arts Festival, 1968 .. 281 Figure 9.7. Pilchuck buildings by Bosworth: Hot shop with flat glass studio building in

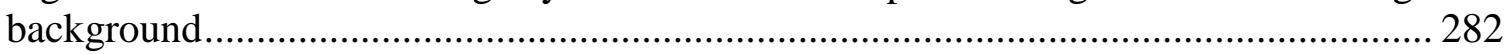

Figure 9.8. Ginny Ruffner teaching at Pilchuck, 1980s............................................. 282

Figure 9.9. 1990 Glass Art Society conference brochure cover, "Pacific Lip Rap"....... 283

Figure 9.10. 1990 Glass Art Society conference photos............................................... 284

Figure 9.11. Foss Waterway development plan, 1990s ............................................. 285 


\section{Chapter 1: Introduction}

In 1971 a summer art workshop took place in rural Washington, on a tree farm north of Seattle. The workshop was an experimental program in glassmaking, organized by Rhode Island School of Design professor Dale Chihuly and California College of the Arts professor Ruth Tamura. The property on which the workshop took place was owned by a couple of Seattle arts patrons, local businessman John H. Hauberg, and his wife, Anne Gould Hauberg. Nearly twenty years later, in 1990, the Glass Art Society, a professional association of glass artists founded in Corning, New York in 1971, moved its headquarters to Seattle, Washington, after holding its second conference in Seattle earlier that year. In 2002, the opening of the Tacoma Museum of Glass institutionalized glass as a Pacific Northwest regional art form.

The last 30 years of the twentieth century marked the strong emergence of studio glass as a new American art form, with a global reputation and practitioners. This emergence became strongly connected with the city of Seattle. However, other places in the region also benefited from this reputation. The reputation of the Northwest as a center for studio glass combined with the fact that its most famous practitioner, Dale Chihuly, was a native of Tacoma and a resident of Seattle since the mid 1980s were major factors in the area's reputation and the creation of the Tacoma Museum of Glass. Tacoma's decision to create a cultural district and to promote the city as a place for artists to live combines two strains of cultural development policy: the emphasis on cultural districts and cultural development in the 1990s and the more recent focus on artists as economic 
producers, and on attracting cultural creatives and the "creative class" (Florida, 2002, 2005; Markusen \& King, 2003, 2004; Markusen, 2005.)

The history of studio glass art in the Puget Sound provides the opportunity to examine the complex interaction among cultural policy, cultural development, social and creative capital, and artist community formation in the postindustrial city. This is a particularly rich topic area for several reasons. One, this geographic shift occurred at a time when Seattle was changing from a primarily working-class, industrial city to an international center of the new high-tech/knowledge economy. Like Seattle, the studio glass art movement represents an American form that emerged from industrial origins and gradually transformed itself to find a new image and audience. From the 1950s to the 1970s, glass art passed through the status of a factory-produced object to a craft form to the realm of the fine arts, while retaining connections to its earlier heritage. Secondly, glassmaking is communal and place-based by definition and practice. The studio glass art movement involved a group of artists who were bound together not only because of a shared interest in a particular form of art, but because of the collaborative working processes that glassmaking required, where skills and knowledge are shared among team members.

This study relies on research on the arts, economics of culture and urban development, urban growth coalitions, theories of social and cultural capital and social networks, which reflects the complexity of the position of the arts and artists in urban culture. The economic literature provides insight into the changing economic view of arts institutions and artists and their contributions to the urban and regional economy. Political economy, cultural capital, and urban growth coalition literature provides insight 
into the larger economic, social, and political forces that play into the goals of urban boosters and forms of support for artistic production and consumption. The literature on artist networks, social capital and systems of support for artistic production can illuminate the nature of artist community formation and the important roles played by social networks and Bourdieu's concepts of embodied, objectified, and institutionalized cultural capital (1986). This project provides an opportunity to examine the range of processes, policies, and actors that interact over the long term to create a vibrant artistic community, seen from an urbanist perspective.

\section{Research Problem and Context}

Artists in the United States and Europe have participated in many ways in shaping urban culture and place. As a group, artists have been seen as change agents, harbingers of redevelopment and gentrification, and also as important contributors to urban economies and vibrant urban culture. However, urban scholars have typically focused on the role of flagship cultural institutions in urban revitalization and economic development engines (DiMaggio, 1986; Zukin, 1982; Strom 2002, 2003; Miles \& Paddison, 2005), rather than the processes of artist community formation. More recently, some urban scholars have examined the roles of artists in neighborhood revitalization and gentrification (Lloyd, 2004; Zukin, 1982) and the role of urban neighborhoods in artist identity formation and cultural industry connections (Lloyd, 2004; Bain, 2003). Comparatively little research has been done on how artist communities develop and grow in cities that fall below the "global city" category in urban studies literature. In particular, what are the processes, cultural and social factors, and place characteristics that nourish a 
new art form and artist community in a city far from the "arts super cities" of Los Angeles, New York City, and San Francisco?

This research is a case study of the studio glass art community in the Puget Sound region. The research examines how glass crafters and Seattle's urban elites built the support structures and "art world" (Becker, 2008) that provided learning and mentoring opportunities, workspaces, artistic validation, audience development, critical and financial support, which helped make studio glass a signature Puget Sound art form. In particular, the research explores the role that artist social networks, social capital, cultural capital and cultural policy have played in building and sustaining this community over time.

The modern studio glass movement, which advocated the use of glass and glassmaking techniques as a fine art medium, began in the United States in the 1950s primarily in New York, Ohio, and California. The geographic center of the movement gradually shifted from its east coast origins to the Pacific Northwest, clustering most visibly in the Puget Sound region, with Seattle at its core. The popular narrative of the studio glass movement in the U.S. showcases its roots through tales of experimental work by a small group of founders who had great artistic ambitions though they lacked all but the most basic technical skills. According to this version of the movement's beginnings, it was this pioneering group's spirit of experimentation and willingness to share knowledge that helped produce strong, localized artist communities and networks with a common interest in the medium of glass. While this story is true, it is by no means the complete story. Over the past few years a more complex story of international interactions and connections has been acknowledged and spread primarily through 
exhibitions. The artists in the studio glass movement not only depended upon each other and drew together in particular places that provided the support systems they needed, but from the start they also realized the necessity to reach beyond their local communities to further their artistic goals.

The growth of the studio glass movement in the Seattle area during the period from the 1971 founding of Pilchuck (a world-renowned glassmaking school) in a rural area 50 miles outside Seattle, to the opening of the Tacoma Museum of Glass in 2002, is the focus of this study. During this era, a large number of studio glass artists came to the Pacific Northwest to study and settled, mostly in Seattle, leading eventually to the city's and region's reputation as an internationally known and respected center for art produced using studio glass techniques. The Puget Sound region's reputation as a center of glassmaking and glass art also contributed to the decision of policymakers, planners and business interests in Tacoma to support the formation of the Tacoma Museum of Glass as a flagship institution in a new waterfront cultural district developed for city's revitalization plan in the 1990 s.

This study contributes to the growing literature on artist communities, and the roles played by social capital, cultural capital, urban growth coalitions and policy at different stages of community development. Results can aid policymakers formulate policies that incorporate the arts as a form of community development.

\section{The Origins of the Studio Glass Movement in the United States}

The origins of the post World War II American studio glass movement closely associated with two people, Harvey Littleton and Dominick Labino, and two experimental glassmaking workshops in Toledo, Ohio. Littleton and Labino were key 
players in the first Toledo glassmaking workshop, hosted by the Toledo Museum of Art in Toledo, Ohio, in March of 1962. This Toledo workshop is widely considered the founding moment of the American studio glass movement, and Littleton himself was profoundly influential in shaping the initial movement.

The glassmaking industry in the U.S. became increasingly mechanized throughout the twentieth century, and the role of the individual glassmaker diminished. When American artists set out to work with glass, they had several issues to deal with before they could make progress in their artistic goals. One was the lack of teachers who knew how to work with glass; another was the lack of tools and materials that were suited to small-scale production of glass objects. Yet another was the inflexibility and unpredictability of glass as a medium. Without knowledge of production techniques and the chemical properties of glass, artists were frustrated by inconsistent results, or worse, no results at all.

Individual artists and craftspeople had been experimenting with reviving the art of glassmaking outside the factory setting, but it required an organized effort to turn these individual efforts into a movement. Harvey Littleton was a major force behind this effort and the first Toledo workshop was part of the strategy. Littleton was born in Corning, New York in 1922, the son of a physicist who worked for Corning Glass works. Littleton was expected to follow in his father's footsteps and become a physicist, but Littleton was more interested in the arts. In 1951, he graduated from Cranbrook Academy of Art with a Master's degree and took a full-time faculty position teaching ceramics in the University of Wisconsin Art Department. The second person associated with the Toledo workshop was Dominick Labino, who was president and director of research at Johns-Manville Fiber Glass Corporation in Ohio. Labino learned to blow glass earlier in his career and he 
practiced it "as an occasional hobby" (Lynn, 2004, p. 54). Labino's interests as a researcher were not confined to the experimental use of glass. He was also interested in developing new tools and processes that would help make glass an artistic medium for the individual studio artist. Labino and Littleton first met when Labino was taking evening classes at the Toledo Museum School of Art and Littleton was teaching there, and their shared interests in furthering the cause of glass as an artist medium was behind the Toledo workshops.

The first Toledo workshops focused on glassblowing. The Toledo Museum of Art provided the workspace, and some company glassblowers from Libbey Glass, a major commercial manufacturer, volunteered their skills to teach an audience comprising arts faculty from various universities, along with a few students (Lynn, 2004, p.54). Labino provided some experimental 475-type glass marbles that were melted for use in the first Toledo Workshop. The 475-type glass was developed as part of his research work at Johns-Manville.

Perhaps because of these technical challenges, studio glass in its early days tended to attract practitioners who were interested in the technical and scientific aspects of the material, like Labino. Many of the early studio glass artists, including Littleton, came to glass from a background in ceramics, in part because of the shared technical and aesthetic aspects of glass and ceramics. Although he was interested in working in glass from an early age, there were few resources at the time even for those who had strong industry connections. Although Littleton worked at Corning briefly during his student years, he did not pursue a career there. As Littleton remembers it: "So the problem was that all the books and everything said you couldn't blow glass by yourself. And I worked in the 
factory long enough to know that I was not a corporate person. I couldn't work that way. ... So I became a potter, finally" (Littleton, $2001^{1}$ ). Issues with the chemical properties of glass and characteristics required for making a fine-arts quality glass would continue to be a major concern, one that inspired new technical and artistic developments throughout the following decades.

In spite of the industrial connections of glass, workshop participants and their followers quickly moved to promote the artistic aims and character of the studio glass movement and disengage the medium from its industrial past. Toledo workshop participants returned to their studios and classrooms with a mission to promote glass as an artist medium. Although they were enthusiastic about working with glass, their efforts were limited by their lack of skill.

Littleton himself was less interested in teaching glassmaking skills than he was in securing a place for glass as a fine arts medium. His famous dictum "technique is cheap," underscored his belief that the artist's concept was more important than the material used. “As Littleton says: 'The 'Technique is Cheap' debate indicated we were not so involved in technique but with the result when you turned people loose with this responsive material. Studio glass is unified by material rather than by technique"" (Warmus, 1998). However, glass is a notoriously difficult medium to work with, and technical skills were necessary to develop an artistic work from conception to completion. These skills were not easy to acquire in the early days of studio glass.

However, the Toledo workshops and the educational materials that Littleton published expanded the limited technical knowledge of glass and attracted many students. After the

\footnotetext{
${ }^{1}$ Harvey Littleton, Oral history interview with Harvey K. Littleton, 2001, Mar. 15, Archives of American Art, Smithsonian Institution. Interview conducted by Joan Falconer Byrd.
} 
Toledo workshop Littleton returned to the University of Wisconsin and started the country's first glass program there. Other university faculty who attended the Toledo workshop did the same at their home institutions, and ensured that glass quickly established a place among university arts programs throughout the United States, at least for a time. The University of Wisconsin glass program was particularly influential, and its graduates include many who are associated with the Pacific Northwest. The most famous of these was Dale Chihuly, a Tacoma native who studied with Littleton at the University of Wisconsin in 1965. From there, Chihuly went on to start the glass program at the prestigious Rhode Island School of Design, and in 1971 he founded the Pilchuck Glass School outside Seattle, Washington.

\section{The Case of Artists in the Puget Sound Region}

Markusen and Johnson (2006) documented the importance of "artist centers" in supporting artist careers and building community in Minnesota, and Jeffri (2002) notes the importance of mentoring and apprenticeship in the careers of jazz musicians. Pilchuck certainly qualifies as an artist center that provided opportunities for formal apprenticeship, bonding among artists with similar interests, and mentoring opportunities for the growing glass artist community. The growth of college programs and of art programs in particular, as a result of the post-World War II GI Bill and other educational policies, had increased the number of arts programs at state universities in the west (see Table A.2); and several glassmaking programs in the area, including one at the University of Washington in Seattle. They provided formal learning opportunities and also teaching jobs for artists. 
The following sections briefly summarize the developments that the dissertation explores in depth.

Support for glass crafters and art forms initially came from Seattle civic and cultural elites who provided land and financial support for the Pilchuck Glass School, as a continued expression of their desire to support and promote regional art and culture as a form of civic boosterism. Seattle elites have a documented history of supporting cultural institutions as a way to promote the city and attract new residents and businesses downtown (Strom, 2003; Gibson; 2004), and supporting a group of artists practicing a new art form can be seen as an expression of this type of elite activity. Dale Chihuly, an art professor at the Rhode Island School of Design, applied for and received funding to run a summer glassmaking workshop in Washington during the summer of 1971. While searching for a suitable location, he was introduced to two wealthy Seattle arts patrons, Anne Gould Hauberg and John Hauberg. The Haubergs were long-time art collectors and Seattle boosters. Anne Gould Hauberg in particular was active in many Seattle nonprofit cultural and civic organizations. For example, she was active in the Municipal Art Commission, which was influential in establishing Seattle's cultural policies and arts agenda in the 1950s, and was a founder of the Committee of 33, an organization that was influential in rallying support for historic preservation activities in the 1960s and the preservation of Seattle's Pioneer Square in the 1970s. The Haubergs offered to let Chihuly run his glassmaking workshop on land they owned outside Seattle. They already had plans to create an art museum, cultural center, and upscale residential development on this land, and an arts workshop fit with these plans (Johns, 2005). Like the Boston 
elites who hoped to benefit socially and financially by starting a symphony (DiMaggio, 1986), the Haubergs actions also served a larger agenda.

Unlike the museum originally planned for the site, the glass workshop, which soon became the Pilchuck Glass School, was a place of artistic production and education, attracting not just tourists or cultural consumers, but cultural producers. Pilchuck operated as the sort of artist center identified by Markusen and Johnson (2006), providing access to learning and mentoring opportunities for a wide range of community members, bringing together amateurs with little arts or glass making experience; teachers, and accomplished artists across many disciplines. It was a place "where artists can learn, network, get and give feedback, exhibit, perform, and share space and equipment... these spaces not only serve artists but contribute to economic and community development in their respective regions" (p. 7). In their study, Markusen and Johnson hypothesize that artist centers are one of the reasons why smaller cities like Minneapolis-St. Paul, Seattle, Boston and Portland have been successful in promoting and sustaining artist communities, and Pilchuck had a tremendous influence on the growth of the glassmaking community in the region.

Participants in Pilchuck's programs came from many places, including the Puget Sound region. Those who were already residents of Seattle and the region came away with an appreciation for glassmaking, and many became supporters, collectors, or producers of studio glass art. And many who came from other places chose to stay in the region.

Pilchuck students, teachers and staff who arrived in the Puget Sound area in the 1970s found an abundant supply of low-priced housing and workspaces in Seattle, 
because of the population exodus that occurred during the local "Boeing depression" at this time. However, because of the economic downturn and the fact that this was a new art medium, artists found few opportunities to show or sell their work at first. Initial support came from other artists and from local colleges and universities who provided facilities, equipment and potential jobs for glass artists.

As the artist population grew, locally based artist networks developed, and the combination of artist networks, artist centers, patronage, and local cultural policy helped build multiple sources of support that made Seattle and the surrounding region a welcoming place for artists. Artist social networks were critical, and the presence of local gathering spots was also important for developing artist social networks and for fostering creative collaborations. Opportunities for formal and informal learning, inexpensive access to equipment and workspaces, opportunities for collaboration and networking among artists all help an artist community develop and grow, and these were important to the studio glass artists. Pilchuck was an important source of training, network building, and information about resources, other artists and the art scene. Other artist centers key to the development of studio glass in the region include the Pratt Fine Arts Center, and at least one commercial studio established in the 1970s, the Glass Eye. The Glass Eye was a commercial glassmaking studio and gallery that Miller (1991) identified as providing jobs and mentoring opportunities for local Seattle artists from 1977 when it was founded, through the end of the 1980s.

Early galleries such as the William Traver Gallery in Seattle played an important role in showing the work of glass artists and validating the art form (Frantz, 1989). Interactions among artists and the wider public provided by exhibitions, presentations, 
and educational programs for a general audience can also help build an audience for artists' work, and help support artists economically (Jackson, 2004; Markusen \& Johnson, 2006). A dense network of artists concentrated in one location can attract other artists who work in the same medium or have similar interests.

The activities of local social and business elites, including the Haubergs, created a bridge between the grassroots bonding activities of the artists in building their networks and the activities of Seattle's elite society, connecting these artists with cultural institutions, funding sources, and markets for their work. Local arts patrons who served on the boards of cultural organizations and arts funding organizations encouraged these nonprofits to support and exhibit the work of artists and crafters working in glass. Washington does not have a single, centralized cultural policy organization or actor, but it has a number of local, state, and regional arts agencies and supports the arts through a variety of measures. In 1961 it established the Washington State Arts Commission, becoming only the third state to have a state arts agency, along with New York and Utah (Schuster, 2003). The state established its first "Art in Public Places" program to fund public art, and also allocated public funding for arts programs at spaces such as the Centrum arts center in Port Townsend, Washington in 1974. Washington published its first arts plan in 1978, providing not only symbolic validation of the importance of the arts to the state, but also financial and other forms of resources to support local and regional artists and arts organizations.

Larger economic and cultural shifts included the transformation of Seattle from a manufacturing and shipping economy to a center for software development. During the 1980s and 1990s, Seattle's economy took off, fueled by software industry growth, along 
with Boeing's renewed success, and new industries like Microsoft, Starbucks, and Amazon.com. Along with this economic shift new forms of consumption and symbols of postmodern culture arose, including coffee, grunge music, and glass art. Lloyd (2004) and Florida $(2002,2005)$ suggest that urban bohemian neighborhoods in particular are attractive to a new creative class, which includes artists, accountants, web designers, and software engineers, among other occupations. During the 1990s, the city's population of young, college-educated residents grew. Some of these residents, most notably the "Microsoft millionaires," benefitted greatly from the region's growing wealth and began building and buying luxury residences in Seattle and its suburbs. As the population grew, neighborhoods that formerly provided affordable artist spaces, like Ballard, Belltown, Fremont, and Lake Union, began gentrifying (Sommer, 1998). What were the repercussions for artists in the increasingly expensive Seattle real estate market? The dot com boom of the 1990s placed financial pressures on the artist communities along with other lower-income Seattle neighborhood residents as real estate prices rose and rents increased in formerly affordable Seattle neighborhoods. Artists who were not financially successful were pushed to the margins of the cities or to more affordable places in the region or elsewhere. On the other hand, increased financial wealth in the area produced buyers with incomes for luxury goods, including fine arts and crafts objects, which provided artists with new audiences and new patrons.

In the 1990s, as its former industrial employers closed down, Tacoma began to plan a downtown revitalization, competing with Seattle to attract the creative classes and tourists. Revitalization strategies included the Thea Foss waterfront redevelopment, renovation of historic downtown buildings including Union Station, and a new downtown 
cultural district. Chihuly, a Tacoma native, approached Tacoma civic leaders with a proposal to start a glass museum, and was surprised by their immediate enthusiastic reaction. In addition to supporting new cultural organizations downtown, the city policymakers also developed plans to attract artists from Seattle to cheaper artist live/work spaces in Tacoma, engaging in typical urban rebranding strategies as described by Eisinger (2000), Strom (2003), and Miles and Paddison (2005), among others. Tacoma engaged in an attempt to claim the title of glass art capital from Seattle, and in doing so, helped strengthen the public brand of the Puget Sound as the center of studio glass art production in the United States.

\section{Organization of this document}

The basic organization of the document is chronological with some overlapping sections where the major topic reached across the chronology of individual chapters. Each chapter explores the processes and context of specific events in each decade between 1970 and 2003 to better understand the development of the studio glass community in the Puget Sound region.

Chapter one presents the background and context for this research, and provides a brief history of the studio glass movement in the United States. Chapter two presents the literature and theory upon which the research approach is based. Chapter three describes the research design and methods used to explore the research topic.

Chapter four focuses on the early 1970s and introduces the basic setting for the beginnings of the studio glass movement in the region. It explores the social, and cultural and economic context of the city of Seattle, as the central location for the arts in the region, and introduces the original group of artists who were active in the studio glass 
movement in the city at that time. One of the main events for this chapter is the first year of the Pilchuck glass workshop, and the people and actions that resulted in the transformation of Pilchuck from a one-time workshop to a permanent fixture on the regional arts scene.

Chapter five examines the factors that brought European and American studio glass artists together over the decades, and details how the artist networks that resulted brought an international faculty to Pilchuck, and expanded the region's reputation as a center for studio glass education and production into the international sphere.

Chapter six turns again to the Puget Sound region, and focuses on the expansion of the studio glass artist community and cultural infrastructure between 1977 and 1985 . Chapter seven explores the claim by many in the studio glass community that Seattle had become the center of the studio glass world and had overtaken Venice as the center of art glass production.

Chapter eight examines the factors the resulted in the proposal of a glass art museum in Tacoma as part of the city's economic redevelopment campaign of the 1990s. Chapter nine presents and discusses the research findings and conclusions. 


\section{Chapter 2: Literature Review}

\section{Theoretical and empirical framework}

What are the roles of the arts and cultural activities in contributing to urban economic growth? Economists and arts administrators have been attempting to answer this question for decades with varied results. In looking at the literature on arts and culture-based development strategies, two basic approaches are evident. The first approach involves strategies and policies that emphasize arts and cultural institutions and promoted the creation of "big entertainment projects" (Eisinger, 2000), and the second approach promotes policies that emphasize smaller-scale activities, urban amenities, and creative producers, including artists. The institutional approaches that feature sports arenas, festival malls, or flagship cultural organizations are designed to bring visitors into central cities or to brand the city in the global arena. Smaller-scale and occupational strategies emphasize the importance of an educated, creative population, or attempt to delineate how artists contribute to urban prosperity and vitality, and how artists' locational choices affect urban neighborhoods. Both the institutional and the peoplefocused strategies are still promoted in varying combinations depending on the goals of the urban boosters, growth coalitions, and policymakers.

Rhetoric about the creative economy, the creative class, and creative cities is common in debates about city planning and economic development. "Culture is both a commodity and a public good, a base - though a troubling one - of economic growth, and means for framing the city" (Zukin, 1995, p. 113). In 1998, the New England Council, a group of business leaders and policymakers, began an initiative to study the economic 
impact of arts and culture in the region and to begin to promote arts and culture as a vital component of the economy. Their view of arts and culture as an industry cluster is one that informs much of the current policy for promoting arts and culture as a form of community economic development.

This literature review presents the major debates in the literature organized into the three categories described in the New England Council's discussion of the creative economy (The New England Council, 2000):

Cultural organizations and related strategies;

Creative producers (in this case, artists) and systems of support;

Geographies of creativity and cultural communities.

\section{Cultural institutions in the urban revitalization process}

Arts and culture activities have been linked with urban development and urban image making in the U.S. since at least the nineteenth century. Collaborations among business and cultural elites in support of cultural institutions are not new either. The Portland Art Museum, for example, was founded in 1893 by a group of prominent local businessmen who also paid for the first artworks, a collection of plaster reproductions of classical sculptures (MacColl, 1988, p. 313). Cultural institutions can help serve landbased business interests by helping create a positive city image, which can in turn attract urban investors and raise real estate values. Cultural elites benefit through an increase in their group's cultural capital and social prestige. The Boston Museum of Art was founded in the nineteenth century by a network of local elites known as the Boston Brahmins. While the motivation and control of the museum came from this group of cultural elites, 
the land for the museum was acquired through the efforts of a developer who was interested in increasing the value of nearby properties (DiMaggio, 1986, p. 202).

Nineteenth-century Brahmins created nonprofit organizations to consolidate their control over local cultural institutions that served their needs, even while they claimed to serve the public interest (DiMaggio, 1986). Contemporary cultural institutions have sometimes been accused of this same strategy, and when nonprofit cultural organizations become too closely allied with the interests of an elite group, the public interest that these institutions claim to serve can be difficult to identify. Strom (2003) places culture-led regeneration within a long historical tradition of urban boosterism but asserts that there has been a "reframing of cultural policies" to further the interests of a variety of stakeholders who hope to benefit from supporting and promoting arts and culture. Strom (1999) documents in detail the "urban arts coalition" partnerships and factors that produced the New Jersey Performing Arts Center (NJPAC) in Newark, and the revitalization of the surrounding neighborhoods. Strom describes the political economy of constructing high-culture institutions in city centers. In particular, arts institutions depend upon the same sort of urban infrastructure required by commercial interests and attract upper-income and elite population groups that business owners also seek to attract as customers. Cultural institutions also serve to promote the reputation and interests of urban elites along with the image of the city.

Public policy, politics, local politicians, and the changing nature of the urban economy over the past fifty years contributed to the processes of decentralization of jobs and housing, urban decline, and revitalization that have transformed the physical, cultural, and economic urban environment. These processes and actions resulted in 
widespread middle-class flight from the cities, abandoned and derelict housing, and vacant or underused industrial spaces while stranding populations of low-income people, particularly minorities, in inner-city neighborhoods with diminished job opportunities and services (Jackson, 1985; Massey \& Denton 1993; Medoff \& Sklar, 1994). During this era, participation in arts-related activities grew, and new arts and cultural institutions including art museums and performance centers were built in cities throughout the United States, often as part of urban renewal projects that were supposed to make cities more appealing to corporations and to the middle and upper classes. In 1954 the New York Times noted that the "city's cultural attractions, including 'the theatre, the opera, nightclubs"” attracted "corporate executives" to the city (Zukin, p. 109, 1995). Increased participation in and support for the arts in the 1950s and 1960s can be attributed to a combination of factors including the population increase, increased education levels and a rise in real income levels (Netzer, 1978).

With the rise of globalization, deindustrialization, and the new economic emphasis on media and knowledge-based industries since the 1970s, arts and culture continue to play highly visible roles in various economic and community development strategies aimed at revitalizing cities throughout the world. To thrive in the global economy, cities must compete to attract not only the mobile capital of multinational financial, technological, and entertainment industries but also to attract the educated and mobile workers with the skills required by these service industries. Cities have developed a range of place-making strategies to compete for position in a global hierarchical network of cities since the 1980s (Stevenson, 2003). Cultural industries and activities have been identified not only as profitable economic sectors in their own rights, for 
example, through tourism and cultural events, but also as important factors in a strategy for place making and identity formation (Florida, 2001; Bulick et al., 2003; Stevenson, 2003; Judd \& Swanstrom, 2004). Many cities focused their entrepreneurial efforts on what Eisinger calls "building a city as an entertainment venue" (2000, p. 252). An urban development approach that emphasized the economic contributions of nonprofit cultural organizations and urban rebranding strategies created support for projects that emphasized the construction of flagship cultural institutions and central city cultural districts (Eisinger, 2000; Strom, 2001, 2003; Tepper, 2002; Evans, 2005; Miles \& Paddison, 2005). The arts were part of the package that comprised an urban quality of life that included factors like natural amenities, attractive and safe neighborhoods, and good schools.

Stevenson (2003) concludes that urban place-making strategies rely more upon symbolic and idealized notions of cities than they do upon people's experiences of actual cities. At one end of the place-making spectrum is the "Americanization" strategy, based on urban spectacles and shopping. These cities launch urban rebuilding projects, often near harbors or on former industrial sites identified as blighted or decayed, to create urban consumption zones that will attract tourists. Americanization-style projects are designed to create an image of a particular city as an attractive and fun place to visit and conduct business, and therefore are explicitly aimed at outsiders. The resulting spaces, such as Baltimore's Harbor Place, Boston's Quincy Market, or London’s Docklands, tend to have a sameness about them that marks them as global place-making spaces.

Stevenson places cities that use a set of development strategies focused on "local cultural identity, the promise of 'authenticity' and the idea of creativity" (Stevenson, 
2003, p. 94) at the opposite end of the spectrum. This strategy, identified as "cultural planning" or "Europeanization," is aimed at combining local cultural activities with social and economic policies to improve the quality of life for residents and foster economic development. Cultural planning is broadly designed to include cultural resources, activities, processes and products, anything that constitutes local culture as defined by urban residents. Despite the language of authenticity and creativity, the cultural planning strategy, in practice, looks similar to the Americanization strategy. Cultural planning tends to rely on image-creating projects, such as historical building renovations and new cultural events to draw people into the city, while investing little in the people who are already in the city.

As the number and scale of large-scale projects increased in the 1990s, critics began to question whether culture-based revitalization projects really delivered the promised benefits. Although the resulting cultural-based development projects sought to attract tourists and technical and managerial "creative class" members, these projects often did not have the hoped-for economic benefits. They not only reflect but can increase income and class inequalities. Even where they create jobs and stimulate additional businesses, the new businesses tend to create low-paid service jobs that benefit relatively few people in a limited area. Instead of generating revenue that benefits city residents, large-scale cultural revitalization projects can result in further straining city resources. In financially strapped cities, these development proposals can graphically represent the social inequality inherent in the choice of "stadiums for millionaires or schoolrooms for poor children" (Eisinger, 2000, p. 262). 
Diaz-Orueta \& Fainstein (2009) and Lehrer \& Laidley (2009) examined urban place-making strategies and noted that the American and European approaches were merging, and both became reliant upon arguments of economic growth for their justification. To these scholars, the new urban "mega projects" represent yet another twist on old-style urban renewal, revised to implement a range of approaches that forestall the accusations leveled against earlier projects that were destructive of urban neighborhoods and benefited only the elite property owners and urban real estate developers. These new projects promise "something for everyone" and include promises of sustainability, quality of life, and public access to waterfronts and other former industrial spaces remade as sites of recreation, tourism, and retail activities. Whatever the promises, in the end, public access is limited, developers and real estate investors benefit much more than others, and low-income ethnic minorities are displaced by these activities and their resulting economic revitalization, just as they were by earlier urban renewal strategies.

Growth machine theory provides one lens for understanding the context in which real estate developers, along with local politicians, use the arts as an urban redevelopment strategy (Logan \& Molotch, 1987). In looking at the actions of local elites, Logan and Molotch noted that it was important to understand that urban elite groups share a common interest in promoting growth. To these groups, "the city is a growth machine" (Logan \& Molotch, p. 199), and it can produce great wealth for those elites that can formulate and carry out strategies to foster growth. The key actors in growth coalitions are local business people with strong interests in land use issues, "place entrepreneurs" who typically have substantial investments in property and are in related businesses such as real estate development and financing (Heying, 1995). Groups with a lesser financial 
stake in land development that are also actors in urban growth coalitions include cultural organizations. These groups contribute to growth by bringing attention and possibly attracting new businesses to an area (Logan \& Molotch). Cultural organizations can be enthusiastic participants in growth coalitions as one way to attract new audiences and to enhance the reputation and status of their own organizations. In the 1990s, many cultural organizations embarked on ambitious new building projects that featured celebrity architects to generate excitement about their organization and attract new, young, upscale urban cultural consumers and tourists. Often the building was more of an attraction than the art it held, such as the Guggenheim Museum in Bilbao, designed by Frank Gehry, which opened in 1997 to worldwide publicity. In their 2012 study of the cultural building boom between 1994 and 2001, Woronkowicz et al. found that the average project cost was about \$21 million dollars, while the median cost was \$11 million. It was often difficult to evaluate the success or failure of the projects, because the goals of the organization were often commingled with larger economic development goals, and frequently there were no specific metrics developed to measure outcomes even within the organization that launched the project. Some of the cultural organizations did not have the resources to support operational costs, and the demand for new buildings did not always justify the decision to build (Woronkowicz et al, 2012). In some cases, the organizations were left with projects that went over budget, and buildings that were too expensive to maintain, straining the finances of the cultural institution long after the project was completed. 


\section{Creative producers and systems of support}

What is it that draws artists to urban areas and what is required to nurture artistic activity in cities? Several scholars have explored theories of artistic systems of support in search of the factors that sustain artistic careers and cultural development. Becker's influential sociological study of art worlds was among the first. Becker (1982/2008) analyzed the embedded cultural structures, systems, and networks required to support artistic production and consumption. Other scholars, including Galligan (2000), Heckathorn \& Jeffri (2003), Jackson \& Oliver (2003), Jackson (2004), Lloyd (2004), Seifert, Stern \& Zaman (2005), Markusen \& Johnson (2006), and Markusen (2006b) propose categories and frameworks for identifying and analyzing support systems for artists based on research that covers multiple cities and includes a diverse range of artistic producers. Goldbard (2006) noted the importance of a cultural infrastructure that provides a foundation for "cultural information and resources" (Goldbard, 2006, p. 73) to support creative expression in communities, while Landry (2000) describes the interaction of people and creative organizations in urban setting as the source for a "creative milieu" that fosters innovation (Landry, 2000, p. xv).

Art movements arise in different places and times, and are shaped by and responsive to the unique characteristics of the time and place of their formation. Similar factors act to support artists and new art forms in a particular place. These similarities can be identified to help support an emerging arts community in other places. Jackson (2004) took a place-based approach to analyzing systems of support for artistic production, and identified six "dimensions" that make a place hospitable for artists: "validation, demand/markets, material supports, training and professional development, 
communities/networks, and information" (Jackson, 2004, p. 45). Becker (2008) proposed that any particular form of cultural production consists of a complex structure of collaborative and cooperative networks of actors and social norms that together worked to sustain a particular form of art in a particular location and time. He called this extended support structure an "art world." Becker's discussion of the different components of an art world is compatible with Jackson's identification of the different dimensions of a support structure for artistic careers, with an additional focus on the extended networks and activities that help create the systems that support a specific art form.

Artist social networks are critical at all levels in forming and sustaining artistic careers and artistic communities. Some forms of art are more visibly dependent upon formal and informal support systems than others. For example, printmakers require access to expensive and heavy printing presses and potentially dangerous chemicals that limit their choice of workspaces and can limit their ability to produce work, especially in their early careers. Artists from all disciplines typically operate in an entrepreneurial fashion outside of institutional work settings. They rely upon social networks for access to educational and financial resources, information, marketing opportunities and shows, social support, and validation (Jackson \& Oliver, 2003; Jackson, 2004; Seifert, Stern, \& Zaman, 2005, Currid, 2007). The dense network of artists concentrated in one location can attract more artists because of the available resources, the benefits of belonging to a community of interest, or simply through a desire to be part of the scene. Once the presence of a local arts community becomes well known, it can also attract the attention 
of national culture industries, who keep an eye out for cultural activities to identify possible new trends ripe for mass-marketing (Lloyd, 2004).

As artists interact in social networks, they create bonds among other artists, patrons, organizations, and among people within the community and far afield. These connections can themselves become resources for future personal, professional or economic exchanges. Social capital is one way of referring to the resources that accrue through social and professional networks (Bourdieu, 1986, Coleman, 1988, Putnam, 2000). "Social capital is the wealth of the community measured not in economic but in human terms. Its currency is relationships, networks and local partnerships" (Goldbard, 2006, p245). The benefits that have been attributed to social capital include access to power, economic advantages, and enhanced civic health. Institutional actors can also be a part of the network through which group relationships are formed that can become the basis for group action beyond the organizational framework (Granovetter, 1973, Coleman, 1988). Putnam categorized capital as either bonding or bridging. Bonding social capital describes the relationships and networks within a group that strengthen group cohesiveness. Bridging social capital describes relationships that extend across group boundaries. Bridging social capital can connect a group to a more diverse range of people, knowledge, and other resources that are not accessible even through the collective resources of a cohesive group with an abundance of the more insular bonding capital. Bonding and bridging ties are conceptually similar to the idea of strong ties and weak ties that Granovetter (1973) described in his work on social networks. The strength of a tie is measured in four dimensions: "the amount of time, the emotional intensity, the intimacy (mutual confiding), and the reciprocal services which characterize the tie" (Granovetter, 
1973). Strong ties basically describe relationships within families, close friends, and some close-knit communities. Weak ties describe connections to casual acquaintances. An extremely cohesive community characterized by a majority of strong ties with few to no weak ties could be fragmented, and unable to successfully work across group boundaries. Bridging ties are important to promote mobility for individuals, for knowledge exchange between groups, and for being able to successfully organize to promote the community's interests in a larger public sphere (Granovetter, 1973).

In Florida's (2005) critique of social capital in Cities and the Creative Class he noted that creative types had limited enthusiasm toward traditional close-knit family, ethnic or neighborhood ties that Putnam (2000) found to be critical to a civic-minded community. According to Florida, bohemians preferred weak ties and more inclusive communities. Weak ties and looser social networks promoted innovation and creativity and therefore were more in tune with requirements for economic growth (Florida, 2005). But what does this say about artists as community members? While Florida's results might imply that artists are not rich in bonding capital, studies of artist networks show that artists' close personal and professional networks are important to their survival (Becker, 1982; Breitbart \& Stanton, 2007). In spite of the persistent myth of the artist as solitary genius, art making activities and art consumption are products of collective activities and systems of support (Becker, 1982, Goldbard, 2006). However, in part because of the strength of the solitary artist myth, artists tend to be ambivalent about the idea of networks (Heckathorn, D.D. \& Jeffri, J., 2003; Bain, 2003.). Artists seek out other artists, but also continue to feel the need to strike out on their own (Bain, 2003). 
Cheap housing and workspaces are clearly important, given most artists' low income levels. The need for large spaces, work processes that often require toxic chemicals (visual artists) or produce noises at hours or sound levels that might cause neighbors to complain (musicians, sculptors) might necessitate spaces in industrial-type neighborhoods or areas shared with other artists. Access to affordable living spaces and suitable workspaces, equipment, personal and professional networks and positive reinforcement of the artist's work are critical to developing an artist community; these resources are typically accessed through social networks.

Other studies have focused on particular urban neighborhoods, including Lloyd's (2004) study of Wicker Park, Chicago, and Bain's (2003) study of Toronto neighborhoods, which examined the construction of artistic identity, and the interrelationship among neo-bohemian indie artist culture and mass-market corporate cultural production. Stansell (2000) researched the formation of Greenwich Village as an American bohemian enclave that influenced the direction of modernism in early twentieth-century U.S. culture. Markusen and King (2003) conducted economic research examining artists' careers, locational choices and employment in Minneapolis-St. Paul to more clearly identify how artists contribute to the local and regional urban economy and what factors affect artists' locational choices.

Urban neighborhoods with particular characteristics play important roles in forming artist identities (Bain, 2003; Ley, 2003; Lloyd, 2004). Bain sees artists as “a social group with a distinctive occupational identity and a heightened awareness of the availability, regulation and character of urban space" (Bain, 2003, p. 305). Artists choose cities because of their energy, for cheap workspaces, proximity to other artists, sales 
venues and customers. The Toronto artists Bain interviewed seek out places with "an edge," marginal spaces "where difference and diversity can be effectively expressed" and where their identities as outsiders can be reinforced, sometimes as individuals, sometimes within a community of other artists. The "organic" nature of an obviously old or decaying structure can feed creativity and provide spaces to be transformed; improvisational space, "residual urban space ... that has not completed a transition from one use to another" allows artists to experiment and manipulate form and space to meet their needs (Bain, 2003, p. 313).

Borer's (2006) analytical categories of urban identities and lifestyles, and social interaction places and practices provides a useful lens for examining this aspect of urban revitalization, as does Gluck's study of the development of modernism and its connection with nineteenth-century Parisian culture (Gluck, 2005). It was in the nineteenth century that the image of the bohemian artist and the identification of artists as urban cultural revolutionaries who reject bourgeois capitalist culture were born. Rejection of middleclass culture and beliefs was expressed historically in nineteenth-century Paris through the choice of the arts as a career, as well as through clothing, behavior, attitudes, and the decision to live a life of voluntary poverty within an urban community (bohemia) of likeminded individualists, marginalized people, and societal outcasts (Gluck, 2005).

The term bohemia may have been coined to describe an artist neighborhood of mid-nineteenth century Paris but this phenomenon still exists today, and "neo-bohemias" can be found in cities across the U.S. and in Europe (Lloyd, 2004). Modern U.S. neobohemias typically thrive in decaying urban industrial centers. As suburban sprawl has proliferated, artists have also been drawn to some older city centers or nearby 
neighborhood downtown districts. The historic picture of the bohemian artist as an urban dweller with a distinct anti-bourgeois subculture has persisted, providing an enduring link between artist identity formation and an example of Borer's interaction places and practices. Questions about how artists develop distinct communities within urban neighborhoods derived from Borer's approach might include the following. What interactions between urban "places and practices" shape artist identities today? What are the processes that support the development of artist communities?

Lloyd (2004), and Markusen $(2003 ; 2004 ; 2006)$ examined why artists are drawn to certain cities, how they build creative communities, and analyzed the ways in which artistic activities feed into larger regional economic systems. While there are no definitive answers to these questions, research provides some insights into how artists function not only within the context of a given cultural economy framework, but as members of a community. Regardless of how they earned the largest proportion of their income, the artist residents in Lloyd's study of Wicker Park, Chicago identified themselves as artists, in part because of the neighborhood itself. In Wicker Park, the "symbolic and material resources" combined to support the formation of an artistic identity (Lloyd, 2004). The neighborhood formed an important part of their identity as artists, just as the artists' presence had shaped the identity of the neighborhood.

The Artistic Dividend (Markusen \& King, 2003), and The Artistic Dividend Revisited (Markusen, Schrock, \& Cameron, 2004), studied the ways in which artists as an occupational class contribute to local and regional economic development. These studies claimed that previous economic studies of the arts neglected the vital contributions that artistic activity makes to the regional economy because they failed to consider the full 
range of artists' economic activities. Traditional economic studies put arts organizations at the center of their analyses and in doing so missed the economic contributions that individual artists, writers, performers, photographers, etc. make to the regional economy. Rather than the standard economic approach to the arts that measures the spending habits and spillover effects from cultural consumption activities and tourist expenditures, the authors focused on the economic activities of artists (Markusen \& King, 2003, Markusen, Schrock, \& Cameron, 2004), bringing policymakers' attention to the economic potential of artistic production activities. Cultural policies developed in the late 1990s placed more emphasis on supporting artists as residents and attractors of other forms of economic development.

Cost of living is a significant factor in attracting and repelling artists. Increased rental costs in an area typically result in a significant out-migration of artists (Markusen, Bain, 2003; Breitbart \& Stanton, 2007). Artists who've been displaced several times may give up on larger cities, choosing instead small affordable cities that they feel are unlikely to become gentrified because they are too far from known cultural centers (Breitbart \& Stanton, 2007). Smaller cities, towns and rural areas with affordable real estate values also offer artists the possibility of purchasing their own homes and workspaces, thus avoiding displacement if and when gentrification follows them to their new home. And, small cities and rural communities are often willing to provide artists with special relocation benefits, with the hopes that a resident artist population can perhaps spur some of the very gentrification effects that the artists are trying to escape.

Artists sought out and continue to seek out urban neighborhoods and postindustrial spaces as valued locations for cultural production activities, while many 
politicians, policymakers and developers essentially abandon these same spaces as worthless. Artists comprise a small but constant supply of potential city residents and provide much of the initial labor and image-creation activities upon which culture-based urban revitalization strategies are based.

\section{Geographies of creativity and cultural communities}

The idea that arts institutions belonged in central urban districts was bolstered by studies such as Heilbrun (1992), who identified cultural activities as urban "central place functions." Heilbrun observed that medium and larger-size cities in general tend to have more arts organizations, but in larger cities with strong cultural activities, these activities are a larger proportion of the economy because the growth rate of arts tends to increase more in larger cities. Heilbrun evaluated empirical evidence to support his claim that large cities contain a "disproportionately large share of a nation's arts activity" (1992, p. 206). One of the reasons that the cultural economy produces this type of scaling characteristic is explained by the agglomeration effects. The presence of cultural activities draws similar industries to the same city to take advantage of the skilled labor force and other inputs, and the presence of a large cluster of arts-related employers draws additional labor and related industries. Agglomerations can also produce new players in the form of new firms or suppliers in a particular industry.

Heilbrun (1992) calculated location quotients for 50 largest U.S. metropolitan areas (SMSAs) according to the percentage of artists within the population. The location quotient is a method for calculating the relative concentration of a particular industry in a location. Heilbrun defined a location quotient to more precisely measure the proportional share of artistic activity for a city by dividing the percentage of artists (defined as the 
occupational categories of actors and directors, dancers, and musicians and composers, painters and sculptors) by the percentage of the population for each of the selected metropolitan areas. The location quotient that Heilbrun calculated for the metropolitan area groups indicated that the 10 largest metropolitan areas had a location quotient of two or more; the next 30 largest had a location quotient slightly more than one, and metropolitan areas below the largest 40 had a location quotient of less than one. A location quotient of one indicated that the industry share was roughly equal to what it would be if employment in that industry in the metropolitan area were proportional to employment in it nationally; a location quotient greater than one indicated a larger concentration of economic activity in that industry. New York City and Los Angeles had the largest concentration of visual artists per 10,000 people. Other cities with a significant artist presence were San Francisco, Seattle, and Washington, D.C. One interesting finding Heilbrun noted was that his data indicated that visual artists tended to be more "footloose" than performing artists with regards to settling in large cities. Performing artists tended to settle closer to performance venues, but visual artists (painters and sculptors in this case), could more easily live in places distant from the galleries and museums that displayed and sold their work. His article emphasizing the central place function of the arts noted: "some visual artists have moved to more congenial or less expensive locations" (Heilbrun, 1992, p. 209), indicating that visual artists did not have the same need for central places as did arts institutions and performing artists. This is a behavior that other researchers have noted in more recent research, and one that smaller cities have used to their advantage as they seek to attract artists to help build an arts or tourism-based economy. 
Cities such as Paris and New York have long been known as magnets for artists. Los Angeles, New York City and San Francisco can be considered as first tier “Arts Super Cities" because of the proportion of artists in the workforce (Markusen, Schrock, \& Cameron, 2004). Second-tier cities include the next eight cities with artist populations greater than the national norm by $10 \%$ in the aggregate. In 2000, these were Washington, D.C.; Seattle; Boston; Orange County; Minneapolis-St. Paul; San Diego; Miami; and Portland, Oregon (Markusen, Schrock, \& Cameron, 2004). Artists were attracted to the top three cities (Los Angeles, New York City, and San Francisco) for several reasons including financial support for the arts, the presence of tourism, opportunities to show/sell their work, spaces for artistic production and residence, and spaces where artists can gather and socialize or work with other artists (Markusen \& King). Other factors included "amenities, quality of life, and an active and nurturing arts community" (Markusen \& King, 2003, p. 3).

Artists tended to locate in certain urban areas and different regions attracted artists with different specialties, creating artistic agglomerations (Markusen \& King, 2003). Although the top three arts super cities were the leaders in all three artistic occupation groups - performing artists, visual artists, writers and musicians - Los Angeles had the most performing artists and musicians among its artist population, while New York had the most authors. In the second-tier cities, Boston had the most writers, while visual artists were more prevalent in Orange County and San Diego. Cities with below-average concentrations of artists included Atlanta, Dallas, Cleveland, and Pittsburgh. Over the past several decades, artists have been moving away from the largest cities in the studies and moving into second-tier cities (Markusen, Schrock, \& Cameron, 2004). Markusen 
and King noted that the existence and activity of "philanthropists, key arts

establishments, new arts venues, and outstanding educational institutions" and a "vibrant arts center" were important to attracting artists (Markusen \& King, p. 15, 2003). The cities they identified as second-tier may be able to compete with the top-tier cities in cost of living and livability. In general, artists who are just beginning their careers look for smaller cities where they can find cheaper living and working spaces, places to sell their work and supportive social networks (Markusen, Schrock, \& Cameron, 2004; Lloyd, 2004). Because their art does not produce enough income to support them, emerging artists also require access to nearby jobs with flexible working hours (Zukin, 1995; Lloyd, 2004).

The increased number of artists in cities can also be traced in part to the increase in middle-class migration to urban centers, and the increased number of artists in the general population, due to population increases and arts programs that were founded in the 1950s as a legacy of the post World War II GI Bill and subsequent policies expanding support for higher education. Ley traced the history of middle-class movement back into the city from its origins in the political unrest and youth counterculture of the 1960s. Widespread economic prosperity for the middle class resulted in "the distance from necessity" that Bourdieu regarded as a requirement for the cultivation of an aesthetic disposition (Ley, 2003, p. 253) and a continuing critique of and disrespect for the corporate world encouraged subsequent generations of youth to seek out similar urban venues and the "voluntary poverty" of the artist life and its rejection of capitalist values. However, the cultural capital of artists and the role that art plays in the marketplace (with 
or without the artist's support) links them to forces of capital that have "appropriated cultural production" and this includes the sites of artistic workspaces and homes.

One of the drawbacks for successful artist communities is that they can spur additional real estate development and gentrification. Often artists are seen as both agents of gentrification and as its victims. In the 1990s some cities were experiencing a sort of urban renaissance as middle-class professionals from the technology, creative industries and other new economy sectors settled in downtown areas and inner-city residential neighborhoods that provided the right mix of cultural amenities and quality of life (Florida, 2001; Markusen, 2003; Evans, 2005; Sullivan, 2006). These new residents often moved into and substantially changed former industrial spaces and urban residential neighborhoods that had been in decline, often triggering gentrification in the process. Seattle was one such city where this occurred.

Sharon Zukin (1982) documented the economic processes that transformed former warehouse and manufacturing buildings of downtown New York first into artist lofts and then arts districts. These same Soho workspaces later were reborn as new luxury loft districts and elite spaces of consumption thanks to the efforts of real estate developers, city policy, artists, and the media. Other scholars have added to this particular literature of urban decay and rebirth, and expanded the literature to document the process by which working-class and low-income ethnic or minority neighborhoods are transformed by successive waves of gentrifiers, often including or beginning with artists (Ley, 2003; Breitbart \& Stanton, 2007). Over the past twenty years, the role of arts and culture-based activities in revitalizing urban neighborhoods has become so well known that it is a standard part of many urban redevelopment strategies (Evans, 2005; Sullivan, 
2006). Indeed, an arts, culture and entertainment strategy has become so important to the revitalization of the urban core that the "three elements making up the downtown renaissance include a cluster of corporate towers, an infrastructure of tourism and entertainment, and neighborhood gentrification" (Judd \& Swanstrom, 2004, p. 368). Urban boosters and policymakers value the arts and culture in large part because of the place-making and neighborhood redevelopment aspects and their ability to attract capital. As resident artists are forced out by expensive rents, new artists cannot afford to move in, so the process of creating a successful artist neighborhood can be selfdestructive for an artist community, although policymakers and property owners can see it as a successful form of economic development. Across the United States, artist enclaves including New York City’s Soho, Boston’s Fort Point Channel, Chicago's Wicker Park, and San Francisco's Mission District have gone through processes that Zukin documented back in 1982. The processes of creating neo-bohemia tend to financially benefit interests that don't include the artists, but that "economically selfsacrificing dispositions find support in the socially structured field of bohemia" (Lloyd, 2004, p. 368). That is, the artists have a culture that values other concerns above the profit motive, and this anti-capitalist stance allows others to exploit them economically (Ley, 2003; Lloyd, 2004).

In addition to his work on social capital, Bourdieu (1986) identified cultural capital as another resource that could provide benefits to an individual or a group, but was not generally included in discussions of economic capital. Cultural capital is the combination of cultural factors including knowledge, education, customs, and family background that facilitate access to economic capital or power, which Bourdieu saw as 
one and the same (Bourdieu, 1986). He identified three forms of cultural capital:

embodied (habitus), objectified, and institutionalized. The embodied and objectified forms refer to the distinctive, internalized cultural preferences and attributes and the external expressions of these that mark a person as members of a specific class, economic status, or cultural group. Academic education, which validates the bearer's intellectual or technical competency, and the status and economic benefits such education provides, constitute the institutionalized form of cultural capital (Bourdieu, 1986).

Ley (2003) connected spaces of artistic production and gentrification with Bourdieu's theory of cultural capital and the field of cultural production. Artists possess cultural capital, and that cultural capital depends in part on being independent from and acting in opposition to economic capital Bourdieu (1993). Education, especially the specialized aesthetic education that defines artists, marks them as members of the middle class, but their role as artists requires them to reject conventional middle-class life and to seek out places that are free from the taint of commodification (Ley, 2003; Bain 2003).

\section{Summary}

The literature reviewed in this section provides some insight into the many, often contentious, instrumental ways that arts and cultural activities are incorporated into urban growth processes and ways of thinking about urban places, and the changing ideas about the place of the individual artist and artist communities in these processes. Artists have been employed as change agents, singled out as agents of gentrification and urban amenities and, most recently, celebrated as the ideal entrepreneurial worker in the new creative city as researchers and policymakers have broadened the scope of their cultural development strategies from the macro-scale that emphasized cultural institutions 
(DiMaggio, 1986; Strom, 1999, 2003; Eisinger, 2000; Diaz-Orueta \& Fainstein, 2009) to micro-scale activities that emphasize urban amenities, and creative producers (Landry, 2000; Florida, 2005). Smaller-scale and occupational strategies emphasize the importance of an educated, creative population, or attempt to delineate how artists contribute to urban prosperity and vitality, and how artists' locational choices affect urban neighborhoods (Stevenson, 2003; Markusen \& King, 2003, 2004; Currid, 2007).

As Heilbrun (1992) observed, art in its institutional form continues to be a central place function. The new emphasis on urban creativity and innovation expands the geographic strategies that embrace cultural development as a form of urban development into neighborhoods and places that might be removed from urban metropolitan areas. The arts and cultural activities and a creative workforce can play an important part in creating a unique character and vibrant urban and regional environment. Cultural policies that seek to attract creative producers (including artists) and promote cultural amenities include tax incentives, cultural districts, live/work spaces, artist relocation programs and other strategies. Often these strategies may overlook the fact that the community is already home to many creative people who do not fit the economists' creative class model. In some cases, what is needed is not necessarily an influx of new people, but a concerted effort to develop the cultural infrastructure needed to support the current community (Goldbard, 2006). Research on people who have engaged in cultural careers has only recently taken center stage in the cultural development literature, and includes Becker's (2008) art world model, and more recent empirical studies by Jeffri’s (2002) study of jazz musicians, Jackson and Oliver's (2003) study of popular musicians, and Jackson's (2004) study of artistic support structures, all of which found that social 
networks were critical for providing the resources that supported artists at various stages in their careers. With their study of artist centers, Markusen and Johnson (2006) demonstrated the importance of informal community centers of various types in facilitating artist education and also helping to connect artists to opportunities. These studies, along with literature on social capital and networks (Granovetter, 1973; Bourdieu, 1986; Coleman, 1988; Putnam, 2000) can shed light on how artists benefit from existing networks and support systems. In particular, the social capital literature aids in the understanding of how the artist networks emerged and expanded from the Pilchuck Glass School to Seattle, and throughout the region. Bonding and bridging capital, and weak and strong ties were all important to the development of studio glass, and the literature provides insights into how social and was a crucial element in building and sustaining the cultural infrastructure in the region.

Creative production, like other social processes, is facilitated, constrained by, and enmeshed within the economic, cultural, political, and social context of the time and place in which it is situated. In order to better understand the forces that shape the forms of cultural expression of a time, it is necessary examine the larger context as well. In researching questions about how and why the studio glass movement became a highly public expression of the artistic culture of the Puget Sound Region in the late twentieth century, it is necessary to explore the factors that influenced its development, from the micro to the macro level. While any such understanding can only be incomplete and fragmented, the literature that explores these factors can lead to a greater understanding, and possibly provide insights into the changing role of cultural production and cultural producers in contemporary urban development. 


\section{Chapter 3: Research Design and Methods}

\section{Introduction}

This case study takes a qualitative approach to examine the factors that supported the emergence and growth of the community of glass artists in the Puget Sound region (Figure 9.1) from the 1970s to 2003. This research analyzes the roles played by cultural policies, organizations, major patrons, urban amenities, housing and studio availability, educational, institutional and informal networks, in attracting and nurturing artists who specialized or worked in glass. Theories regarding culturally embedded systems of support for artistic production and consumption inform the framework employed by this study. These theories include Becker's (1982/2008) art world model; research on artistic activities, careers and locational choices by Markusen \& Johnson (2006) and Markusen (2006, 2006b); and Jackson's (2004) research on artist support structures.

\section{Research questions and expectations}

The emergence of a large and internationally renowned community of artists and crafters working with studio glass in the Puget Sound region over the last 30 years of the twentieth century provides a unique opportunity to examine the processes that shaped this community in this place, and the factors that have sustained this artistic community over the long term. This study adds to the literature on urban artist communities, and can help policymakers and scholars better craft policies and processes to support a vibrant urban cultural community at different stages of development. This case can potentially shed light on the various factors that comprise what Becker defined as an "art world" (2008) and how art worlds develop in contemporary, smaller cities. 
The overarching question behind this research is this: how did an art form that first emerged in the Puget Sound region with a small group of counterculture artists experimenting with new art techniques (Figure 9.3) evolve to become a mainstream form seen as a tourism draw and instrumentalized as an economic development strategy (Figure 9.4)? To answer this larger question, the research focuses on three major themes: 1) processes that generated and shaped artist social networks that support artist communities at the grassroots level; 2) roles that urban elites and growth coalitions played in building support for new/emerging art forms; and 3) policies that supported artists and artistic production in contemporary urban places. Embedded within these themes are questions about the ways in which this movement was tied to larger cultural and economic shifts in the region. This study proposes the following research questions to address these themes.

First, how and why did this artistic form of production emerge and thrive in the region between 1970 and 2003, becoming a prominent art form associated with this particular place? That is, what factors led to the regionalization of this art form during this period? Second, what roles did artist social networks, social capital, cultural capital, and cultural policies play in the community's formation and growth, and in sustaining the community over the long term? Finally, how did the separate interests of urban civic and social elites, and studio glass artists intersect to create the structures and systems to sustain and grow this regional artistic community?

The expectations for this research are that the processes involved a complex mix of factors which changed over time and which reflect the changing social and economic situations in Seattle and the Puget Sound region. Throughout the changing social and 
economic conditions, the interplay of social and cultural capital and the importance of artist social networks can be seen as constant factors in sustaining the studio glass art community. When studio glass artists first arrived in the Seattle area, individual artists were supported by the availability of low-priced housing and workspaces, and through informal and formal learning and exhibition opportunities that facilitated social network formation. Local and regional cultural policies and cultural organizations also provided support ranging from public commissions to grants. Additional support came from Seattle's cultural and business elites, who promoted cultural development as part of an urban growth strategy and to bolster Seattle's cultural capital. Larger economic and cultural shifts included the transformation of Seattle from an industrial base for manufacturing and shipping, to a city known as a center of software development. Along with this shift in image arose new forms of consumption and symbols of postmodern culture, including coffee, grunge music, and glass art. As Seattle's economy expanded in the 1990s, the audience and market for glass art grew. At the same time, rising real estate prices forced some artists out of the city into cheaper nearby areas, while financial success may have prompted others to move because they could afford to move and no longer needed immediate access to the professional networks and resources of the city.

\section{Research Approach}

The research examines five developments that shaped or reflected the movement's trajectory in Seattle and the nearby region between 1970 and 2003. For each of these developments, the processes and regional context of the developments and their importance to the studio glass community in the Puget Sound region are analyzed. 
The first is the establishment of a summer glassmaking program in 1971, which evolved to become the Pilchuck Glass School. Originally planned as a one-time summer workshop by two art professors, Dale Chihuly and Ruth Tamura, the workshop was located on a tree farm north of Seattle, and its life was extended beyond the first year due to the involvement of Anne G. and John Hauberg, a wealthy couple from Seattle who were actively involved in several of the city's cultural organizations (Miller, 1991, Oldknow, 1996).

The second development is the increasing contacts between European and American studio glass artists over several decades, and including an international faculty at Pilchuck, expanding the region's reputation as a center for studio glass education and production into the international sphere.

The next development was founding of a community arts program in Seattle's central district neighborhood in 1978, and the processes that linked that program to the studio glass artists and the Glass Art society, a national organization founded by artists to promote studio glass. These processes resulted in the creation of an urban artist center with a special focus on glassmaking, which served the city's studio glass community, and linked it to the regional and national network of studio glass artists.

The fourth development is exemplified by the claim of the region's studio glass artists that Seattle was a world center of the studio glass world by 1990 . This claim is examined as a symptom of the growth and maturation of the studio glass movement in the region. Two events are analyzed: the Glass Art Society Conference held in Seattle in 1990 for the second time in the organization's history, and Chihuly over Venice, an installation by Seattle artist Dale Chihuly, which took place in 1996. These events 
provide an opportunity to explore the growth of the city's cultural infrastructure and the pre-eminent place of studio glass not just in the city but also as a regional art form with an international reputation associated with the region.

The fifth and final development is the campaign to build the Tacoma Museum of Glass, which opened in 2002. This development marks, in a quite literal sense, the formal institutionalization of the Puget Sound region as the center for glass art. The museum's connection with the city's redevelopment of the Thea Foss Waterway near downtown Tacoma was part of a strategy to rebrand Tacoma's downtown to attract tourists from around the world and to convince middle-class, creative-class residents and businesses to relocate from Seattle to Tacoma.

Analysis of the data was based on a framework that combined Jackson's (2004) study of the support structure for U.S. artists, and Becker's (2008) theory of art worlds, with a focus on change in art worlds. Jackson (2004) proposed place-based criteria for identifying and examining the cultural dimensions that make artistic careers possible, and Becker's (2008) art world theory provides a more expansive approach to identify how the collective activities of the actors involved with cultural production contribute to the emergence and decline of culturally-specific art forms at certain times and places. This research combines both approaches to identify and analyze the factors that shaped the studio glass artist community in the Puget Sound region.

\section{Sources and Data Collection}

The research design used a combination of primary and secondary sources and interviews with artists, arts administrators and others involved in the arts community during the study period. Data sources included media reports and cultural policies; semi- 
structured interviews; and archival research in organizational records and government documents.

\section{$\underline{\text { Archives, Professional Associations and Oral Histories }}$}

Several archival sources provided access to primary records and papers of people and organizations involved in the evolution of glass art in Seattle, including the Special Collections department at the University of Washington Library, the Seattle Municipal Archives, and the Seattle Art Museum. Documents from the City of Tacoma regarding the redevelopment of the Thea Foss Waterway were available for this study. The Tacoma Museum of Glass provided contact information for several key people who were instrumental in the studio glass movement, which was beneficial in starting the research process.

The Glass Art Society records included newsletters and conference proceedings available for review, along with information about practitioners and members. They also maintain a list of active members, organized by state, which provided a resource on the numbers of artists in the region, and networks of glass artists.

The Archives of American Art at the Smithsonian Institution holds archival resources related to the development of the studio craft movement in the United States, including the studio glass movement. In particular, the Nanette L. Laitman Documentation Project for Craft and Decorative Arts in America contained transcripts of oral histories conducted with several artists who were instrumental in the development of the studio glass movement, including many who worked and taught in the Seattle area. 
The City of Seattle Municipal Archives included archival records related to the founding of the Pratt Fine Arts Center, and the City of Seattle website provided access to documentation regarding state cultural policies.

The papers of Anne and John Hauberg, long-time Seattle art patrons who were instrumental in supporting many of Seattle's artists and cultural organizations from the 1950s, are housed at the University of Washington Special Collections. The Haubergs provided the land and initial financial support for the Pilchuck Glass School, sat on the boards of Seattle cultural organizations, were members of many civic organizations, and supported many Seattle artists, including Dale Chihuly and other artists who worked in glass. The papers of LaMar Harrington, an arts consultant and a director of the Bellevue Art Museum from 1985 to 1990, are also at the University of Washington Special Collections. This resource included two boxes of material regarding the Pilchuck School. Newspapers, Journals, Specialty Publications

Secondary sources included local and regional newspapers, art journals, and general interest and tourism-focused magazines. Regional lifestyle magazines with tourism-related articles indicated a broader audience for glass art and arts organizations. Major Seattle and Tacoma newspapers with articles about arts-related events and activities included the Seattle Post-Intelligencer, the Seattle Times, and The News Tribune from Tacoma. Articles from these newspapers were accessed online and through the LexisNexis online database.

Arts periodicals, along with professional craft and glassmaking periodicals were reviewed for articles on artists working in glass and reviews of shows of glass-based crafts and artwork. These journals include the Glass Art Society Journal, Craft Horizons, 
Craft, and Glass Art Magazine. Articles in these magazines indicated important locations for glassmaking activities and education, and identified the major artists and teachers in the fields. Online searches for information on Seattle arts, studio glass art and artists, Tacoma arts, glass exhibits, Pilchuck, Chihuly, and other prominent artist and arts supporters connected with the glass arts in Seattle and the region through the Lexis/Nexis database, and online archives available on newspaper websites provided additional sources. Articles about glassmaking activities, glass artists, and events in the Puget Sound region indicated the level of general public interest in glass, and the role of glass art as a known regional activity and tourist attraction.

\section{$\underline{\text { Interviews }}$}

While archival and secondary sources provide valuable information about the arts community, interviews can clarify the information and reveal the connections, details, and personal experiences of the people involved. Snowball sampling was employed to identify individual artists, community members and other key stakeholders and actors in these events and activities. 


\section{Chapter 4: Building a Cultural Infrastructure}

\section{Introduction}

The story of studio glass in the Puget Sound region typically begins with Dale Chihuly and the first Pilchuck glass workshop in 1971. Although this event is critical to the region's emergence as a center for studio glass, it represents only one element in that story. As a group of artists working with a new medium in a new location, studio glass artists in Seattle during the early 1970s were challenged to create the cultural systems they needed, or work with the existing cultural framework. Before delving into the story of studio glass in the Puget Sound region, it is necessary to set the social, economic, and cultural context in the region and in particular, the city of Seattle. This chapter details the growth of an arts infrastructure in Seattle during the post-war years, beginning with the Seattle's World Fair development, the strategies pursued by urban elites to support the arts, and an increased level of support for the arts expressed through expanding educational programs, funding sources, and galleries. During this era, city business elites, policymakers, and activists were expanding the processes and institutions started in the 1960s that would transform Seattle from a regional city to a networked city with multinational ties (Abbott, 1992). The rebuilding of the city's port, the continued dominance of Boeing in the aerospace industry, the emergence of the University of Washington as a world-class research university, the influx of educated workers into the city, and the Seattle World's Fair all helped the city survive the downturn of the early 1970s and emerge as a networked city with international aspirations in the changing economy of the late twentieth century. When Dale Chihuly arrived in 1971 to set up a 
one-time summer workshop in rural Puget Sound, he was introduced to Seattle arts patrons who connected the artist and the workshop to Seattle's cultural infrastructure, helping to ensure the success of both.

\section{Postwar Seattle: escaping the esthetic dustbin}

Pre-World War II Seattle had never been known as a cultural capital, even among the limited venue of the West coast. The University of Washington, the Seattle Art Museum, and the Seattle Symphony were the largest cultural organizations in post-WW II Seattle. Neither the Seattle Art Museum nor the Seattle Symphony was considered a world-class organization, even by their supporters. John H. Hauberg, Seattle business leader and arts patron, served as a general manager of the Seattle Symphony from 19501952, and was involved with the Seattle Art Museum from the 1950s on, serving first as a trustee and later as museum president from 1973 to 1977 . He described Seattle's cultural scene in the 1940s as small and close knit, but not very impressive in terms of quality. "Like all the cultural institutions in Seattle in those days, the symphony's board was made up of prominent citizens who gave money from their own pockets, not expecting professional quality, nor striving to rise above the levels that their personal contributions could afford. The Seattle Art Museum was almost completely financed by Dr. Richard E. Fuller, grand opera was imported from San Francisco ...” (Hauberg, 2003, p. 245). During the last part of the century, both institutions initiated campaigns to enhance their reputation and strengthen their financial standing. These campaigns were among the many fueled in large part by local elites to support the city's cultural activities.

In the 1950s, culture became important to the city's business and cultural elites, who began a concerted campaign to strengthen the city's cultural identity. This effort was 
response to two related forces: a desire by Seattleites to shake Seattle's reputation as a cultural backwater, and the boosterism involved with planning the Century 21 Exposition, Seattle's 1962 World's Fair. Seattle briefly enjoyed the international arts spotlight in the early 1950s when a group of local painters, including Mark Tobey, Morris Graves, Kenneth Callahan, and Guy Anderson, dubbed the "Mystic Painters of the Northwest" by Life magazine in 1953 (Lasking, 2006). The group also attracted critical acclaim from the east coast arts establishment and media such as Life and Time magazine along with arts journals and the New York Times arts section. Seattle residents took pride in their local artists, if only because of the attention the group brought to the city nationally, and internationally. However, the positive effects were not long-lasting. Tobey became the most famous of the group, and he left Seattle to settle in Switzerland after gaining an international reputation. "In his latter days, Tobey regarded Seattle with bitterness. 'He used to rave and rant about how much he did to make Seattle famous," Willis noted. 'He had made it known throughout the world for its art movement. Seattle infuriated him as it never really appreciated him or paid him adequate homage." (Willis, quoted in Ament, 2001). The memory of Tobey and the Northwest mystic painters would be evoked time and again by people and organizations seeking to retain or to claim a regional artistic heritage, and they remained the most famous visual artists associated with the city until Dale Chihuly achieved international fame later in the century.

Throughout the 1950s, Seattle's population grew, and the city's cultural organizations grew as well. The University of Washington expanded its programs and increased the number of students enrolled due to the influence of the GI Bill that funded veteran's education, and due to an increase in research funding. Boeing, with its demand 
for engineers and managers, brought a substantial number of college-educated residents to the area. This was one of the factors that increased the numbers of young, middle-class people in Seattle with ties to places beyond the city and the region (Abbott, 1992). Many of these newcomers were enthusiastic about urban living, and because of this became involved in urban politics and cultural activities, creating new groups to promote their interests. One of the most influential of these groups began at the University of Washington when a few arts and architecture faculty and friends who shared interests in art, architecture and culture started a "Beer and Culture Society" in 1952. As the group became involved with more civic projects, they changed the name to "Allied Arts." Allied Arts was a significant actor in the 1962 Seattle World's Fair planning. The group also actively supported the creation of the Municipal Arts Commission in 1955 (which later became the Seattle Arts Commission) the Washington State Arts Commission in 1961 (Peck, 1985), and played major roles in the campaigns to save the Pike Place Market and Pioneer Square.

The new cultural groups and activities did not attract much interest outside the region. Indeed, the city's cultural reputation took a hit when a 1955 Time magazine article reported former Seattle Symphony conductor Sir Thomas Beecham's condemnation of Seattle as a 'an esthetic dustbin' and it jolted the Seattle establishment into action (Peck, 1985; Hauberg, 2003). “This highly quotable judgment went all over the United States like a new dirty joke. But it went to the hearts of the new post-World War II leadership of Seattle. Bill Allen, CEO of Boeing, and Paul Pigott, the heavy truck manufacturer determined to make the annual 'Community Chest' drives a success...." (Hauberg, 2003, p. 245). The Community Chest organization raised money for local charitable causes. 
Certainly the increased support for this was appreciated by the local charitable organizations that received the much-needed extra support. However, Community Chest funds did not go to cultural organizations, so this response did not address Beecham's accusation directly. Instead, the energies of the city's boosters were soon caught up in planning and running Century 21 - the Seattle World's Fair, an event designed to provide the city some international coverage, and which featured science, technology, and images of the future. Attention to long-term cultural funding could wait until after the Fair.

The 1962 World's Fair motivated Seattle elites to embark on several urban development projects and when it was over, it left the city with the Seattle Center, a park near the heart of downtown. The park was home to several built-in tourist attractions in the form of the Space Needle, the Monorail, a performance center, art pavilion and a new Science Center, all of which attracted visitors to events and exhibitions (Sale, 1976; Abbott, 1992). Another less visible legacy of the 1962 World's Fair was a network of nonprofit organizations, groups, and people with an interest in supporting regional arts and culture. After the fair ended, many of the people and groups involved with the fair continued turned their attention to other projects in other parts of the city. Allied Arts helped reshape the downtown streetscape and cultural life of Seattle when they successfully took on two major urban historic preservation campaigns during the 1960s: the Pike Place Market renovation and the preservation of Pioneer Square (Peck, 1985; Morley, 2011). Morley (2011) describes this group of cultural advocates and their allies in revitalizing Pike Place Market as a farmers' market for the working-class and middleclass population of downtown Seattle and the surrounding neighborhoods as a new "emerging cultural elite" whose activities opposed the "downtown business elite" made 
up of many of Seattle's traditional urban boosters (Morley, 2011, p. 213). Morley (2011) may be correct in her take on the Pike Place Market divisions, but there was also cooperation along with conflict between Seattle's cultural elite and downtown business elite during this era, except when business interests were pushing to turn historic buildings into parking lots, or constructing freeways through the center of neighborhoods. Both groups sought to revitalize the city's downtown neighborhoods. One major difference between them was that the cultural advocates wanted to celebrate and to build upon the city's existing built environment, while the business establishment group wanted to tear down the old and start new. In describing this new, young, professional population who lived and worked in or near downtown Seattle, Sale (1976) noted that they shared some common interests: "Most were interested in the arts, in the development or renewal of neighborhoods, in historic preservation, in stopping the construction of new big highways, in placing city offices in various old downtown buildings and not in new ones. In effect the basis of new possibility was old Seattle, the city that had been built by 1915" (Sale, 1976, p. 225). Meanwhile, the city's old guard, made up of the traditional downtown business establishment, promoted projects to create new highways, tear down historic structures and build a new stadium downtown. Both groups enjoyed some successes in their campaigns, suffered some setbacks and negotiated compromises in their quest to reshape the city. The division between those who belonged to the cultural elite and the business elite categories was not always clear. Seattle's cultural institutions were supported by many long-time Seattleites who were also members of the city's traditional business growth coalition. The same "prominent citizens who gave money from their own pockets" (Hauberg, 2003, p. 245) to support the symphony, the opera, and 
the Seattle Art Museum also took an active interest in the city's art and history, and often collaborated with the new generation of cultural elites to support historic preservation projects and new expressions of arts and culture visible in the city. The World's Fair serves as one example of this collaboration. Even Seattle's suburbanites were involved in promoting the arts. Bellevue, a post-war suburb across Lake Washington from Seattle, first hosted an arts and crafts fair sponsored by the Pacific Northwest Arts and Crafts Association in 1947 as a way to attract people to new real estate development in the town (Johns, 2005). The Pacific Northwest Arts and Crafts Fair was successful from the start, and quickly grew to an event that attracted artists, residents, and tourists from throughout the region.

\section{Craft in the Pacific Northwest in 1950s and 1960s}

The Pacific Northwest has been known for the number of well-known and influential designer-craftspeople since the 1950s, and the history of strong craft education programs and production predates the postwar era. As veterans entered college programs in the 1940s and 1950s funded by the GI Bill and other federal policies to expand higher education, the number of university-level academic programs in the arts nationwide multiplied, and the Pacific Northwest followed this trend. These programs brought students and teachers to the area, produced a large number of practicing artists and craftspeople in the region, and helped build a regional appreciation for crafts. Harrington (1979) describes academic programs in the Pacific Northwest as incubators for a growing regional craft movement whose center slowly shifted throughout the region, from Oregon in the pre-war and early post-war days, to Montana and Idaho in the 1950s and Washington in the 1960s and 1970s. The University of Washington in Seattle developed 
a strong ceramics program in the 1960s, and was also known for its metalsmithing and jewelry program, headed by Ramona Solberg. University of Washington’s faculty included influential makers like the jewelry-maker Ruth Penington and potter/ceramicist Robert Sperry, whose works challenged the traditional boundaries between arts and crafts. Seattle craftspeople were active in the national studio crafts activities; Penington was a regional representative on the American Craftsmen's Council, a national craft organization. Penington and Sperry were part of a group of artists who founded a regional organization in 1954 to generate interest in craft and support excellence in craft and design, called the Northwest Designer Craftsmen (NWDC, 2012). By the 1970s Washington had become the key center for contemporary crafts, with the University of Washington in Seattle at its core (Harrington, 1979).

Beyond the classroom, the university's Henry Art Gallery held regular exhibitions promoting regional makers. In the 1950s, the museum's exhibitions began to focus on work by local craftspeople, especially those who were connected with the university. It hosted the annual Northwest Craftsmen's exhibitions beginning in 1953 (Johns, p. 106). This annual exhibition eventually became the biennial Northwest Crafts Exhibition in the 1970s (Henry Gallery website). The focus on craft was due in large part to a local arts administrator, LaMar Harrington, who became involved with the regional arts scene in 1951 when she worked as a volunteer at the Pacific Northwest Arts and Crafts Fair in Bellevue. She began working at the Henry Gallery in the 1950s and was promoted to associate director, a position she held until 1975. The museum became an influential presence on the contemporary arts scene due to Harrington's interest in new art forms and in supporting local and regional arts. "There really wasn't much in Seattle until the Henry 
Gallery started—with LaMar Harrington being so interested in crafts" (Shores, 1984²). In addition to her work at the Henry Gallery, Harrington was involved in many aspects of Seattle's arts community and activities promoting regional arts and artists. She acted as a juror on local one percent for arts commissions, and was a judge for local arts festivals and public arts programs.

\section{Anne Gould Hauberg and The Friends of Craft}

Commercial venues for showing and selling crafts were limited at this time, but artists and patrons worked to share their enthusiasm for the studio craft movement and create a market for crafts. Admirers and patrons also did what they could to promote local craft, and in 1964 three local arts supporters, Anne Gould Hauberg, Don Foster, and Elizabeth Bayley Willis cofounded the Friends of the Crafts to promote crafts and support the work of local artists. At that time, the Northwest Designer Craftsmen was the only group representing makers in the region and it was an all artist organization. The Friends of the Crafts was founded to bring patrons into the mix. To help increase the audience for craft, the group's plan was “to both present exhibitions and establish a crafts museum" (Johns, 2005, p. 107). At the same time, John Hauberg became a trustee in the national organization, the American Craftsmen's Council and the two connected with the craft community. Foster and the Haubergs were influential in the city's art scene during the 1970s, and became enthusiastic promoters of studio glass art in the region.

Well before getting involved with the craft scene, Anne G. Hauberg was active in several Seattle nonprofit cultural and civic organizations and she helped create a few new ones. Hauberg, born Annie Laurie Westbrook Gould, was the daughter of a prominent

\footnotetext{
${ }^{2}$ Ken Shores, in the Oral history interview with Maurine Hiatt Roberts, 1984 Aug. 29-31. Archives of American Art, Smithsonian Institution. Interview conducted by Ken Shores.
} 
Seattle family. Her father, the architect Carl F. Gould, designed many Seattle landmarks including the original Seattle Art Museum at Volunteer Park, the Suzzallo Library and the Henry Art Gallery at the University of Washington. He also founded the university's Architecture Department. When she was a child, Anne took an art class taught by Mark Tobey, and her interest in the arts continued throughout out her life. She was an avid promoter of Tobey's works, and supported other local artists, especially those associated with the University of Washington. In 1941, Anne Gould married John Henry Hauberg, local Weyerhaeuser executive, and the two of them became active participants in Seattle's cultural life.

Anne G. Hauberg became involved with the local crafts scene through her work as a volunteer at the Seattle Art Museum, where John Hauberg had served on the museum board since 1949. Anne Hauberg threw parties to connect local artists with patrons, hosted Friends of Craft exhibitions in their home, and invited local artists to display their work alongside work she and her husband purchased (Johns, 2005). Some of the organizations she helped start included the Municipal Art Commission, which helped establish Seattle's cultural policies and arts agenda in the 1950s. In 1968 she founded the Committee of 33, a women's organization that was influential in fundraising and rallying support for historic preservation activities in the 1960s, including the preservation of Seattle's Pioneer Square.

Craft organizations that Anne G. Hauberg founded or cofounded included the Friends of the Crafts, the Pacific Northwest Arts Center, and Pilchuck Glass School. Through her work she developed a network of connections with craftspeople in the region and beyond, including a friendship with the well-known successful textile designer 
Jack Lenor Larsen, who was born in Seattle and studied architecture at the University of Washington before moving on to a successful career in New York City. It was through Larsen that the Haubergs learned about Chihuly and a proposal for a summer glassblowing workshop.

\section{The Boeing depression}

After the success of the World's Fair, it looked as if the 1970s would be a decade of ambitious projects and urban growth. However, the history of Seattle is punctuated by cycles of booms and busts and in the early 1970s it was mired in the midst of one of its deepest busts in its history. Seattle's economic outlook seemed particularly bleak during this “Boeing depression." The region's largest employer went from “over 100,000 jobs in 1968 to less than 40,000 by April of 1971" with one side effect being the rise in Seattle's unemployment rate from 2.5 percent to 17 percent (to as high as 47 percent for minorities) over the same period (Brown \& Morrill, 2010, p. 168). The job losses combined with the popularity of suburban living created a population loss in the city. Between 1960 and 1970 the city of Seattle experienced a five percent decrease in population (from 557,087 to 530,831). Between 1970 and 1980 the population decreased by an additional seven percent, from 530,831 to 493,846 (City of Seattle, 2001).

Downtown business districts were struggling and residential districts throughout the city suffered population losses and neighborhood decline.

An article in The Economist reported that, "The city has become a vast pawnshop" with foreclosures skyrocketing and food banks overwhelmed and having to reduce their days opened because of the demand from those in need (The Economist, 1971, p. 57-58). The article was accompanied by a photograph of the now-famous 
billboard commissioned by a couple of local realtors that summed up the mood of the time "Will the last person leaving Seattle turn out the lights." The billboard even inspired a song by country music singer Waylon Jennings. Readers of Time magazine during this time were kept informed about Seattle's plight by articles like “Aerospace: End of the Gravy Years” (1970), “Seattle under Siege: The Troubles of a Company Town” (1971), "Cities: Hunger in Seattle" (1972), and "Shortages: A Time of Learning to Live with Less" (1973).

Like other major cities throughout the United States during this time, the city was also the site of countless political demonstrations and activities started by various groups and individuals attempting to make their voices heard, effect political change, or improve the city in some way. As urban renewal projects threatened historic districts and poor and minority neighborhoods, local activists fought to preserve them. Anti-war demonstrations, the continued struggle for civil rights, marches for equality, and the end to employment discrimination also marked the era from the late 1960s through the early 1970s, sometimes erupting into violence, with one Life magazine article claiming that radicals in the city were responsible for "more bombings than (66 in 18 months) than any metropolitan area outside New York" (O’Neil, 1970). It was as if everybody in the city was determined to make their presence felt and their voices heard, by whatever means possible.

Even at the time, there were people who felt the predictions of Seattle's dire future were not warranted, and the city was moving beyond its dependence on Boeing for its economic future. Journalist Paul O'Neil, who visited his former home town of Seattle to write a story for Life magazine, noted, after a lengthy laundry list of the city's 
problems, that the city was not without its bright spots. "All these vexing phenomena are evolving differently, however ... than might have been expected. The Boeing depression washes around islands of prosperity: the port is busy and the building trades and Harbor Island shipyards are still running full blast. Student disturbances have been handled with restraint by both the university administration and the maligned police" (O'Neil, 1970, p. 32). Even if they have nothing else in common, the number and variety of grassroots campaigns and political and community activities are evidence that Seattle's civic life was in better shape than its economic conditions implied. The campaigns to save Pioneer Square and Pike Place Market grew out of grassroots activities, an appreciation of urban culture and history, and a belief in the city's future. Voters in King County also took part in redeveloping the region, approving new bonds as part of the 1968 Forward Thrust campaign to fund capital improvements in the King County's built infrastructure, including a stadium, new freeways, parks and other improvements to neighborhood built environments (Abbott, 1992).

Artist Buster Simpson who moved to Seattle after arriving to take part in the first Pilchuck workshop in 1971 remembers: "I moved to Seattle in 1971. I was attracted to the town, not because of the artist community necessarily, but because of an attitude that I felt was unique among big cities in the United States. In Seattle, there is still the belief that the citizenry can make a difference" (Simpson, 1990, p. 13). New people and new ideas were changing the cityscape. Not all of the changes were political in nature, but political battles were often required to carry out the changes. After years of activism and debates, Pioneer Square was declared a Historic Preservation District in 1970, and the Pike Place Market Historical District was established in 1971. At the edges of the city's 
International district and the Pioneer Square Historic District, construction began in 1972 on the Kingdome, Seattle's new stadium.

\section{$\underline{\text { Cottage industries, galleries, and university glass programs }}$}

By the time Pioneer Square and Pike Place Market were designated as historic districts, they had already evolved into cultural and entertainment districts that attracted the city's young and middle-class population. Sale (1976) noted that entire neighborhoods, including Pioneer Square and Pike Place Market were bustling with entrepreneurial activities even during the worst of the Boeing depression. "But if the historically preserved Market and Pioneer Square were focal points for a newly cosmopolitan consumer, they were only that, and throughout old Seattle in the last five years similar changes have been taking place on commercial streets. ... Cottage industries appeared with such profusion that it began to seem that everyone laid off at Boeing had been nursing a secret desire to throw a pot, turn a lathe, cast in metal, or make an omelette. Hippie capitalists took over the north end of the Market, parts of the Fremont district, and a good deal of University Way" (Sale, 1975, p. 240) (Figure 9.5). Seattle's strong craft community continued to thrive as a result of several factors: the strength of regional academic programs, the promotion of craft through university-related activities and the efforts of local artists and patrons. As the largest city in the region, Seattle was the obvious place for artists to attempt to sell their work. As Sale noted, makers were actively selling their works at several city neighborhoods street fairs, and at regional fairs, like the Pacific Northwest Arts \& Crafts Fair in Bellevue. This fair was one of Chihuly's earliest public venues in the region, when in 1968 the artist demonstrated glassblowing there (Figure 9.6). A few years later, in 1971, students attending the first 
summer glassmaking workshop at Pilchuck traveled to the Anacortes Arts and Crafts Fair to demonstrate glassblowing and sell their creations (Oldknow, 1994). Both the Bellevue and the Anacortes crafts fairs were regular occurrences and still take place today. The Bellevue event became so successful that its organizers were inspired to create the Bellevue Art Museum in 1975 to host exhibitions year round.

Fairs were not the only venues for showing and selling artworks in the city; some of the city's artists and supporters launched galleries too. Listings in Seattle City Guides from 1965 to 1980 (Polk, 1965, 1970, 1975, 1980) indicate that the number of galleries in Seattle increased from the mid-1960s through 1980. The Seattle City Guide lists nine art galleries in 1965. In 1970 there were 30 art galleries listed and by 1975 the number had increased to 48 . The increased number of art galleries indicated a growing visual arts market in the city. In his article on the early gallery scene in Seattle, art critic Matthew Kangas (2002) interviewed gallery owners Gordon Woodside and Francine Seders, who started galleries in the 1960s. Both noted that the limited gallery scene in the early $1960 \mathrm{~s}$ catered primarily to the city's elite. Galleries began to multiply when the gallery owners began working to attract middle-class buyers. "After 1970, things really opened up with the middle class in Seattle. The Tobeys I was selling were a lot more expensive than the work of some of the University of Washington Art School faculty I began showing so they made a big difference" (Seders, in Kangas, 2002). Both Seders and Woodside featured fine arts in their galleries, but with the abundance of craft producers in the region, galleries that featured crafts began to show up in the late 1960s and early 1970s. Small businesses are notoriously prone to failure and the city guide entries demonstrate the unstable nature of the gallery business. Of the 30 Seattle art galleries 
listed in 1970, only eight (including the University of Washington Henry Art Gallery) were still in business in 1980 (Polk, 1970, 1980). Two of the short-lived galleries included the Pacific Northwest Arts Center Gallery and the Polly Friedlander Gallery. The Pacific Northwest Arts Center Gallery, which appeared in 1975 and lasted only a brief time, was connected with the Haubergs' plans to start a regional museum for craft and folk arts, and was also briefly linked to the Pilchuck Glass School. In 1977, the Polly Friedlander gallery hosted the first Pilchuck Glass School exhibition to be held in a commercial gallery. Kangas (2002) documented what he called "the big six:" gallery owners who founded galleries that started during the 1970s and lasted to the beginning of the $21^{\text {st }}$ century. Two of the galleries owned by the big six quickly saw the attraction of studio glass and regularly exhibited studio glass art: the Foster/White Gallery, and the William Traver Gallery (which started in 1977).

Galleries that catered to the middle-class began to cluster in the same neighborhoods that were home to the "cottage industries" and "hippie capitalists" that Sale (1976) described. The most well known cluster of galleries was found in the emerging cultural district centered on Pioneer Square. One of the first galleries to open in Pioneer Square was the Richard White Gallery, which opened in 1968. Its founder, Richard White, was one of the people credited with helping revitalize Pioneer Square at that time (Kangas, 2002; Blecha, 2010). Don Foster bought the Richard White Gallery, changing the name to the Foster/White Gallery in 1973. White helped the neighborhood become known as an arts district, while Foster is credited as an art dealer who "helped shepherd Seattle's small, regional art community into the vibrant, far-reaching scene that it is today" (Clemans, 2012). Foster became interested in the arts through his work as 
director of exhibits at the Century 21 World's Fair Exposition. After the fair ended, he moved into arts administration and served in different high-level positions at the Seattle Repertory Theater from 1964 to 1970, and at the Ford Foundation until 1972 (Blecha, 2010). He was a cofounder of the Friends of the Crafts along with Anne G. Hauberg, and brought his interest in crafts to his gallery. Under Foster's direction, the gallery exhibited fine arts and crafts together. "Because of this, the tradition began of displaying crafts alongside fine arts and this, in turn, put Seattle on the map as a city where craft art is given equal status" (Kangas, 2002). Dale Chihuly had his first gallery exhibition at the Foster/White Gallery in 1977, and other well-known studio glass artists were featured there over the years. Other galleries also opened in the neighborhood, including a gallery operated by the Friends of the Crafts, which opened in 1971 on Occidental Avenue in Pioneer Square. Included in the gallery's first show were works by the Northwest Designer Craftsmen, alongside works by students and faculty from the first Pilchuck glass workshop. Studio glass artists and traditional craftspeople who worked with glass arrived in the city just as the arts and gallery scenes were converging. These people added their own studios to the mix of new galleries and shops in the city's historic neighborhoods.

Greg Englesby, Russell Day, Michael Whitley, Richard Marquis, and Rob Adamson were prominent in the small group of artists who worked in glass in the region in the 1960s and 1970s before Chihuly and Pilchuck became major names. Day, Whitley, Marquis were all faculty at regional colleges, and were most influential as teachers. During the early 1970s several regional universities briefly expanded their ceramics programs to include glass blowing or other glassmaking techniques, including the 
University of Washington in Seattle. Other academic programs started new, ran for a few years, and then disappeared, but not without adding to the knowledge base and history of glass in the region. Table 4.1 lists academic institutions in the Puget Sound region that offered formal programs in glass art in the late 1960s and early 1970s.

Table 4.1: College and university glass programs in the northwest, 1968-1978.

\begin{tabular}{|l|l|l|l|}
\hline Name & Date(s) & $\begin{array}{l}\text { Instructors associated with the } \\
\text { program }\end{array}$ & Location \\
\hline $\begin{array}{l}\text { Central Washington } \\
\text { University }\end{array}$ & $\begin{array}{l}1969-\text { early } \\
1970 \text { s }\end{array}$ & Michael Whitley & Ellensburg \\
\hline $\begin{array}{l}\text { Everett Community } \\
\text { College }\end{array}$ & $1950 \mathrm{~s}-1970 \mathrm{~s}$ & Russell Day & Everett \\
\hline $\begin{array}{l}\text { Highline Community } \\
\text { College }\end{array}$ & 1968 & Michael Whitley started program & Des Moines \\
\hline $\begin{array}{l}\text { Pacific Lutheran } \\
\text { University }\end{array}$ & 1969 & David Keyes & Tacoma \\
\hline $\begin{array}{l}\text { University of Washington, } \\
\text { Seattle }\end{array}$ & $1970-1971$ & Richard Marquis & Seattle \\
\hline $\begin{array}{l}\text { Washington State } \\
\text { University }\end{array}$ & $\sim 1968$ & $\begin{array}{l}\text { George Lassner (sculpture } \\
\text { professor) }\end{array}$ & Pullman \\
\hline $\begin{array}{l}\text { Western Washington } \\
\text { University }\end{array}$ & $1970 \mathrm{~s}$ & & Bellingham \\
\hline
\end{tabular}

Source: Miller (1990, p. 10).

The most influential university glass program of the early 1970s was housed at Central Washington University, founded by Michael Whitley. For the first generation of Puget Sound artists, Michael Whitley and Russell Day are remembered as influential teachers. Whitley "was probably the first glassblower in Seattle" (Englesby, 2003). Like many of the first generation of American studio glass artists, Whitley studied under Harvey Littleton, the "founding father" of the American studio glass movement and head of the glass and ceramics programs at the University of Wisconsin, and then honed his technical skills by studying abroad. However, before Whitley left Washington state, he first took classes at Everett Community College, where Russell Day, a respected arts educator who also experimented with glass, was the head of the art department. According to Miller (1991), it was Day who recommended Whitley to Harvey Littleton. 
Day had spent time at the University of Wisconsin in 1964, where he studied with the German sculptor Erwin Eisch, and Day experimented with glass earlier than this, producing a fused glass work for the Seattle World's Fair in 1962 (Dreisbach et al, 2003, p. 77).

At the University of Wisconsin, Whitley studied alongside two other artists who would become important to the regional glass community, Chihuly and Fritz Dreisbach. Chihuly went on to study at the Rhode Island School of Design, while Whitley headed for London to attend the Royal College of Art. After his stint in London, Whitley returned to Washington and started a glass program at the Highline Community College in Des Moines, Washington, just south of Seattle. In addition to the program at Highline Community College, Whitley taught at Central Washington University in Ellensburg, Washington, and started a glassblowing class for high-school students while he was artist-in-residence for Washington State University (Dreisbach et al, 2003). Whitley's teaching was influential in helping start the glass movement in the area, but unfortunately he did not live long enough to see glass take off as a medium in the region. Whitley died in an auto accident in 1972.

Whitley was the most influential of the early studio glass artists in Washington, but faculty and students at other colleges in the area were also experimenting with glassblowing and other glassmaking techniques at the time. None of these programs or experiments lasted more than a few years, but the people involved were important links in the community that began to form. One of the programs that did not last long was at the University of Washington, where California artist Richard Marquis briefly taught ceramics in 1970-1971 and added glass to the program (Miller, 1991). He stayed in 
Seattle long enough to visit Pilchuck and allowed the first group of students to use the hot shop he set up at the University of Washington.

\section{From the university to the studio, studio glass artists create places to work in Seattle}

Marquis was born in 1945 in Arizona, and attended the University of California, Berkeley, where he studied ceramics and glass with Peter Voulkos and Marvin Lipofsky, both pioneers of the studio craft movement in their respective fields. Marquis was Lipofsky's teaching assistant at Haystack School of Craft in Maine in 1967, and he traveled and worked in Venice from 1969-1970, courtesy of a Fulbright-Hayes Fellowship to Italy. In 1970 Marquis had just returned to the United States after spending time in Venice, where he learned traditional Venetian glassmaking techniques and became especially skilled in producing pieces employing the murrine ${ }^{3}$ technique. He moved from California to Seattle to take a temporary position at the University of Washington, filling in for a ceramics professor who was on sabbatical. "Dick was probably one of the biggest influences on all of us because he actually knew how to blow glass and he was making pieces that were really cool. ... Fritz and Pilchuck opened up a whole other thing." (Adamson, quoted in Dreisbach, et al, 2003, p. 76). Marquis was not only influential in Seattle, but traveled throughout the world, teaching glassmaking techniques. During his time in Seattle he was a respected teacher, and the studio at the University of Washington became another resource for local studio glass artists, including the first group of Pilchuck students. Marquis eventually settled on Whidbey Island in the Seattle area in 1983. Other programs in the area were also short-lived, but the number of programs that sprang up at this time demonstrated the interest in the

\footnotetext{
${ }^{3}$ The murrine technique involves creating long glass rods (canes) composed of different glass colors, and then slicing the canes to reveal flat disks with complex patterns.
} 
medium, and reflects the willingness of studio glass artists to experiment whenever and wherever they had the opportunity.

One of the drawbacks to working with glass is the need for a high-temperature furnace to melt the ingredients to make the glass batch, and to hold the supply of melted glass (the batch) at the right temperature for working. The resulting fuel usage and costs is one of the reasons glass can be an extremely expensive medium to work with, especially for glassblowers. During the energy crises and fuel shortages of the 1970s and due to cost-cutting measures that also took place at many public universities, many glass programs did not survive beyond the initial burst of enthusiasm. There was also a question about whether the number of students interested in glass justified so many programs, especially given the high cost of materials. Many glass programs that shut down were in state-run colleges and universities, where politics and budgets tended to overshadow support for experimentation in the arts. Academic glass programs did not enjoy the same sort of growth again until the 1990s when glass was accepted as yet another arts medium to be included as part of an existing program.

Like other newcomers to the area, artists who arrived in the Puget Sound region in the 1970s found an abundant supply of low-priced housing and affordable studio spaces in and near Seattle, because of the population exodus that occurred during the economic recession. However, there were few opportunities for artists or craftspeople that provided enough income to subsidize their careers. Some artists, like Whitley and Marquis, taught to supplement their income. University programs provided faculty and student artists with workspaces and even materials to use for making work, but program closures left many studio glass artists with limited places to go for learning skills and creating work in glass. 
Artists who were not part of the university system also faced challenges in finding places to work and to sell their art. The identity of glass as a new medium without an established following and patrons in either the craft or arts fields presented a challenge for artists trying to earn a living solely through working with glass.

The first generation of Seattle-area studio glass artists dealt with these issues in the 1970 s in many ways. Some private commercial studios allowed the artists to experiment, or at least use their equipment. For example, one of Whitley's students commissioned him to build a hot glass studio at J.D. Ott Manufacturing Company in Seattle (which the student owned). He then allowed his employees to use the studio at night. Others sought out funding sources. According to Adamson (2003): "At that time, Seattle was a neat place because you could get a studio space for very little rent -50 dollars a month... In those days, we advertised for the gas companies. They gave us free gas if we would show their sign at our demonstrations" (Adamson, in Dreisbach et al, 2003, p. 77).

The arts community was small enough that those who had an interest in glass making seemed to find each other easily, and the incentive to work together to support each other was high. Among the strategies artists employed to support their work was to start cooperatives and to establish their own commercial studios, some with retail spaces. Several artists followed that route, including Greg Englesby and Rob Adamson. Englesby arrived in Washington in 1969 and went to work building a small hot shop immediately. In 1971 he started a small glassblowing storefront business near Pioneer Square called the Glasshouse Studio and Gallery, which is still in business today. He ran the business for almost 15 years before selling it and moving on in 1985. Englesby remembers that the 
rent was cheap during the 1970 s, but it was difficult to make a living from the work, and like many artists he had to seek outside income. "I had to work with a machinist for two years when I started with the Glasshouse Studio and Gallery. We couldn't make any money out of it. Our rent was $\$ 150$ a month and the gas bill was $\$ 180$ a month, but still it was hard" (Englesby, in Dreisbach et al, 2003, p. 77).

Rob Adamson graduated in 1967 from the University of Washington and joined the Peace Corps soon after. He became interested in glassblowing after seeing glassblowers working in Mexico during his Peace Corps training. Adamson returned to Seattle in 1969 and reunited with another Peace Corps volunteer named Steve Beasley who was also interested in glass. "In 1970 we formed a group called the Art and Crafts Co-op of Seattle. We also visited Marquis's glass shop at the university. Around that time I met Roger Vines at the first university street fair. Marvin Lipofsky also came by that year and gave me a 'Blow Glass' button”' (Adamson in Dreisbach, et al, 2003, p. 75). The Arts and Crafts Cooperative was located in a vacant city-owned building, and it "provided one of the few places in Seattle outside a school setting for artists to blow glass" (Miller, 1991, p. 11). Adamson soon moved on from the cooperative into a commercial venture, The Glass Eye.

Norman Courtney was another early arrival in Seattle's glassmaking scene. Courtney arrived in Seattle after a stint in the Navy, and just about the same time as Adamson founded the Arts and Crafts Cooperative. He had become interested in glass after seeing glassblowing in Venice, and soon joined the Arts and Craft co-op where he learned glassblowing from Adamson. Courtney then taught glassblowing at the Arts \& 
Craft Co-op from 1974 to 1975. In 1975 he traveled to Ohio and Toledo where he learned sand casting from Swedish artist Bertil Vallien (Dreisbach et al, 2003; Courtney, 2011 ${ }^{4}$ ).

Table 4.2 lists independent glass studios and workshops in the 1970s.

Table 4.2. Independent glass studios and workshops - 1970s Seattle

\begin{tabular}{|l|l|l|l|}
\hline Name & Date(s) & Notes & Location \\
\hline $\begin{array}{l}\text { Arts and Crafts } \\
\text { Cooperative }\end{array}$ & $\begin{array}{l}1971-\text { mid- } \\
1970 s\end{array}$ & $\begin{array}{l}\text { Steve Beasley, Roger Vines, Rob } \\
\text { Adamson }\end{array}$ & Seattle \\
\hline Glass House Art Glass & 1972 & $\begin{array}{l}\text { Eric Brakken, Greg Englesby, Tom } \\
\text { Andre, Dave Stone }\end{array}$ & Seattle \\
\hline Penberthy Electromelt & $\begin{array}{l}1960 \mathrm{~s}- \\
1970\end{array}$ & Roger Ek, Spectrum Glass founders & Seattle \\
\hline San Juan Art Glass & $1970 \mathrm{~s}$ & Rob Adamson & Seattle \\
\hline Spectrum Glass & 1974 & $\begin{array}{l}\text { Jerry Rhodes, Don Hanson, Ron Smids. } \\
\text { Developed and supplied glass to } \\
\text { Pilchuck, stained glass enthusiasts. }\end{array}$ & Woodinville \\
\hline & & $\begin{array}{l}\text { Rob Adamson, Sheila Blomdahl, Walter } \\
\text { Lieberman, Charles Parriott, Mark } \\
\text { Graham. }\end{array}$ & Seattle \\
\hline
\end{tabular}

Sources: Miller (1990); Glass Art Society (2003).

\section{Penberthy Electromelt, Spectrum Glass}

Another difficulty in working with glass was the lack of raw materials for making high quality glass objects and the lack of good glass to work with. Penberthy Electromelt was a Seattle firm that sold electric glass furnaces. Adamson (2003) remembered working with a man named Hans Oldenfeller at Penberthy who made glass paperweights and "would let us come down and play" (Adamson in Dreisbach et al, 2003, p. 77). Spectrum Glass grew out of Penberthy Electromelt, and was connected to Chihuly and Pilchuck through Chihuly's cousin, Roger Ek, who worked for Penberthy. Chihuly called Ek for technical advice on improving the quality of the glass they were trying to work with at Pilchuck in the first or second summer there. Ek contacted a few friends and former co-workers from Penberthy and they started a new company to melt and supply glass, called Spectrum Glass (Spectrum Glass Company, n.d.). Pilchuck was not

\footnotetext{
${ }^{4}$ Norman Courtney, interviewed by the author, August, 2011.
} 
Spectrum's only customer. The popularity of stained glass and lack of local competition in the area provided them with a large local customer base.

As the decade continued, these people and organizations would be key to promoting the growth of studio glass in the region, and they were joined by other groups and organizations.

\section{Arts funding}

Soon after the World's Fair, in 1963, several local businessmen created a new organization called the Patrons of Northwest Civic, Cultural and Charitable Organizations (PONCHO) to address the funding woes of the cultural scene, starting with a Seattle Symphony budget deficit. The immediate goal of the organization was to raise funds for the symphony. The long-term goal of PONCHO was to help move Seattle in the direction of becoming the "Venice of the West" (Hauberg, 2003, p. 245); that is, to build up Seattle's cultural organizations and help the city become the cultural center of the region, while continuing to fund the kinds of charitable organizations previously supported through Community Chest drives. PONCHO existed to support Seattle area arts organizations and the organizations provided a consistent funding source for a wide range of Seattle arts organizations for the next 50 years.

Some of the Seattle-based cultural organizations, like PONCHO, the symphony, and the Seattle Art Museum, were founded and supported by Seattle's business leaders and social elites in part to support cultural activities that would meet their aims of enhancing Seattle's reputation in the wider world as an attractive, modern city of many assets, including the arts. Others, like Allied Arts had a more aesthetic aim and hoped to create and sustain aspects of the city that enhanced the quality of urban life and could 
expand and support a broad range of cultural activities. Generally speaking, these cultural organizations did not support individual artists but created an environment where certain art forms that gained approval could thrive.

Other contributions to the cultural infrastructure included arts and cultural policies instituted during the post-war era, and the increase in local and regional arts organizations and university programs in the arts. Supporting the arts in the cold war era was not solely the task of local nonprofits or civic boosters. This was the era when the government became interested in supporting the arts through policies and agencies such as the National Endowment for the Arts (NEA) and National Endowment for the Humanities (NEH). Individual states, counties and cities developed their own arts policies, depending on the level of local support arts advocates could muster. Some of these groups, including the NEA and some local arts commissions, supported individual arts through competitions and commissions. Through the lobbying efforts of Allied Arts, Washington state and Seattle both had arts commissions, the Washington State Arts Commission (WSAC), the Seattle Commission for the Arts, and the King County Commission for the arts, which provided artist grants. There was some funding for the arts available from state or locally-funded arts programs such as the Artists in Residence Program and the Art in Public Places Program which were started in the 1970s. Programs that provided funding to individual artists proved useful for many artists in the region. In the early 1970s Steve Beasley and Rob Adamson of the Arts and Crafts Co-op applied for and received at least one arts commission grant from the King County Commission for the Arts to fund a traveling glassblowing demonstration (Miller, 1991, Dreisbach et al, 2003, p. 77) which helped their careers and also increased the visibility of studio glass locally. 
Pilchuck's Founding

While there were artists and programs that focused on glass making in the region from Bellevue, Washington to Eugene, Oregon, the biggest factor in the growth of studio glass in the Puget Sound region is far and away the Pilchuck Glass School, located north of the city in rural Stanwood, Washington. In spite of its rural location, the story of Pilchuck is closely tied with the story of Seattle's art scene and the city's cultural patrons. It is also tied to the story of several academic institutions far from Seattle, in particular, the Rhode Island School of Design, the California College of Arts, and the University of Wisconsin, where many of the original teachers and students came from.

While the Seattle-based artists were making use of the existing cultural infrastructure and developing new support systems that would help them to establish studios, learn their craft and sell the resulting artwork, it was Chihuly who connected the emerging art world with Seattle's cultural elites. How did it all begin?

In 1970, Chihuly was a young sculpture professor at Rhode Island School of Design (RISD). Chihuly and Ruth Tamura, an art professor at California College, were planning to hold a summer glassblowing workshop near Chihuly's hometown, funded by a $\$ 2,000$ grant from the Union of Independent Colleges of Art (UICA). They were hoping to find a rural setting, where students and faculty could be fully involved in arts activities without distractions from the outside world, someplace like Haystack Mountain School of Crafts off the coast of Maine, where Chihuly taught over the past two summers. A native of Tacoma, Washington, Chihuly graduated from the University of Washington in Seattle in 1965 with a B.A. in interior design and then went on to study glass at the University of Wisconsin with Harvey Littleton, and ceramics at Rhode Island School of Design. During 
his time at University of Washington, while working at a local architecture firm in Seattle, he met textile designer Jack Lenor Larsen. It was Larsen that arranged an introduction to local arts patron Anne G. Hauberg. "Dale Chihuly, having so successfully learned to blow glass, came to me with the idea of a new glass school near Seattle-in tents! ... I suggested to Dale his talking to Anne Hauberg about this" (Johns, 2005, p. 8). When Chihuly arrived in Seattle to scout out possible locations, he set up an appointment to meet Anne and John Hauberg. Hauberg described how the couple met Chihuly in a 1971 interview:

We had never heard of Dale Chihuly although he graduated from the University of Washington and was a Tacoma - or Bremerton - born man. But he had become a protégée of Jack Lenor Larsen, and Jack Larsen studied at the University of Washington when Annie's father was the head of the architectural department out there. And we've maintained a fairly close relationship with Jack Larsen over the years. All of a sudden we had a letter from Jack saying he was sending out a young man who was sort of a protégé of his named Dale Chihuly, who wanted to start a glass center up in the San Juan Islands. So he called up Annie when he got here, and he never got to the San Juan Islands. I'd met him, and was very much taken by him and his enthusiasm. ... You really have to give the credit to Jack Larsen for steering Dale Chihuly to us (Hauberg, 1978, p. 18-195).

After meeting with Chihuly, the Haubergs agreed to let the group use a small portion of land on their tree farm outside Stanwood for the summer glass workshop. This initial gesture expanded to include a fair amount of financial support over many years,

\footnotetext{
${ }^{5}$ John H. Hauberg, Interviewed by Sue Ragan, January, 1978, Archives of Northwest Art. John H. Hauberg papers. Special Collections, University of Washington Libraries, Seattle, Washington.
} 
and to the transformation of Pilchuck from a temporary summer arts camp for a few arts students to an internationally renowned school for glassmaking, on par with the earlier, similar crafts schools located on the East Coast, Penland in North Carolina, and Haystack Mountain School of Crafts.

It was at this point that the Haubergs' ambitious plans for an arts center on their Pilchuck Tree farm intersected with Chihuly's search for a temporary location for a rural arts workshop, with the result of making the region a center for studio glass art, although at the time neither party was making long-term plans about a glass-related facility. The Arts Patrons and the Tree Farm

To understand why Larsen immediately suggested Chihuly talk to Anne Hauberg and why the Haubergs were so enthusiastic about the glass workshop, it is necessary to first understand how the Haubergs and their tree farm were connected to Seattle's cultural ambitions. For a start, the Haubergs were long-time arts patrons and Seattle boosters. As a couple, the group represented the merger of Seattle's traditional business elite and the social and cultural elite. For much of their lives together, the description of their activities could be summed up by saying that Anne was seen as the creative thinker and the one with the soul of an artist and real understanding of the arts, while John was seen as the one with the money to make things happen. There is surely some truth to this, but in looking back on their legacy as a couple, and as individuals, it is clear that they both had a love for the arts, and supported their preferred art forms in their own ways.

Anne and John Hauberg were participants together in Seattle's social and cultural life, from the time that they returned to Seattle after World War II so John could study forestry. "Now it was back to Seattle for three years at the University of Washington's 
College of Forestry and the turbulent cultural scene of a city wanting to shed its reputed dependence on timber, fish, and Boeing” (Hauberg, 2003, p. 244). John Hauberg's early interest in the arts revolved around music, as both parents participated in musical events as amateurs. He minored in music at Princeton, so it is not surprising that his first forays into Seattle's cultural scene involved the Seattle Symphony; he joined the board of the Symphony in 1949. John's second major area of artistic interest was Native American art; he might have inherited that interest from his father, who actively collected Indian artifacts while Hauberg was a child. The Haubergs traveled extensively and typically sought out artwork when traveling. They bought some Navajo pieces on a trip to the American Southwest in 1949 and collected pre-Columbian art on trips to Mexico and further south. During work-related visits to forests in the Pacific Northwest, the Haubergs visited “abandoned Haida, Tlingit, Tsimshian, and Kwakiutl (Kwakwaka’wakw) villages" (Hauberg, 2003, p. 279) which stimulated their interest in Pacific Northwest coastal art.

\section{The Pacific Northwest Arts Center}

In 1972, the Friends of the Crafts Gallery acquired a new neighbor named the "The in-Town Gallery" which was the "planning and membership center for P.N.A.C." which was formed to support a gallery named for Mark Tobey to "celebrate, preserve and exhibit arts of the region from prehistoric times to the present day" (Voorhees, 1972, A15). The Seattle Times article poses the question about whether the Mark Tobey gallery might be at the Haubergs' tree farm but provides no further details.

John Hauberg's activities in support of Seattle's arts organizations were notable, but of course they were not his full time occupation. He was an executive at 
Weyerhaeuser, and also owned his own tree farm where he could practice another of his interests, forestry practices. When Hauberg entered the forestry program at the University of Washington, he was already in his 30s, and wanted to put into practice some of what he was learning. In 1948, he purchased "about eleven hundred acres" (Hauberg, 2003, p. 207) of forested land on the east side of Pilchuck Creek, on land that was previously known as the Parker Ranch. By 1960, after methodically acquiring land from the farmers and others nearby, Hauberg had accumulated about ten thousand acres (Hauberg, p. 212). Hauberg paid for the land from his trust fund, intending to use it to research forestry techniques. Hauberg named the tree farm after the creek that runs through it. Pilchuck is a Chinook word, meaning "red river."

Pilchuck tree farm is located about 50 miles north of Seattle, outside the town of Stanwood, Washington. Hauberg described the location as follows: "Geographically: Pilchuck Tree Farm lies between Interstate 5 (I-5) on the west to the North Fork of the Stillaguamish River on the east, and from the city of Arlington on the southeast to Conway at its northwest corner. ... But we are only twenty-five miles north of Everett and about the same northwest to Mt. Vernon. The Pilchuck Tree Farm office can be reached easily in an hour from Seattle" (Hauberg, p. 220).

As early as the 1960s the Haubergs began planning to turn at least part of their Pilchuck tree farm to other uses, including a residential development to be called "Tatoosh." By 1970, they had contracted an architect to create a site plan and models for a possible museum and some detailed plans for housing and artist studios to develop one section of the hillside as an upscale housing development. The plans included a resident community of artists and craftspeople, and an arts and crafts museum with focus on the 
culture of the Pacific Northwest. The museum was also to include a gallery for Northwest Coast tribal art, and regional crafts, both reflecting additional personal interests of the Haubergs. Letters from LaMar Harrington in 1970 and 1971 while she was director at the Henry Gallery suggest the museum plans were known and taken seriously at that time. Harrington wrote to John Hauberg in 1970 suggesting a meeting to work out what to do about "overlapping areas in your plan and the Henry Gallery program" and suggested collaborating with the Haubergs and proposed the possibility that some of the gallery programs might move to the new museum (Harrington, 1970). In a letter to collectors in New Mexico who were loaning the Henry Gallery some pieces for a Balkan art exhibition, Harrington wrote: "Some other friends in Seattle are about to build a new museum (... Mark Tobey Gallery), and a decorative arts center north of the city" and suggested that the collectors might consider donating or loaning their folk art collection to the museum. She referred to the friends as "people of means (he is a Weyerhaeuser) who own a 4800 acre site (tree farm) and wish to develop it to the best advantage ecologically, aesthetically, and economically..." (Harrington, 1971).

One of the problems with this plan was that Mark Tobey had no interest in the museum. By the time the Haubergs' community and museum was in the later planning stages, the artist had resettled in Switzerland and did not want to return the Seattle. The Haubergs offered him a stipend and a position at the museum in 1971, and they even paid him while he was still in Switzerland, but they could not convince him to return to Seattle even for a museum that was to be dedicated to his work. According to Seattle art critic Deloris Ament Tarzan (2003):

Hauberg proposed to hire Tobey as a consultant, paying him \$1,000 a month, and 
said they also wanted to buy paintings for the museum. He told Tobey he had taken an option on a house at the corner of 14th Avenue and East John Street in Seattle, with a cottage in the garden, where he would be pleased to have Tobey live. Tobey preferred to stay in Basel (Ament, 2003).

Plans for the Pacific Northwest Arts Center continued through the mid-1970s. At one point they considered renovating several of the old farm buildings on the site and turning the area into a museum of western historical life, in the model of Sturbridge Village in Massachusetts, called Freeborn Hill. While the Haubergs continued to support the annual Pilchuck glass workshops and even folded the glass program into the organizational umbrella of PNAC, Anne G. Hauberg continued to work toward the realization of her larger dream. In a 1973 interview in Sunset magazine she talked about their plans for a larger project that encompassed a music festival theater along with: ... a cultural park on part of our 4,000 acres of forest and meadow land 50 minutes north of Seattle ... our planned Mark Tobey gallery and a Northwest Indian art center... We also need a village for handcraft workers, and some inexpensive studios and homes for artists and retired people (Hauberg, in Quist, 1973, p. 111).

However, none of these plans became reality. The Boeing slump affected real estate values and plans for the residential portion of the development were placed on hold, never to return in John Hauberg's lifetime. Plans for the Tobey museum were also scrapped due to the artist's opposition. In 1972, the Pilchuck glass workshop would be briefly absorbed into the organization the Haubergs founded to support a proposed Mark 
Tobey museum and regional craft and folk museum, called the Pacific Northwest Arts Center.

The crafts and cultural center ideas remained in place for at least the rest of the decade, as the Haubergs continued to brainstorm possibilities. "When the froth had blown away, or settled down, we found that we had not succeeded in getting Mark Tobey's approval of a museum to be named for him, we had not created a Pacific Northwest Council of interested people from Portland to Vancouver and Boise, but we had created the now-famous Pilchuck Glass School with Dale Chihuly's idea and our funding and guidance" (Hauberg, 2003, p. 290).

\section{Pilchuck's first year}

Pilchuck Glass School, as it was later called, was located 50 miles north of Seattle. The location, far from urban amenities, met Chihuly's goals of removing the students from hectic nature of city life, and more generally reflected the back to the land philosophy of the early 1970s counterculture. During the first year, Pilchuck was an "art for art's sake" enterprise that emphasized freedom and creativity, a DIY ethic, and process over product. In his funding proposal for the second year, Chihuly (1972) reiterated the philosophy and rationale behind the school and the importance of a rural location.

Ten years ago glass blowing schools in this country were non-existent. Now there are over sixty. For the first time in history glass has broken away from the traditional needs of the consumer and his factories. In the summer of 1970, Ruth Tamura and I began planning for a glass center that would have a rotating faculty representing the various new approaches and attitudes towards glass. It was time 
to provide an atmosphere where people could get together to discuss and explore these new ideas. From the beginning we wanted to be located in an isolated setting, feeling that such an environment would be conducive to concentration and total involvement (Chihuly, 1972).

Pilchuck brought together professional artists with college students who applied through their art departments for admissions. The first year, Pilchuck did not have an official name, although sometime during the summer it acquired the nickname of "The Peanut Farm." The students came from universities that were members of the UICA. That first year, 20 students attended Pilchuck, and they paid no tuition, courtesy of the UICA grant (Chihuly, 1972).

Students were told to bring everything they needed to camp out for the summer, but few did. It was likely that few of the students even knew what to bring for a summer of camping out in the soggy Pacific Northwest. Still, it was a time when many young people were interested in getting back to nature and back to the land, and this first group of students brought their enthusiasm for starting something new, in an unfamiliar but beautiful, rural setting. Many also brought friends. The first year was all about glassglass and building.

After the first year, the curriculum was expanded somewhat to include a media program, which didn't survive much beyond the second year. Initial funding did not go very far in purchasing supplies and shelter for the essentially open and forested land that was almost (or completely) lacking in any kind of permanent shelters. Despite the do-ityourself shelters and cooking arrangements and free use of the land, the UICA grant was not enough to cover expenses. As Chihuly noted in his search for funding for Pilchuck's 
second year, "Although we received a UICA grant, private donations, and additional income from the glass sales, I still lost $\$ 2,000$ of my own funds" and as a result of the budget shortfalls, the proposed tuition was set at " $\$ 400$ tuition for the ten-week session, which covers about one-fourth of our expenses" and was the maximum amount that would both help pay expenses and still keep the tuition affordable (Chihuly, 1972). At this time, Chihuly was the "Pilchuck Project Director" and he was still on the faculty of Rhode Island School of Design.

For the first year, shelter, food, and basic necessities were challenges that took up much of the students' time. People slung tarps over tree branches for basic shelter; those with greater building skills and knowledge set about creating more durable and waterproof shelters out of material gathered or scavenged locally. Basic equipment and materials for glassmaking were also lacking. One of the first group projects was to design and build glass furnaces, which were sheltered under a massive tarp (Figure 9.3). Not surprisingly, the first furnaces did not work very well, but the students did the best they could with what they had. According to Chihuly (1972):

Equally encouraging was the hope and enthusiasm young people have when given an educational atmosphere that allows them the opportunity to express themselves fully without the usual distractions and restrictions of our overcrowded and confusing cities and their highly structured schools (p. 2).

According to Pilchuck's founders, the distractions of the city hindered full artistic expression. However, in spite of the importance Chihuly, Tamura and later faculty placed on the rural setting, Pilchuck ties to Seattle were strong and important for the school's survival from its inception. 
One of Seattle's resources they needed to use were the art studios at the University of Washington art department. At that time Marquis was the studio manager and a temporary faculty member at the university. During the first year, faculty and students from Pilchuck would drive to town to use the UW kilns/furnaces to produce the basic batch required for working (Oldknow, 1996). The batch is the raw material, mixed from silica, soda ash, and lime and melted with various metals to make glass of different colors. The batch is then melted again at a lower temperature for glassblowing, kiln forming, and other glassmaking techniques. One of the first year students remembered his role in getting the school operational:

My duty, for most of the summer, was to go to the University of Washington, and with their help, we mixed batch formula glass. We received materials such as soda ash and sand free from the Northwest Glass Company, who made Coke bottles and jars and stuff like that. And we got cryolite, one of our formula constituents, from an aluminum recycling place and we purchased some of the materials. ... Within three weeks, I would say, we had furnaces operating and glass, which was made from batch in the furnaces at the University of Washington. We pulled the glass out of the furnaces and poured water on it to make frit, which is, you know, broken up pieces of small glass. We brought it out to the country, near Stanwood, to Pilchuck, and we remelted it (Borris, 19846). The necessity to travel back and forth from Seattle to make the raw materials required for glassblowing put a kink into their plans for a completely self-sufficient arts community removed from urban life. But, in fact, Pilchuck was connected in several

\footnotetext{
${ }^{6}$ Marshall Borris (artist), interview with LaMar Harrington, February, 1984. LaMar Harrington Papers. Special Collections, University of Washington Libraries, Seattle, Washington.
} 
ways to Seattle from its inception. It was connected to Seattle's elite community through the Haubergs and their land and plans for improving the cultural reputation of the city. It was connected to Seattle's educational institutions through Chihuly's University of Washington connections and also through the need to use University of Washington facilities and supplies during its initial years. It was also connected to Seattle's crafts community, at the least through Chihuly's connections to the Pacific Northwest Arts \& Crafts Fair in Bellevue, and also through Jack Lenor Larsen's support and the participation of Seattle's small group of practicing glassmakers. "I first heard about Pilchuck in 1971.... And I went up to see what was going on and there were a couple of furnaces in the field and these guys were in tents around. It looked pretty barbaric at the time. These were all 'young hippies' at the time” (Adamson, 1984, p.1).

At the end of the first summer, Pilchuck student and faculty work was exhibited in the gallery that Anne Hauberg started, the Friends of the Crafts Gallery in Seattle. "Probably the most satisfying aspect of the eight week program was the obvious skill and spirit that almost everyone displayed in an exhibition we held in a Seattle gallery, where we raised $\$ 800$ towards our $\$ 2,900$ deficit” (Chihuly, 1972, p. 2). The Haubergs did more than support the school, they also supported the individual Pilchuck teachers and students by collecting their work, encouraging their friends to collect Pilchuck glass, and sponsoring exhibitions in local galleries, first in the nonprofit Friends of the Crafts Gallery, and then in the for-profit Polly Friedlander Gallery. "In a couple of years our Pilchuck artists/teachers were also instructing at Haystack Mountain and Penland summer craft schools. And slowly a market developed with Pilchuck alumni in the lead" (Hauberg, 2003, p. 290). 
Discussion

The artists that lived and worked in Seattle in the early 1970s were isolated from the art world centered on New York City, and they operated beyond the realm of the art journals and critics who could make and break careers at that time. They had few options available for accessing the New York City art world from a city located at the opposite coast. Given Seattle's economic conditions at that time and the limited number of cultural institutions in the region, prospects for establishing and sustaining a vibrant arts community based on local cultural support systems also seemed limited.

The city, indeed the region, had few of the elements that Jackson (2004) and Becker (2008) identified as necessary for supporting artistic careers or art worlds. Among the necessary components required for supporting cultural producers that both Becker and Jackson considered necessary were markets, an audience, sources of professional training, and a system for critically evaluating the work that artists created (Jackson, 2004, Becker, 2008). There was no market demand or audience for studio glass as a unique art form in the Puget Sound region. The gallery scene was small, and only beginning to open up to makers who produced objects or used mediums classified as craft rather than art. Because of the economic downturn and the fact that this was a new art medium, artists found limited opportunities to show or sell their work through established galleries. There were no formal aesthetic criteria (Becker, 2008), or systems for validating work that studio glass artists produced (Jackson, 2004) that could serve as a basis for classifying, critiquing, and valuing studio glass objects in terms of quality. Local training opportunities were limited, as the artists involved were only just learning the materials and processes themselves. 
Given these factors, Seattle in the early 1970s would have to be considered inhospitable to artists and an unlikely place for a new art world based on studio glass to emerge. The region's studio glass artists were not completely without resources, however. Although there were few formal training opportunities at first, it did not take long for artists to connect with regional colleges and universities which were offering new and expanded arts programs, due to the increase in funding and students (Netzer, 1978; Harrington, 1979). Local studio glass artists both taught and took classes at these institutions, and through these activities strengthened local artistic networks, and gained access to facilities, equipment, and income to support their production. Neighborhood street fairs and regional arts and crafts fairs provided opportunities for area studio glass artists to show and sell work and to begin the process of developing an audience and a market.

The population of studio glass artists in Seattle in the early 1970s shared basic demographics with the artists residing in Wicker Park, Chicago in the 1990s that Lloyd (2004) documented. Both groups were young, college-educated, and poor, and both groups sought out cheap living and working spaces in urban neighborhoods. Lloyd (2004) found that the first group of artists to settle in Wicker Park remained isolated from one another because the area was not known as an artist neighborhood and there were no community spaces for artists to congregate and socialize. In contrast, studio glass artists in Seattle found each other fairly quickly, in part because of the city's small cultural scene. The limited number of art venues meant that artists were more likely to encounter each other at one of the city's cultural venues or to hear about other artists working in the same media. The need to share information provided incentive for artists to work 
together, spurring the growth of an artist network that encompassed local, personal connections established through face to face interactions and working relationships, and a broader professional network established through educational and organizational ties with artists and institutions far from the region.

Studies by Zukin (1982) and Bain (2003) found that artists were attracted to former industrial spaces that provided large, flexible, and affordable working and living spaces. The artists in Toronto that Bain (2003) studied were attracted to urban neighborhoods that featured buildings that were old, decaying, and open to new creative uses. In Seattle, cultural production and consumption activities were located in several city neighborhoods. The two most visible downtown locations were Pioneer Square and Pike Place Market, which were prime spots for artist studios, galleries, and street fairs. The rundown nineteenth-century buildings in Pioneer Square and the decrepit state of Pike Place Market fulfilled the needs of local artists for workspaces and places to make over for new uses.

As Ley (2003) found in his study of Vancouver, BC, artists were not the only people attracted to the built environment left behind from an earlier industrial age and to poor and working-class urban neighborhoods, and in Seattle they were not the first to rediscover and reclaim such sites for the middle class. The entrepreneurial activities that Sale (1976) documented and the grassroots activism of historic preservationist groups like Allied Arts that helped turn the Pioneer Square and Pike Place Market neighborhoods into tourist destinations were evidence of the attraction to urban spaces that Ley (2003) found typical of the new "aesthetic disposition" displayed by the first waves of the baby boom generation that benefitted from the expansion of college 
programs in the 1960s. These activities also represented the increasing influence of what Morley (2011) labeled the new cultural elite, and this group's successful campaigns preserve and revitalize these neighborhoods were signs of the urban restructuring that would change the city dramatically over the next 30 years.

As Morley (2011) noted, the traditional coalition representing downtown business interests also had an interest in Seattle's downtown neighborhoods, but the large-scale redevelopment projects that they advocated did not include building new downtown cultural organizations or districts in the early 1970s. Several group members did have an interest in culture, but it was directed more to supporting the existing high-culture institutions like the Seattle Symphony and the Seattle Art Museum. DiMaggio's (1986) study of wealthy Bostonian's support for the arts in the nineteenth century found that the search for cultural capital spurred Boston Brahmins to create and support cultural institutions that helped set the boundaries between high culture and popular culture to shore up their own social position as the city around them changed. Seattle's leading citizens had followed a similar path, creating their own cultural institutions, not just to set themselves apart as an elite group within the city, but also as a place making strategy to set the city apart as a cultural center in the West. By the 1970s, some of Seattle's wealthy arts patrons, including the Haubergs, wanted more than institutions, they wanted to find a homegrown cultural expression that they could claim, to increase the city's cultural capital.

Like the nineteenth-century Boston Brahmins who hoped to benefit through their support of an art museum and a symphony (DiMaggio, 1986), the Tobey Museum and Pacific Northwest Arts Center that the Haubergs planned to build on the site of their rural 
tree farm also served a larger agenda. As a tree farm, the Pilchuck Mountain property was an investment in the region's traditional economy based on extraction of natural resources. As a planned site for cultural and educational organizations it represented the couple's commitment to culture and education, and fortified their vision of Seattle as a world-class city with a cultural life equal to that of other major cities in the United States. When Chihuly convinced the Haubergs to support a summer glassmaking workshop on land that the couple had already set aside for a museum dedicated to Seattle artist Mark Tobey and to regional art forms, this began the process that connected studio glass artists with Seattle's wealthy and influential cultural patrons, and through them to the city's cultural infrastructure (Figure 4.1). However, none of this was evident during the Pilchuck Glass School's early years, and indeed, it was not clear whether the program would even last longer than a year or two, given the somewhat chaotic and primitive initial conditions and the lack of stable funding. 


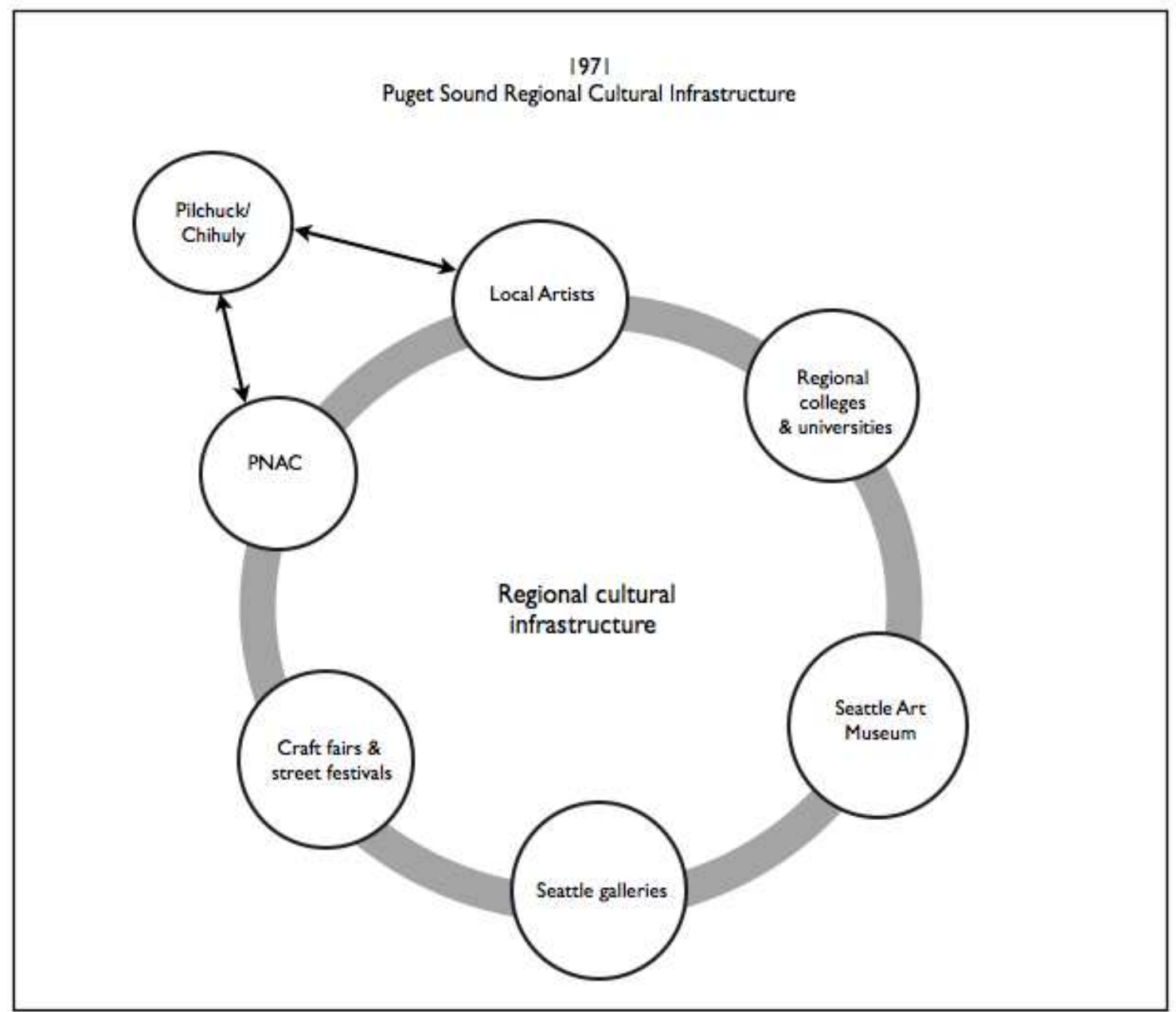

Figure 4.1. Cultural infrastructure of the Puget Sound region, 1971

In Becker's study of change in art worlds, he noted that: "only changes that succeed in capturing existing cooperative networks or developing new ones survive" (Becker, 2008, p. 300). Artists who arrived in the Seattle area in the early 1970s found a city in economic distress, but with a vibrant cultural and civic life. To succeed as a group, they needed to connect to the city's existing cultural infrastructure or create their own support systems. Key elements in the existing framework were several regional academic programs in the arts, a few policies that supported the arts, a small group of patrons and galleries that provided a potential audience and market, and a lively regional scene that included craft fairs and impromptu cultural events. The success of the studio glass 
movement depended upon the community's ability to successfully mobilize resources and build place-based networks to support the conventions, skills, and people required to create a new art world in this new location. By the mid-1970s studio glass artists had already developed new artistic networks in the region, and had succeeded in "capturing" a portion of the existing networks. Within a decade, Seattle galleries would showcase work by regional studio glass artists, with Pilchuck faculty and students prominent among them. However, studio glass artists still had significant challenges ahead of them, given the limited institutional venues, audience, cultural media, and resources available to support their art or to create a sustainable art world in the Puget Sound region. 


\section{Chapter 5: International Connections}

\section{Introduction}

Seattle studio glass artists were not the first to travel to Europe to seek out European masters and learn from them. However, the interaction between Seattle glassmakers and their European counterparts not only had a profound impact on the individual artists, but also upon the position of Seattle as an international center of glassmaking. These exchanges even influenced the development of European glassmaking. This chapter explores these connections and their influence on the emerging studio glass community in Seattle in the 1970s and 1980s.

Why did Seattle artists go to Europe and what did they bring back from their experiences? What did the European artists gain from this exchange, if anything? It's not surprising that American artists just beginning to explore what was to them a new medium would travel to Europe where the long tradition of glassmaking was still thriving. It is less clear what European glassmakers had to gain from letting American artists into their studios, where both tradition and market competition demanded secrecy. The following sections attempt to answer these questions. To do so, the chapter selectively highlights the activities and careers of a few key artists and glassmakers from the Pacific Northwest, Northern Europe and Italy who developed strong connections to the Seattle area and were influential in development of studio glass in the Pacific Northwest. 
The Seattle connection

During the 1970s, formal and informal arts education programs including Pilchuck, Pratt Fine Arts Center, and the glassmaking program at the University of Washington emerged in the Seattle region. These programs provided learning opportunities for aspiring studio glass art students. However, along with these local sources of knowledge, Seattle artists understood the necessity of connecting with European glassmakers to gain the technical skills and knowledge they needed to work with glass as an artistic medium. The international connections that these artists established, and the knowledge and skills they gained, helped individual artists and the studio glass movement in general quickly advance and helped strengthen Seattle's reputation as an international center for artists and collectors of studio glass work.

The Seattle artists discussed in this chapter traveled to Europe early in their careers, before they moved to Seattle. In doing so they were following the example of one of the founders of the studio glass movement, Harvey Littleton. Littleton's artistic path included a search for methods to match his ambitions. He was among the first of the studio glass artists to visit Europe, with a 1958 trip sponsored by Corning Glass Works. Littleton set out to find processes for working with glass that also fit the standard Western model of the artist at the time. To qualify as an artistic medium, glass had to meet certain qualifications. In particular, individual artists using glass must be able to use the material to produce unique work that only their hands had touched. The American factory model, with its emphasis on mass production and utilitarian objects, did not fulfill these requirements. Post World War II Europe was home to several regions where traditional glassmaking was still practiced, and Littleton visited studios in Naples, 
Murano, and Paris, looking for evidence that small-scale glassmaking production was practical. According to Lynn (2004) Littleton's experiences there, and in particular his visit to Spanish artist Jean Sala's small studio in Paris, convinced him that the idea that glass could be a medium for individual artists was viable (p. 52). This realization formed part of the inspiration for the 1962 Toledo Workshop.

The first generation of artists who studied with Littleton or other studio glass pioneers and were affiliated with a college or university could arrange to travel abroad through internship or fellowship programs. Many studio glass artists traveled to Europe in the 1960s and 1970s to glean what they could from the European glassmakers and designers there, often using their educational credentials as a calling card. As more American artists traveled to Europe to study and learn from European masters, interest in the glassmaking activities taking place in the United States spread within Europe. Some European artists became interested in traveling to the United States to teach and to experience firsthand the experimental processes of American artists. Former Pilchuck Education Coordinator Benjamin Moore recalled: "In the late 1970s and early 1980s prominent European artists began to go to Pilchuck. The first was Erwin Eisch, in 1972. In 1974, Ludwig Schaffrath was there" (Moore, 20107). In the late 1970s the first of the Italian artists arrived at Pilchuck to teach, and by the 1980s other European artists, including Swedish artists Bertil Vallien and Ulrika Hydman-Vallien, and Czech artists Stanislav Libensky and Juroslava Brychtova. The master glassmakers and artists arrived first and their students soon followed. This international mixture of artists in Seattle drew more artists, to experiment, play, and learn together and to bring back what they learned

\footnotetext{
${ }^{7}$ Benjamin Moore (artist), interview with the author, 2010.
} 
to their homes. In some cases, such as in Japan and Australia, artists returned from the U.S. and started glassmaking programs based on American models provided by Pilchuck and other regional schools.

\section{Artist Exchanges - Germany, Sweden, and Italy}

While American artists were attempting to create new artistic forms in glass, European designers were developing their own studio glass movement. In many other countries, the traditional glassmaking industries comprised regional glassmaking facilities where craftspeople practiced techniques handed down through the generations, creating work designed by the factory designers who were graduates of university art programs. During the 1960s, these university-trained designers raised questions about the role of art, craft, beauty, industrial production and their own roles in modern society. During this time, European glass designers actively sought out occasions to travel, study and work internationally, and to share their ideas with others. Some were drawn to the U.S. because they had heard of the studio glass movement's activities. Among these were the German artists Erwin Eisch and Klaus Moje, and the Swedish artist/designer Bertil Vallien. These artists visited several arts programs in the United States to showcase their work, demonstrate their techniques, and see what American artists were doing.

In 1980 Pilchuck began an artist-in-residence program that drew artists from around the world, including contingents from Italy, Germany, Sweden, and Czechoslovakia. Klaus Moje, Ludwig Schaffrath, Bertil Vallien, and Ann Wolff were among the northern European artists who made teaching at Pilchuck a fairly regular summer event. 
Germany

German artist Erwin Eisch was the first European to teach at Pilchuck, in 1972, but it was not the first time he had worked with American artists. The earliest exchange between American and German studio glass pioneers dated to the beginning of the glass movement, in 1962 when Littleton visited Eisch during a trip through Europe. Both shared an enthusiasm for experimentation with glass and an interest in using glass as an artistic medium, and they became friends. Eisch visited the U.S. several years earlier to teach in 1964 at a summer workshop that Littleton offered at the University of Wisconsin (Oldknow, 1996, p. 37). In 1969 Chihuly visited Eisch in his studio in Germany, and Eisch in turn traveled to Seattle as a visiting artist at Pilchuck Glass School in 1972, only one year after the school was founded. He brought traditional skills learned through his family background and the German system for educating industrial designers, along with a modernist approach to the material. His presence in the early years of the school testifies to the early connections to international artists that Littleton, Chihuly, and other Americans made during their individual study trips to Europe. Like Eisch, other international glassmakers invited to Pilchuck would find themselves working with people they had met or even tutored at their home workshops and factories.

Erwin Eisch and Klaus Moje were both traditionally trained in techniques that involved working with flat glass but became best known for their sculptural work. Eisch was born in 1927 in Frauenau, Germany and learned glass engraving from working for his father, who had an engraving workshop. He studied glassmaking in Zweisel, and also at the Academy of Fine Art in Munich. He later studied sculpture, and from the late 1950s he experimented with glass techniques to create sculptural forms. His work is also 
notable for its use of surface decoration, as he typically employs painting, enameling, etching and other techniques. According to Oldknow, Eisch's "philosophies would become a major ideological force in the American studio glass movement" (Oldknow, 1996, p. 37).

Klaus Moje was also born into a glassmaking family. Born in Hamburg in 1936, he learned glass grinding and glass cutting in the family business and through study at Rheinbach and Hadamar glassmaking schools. Moje ran a studio with his wife and fellow artist Isgard Moje-Wohlgemuth during the 1960s. According to Edwards, glassblowing "was never to draw Klaus Moje, whose roots were planted firmly in the northern tradition of glass-carving and glass-engraving" (Edwards, 1995, p. 12). Moje's interest in color and experiments in glassmaking led him to work with the new colored glass panels developed by Bullseye Glass in Portland, Oregon and to develop techniques of kilnformed glass. These interests also brought him to Pilchuck in the 1970s, where he taught at Pilchuck in 1979. He returned to the Pacific Northwest many times since to work and teach. Moje moved to Australia in 1982 to start a glass program at the Canberra School of Art and he continues to influence artists internationally with his sculptural work in kilnformed glass.

American artists also traveled to Germany to expand their working knowledge of glass and to study glass manufacturing processes. Paul Marioni, Seattle artist and longtime Pilchuck teacher, traveled to Germany to experiment and expand his technical and artistic boundaries. Marioni was born in 1941 in Cincinnati, Ohio. After graduating from the University of Cincinnati he moved to San Francisco, where he began working with glass. In 1972 he had his first show of stained-glass wall panels. After hearing about 
that show Chihuly, Fritz Dreisbach, Richard Marquis, and Marvin Lipofsky all contacted Marioni to invite him to work with them to promote the medium. In 1974 Marioni began teaching at Pilchuck, and moved to Seattle in 1978, soon after he began teaching. In 1976 he was awarded a National Endowment for the Arts (NEA) grant to study in Germany. Marioni was interested in experimenting with different glassmaking techniques, particularly glass casting, and felt that the German factories had the technical knowledge and materials that could help him. He found that the glassmaking factories were not very interested in letting American artists into their studios to learn or experiment, but he did eventually get permission to work at the A.C. Fischer Glashutte factory.

When I started in late '69 industry wouldn't talk to us - wouldn't let us in or any of my friends that worked with glass. They were very, very guarded. Glass had been a carefully guarded industrial secret for 5,000 years, and who were these young upstarts that were coming along trying to steal the fire, was basically their attitude. ... But by about '77, '78 we were making incredible gains, the glass artists, because we were cooperating. ... So we pretty quickly out-distanced industry. And in '76 I got my first National Endowment grant and applied to A.C. Fischer to work in their factory, used the grant to go to Germany and work in their factory" (Marioni, 2006 ${ }^{8}$ ).

Marioni's description of his time working at A.C. Fischer conveys some sense of anxiety. He was worried about his grant running out, and never received much feedback from the factory manager about his work. So, when he reached the end of his time there, he approached the manager to find out what he owed them for letting him work there. He

\footnotetext{
${ }^{8}$ Paul Marioni, Oral history interview with Paul Marioni, 2006 Sept. 18-19, Archives of American Art, Smithsonian Institution. Interview conducted by Mija Riedel.
} 
describes the manager pulling out an invoice or bill from the desk drawer, and with a flourish, tearing it up and throwing it away because each of them had received something of value from the experience. Marioni has taught at Pilchuck frequently since the 1970s and is well known for his innovative approach to the material and his surrealistic imagery.

$\underline{\text { Sweden }}$

When founding director Thomas Beuchner put together the contemporary section of the newly founded Corning Museum of Glass in 1951, "the contemporary section was primarily production pieces by well-known designers, with Sweden dominating" (Oldknow, 2005, p. 4). In Sweden, art school training in the $20^{\text {th }}$ century was meant to prepare students to work in industrial design. There was not the same separation of art and industry in Sweden as was found in the U.S. Sweden had a longstanding tradition of glassmaking, and Swedish designers actively participated in the contemporary design arena, producing work renowned for its modernism and high quality.

Bertil Vallien, a well-known Swedish glass designer/artist who would spend many summers at Pilchuck, first traveled to the U.S. to work at a commercial ceramics studio in Los Angeles in 1959. Vallien was born in 1938 in Stockholm, and studied ceramics at the School of Arts, Crafts and Design in Stockholm, graduating in 1961. After spending time in the United States, Vallien returned to Sweden to work as a designer for the Kosta Boda/Afors Glass factory in Smäland, a traditional glassmaking region in Sweden. By the 1960s, some traditionally trained designers, including Vallien, began to see themselves as artists as well as designers and wanted more artistic freedom. When Vallien signed his contract with Kosta Boda/Afors, he negotiated to have six 
months of freedom to pursue his own work, and he used the time to develop innovative techniques and pursue sculptural work. His experience in Los Angeles working with experimental potters and ceramic artists had left him wanting this type of creative freedom at home. In the 1960s Vallien gathered a group of like-minded young artistdesigners to collaborate and to socialize at his studio in Smäland. This group included artist Ann Wolff and her husband. In part due to these activities, which attracted media attention and in part because of his innovative factory designs and his sandcast sculptures, he became the most famous artist in Sweden during the 1960s (Lindquist, 1990). At the same time, he also felt a responsibility to the employees of Kosta Boda/Afors and the people in the surrounding communities who depended upon the glass factories for their economic survival and he continued to actively pursue his work as a designer at the company. In some sense, he remained a hybrid of traditional and modern, artist and designer.

In 1980 Vallien returned to the U.S. as artist in residence at Pilchuck along with his wife, fellow artist and designer Ulrica Hydman-Vallien. Vallien taught sand-casting techniques, a specialty that he developed working in the factory. He used his time at Pilchuck, and he went there often, to experiment not just with his signature sandcasting techniques, but also with performance, which he also practiced when he was teaching in Stockholm his time off from Kosta Boda/Afors.

Vallien's enthusiastic approach to experimentation and all forms of art have influenced artists who studied with him. In the technical realm, his sandcasting techniques are used by artists interested in creating solid sculptural forms and using glass 
that does not necessarily look like glass, but can take on the appearance of other material or showcase effects of light and glass.

Sonja Blomdahl is an example of a renowned American artist who traveled to Sweden to learn the glassmaking craft, and also benefited from working with international artists who came to Pilchuck. Originally from Massachusetts, Blomdahl graduated from the Massachusetts College of Art in 1974, where she studied glassblowing with Dan Dailey. In 1976 she traveled to Orrefors, Sweden to study at the Orrefors Glass School for six months. She learned glassblowing, but did not find the work or the approach aesthetically satisfying, so she left (Hackett, 1992).

Blomdahl moved to Seattle in 1978 to work as Dan Dailey's assistant at Pilchuck, and it was there that she developed her interest in expressing symmetry and beauty through her work. It was also at Pilchuck that Blomdahl first worked with the Italian glassblower Checco Ungaro and learned the Italian incalmo technique ${ }^{9}$. After her experience at Pilchuck, Blomdahl remained in Seattle, working and teaching in the city. "In the fall Blomdahl moved to Seattle, working at the Glass Eye with Rob Adamson and Charles Parriott, making art nouveau-type lampshades. Nights she'd teach glass at Pratt Arts Center and was able to use Pratt's equipment to do her own work" (Hackett, 1992). In 1981 she had her first show, at the William Traver Gallery, and by the late 1980s her work had gained critical acclaim.

Blomdahl honed her technical skills in Sweden, but she became known for styles and innovations she developed after she studied at Pilchuck with the Venetians. Pilchuck

\footnotetext{
${ }^{9}$ Incalmo is an Italian technique of joining two glass bubbles of the same diameter together to create a vessel or other glass object. See Appendix D for additional descriptions of glassmaking techniques and terminology.
} 
in particular is known for the influence the Venetians had on artists who studied there, and on the artists in the Seattle region.

Italy

Perhaps most notable of the American study trips were those made to the historically closed studios of the Venetian glassmakers. Pilchuck, with its early emphasis on glassblowing, was particularly indebted to the Venetians. Early in their careers, Seattle-based artists Dale Chihuly, Richard Marquis, Dante Marioni, Benjamin Moore, Ginny Ruffner, and others traveled to the Venini Fabbrica glassworks in Venice to observe, work, and even design pieces for commercial production. When these artists returned to the U.S. they shared their knowledge with other artists at workshops in Seattle area colleges, informal arts workshops, and at Pilchuck.

The Italian glassmaking tradition dates back to the Roman era, and in the northern city of Venice, evidence of glassmaking factories dates back to the seventh or eighth century (Toso, p. 25). Perhaps equally old is the tradition of secrecy. The glassmaking factories are concentrated on the island of Murano in the Venice Lagoon, and factories are typically family run, with workers passing down their skills within the family from one generation to the next. Venetian glass has been admired and traded internationally as a luxury item since the fifteenth century. According to Santillana "To be of Venetian origin was considered a prerequisite for wares and artefacts fashioned from glass destined for Europe's nobility and courts - and if not from Venice itself, then at least blown à la façon de Venise” (Santillana, 2000, p. 9).

Pride in their work and upholding traditions were important parts of the Murano glassmaking community's identity. The long tradition of glassmaking and a system of 
early apprenticeship and training produces the most highly skilled glassmakers in Europe, while the island society and close family connections also produce a suspicion of outsiders. Venetian glassmaking studios and factories produced objects to sell in a competitive market. Once a design went into production, other glassmakers often immediately copied it. The Venetians took great pains to keep their designs secret, to keep competitors from stealing the designs before they went into production. In addition, studio workers were often from the same community, even the same family, and business, family, and community were intermingled. Betraying a company secret could bring shame upon one's family. As artists like Chihuly and Moore discovered when they contacted various glass factories in Venice, most had no interest in allowing foreign artists into their workshops to learn their trade secrets.

Despite this tradition of secrecy, not all of the factories were completely closed to outsiders all of the time. It was not uncommon for some of the more adventurous factory owners to invite guest artists and designers to design works that the local glassmakers produced. For example, in the early 1960s the American designer Thomas Stearns and the Finnish designer Tapia Wirkkala both created work for Venini. However, guest artists were not involved in production. This was to change as the American studio glass artists arrived, first as observers, then as students, eventually as friends and colleagues. Their destination was invariably Venini Fabbrica.

Venini was considered one of the more daring and influential factories on the island in terms of its designs. Partners Giacomo Capellin and Paolo Venini established the Capellin Venini \& C. Glassworks in 1921 on the glassmaking island of Murano. Capellin was an antiques dealer from Venice, and Venini was a lawyer from Milan with 
an interest in glass. From the start, Venini had a more open and experimental attitude compared with other studio factories. The first designer they hired was the artist Vittorio Zecchin, whose award-winning designs influenced Venetian glass styles of the time. When the partners split in 1925, Venini continued on, hiring sculptor Napoleon Martinuzzi as artistic director. Martinuzzi was followed in the 1930s by Italian architect Carlo Scarpa, whose classic designs based on antiquity had a dramatic impact on several of the American artists (Ricke \& Schmitt, 1997, p. 17). In 1959, after Paolo Venini died, his son-in-law, architect Ludovico Diaz de Santillana took over the factory. Santillana continued Venini's tradition of openness to new ideas and welcomed several generations of American studio glass artists.

The first of the studio glass artists who studied in Venice and later settled in Seattle was Chihuly, who received a Fulbright Fellowship to study in Italy in 1968. He wrote to several glass factories in Murano seeking a place to study. Only Venini replied with an invitation. Chihuly was allowed to observe the glassblowers at work and engaged in some design work, but did not do any glassblowing during his stay. In addition to observing the teams of skilled glassblowers in action, Chihuly also observed artisans performing glass casting, making murrine canes, grinding glass, and making glass molds. (Frantz, 2007, p. 24-25).

Richard Marquis traveled and worked in Venice from 1969-1970, also courtesy of a Fulbright Fellowship. After his first visit to Murano in 1969 he returned many times. On his first trip to Venice, in 1969, Marquis was determined to get some hands-on experience working with Venetian glassmakers. He decided to contact local glassmakers after he arrived on Murano to try to find a sympathetic host. His first experience was with 
Salviati \& Co., where he was allowed to observe. He soon approached Santillana at Venini. As with Chihuly, Santillana offered Marquis the opportunity to design some pieces, some of which Venini put into production. Marquis also performed time-motion studies of the glassblowing operations before he finally got his wish and was allowed to blow glass. Marquis remembers, "It was just amazing, everything I saw and no one really knew why I wanted to blow glass... because I was skilled like about a 10 year old but I wanted to do it myself and so they helped me out" (Pottinger, 2008.) He worked with maestro Francesco "Checco" Ongaro's team (Frantz, 2007, p. 25), and became particularly interested in working with murrine glass. Murrine is a Murano glass specialty and Marquis became known for works that incorporated murrine. The murrine technique involves creating long glass rods (canes) composed of different glass colors, and then slicing the canes to reveal flat disks with complex patterns. Marquis acknowledged the influence of the designer Scarpa on his work through his "Marquiscarpa" series created in 1995 in which Marquis showcased the murrine technique but with modern forms and colors. In 1970-71 Marquis taught classes in glass and ceramics at the University of Washington in Seattle, and in 1983 he moved to the Puget Sound region. He also taught for many years at UCLA and spent much of his career traveling, teaching, collaborating with other artists, and producing solo works.

Benjamin Moore, who worked at Venini in 1977-1978, represents the next generation of Seattle studio-glass artists to travel to Europe. Born in 1952 in Olympia, Washington, Moore graduated from the California College of Arts and Crafts in 1974 with a BFA in ceramics. While there, he also studied glassmaking under Lipofsky. After graduating he attended a workshop at Pilchuck, where he first met Chihuly, who 
encouraged him to attend Rhode Island School of Design (RISD). He graduated from RISD with an MFA in 1977. Moore knew that if he wanted to develop skills and learn the craft, he had to go to Europe. He remembered that he "wrote about 15 letters to various studios in Venice. Received one terse reply, from Venini's factory. It was from Ludovico de Santillana, son-in-law to Venini” (Moore, $2010^{10}$ ). With the invitation from Santillana, Moore headed to Venice in the fall of 1977, and spent about nine months working and studying at Venini.

By the late 1970s, the studio glass movement in the United States had moved far beyond the drippy glass blobs that had characterized the early experimental work, and artists like Benjamin Moore were justly proud of their glassmaking abilities. Moore had prepared a demonstration for his first week at Venini to show off his skills, but quickly realized upon arrival that his abilities were nowhere near the level of the Venetian masters, and the Italians were hardly impressed with his demo. But, as Moore remembers it, "Lino and the Italians first saw a Neanderthal approach and skills, but they admired the no-holds-barred attitude to the material..." (Moore, 2010 ${ }^{11}$ ). Moore was a keen observer and student of all aspects of glass production and techniques at Venini, and he learned quickly while working as a member of maestro Checco Ongaro's team. Eventually Moore designed work that sold under the Venini name. However, his work did not appear in the glassmaker's catalog raisonné published in 2000, which art critic Matthew Kangas (2005) said reflected the Venetian glassmakers' discontent with Moore's role in bringing Venetian techniques and Venetian glassblowers to Pilchuck, and through Pilchuck, to the United States. A 2005 Glass Quarterly article identifies Moore

\footnotetext{
${ }^{10}$ Benjamin Moore, interview with the author, February, 2010.

${ }^{11}$ Benjamin Moore, interview with the author, February, 2010.
} 
as "at the forefront of the Murano-Pilchuck interchange of ideas, techniques, and talent" and credits Moore with indirectly changing Murano glassmaking traditions through this interchange (Kangas, 2005, p. 27). Moore was one of the few American artists at Venini who spoke Italian; he even learned the Venetian dialect to better communicate with the factory workers (Frantz, 2007, p. 29). Like Marquis, he made personal connections with several of the workers and became friends with Ongaro and his family. He also carefully studied everything he encountered, and brought detailed information about all aspects of the glassblowing processes to Pilchuck. And at his studio in Seattle, Moore collaborated with and mentored other artists to produce high-quality works that incorporated techniques learned from the Venetian masters.

After his European experience Moore returned to Seattle in 1978, becoming the first educational coordinator at Pilchuck, and was in charge of the visiting artist program at Pilchuck. It was Moore who convinced the first of the Venetians to teach at Pilchuck. "In Spring of 1978 I asked Ongaro to come to Pilchuck. ... Ongaro was the first true Venetian master to come to U.S. to teach glassmaking" (Moore, 2010 ${ }^{12}$ ). Although Ongaro's teaching experience was quite successful, he declined an invitation to return for a second year and suggested instead that they talk to his brother-in-law, Lino Tagliapietra.

Tagliapietra was born in 1934 on the island of Murano in Venice, and began his apprenticeship in glassmaking soon after he was 10 years old, working at Archimede Seguso. In 1955, after returning from military service, he began working at the Galliano Ferro factory, where he specialized in making goblets, and by age 22 he earned the title

\footnotetext{
${ }^{12}$ Benjamin Moore, interview with the author, February, 2010.
} 
of maestro. A few years later, in 1960 his goblets were exhibited at the XXX Venice Biennale. Tagliapietra's goblets were designed by someone else, but as early as 1966 he showed an interest in design and began to move in that direction, while continuing his work as a master glassblower (Frantz, 2008, p. 155). In 1968 he started La Murrina glassworks along with two partners and began producing work that he designed along with producing work by other designers; in 1977 he became head of design and production at Effetre. Until this time, his entire career had taken place on Murano, and had followed a fairly traditional pattern for master glassblowers there. This changed when, in 1979, Tagliapietra was invited to demonstrate glassblowing at Pilchuck. He returned every year for the next 10 years. Eventually he established a studio in Seattle, and traveled between Seattle and Murano regularly. Tagliapietra "had a huge impact on the scene" (Moore, 2010 ${ }^{13}$ ), and he influenced many Pacific Northwest artists through his teaching at Pilchuck, Pratt, and Bullseye Glass in Portland. Prominent Seattle artists who studied with Tagliapietra include Dante Marioni and Preston Singletary among numerous others.

The flow of American students who visited and worked at Venini continued through the 1980s, 1990s, and beyond, and included many of Seattle's most well known studio glass artists, including Ginny Ruffner, Dante Marioni, etc. However, with the arrival and continued presence of the Venetians at Pilchuck, Seattle became prime destination for students who wanted to learn the Venetian glassmaking techniques but who could not afford to travel to Venice or were not allowed access to Venetian factories. This group soon included glassmakers and artists from other countries.

\footnotetext{
${ }^{13}$ Benjamin Moore, interview with the author, February, 2010.
} 
A 2007 exhibition organized by the Carnegie Museum of Art, Viva Vetro! Glass Alive! explored the interaction between American studio glass artists and Venetian glassmakers. The works showcased by this exhibition clearly demonstrate the influence of the Venetians on the Americans. What did these artists bring back? Each found something different, but they all gained an instant respect for the incredible skills of the Italian glass designers and glassmakers that they met. Marquis became a master of the Venetian cane technique. Moore developed the skills to create extremely thin-walled, classical shapes in glass, and also learned skills that enabled him to design work for commercial production in the United States. Blomdahl mastered the difficult incalmo technique.

One of the major influences of the Venetians upon the Pacific Northwest artists was the adoption of the team approach to glassmaking. It is somewhat ironic that Chihuly, who shared Littleton's ambition of making glass an accepted fine arts medium, drew the opposite conclusion from his Italian sojourns that Littleton arrived at after his European visits. Chihuly concluded that the idea of an individual artist working in isolation would not work well with glass, and the team approach was a better idea. His experiences at Venini and at the Haystack Mountain School of Crafts in Maine provided two primary models for Pilchuck.

Another influence was aesthetic. Like most of the American artists who spent time in Venice, Chihuly was impressed by the work of the Venetian designers of the early twentieth century, including Venini designer Napoleone Martinuzzi. One of Chihuly's most highly regarded series, "The Venetians," which he began in 1988, was inspired by the work of Martinuzzi and Scarpa and was his homage to Venice and Venetian glass, 
and Tagliapietra was the chief glassblower for the project. Other artists, including Moore and Marquis, were strongly influenced by the architect/designer Scarpa's work.

Venetian studios had played host to foreign artists before the wave of U.S. artists arrived in the 1960s, and Venetian glassblowers were used to fabricating works based on designs created by major European artists including Pablo Picasso, Jean Arp, Max Ernst, and Seattle artist Mark Tobey. The difference was that American studio glass artists were not content to simply create designs and let the Venetian master craftsmen execute them. The American artists wanted to get in there and work with the Venetians, to use their tools and learn their processes, and take this knowledge away with them. This did not always sit well with the factory workers and master craftsmen. In one essay in the Venini Catalog Raisonné, curator and writer Victoria Milne describes the "importance of beauty" as a shared interest of Venini studio and the U.S. studio glass movement (Milne, 2000, p.33). She goes on to compare the influence of Venini on American studio glass to the influence of the tomato on Italian cooking. In summary, she compares Italian glassmakers with the Catholic missionaries bringing the Word to the Americas, with the results being a new religion that mixes the old and new cultures and beliefs. "In our American excitement, we have created a glass working culture that in some respects, may be considered at least pointless and at worst sacrilegious to the old world of Murano" (Milne, 2000, p. 36-37).

Venetians clearly thought highly of their contribution to the American studio glass movement, but the early generations of studio glass artists were not short on bravado and confidence in their own talents. Marquis remembers, "In the "60s blowing glass in Berkeley California, we pretty much thought we were inventing glassblowing" 
(Pottinger, 2008). They learned the truth about their own skills when they went to Europe.

Marquis and Moore successfully established working relationships and friendships with Murano glass workers. Marquis was working at Venini during the 1960s, when there were many strikes and labor disputes between the glass factory workers and managers and he "stood with the workers during the strikes so that he might preserve his relationships with them" (Frantz, 2007, p. 25). Given that Marquis was a politically active art student from Berkeley, whose artwork reflected his anti-establishment politics, supporting striking workers was probably more than just a symbolic gesture, and perhaps helped break through some of the suspicion often directed toward foreign visiting artists. A few years later, Moore's friendship with Ongaro was a major factor in the Italian's decision to accept an invitation from Moore to teach at Pilchuck in 1978. Ongaro decided he preferred to work in Murano, but thought well enough of his experience at the school to recommend it to his brother-in-law, Lino Tagliapietra. Tagliapietra, widely renowned as an international master artist working in glass, eventually settled in the Seattle area and became part of Seattle's artist community.

\section{Discussion}

There is no doubt that the connections that the interactions between artists from the United States and from Europe advanced the spread of technical knowledge, especially among American studio glass artists. They also expanded the artist networks beyond the initial, university-based connections into the traditional centers of glassmaking production in several European countries. American studio glass artists were motivated to seek out the traditional knowledge embedded within these European 
networks, and they were supported in many cases through state cultural policies established because it was seen to be in the interest of the nation (Becker, 2008). The mechanisms of state support in this case were the Fulbright fellowships and National Endowment for the Arts (NEA) grants that a few select artist received to subsidize their travel and time spent in Europe. The Fulbright Fellowship got its start in 1945 when the U.S. Congress established the program with the goal of supporting international student exchanges as a way of generating improved "international good will" (Fulbright website, 2013). The NEA was created in 1965 under President Lyndon B. Johnson, to promote American arts and cultural traditions. These programs did not directly commission or fund a specific artistic production in this case, but they became part of what Jackson termed an artist "support structure" by providing both validation and material support (Jackson, 2004). Being awarded a grant or fellowship by a respected source not only provided an artist with a personal sense of accomplishment, but also provided an official credential of artistic identity (Jackson, 2004). An official grant from an academic or government organization was also helpful for artists trying to bridge different cultural systems and geographic networks.

Regional glassmaking centers, like the island of Murano in Venice, and Smäland in Sweden, were centers of specialized knowledge. The people who worked in the glassmaking factories were members of local social networks characterized by Granovetter's (1974) definition of strong ties, reinforced by the amount of time spent together, and neighborhood and family connections, which in some cases extended back generations. These networks were essentially closed to those who were not from the community. For the Venetians, inviting American artists to work in a studio or worse, 
traveling to the United States to teach American students Venetian glassmaking secrets was not without risk. As Benjamin Moore remembers: "At Pilchuck, sharing was typical; this was not typical of Europe. Especially the Venetians. When Lino Tagliapietra came over to teach at Pilchuck, other Venetians began calling him 'Americano' - it was an insult. He got many derogatory comments and grief from other Venetians. For example...Carlo Tosi was asked about Lino's decision to teach in the United States and the influence of Lino Tagliapietra and replied 'it was like selling your wife on the street'" (Moore, 2010 ${ }^{14}$.

Given this situation, what did the European glassmakers have to gain from letting American artists with little background in or skills with glassmaking into their studios, where both tradition and the market demanded secrecy? The American studio glass artists were drawn to Europe by the need for knowledge, and some European studio glass artists and glassmakers were also interested in the glassmaking activities going on in the United States. The relationships that were established between the American artists who traveled and worked in Europe provide examples of social capital in process (Granovetter, 1973, Coleman, 1988, Putnam, 2000). The original connections were examples of weak ties, as they were not based on personal or local relationships but were created through the actions of student artists petitioning to be allowed to work and study at local glass factories. As the artists worked and socialized together, they built up trust and a level of reciprocity, which strengthened the personal ties, and created stronger bridging social capital (Putnam, 2000). When the European artists began making regular trips to

\footnotetext{
${ }^{14}$ Benjamin Moore, interview with the author, February, 2010.
} 
educational institutions in the United States, including Pilchuck, these relationships deepened.

At Pilchuck, European and American artists got a chance to interact with students and fellow glassmaking masters from around the world, something they could not experience on their home turf, where collaborating and exchanging technical knowledge would have been seen as a betrayal of trade secrets and tradition. Moje described the atmosphere during these international interactions, "The Italians were looking at the Scandinavians, the Scandinavians at the Italians, the Americans were in awe of both of them, and I was watching all of them together" (Guenther \& Klein, 2007, p. 40). Through these interactions, new bridging capital was created among different European studio glass artist networks, not just between European and American studio glass artists. These new networks and opportunities to experiment and work together with an international cohort of studio glass artists at Pilchuck in particular, opened up new opportunities for European artists.

Some of the Europeans experienced a freedom to experiment that they did not have at home. They tried experiments that resulted in innovations and a new sense of creative freedom. Another effect was the blurring of the line between artisan and artist. As a maestro on Murano, Tagliapietra enjoyed a position of status and prestige in his community, but his actions and future were circumscribed by tradition. In Seattle, he went from being a master craftsman in a small community to a career as internationally renowned artist. In an interview with Seattle art critic Matthew Kangas, Tagliapietra discusses this as a reason for staying in the U.S. "I was born on the Rio de Vetrai, the 'glassblowers channel' in Murano but, in America, I became a better artist... Now, I 
make what I want" (Tagliapietra, in Kangas, 2007, p. 17). The Europeans could also relax and let go of some of the professionalism required by the factory system with its designer/worker hierarchies. When Vallien was asked why he went to the U.S. he replied: “They dared to make mistakes, in order to find new directions" (Lindquist, 1990, p. 19). Making mistakes was not encouraged in a factory setting.

Unlike many European educational organizations, Pilchuck had no industry connections and the Europeans could work on personal projects if they liked. Because of the separation between artistic education and industrial applications, students and faculty did not have to worry about the marketability of their work, at least not while they were in the educational setting. Vallien noted that he enjoyed teaching in the United States because he was free to ignore industrial applications and potential markets when discussing and introducing new ideas (Lindquist, 1990). This separation of market and art brought a new source of energy and innovation into the more tradition-bound European studios. Some artists brought new ways of working back to their individual studios and their industrial workshops. For example, Vallien designed projects that encouraged the glass factory workers to individualize each piece, creating a hybrid of mass produced and unique handmade object (Lindquist, 1990, p. 66). Others decided that they preferred an approach or environment found in one of their host countries and stayed on as residents; some went on the found new schools and programs in countries that did not have a tradition of glassmaking, as Moje did in Australia, and few, like Lino Tagliapietra split their time between their original country of origin and the United States, maintaining successful careers in both places. 
American artists came away from their international experiences with increased skills and technical abilities, increased knowledge of the history of glassmaking and the achievements of European artists, designers, and craftspeople. The technical skills included knowledge of better tools, processes, and techniques including how to create glass canes, murrine and filigree, improved glassblowing skills and experience working with color. Glass casting, pâte-de-verre ${ }^{15}$, working with flat glass and stained glass, and an increased knowledge of architectural glass design helped artists move into the realm of public art. Studio glass artists passed on this knowledge, which provided the foundation set of skills for the following generations of artists, allowing the work, the material and the artist conception to take center stage as needed. Interactions with Europeans also enhanced the international reputation of many American artists, including Chihuly, Marquis, Moore and others. Other artists and students were attracted to settings where they could work with people who had studied in Europe. After European master glass artists showed up regularly at Pilchuck to teach, the reputation of the school increased. This meant that more artists from more places, nationally and internationally, came to Pilchuck, and many stayed in the region to become part of the artist community there.

The history of international connections between U.S. artists and European glassmakers is one of cross-fertilization and collaboration, along with some suspicion, and confidence on both sides that each brought some unique knowledge to the exchange. These exchanges helped foster an international community of artists, and represented a significant expansion in the social networks of the studio glass communities in both Europe and the United States. European glassmakers typically were part of close

\footnotetext{
${ }^{15}$ See Appendix D for descriptions of glassmaking techniques and terminology.
} 
networks of fellow glassmakers and designers, but these networks were limited to their local regions and in some cases, tied to local factories and families, where knowledge was tightly held rather than shared. These early international exchanges, together with the professional associations and conferences that sprung up in the 1970s, propelled the studio glass community into the international sphere, as people forged friendships and working relationships that transcended geographic boundaries, and this international expansiveness continued over the decades. The openness of the exchanges developed through the expanded artist networks meant that old traditions and new ideas could spread quickly throughout the studio glass community. Traditional knowledge and new skills were passed from one artist to another, with artists free to take glass in yet another direction, as they grew more familiar with the material. Expanded networks opened up new avenues of information exchange.

The artist networks created were international and were based on knowledge exchange and shared working experiences rather than geography. However, these interactions took place in a few key locations, which were formal or informal learning institutions. One of these was Pilchuck. Pilchuck earned a preeminent position in the network because it had offered some advantages over the standard academic visiting artist situation. At Pilchuck, not only did students and faculty have the opportunity to work with a diverse group of international artists who made the summer workshops a regular stop on their itinerary, but also the workshops were longer, which provided more opportunity for more intense learning experiences. As the same artists returned year after year, shared experiences helped create increased trust and reciprocity, and relationships deepened, creating stronger networks. In some cases replacing bridging social capital 
with bonding social capital, especially among the small group of artists who were the first to experience the European sojourns. The sites of knowledge exchange were still placebased, located at a relatively small number of locations, including the Pilchuck Glass School in Stanwood, Washington and expanding to include Pratt Fine Arts Center in Seattle. 


\section{Chapter 6: Consolidation and Fragmentation: 1977 - 1985}

\section{Introduction}

The years between 1977 and 1985 were critical for establishing glass as the medium associated with the Puget Sound region, and for establishing Pilchuck as the premier arts education program for working with glass. These years were marked by rapid change at Pilchuck, which encompassed a major building campaign, a new organizational structure, and a drive to recruit an international faculty and student body. Organizational changes transformed Pilchuck "from camp to campus" (Oldknow, 1996, p. 148). The arrival of European artists in 1978 and after, and the sustained efforts by the school's representatives to bring Pilchuck artists and glass art to the notice of collectors, critics, dealers and the media, helped create and publicize an association between glass art and the Puget Sound region. The school's increasing fame and the growing numbers of artists in Seattle attracted media attention and brought more glass artists to the region.

During this time, debates about craft versus art, self-taught versus academically trained, process and theory versus product intensified. The original attitudes that anything goes and everyone was welcome became more contentious. These conflicts played out among artists at Pilchuck, at private studios, and in the marketplace, as artists moved beyond basic technical issues of how to work with glass and began to think about what they wanted to express through their work, their careers, and how to make a living while continuing to work in their chosen medium. These conflicts produced splits within the community. At the same time, the teamwork that glass required and the specialized knowledge that the veteran artists had acquired meant that artists who produced work for 
different reasons and different markets continued to work together as needed, especially as demand for their output grew and projects became more ambitious, incorporating multiple approaches and multimedia.

Economic changes, population growth, cultural policies that supported public art, more art galleries, and a commercial construction boom in the downtown core provided additional places for showing and selling art. Glass art moved from street fairs to new galleries and local arts institutions, and became more mainstream. The Seattle Art Museum had its first exhibition devoted to glass art in 1977, and studio glass art was featured regularly in galleries throughout the region. Many of the artists who went on to achieve success as independent artists or as members of Chihuly's glassmaking team arrived at Pilchuck in the late 1970s and settled in Seattle, where they played a critical roles in growing the city's art scene, and changing the cultural landscape.

\section{The Seattle scene: 1977 -1985}

If the 1980s could be said to be the era when Pilchuck shed its countercultural, hippie past in favor of a more organized, hierarchical, institutional outlook, then in some measure it was treading the same path as Seattle, where business interests, political elites, and grassroots neighborhood activists were hard at work trying to remake the city. The economic picture at the end of the 1970s was not completely rosy, but by the mid-1980s the city was in the midst of an economic and physical transformation.

Industries that depended on natural resource extraction like the timber industry declined, but at the same time, other industries began to expand, and in Washington, "high-tech employment increased 28 percent during those tough four years" (Boswell \& McConaghy, 1991). Among the high-tech firms was a small startup named Microsoft 
that moved from Albuquerque, New Mexico to Redmond, Washington, across Lake Washington from Seattle in 1977. Microsoft would soon grow beyond anyone's wildest dreams, except perhaps those of its founder, Bill Gates. In downtown Seattle, Starbucks, a small, local coffee shop started by a couple of former teachers, hired Howard Schultz as a partner in 1982. Schultz almost immediately proposed that the business expand within the city and consider opening locations outside Seattle. A weak American dollar and a revitalized Port of Seattle brought increased trade between Seattle and Asia, and Boeing employment had recovered from its 1970s slump (Abbott, 1993, Moody, 2003).

Downtown developers encouraged by the improved economy built many new office towers in Seattle's downtown area, and city planners and boosters drew up ambitious plans to create new venues for local arts institutions, including the Seattle Art Museum and the Seattle Opera. From 1971 to 1985, according to Moody (2003) developers built "fifteen million new square feet of office space" downtown (p. 66). Along with all of this new activity came an influx of new residents, who flocked to new cultural activities and entertainment venues including new restaurants, galleries, and clubs, where they could meet other newcomers, dine on local cuisine, view the latest local artistic creations, and listen to a local music, including several local bands that would later be grouped together and marketed as a new movement, labeled grunge music.

Seattle's new residents included a noticeable contingent of artists. Several of the city's former industrial areas hit hard by the 1970s recession became home to artists. Artists settled into studios in the Pioneer Square, Lake Union, Fremont, and Ballard neighborhoods. Lake Union, an industrial neighborhood alongside a small lake and a canal that connects Lake Washington to Puget Sound, was home to a cluster of artists and 
art studios and an old industrial gasworks that was remade into an urban park. Fremont and Ballard were working-class neighborhoods just north of the Lake Union canal that also contained a large number of old industrial buildings suitable for remaking into art studios.

In the downtown area, Pioneer Square supported a healthy arts and club scene in the 1970s and 1980s, whose presence attracted media attention beyond the city. In 1986 a national art magazine, Art in America, published a two-part article featuring Seattle's art scene. According to Seattle Times art critic Regina Hackett, it had been 10 years since the national visual arts world had taken an interest in arts activities in Seattle (Hackett, 1986, p. C7). The Art in America article was written by critic Bill Berkson and featured Seattle artists considered to be the top artists of the time in the city, organized by discipline. The article paid most attention to the status of painting and the persistent influence, or lack of influence, of the Pacific Northwest School, the only art movement from the region to catch the fancy of the New York art world up to this time. Berkson described the current artistic styles as "anywhereisms complicated by the near impossibility of ignoring the local climate and regional history" along with a lack of a regional aesthetic or style (Berkson, 1986, p. 29). The article placed the work of studio glass artists in the sculpture category, identified Chihuly as "The old master of the 'studio glass' movement," noted his role at Pilchuck and his current Macchias series. Chihuly gets only a few more words devoted to his work than fellow Seattle studio glass artists William Morris, Keke Cribbs, Richard Marquis, Flora Mace, Joey Kirkpatrick, Charles Parriott and Walter Lieberman. Artists Nancy Mee and Ginny Ruffner were noted for their "feminist content" along with their chosen medium of glass (Berkson, p. 38). Berkson's article represented a victory of 
sorts for the studio glass artists, as it clearly put the work into the fine arts realm, and noted the conceptual nature of the work when that was the artist's intent.

\section{A market emerges: galleries and glass}

Just as Pilchuck was remaking itself into a more academic organization that emphasized theory over making, studio glass artists in Seattle chose to promote themselves and their work either as art or craft, reflecting the larger arguments and divisions within the art world of the time. Pilchuck had a reputation as a center for glassblowing, a traditional technique for making vessels, a recognized utilitarian and craft form, but not commonly identified as a fine arts sculptural form. For a vessel to be considered a sculpture, it had to lose its identity as a vessel, even if it maintained the form. During this time, Pilchuck's public affirmation of its academic status, and the program expansion into other methods of glassmaking production and increased emphasis on theory were all part of an attempt to position the school as a fine arts school rather than a craft workshop. For studio glass artists, the art versus craft distinction was less about how the makers produced their work as it was about their intent, how they marketed themselves and where they exhibited and sold their work. Art galleries and art museums sought work for exhibitions that was not of the conventional glass vessel variety, but reflected a more theoretical and experimental approach to glass as sculpture. "The difference between art and craft and who falls into what camp, and the difference between innovation and novelty" (Hackett, 8/2/1981) were hot topics that Seattle artists argued and debated at the time. Many artists working in glass abandoned the vessel form in favor of sand casting, or kiln formed glass, or produced multimedia work that incorporated glass elements as minor or major components of the work. For Chihuly, the 
consummate vessel maker, the increasing scale of his work precluded utilitarian connections. He categorized himself as a sculptor and an installation artist early in his career, and he continued to do so. With the rise of feminism and postmodernism, the line between art and craft was challenged repeatedly, and galleries and museums began to exhibit work that they would not previously have admitted into the fine arts category.

Until the mid-1970s opportunities for showing glass in museums and galleries anywhere in the United States outside the Corning Museum of Glass, and the Renwick Gallery of the Smithsonian American Art Museum (which opened in 1972) were limited. In 1976 the Heller Gallery in New York City began to specialize in studio glass art, becoming the first gallery to do so in that city. During the latter part of the decade the number of galleries displaying studio glass art began to grow and studio glass found a market (Oldknow, 1996, p. 156). This was the breakthrough era for anyone who had a stake in promoting the art of glass in the Seattle area, and that included Pilchuck artists, patrons, and gallery owners.

The arts scene in Seattle was still fairly small in the late 1970s, and was centered around Pioneer Square and nearby Occidental Park, both of which had been saved from demolition and revitalized in the early 1970s thanks to the efforts of urban activists and historic preservationists. The galleries in that neighborhood included Polly Friedlander, Silver Image, Foster/White, Linda Farris, and Davidson (Hackett, 2006). In the late 1970s a few new galleries emerged, including the Traver Sutton gallery. William Traver is a Seattle native who attended Cornish Art School, and realized at that time that many of the artists he studied with needed someone to help them market their work (Traver, $2010^{16}$ ).

\footnotetext{
${ }^{16}$ William Traver (gallery owner), interview with the author, 2010.
} 
He started the Traver Gallery in Belltown, near downtown Seattle in September of 1977 to promote the work of Northwest artists.

There was a minimal arts scene in Seattle at that time... we were the new kids on the block. We found this space in a deserted part of town, which was in Belltown. ... You could rent a space for about $\$ 50$ a month (Traver, $2010^{17}$ ).

Soon after Traver opened his gallery, Pilchuck patron Anne Gould Hauberg approached Traver and asked him to do a show of Pilchuck artists. The show became an annual event and helped establish Traver Gallery as a leader in the exhibition and marketing of studio glass art in the Pacific Northwest (Traver, 2010 ${ }^{18}$ ).

By 1977 it was easy to find studio glass art on exhibition in Seattle, especially shows featuring artists with Pilchuck connections. In addition to the Traver Gallery, the Polly Friedlander Gallery and the Foster/White Gallery began regularly to show the work of studio glass artists. Even the Seattle Art Museum got into the act. A visitor to Seattle in October of 1977 had a choice of three studio glass exhibitions, all featuring Pilchuck artists. During this time, the Seattle Art Museum's Modern Art Pavilion at the Seattle Center was showing work by Chihuly and fellow studio glass artists Italo Scanga and James Carpenter. The Foster/White Gallery was showing Chihuly's work, and the Polly Friedlander Gallery featured work by Pilchuck teachers and students (Campbell, 1977). In addition to having his work in all three exhibitions, Chihuly curated the Polly Friedlander exhibition, which included work from more than 20 Pilchuck artist and teachers. Local artists Fritz Dreisbach, Paul Marioni, Robert Adamson, and Benjamin Moore also had work in the Pilchuck group exhibition (Oldknow, 1996).

\footnotetext{
${ }^{17}$ William Traver (gallery owner), interview with the author, 2010.

${ }^{18}$ William Traver (gallery owner), interview with the author, 2010.
} 
The 1977 exhibition at the Seattle Art Museum was that institution's first exhibition devoted to glass. New York City art dealer Charles Cowles curated the show, which featured Chihuly's Pilchuck Basket series. The Basket series had regional connections; it was inspired by Native American baskets Chihuly saw at the Washington State History Museum. The Seattle Art Museum exhibition also included works by James Carpenter, Chihuly's long-time collaborator from Rhode Island School of Design, and by Italo Scanga, Chihuly's close friend and Pilchuck faculty member. The Seattle Art Museum sponsored annual Pilchuck shows when Pilchuck was part of the Pacific Northwest Arts Center (PNAC) from 1972 to 1975, but these shows were modest events, typically held in a small, downtown gallery space in Pioneer Square. The Modern Art Pavilion at Seattle Center provided a more conspicuous venue, in one of Seattle's top tourist destinations. Tourists from around the world could see studio glass art by Pilchuck artists on their way to or from the Space Needle.

Chihuly received the most exposure in Seattle galleries at this time, but others were given credit for being more avant-garde. Seattle art critic Matthew Kangas (1991) noted that studio glass artists in this era "challenged basic assumptions of their medium, like transparency and perfection of form, jerry-rigged it to conceptual and often political content, and emerged with individual statements" (p. 58). This description fits several artists who arrived in Seattle during this period, including Walter Lieberman, Paul Marioni, Ginny Ruffner, and Therman Statom. However, the 1980s also brought new artists to Seattle who had their own interpretations of the medium, not all of them interested in "challenging the form" (Kangas, 1991, p. 58) 
Therman Statom and Sonja Blomdahl provide examples of two artists whose work represents the spectrum of studio glass art being shown in Seattle's fine arts galleries during the early 1980s.

Statom attended Pilchuck during its first year of operation in 1971, and from there went on to study sculpture at Rhode Island School of Design under Chihuly. After graduating in 1974 he earned an MFA from Pratt Institute of Art and Design in New York. By 1980 his work was included in the exhibition "Four Leaders in Glass" at the Craft and Folk Art Museum in Los Angeles along with Dale Chihuly, Richard Marquis, and Dick Weiss (January 29-March 23, 1980). A glass installation he created at the Traver Gallery in April of 1980 was featured in a half-page article on studio glass artists in Seattle (Hackett, 1981).

Statom's work did not fall into the traditional glassblowing categories celebrated at Pilchuck. "I taught glass at Pilchuck when everyone was obsessed with the Italians, and they didn't do jack with it at first. I hated Italian glass, I hated Lino, the whole thing. People were thinking about how to do things rather than what they were doing" (Statom, 1997, p. 62). Statom experimented with glass as a sculptural medium, and combined cast and flat glass, paint, and other materials to create works that ranged from palm-size sculpture to gallery-size installations. His imagery included sculptural forms of houses, chairs and ladders with abstract painted marks on their surfaces. Chairs and ladders both became long-running themes in his work. "The chairs and ladders are really by-products of my installations. No one wanted a chair until I put one in a show at the American Craft Museum; then everyone wanted it" (Statom, 1997, p. 62). Statom's working methods 
and approaches placed him in the category of an artist who works with glass, beyond the label of studio glass artist.

Sonja Blomdahl's work is about the perfection of the form, and the form is always a vessel, created using traditional glassblowing techniques. Blomdahl graduated from the Massachusetts College of Art in 1974, where she studied glassblowing with Dailey. In 1976 she traveled to Orrefors, Sweden to study at the Orrefors Glass School for six months. She learned glassblowing, but did not find the work or the approach aesthetically satisfying (Hackett, 1992). Blomdahl arrived in Seattle in 1978 to work as Dan Dailey's assistant at Pilchuck. At Pilchuck she worked with the Venetian maestro Lino Tagliapietra and it was there that she discovered an interest in expressing symmetry and beauty through her work, and developed her mature style. After her experience at Pilchuck, Blomdahl remained in Seattle, working at her Lake Union Studio and teaching at Pratt Fine Arts Center in the city. "In the fall Blomdahl moved to Seattle, working at the Glass Eye with Rob Adamson and Charles Parriott, making art nouveau-type lampshades. Nights she'd teach glass at Pratt Arts Center and was able to use Pratt's equipment to do her own work" (Hackett, 1992). Her career took off in the 1980s.

In 1981 Blomdahl had her first show, at the William Traver Gallery, and by 1985 her work had gained critical acclaim and was widely known and popular first in Seattle and then worldwide (Waggoner, 2000; Moody, 2003). Rather than trying to avoid or work against the beauty and physical qualities of glass as so many of her contemporaries did, Blomdahl embraced these qualities and worked with them. She created her simple, colorful bowls and vases using a traditional Venetian technique for creating bands of color in glass. While the resulting forms are simple and classical shapes, the technique is 
challenging and requires great skill to execute. When asked about critics who said her work "lacked content" Blomdahl replied: "I have never followed trends in glass or art. But I feel my work has content that is communicated through color, light, reflection and the vessel form itself. The response I get from galleries and collectors is that in a room full of glassworks, these pieces have their own voice" (Blomdahl, quoted in Waggoner, 2000). Blomdahl represented the craft artist, and she brought together the factory traditions of glassblowing with a $20^{\text {th }}$ century sensibility in her work.

\section{Spaces for artistic production}

Blomdahl was one of the few Seattle studio glass artists who had her own glassmaking studio in the early 1980s, but she was perhaps unusually practical for an artist of the time. Blomdahl was determined to do things her way and make a living as a professional artist, and she was not a Pilchuck insider. To be able to work independently she had to sell her work for an amount that could support herself and her work as a professional. At that time, Blomdahl decided that was about $\$ 300$, because as she stated: "I had just been to the dentist, and that cost me \$300. I'm a professional, too, and I thought that seemed a fair price" (Blomdahl, quoted in Waggoner, 2000). At that time, most artists did not expect to make a lot of money from selling their work, and the cost of setting up a glassmaking studio was high. To get their work done, studio glass artists would barter for studio time and trade labor, working on each other's teams to complete projects (Kirkpatrick, 2011 Moore, $2011^{19}$ ). Even Chihuly continued to produce his work at Pilchuck and then at The Glass Eye, a commercial production studio, from when he first moved to Seattle in 1982, until he set up his own hot shop there. After Chihuly

\footnotetext{
${ }^{19}$ Joey Kirkpatrick and Benjamin Moore, speaking at a Tacoma Art Museum panel discussion, with artists Joey Kirkpatrick, Flora Mace, Benjamin Moore, and Richard Royal, September, 2011.
} 
provided the model, other studio glass artists set out to establish individual studios (Kirkpatrick, 2011).

$\underline{\text { Artist studios, production studios, commercial studios }}$

When studio glass artists talk about studio spaces, they tend to categorize them several ways that can be confusing. The common terms used include: artist studios, production studios (also known as artist production studios), commercial studios (sometimes also called production studios), and open access or public access studios. Each represents a different type of studio based on the category and destination of the work, the scale or number of pieces produced, and even the artist whose work is being produced. The terms were often used interchangeably, which demonstrates that the categories were not clearly defined, or were contested by those who don't find the distinctions valid. While these are the terms used currently, it's not clear that the distinctions were as meaningful in the 1970s or early 1980s when the community was smaller and the working arrangements more informal; studio glass artists were likely to work and to produce their work in any space that was available.

Artist studios belong to a particular artist and are primarily used to produce that artist's own work, although artists with individual studios might also work with partners, friends, or a paid team, and might invite friends to work in their studios for free or in exchange for labor. Production studios or artist production studios are owned by an artist who contracts with other artists to provide studio time, with or without the services of the artist owner and an in-house team, to produce work for the fine arts market-including public art commissions, gallery pieces, and museum exhibitions. BPM studio, owned by Benjamin Moore, represents this type of studio. Commercial studios or commercial 
production studios are those studios that produce studio glass art and glass craft objects for the commercial marketplace, including tourists, fairs, or a retail gallery associated with the studio. This category includes two well-known Seattle studios that began in the 1970s, Glasshouse Studio and The Glass Eye. These commercial studios focus on quantity production (along with quality) and catered to tourists visiting Seattle and the retail trade. They produced lampshades, Christmas ornaments, and paperweights, along with vases and bowls and whatever else there is a market for. Open access studios are rare; they typically provide low-cost access to studio space and equipment, rented by the hour. In Seattle, Pratt Fine Arts Center was the first open-access studio and hot shop in the city, and it remains one of the few of its kind nationally.

There is also a distinction between hot shops and studio glass art studios. The production and commercial studios are hot shops, which means that they include a glass furnace, annealing ovens, and other specialized glassmaking equipment. These are the most expensive studios to outfit, and not many existed outside of schools. An artist studio might or might not be a hot shop. Artists Joey Kirkpatrick and Flora Mace, like Moore, acquired a hot shop from another artist. Moore bought his from Adamson, while Kirkpatrick and Mace purchased Chihuly's former hot shop when he moved to a new space in 1991. Moore recalled that when he put together his studio in 1985, it cost about $\$ 40,000$ to build the furnace, and $\$ 10,000$ per annealer ${ }^{20}$. Once the shop was in business, it cost about $\$ 2,000$ per month to run (Moore, $2011^{21}$ ). Those prices were well out of

\footnotetext{
${ }^{20}$ An oven used to cool hot glass at a controlled temperature. See Appendix D for additional technical terminology.

${ }^{21}$ Benjamin Moore, speaking at a Tacoma Art Museum panel discussion, with artists Joey Kirkpatrick, Flora Mace, Benjamin Moore, and Richard Royal, September, 2011.
} 
range for most artists, which is why access to alternative working spaces was so important at the time, and remains important today.

Artists who did glass casting, sandcasting, slumped or fused glass also faced high startup costs, although the monthly running expenses were likely to be much less than studios with a hot shop, as glass furnaces were typically left on to keep temperatures steady and high. Fused glass artists could work with a variety of kilns depending on the size of the finished work, so these were more like standard pottery studios. In contrast, glass-casting studios have equipment that resembles the working studios of metal sculptors. Glass engravers also required specialized equipment but didn't have the same fuel costs to contend with as hot glass artists. Stained glass artists and others working with cold glass techniques had the easiest task in finding and setting up studio spaces. Many artists employed combinations of working methods. They would typically create part of the work in their own studios, and work with other artists or use another artist's studio to incorporate different techniques. For example, an artist primarily known for engraved or painted pieces could hire or barter with another artist to create a blank piece of blown glass, a vase or a globe for example, and then engrave or paint the blank piece to create the finished work.

\section{The Glass Eye and Benjamin Moore Studios}

When Pilchuck formalized its program and tightened its entrance requirements, that left few places for people without academic credentials to study and make studio glass art. The energy crisis of the early 1970s along with other factors had reduced the number of glass programs in local universities so even those people with academic credentials had limited options for working with glass. Once artists finished their stints at 
Pilchuck or arrived in Seattle from other places expecting to work with glass, their options were limited. Commercial studios offered artists an opportunity to develop and improve their glass skills. For some, work in commercial studios provided an income while they created their own work on the side; for others, working in a commercial studio became a career in itself. By 1980, Seattle was home to two major commercial production studios. They were Glasshouse Studio, founded in 1972 and The Glass Eye, founded by Adamson in 1977.

After Adamson quit his position at Pilchuck in 1977, he focused his energy on a new venture, The Glass Eye, which he founded along with Charles Parriott, Walter Lieberman, Sonja Blomdahl, and Mark Graham. The Glass Eye included a glassblowing furnace and retail store located in Post Alley, close to Pike Street Market. They specialized mostly in lampshades "which Adamson peddled up and down the west coast out of his VW van, wiring the money back to the Eye so they could continue production" (Miller, 1991). The Glass Eye quickly became a significant feature of Seattle's studio glass artist community, employing most of the artists who would become the key figures associated with the glass movement in the region.

Adamson represented the craft contingent of the arts versus craft divide that was on everyone's mind during this era and was no doubt part of the hippie element that Thomas Bosworth was brought in to eliminate from Pilchuck. Adamson was also a highly respected part of the community. Adamson had an early role as an independent studio glass artist in Seattle, and was co-founder of the Arts \& Crafts Cooperative in the early 1970s. During the 1981 Glass Art Society conference, Adamson was featured as the key player in Seattle's glass community, even more so than Chihuly, who is barely 
mentioned. Statom refers to Adamson as "the godfather of Seattle glass" (Bernstein \& Hansen, 1981) and Adamson is credited with helping start the regional glass movement: "as much as anyone, the Seattle/Northwest glass movement is Rob Adamson" (Bernstein \& Hansen, 1981). This is perhaps because Chihuly, while already gaining in fame and artistic reputation, had not yet become a full-time resident of Seattle. While Chihuly's presence and influence was felt at Pilchuck and in the fine arts galleries, neither Chihuly nor Pilchuck was a full-time actor in the region's artist community at this point, and they have both distanced themselves from the craft scene.

Many of Seattle's studio glass artists passed through the doors of the Glass Eye, and found it a place where they could earn an income producing glassworks that were not sold in galleries but in the Glass Eye's retail shop to and in department stores. At the time of the 1981 GAS conference Adamson had recently purchased a former church on King Street in Seattle's International District, close to Pratt's nonprofit facilities, which he was remodeling to create new facility, called "The Private Eye." According to Bernstein \& Hansen (1981):

The studio facilities at the Private Eye will be used to execute designs by a number of different artists. Adamson sees this system, similar to that established in Europe, as a natural evolution. 'When I started here during the 60's, everybody was just into the medium for what it was. They were interested in the process. They only wanted to survive, to make glass and have a good time. A lot of those people are among the major production people today' (Bernstein \& Hansen, 1981).

The Private Eye became the new Glass Eye, serving as the production facility for the Glass Eye retail shop, which remained on Post Alley, near Pike Place Market. Artists 
not only practiced their skills there, but later generations got their first experience in glassmaking there, including Dante Marioni (artist Paul Marioni's son) who started working there when he was 15 years old (Miller, 1991). Moore worked for Adamson at the King Street studio for one season; he first designed a giftware line for the Glass Eye. Richard Royal, another other well-known studio glass artist and like Moore, one of Chihuly's team members, worked there too. At that time, Adamson had 17 people working in the studio. "It was a who's who of the studio glass world" (Moore, 201022). Moore and Royal worked on glass ornaments to sell, and they sold quite well; eventually the studio ran two shifts to handle the demand. The Glass Eye soon outgrew its new King Street space, and in 1984 Adamson moved the studio to a new, larger facility, his third.

Moore first rented the King Street building from Adamson in 1984, and bought it in 1985 . When he bought the space he had plans to create a traditional production studio based on the Venetian glass studios, something like the Venini factory in Venice. At first he did some work producing glass objects for Nordstrom and Neiman Marcus. After dealing with sales reps and other issues relating to retail production, he decided that wasn't what he wanted to do. Moore realized he could provide a service to other artists, and started doing production work for artists whom he knew through his Pilchuck connections, including Toots Zynsky, Chihuly, Fritz Dreisbach, and Ginny Ruffner. Like Adamson, Moore employed many artists in his studio who later went on to become wellknown Seattle artists, including Dante Marioni and Preston Singletary. Dante Marioni worked for Moore after Adamson moved the Glass Eye, and artist Preston Singletary, who was a friend of Marioni, started working there while he was high school. Moore

\footnotetext{
${ }^{22}$ Benjamin Moore, interview with the author, 2010.
} 
credits his success with being in the right place at the right time. "I had it easy, in 1985 I had one of the very first studios in town before Dale's hot shop. There were not a lot of places for young, talented people to go to. I had a list of people wanting to use my studio from the start" (Moore, $2011^{23}$ ). Moore's studio continues to provide experience and training in production methods for local glassblowers, and serves as a high-end production facility for nationally known artists. His studio is an artist production studio category with a focus on making work for other artists, and he had plenty of demand for his services.

In addition to the range of studios, by 1980 the Puget Sound region was home to two informal educational organizations that provided training in glassmaking techniques, Pilchuck and Pratt. Pilchuck was oriented to academically trained artists, although a degree was not required to study there.

\section{Pilchuck: Professionalizing the program; eliminating the "hippie elements"}

During the 1970s John and Anne Gould Hauberg continued to support Pilchuck, acting as patrons to the school and its artists and even making up budget shortfalls from their personal income. The Haubergs also took steps to make the school part of the Seattle area cultural scene. From the beginning of his involvement with Pilchuck, John Hauberg worked to create a formal administrative structure that would move the school into the purview of Seattle cultural organizations. He started this in 1972, when he placed Pilchuck under the auspices of the Pacific Northwest Arts Center (PNAC), an organization the Haubergs created to support their earlier plans for a museum of northwest arts and crafts on the site of Pilchuck's first summer program. The PNAC

\footnotetext{
${ }^{23}$ Benjamin Moore, speaking at a Tacoma Art Museum panel discussion, with artists Joey Kirkpatrick, Flora Mace, Benjamin Moore, and Richard Royal, September, 2011.
} 
staged annual exhibitions of work by Pilchuck artists alongside well-known Pacific Northwest artists in its downtown Pioneer Square gallery, increasing Pilchuck's visibility in Seattle. When he became president of the Seattle Art Museum's board of trustees in 1973 Hauberg stepped down from his role as president of PNAC and Pilchuck. However, he continued to support the school financially, and basically controlled both organizations even after stepping down from the board. In 1973 he hired architect Tom Bosworth to design permanent structures for the school and a comprehensive campus plan for future expansion.

From 1974 through the mid-1980s, Hauberg instigated a number of changes to the school's administrative and power structure as he moved the school toward economic self-sufficiency — or tried to. Soon after taking over the Seattle Art Museum board, Hauberg successfully lobbied to make PNAC (and as a result Pilchuck) part of the museum in 1974 (Oldknow, 1996, p. 140). He also hired Pilchuck's first professional, part-time administrator, Mimi Pierce, who served in that role from 1974 to 1977. Placing PNAC/Pilchuck under the administrative control of the Seattle Art Museum helped the program gain visibility and additional exhibition opportunities in Seattle, but this proved to be a temporary measure as Hauberg continued to be the school's main financial patron, a situation that he wished to change. In 1976 Pilchuck separated from the PNAC and became an independent nonprofit organization named the Pilchuck School (Campbell, 1977), later changed to Pilchuck Glass School. Both John and Anne Hauberg were on the board of trustees of the new nonprofit Pilchuck School.

Hauberg basically transferred control of Pilchuck to the board when the school became independent in 1975 although he remained an influential voice in the running of 
the school. At the time of Pilchuck's independence the PNAC board was made up of close personal friends and business associates of the Haubergs and these people became part of the first Pilchuck board of trustees. In addition to John Hauberg, the members of this first Pilchuck board included his close personal friends Frank Kitchell and Joseph McCarthy, along with Patricia Baillargeon (a member of a prominent Seattle family who held positions in several trade-related organizations) and Seattle businessman Phillip Padelford (Campbell, 1977). Hauberg soon recruited additional members and the board expanded several times. By the early 1980s the Pilchuck board comprised 21 members, mostly members of Seattle's cultural and business elites such as the Benaroyas; it also included a few prominent studio glass art collectors drawn from outside the region.

Along with changes to the board, Hauberg's plan to make Pilchuck into a mainstream arts institution required some organizational and cultural changes. Pierce began the process, but her authority was challenged from the start, and Hauberg and Chihuly decided to bring in a new part-time administrator with more clout. Thomas Bosworth, the architect of the campus site plan and building program, was named Pilchuck director in March of 1977, replacing Pierce. The rumor was that Chihuly was not happy with Pierce, but there may have been several factors and other people involved. Both Chihuly and Hauberg had ambitious plans for making the school a world-wide destination, and Hauberg had previously expressed dissatisfaction with the casual and what he saw as disorganized approach to the program that he was funding. Pierce had formalized some elements of the Pilchuck administration, but additional changes were needed if Pilchuck was to move into center stage as a place for making world-class art and produced world-class artists. Bosworth was selected to enhance the school's national 
reputation. "Indeed, Bosworth, a Yale graduate, could give the young institution an East Coast, academic cachet that would bolster its already excellent reputation and attract students" (Oldknow, 1996, p. 147). By 1977 three of the new buildings that Bosworth designed, the hot shop, the flat shop and the lodge were completed (Figure 9.7). Bosworth had impeccable academic credentials, was familiar with the campus and the school's program, knew Chihuly, and had an amicable working relationship with Hauberg. Under Bosworth, Pilchuck became an institution with a unified direction and identity as an art school with high ambitions. Between 1978 and 1980 the number of faculty expanded from eleven to seventeen, and more summer teaching sessions were added (Herman, 1992, p. 36). The school also declared its specialization with its name change to the Pilchuck Glass School. Administrative changes and rule making that began with Pierce continued under Bosworth. Like Pierce, Bosworth met with resistance from the artists and students. This is not surprising given that Bosworth came in with a mission to change the character of the place, and to eliminate what remained of the seventies-era hippie atmosphere. Artists and administrators involved with Pilchuck during the Bosworth reign repeatedly bring up the references to the program's "hippies" or "hippie elements" or lack of organization, and Hauberg's determination to remove the remnants of the original "hippie camp" culture.

The Pilchuck student experience during this era typically involved shared tasks, construction projects, and camping, although the school provided wooden tent platforms and supplied the tents for students to use as dormitories. Students and faculty shared responsibilities for tasks required to keep the program operating through the summer, from cooking to rounding up supplies and performing routine maintenance. One change 
Pierce began that Bosworth continued was to replace unpaid voluntary artist labor with paid positions, typically staffed by artists, to manage the practicalities of running a school in the woods. In describing what Pilchuck was like when he began his reign as director, Bosworth remembers working in the kitchen cleaning up after a meal with Pilchuck faculty member Ludwig Schaffrath as part of "the tradition of everyone working a few hours a each week for the general good-like a kibbutz" (Bosworth, 1990; Oldknow, 1996, p. 155). This tradition ended during Bosworth's reign. Paid staff included several of the regulars who had previously worked in exchange for classes or time in the hot shop, new artists who were invited by the regulars, along with students who needed the income.

Benjamin Moore became the first educational coordinator in 1978. William Morris and Richard Royal arrived at Pilchuck in 1978 as employees. Royal remembers getting a call from his friend and former business partner Moore (they had been partners in a ceramics studio in California) urging him to come to Pilchuck in 1978. "He called me and said that there were two positions open. One was for a maintenance man and it paid $\$ 100.00$ per week, the other was to drive the truck and it paid $\$ 50$ a week. I took the maintenance job. It was $\$ 100.00$ more per week than I was making at the time. Bill Morris took the truck driver job. It was the last time I made more money than Billy" (Royal, 2011 ${ }^{24}$ ). Morris, Royal, and Moore went on to become gaffers and prominent members of Chihuly's inner circle of glassblowers, traveling with Chihuly to locations around the world. All three later launched successful careers as independent artists.

\footnotetext{
${ }^{24}$ Richard Royal, speaking at a Tacoma Art Museum panel discussion, with artists Joey Kirkpatrick, Flora Mace, Benjamin Moore, and Richard Royal, September, 2011.
} 
Bosworth also had a reputation for being concerned with hierarchy; Seattle art historian LaMar Harrington called him “authoritarian” (quoted in Oldknow, 1996, p. 151), as did some of the artists (Herman, 1992). His attitude did not sit well with the artist faculty who were used to a more democratic way of doing things. Artist Norman Courtney remembers that when Bosworth would bring visitors to Pilchuck, he only introduced them to Chihuly, and ignored the other artists and faculty present (Courtney, $\left.2011^{25}\right)$. Bosworth's academic and formal management style highlighted, perhaps magnified, the divide between those who were interested in the mastering the craft of glassmaking techniques and those who favored the conceptual over the craft approach. Oldknow (1996) also identifies increased conflicts between artists who came from academic backgrounds and self-taught artists during this time as being another source of tension.

In hiring Bosworth, Chihuly and Hauberg sent the clear message Pilchuck was consolidating its reputation as an arts program where craft was secondary. Glass, the school's primary medium may have been considered a craft material, but Pilchuck's program emphasized artistic concepts and experimentation over producing objects for the craft market (Campbell, 1977). Adamson and Courtney were two of the long-time artists whose attitudes clashed with Bosworth's approach. Adamson served as assistant director, shop coordinator and technical coordinator under Mimi Pierce from 1974 to 1977. Adamson was responsible for supplies, and for maintaining furnaces and keeping other equipment in running order. He also took over some of the operational responsibilities

\footnotetext{
${ }^{25}$ Norman Courtney (artist), interview with the author, 2011.
} 
that had previously fallen to Chihuly or had been performed by other artist volunteers. Courtney was hired as shop coordinator to run the hot shop along with Rob Adamson. Adamson described his experiences with Bosworth as a clash of values "I had a certain set of values and he had a certain set of values and we could see we weren't going to be able to work well together. ... His biggest contribution was pushing through the architecture" (Adamson, 1984, p.4). In 1977 Adamson resigned his position at Pilchuck to start the Glass Eye, a production studio located in downtown Seattle near Pike Street Market. Courtney left Pilchuck and focused his attention on starting a glass studio in a new community-based arts center in Seattle's central district, called the Pratt Fire Arts Center (later renamed the Pratt Fine Arts Center). Oldknow (1996) and others noted that several long-time Pilchuck regulars left at this time, but do not identify individuals. Adamson and Courtney perhaps had the most openly combative relationship with Bosworth, and they were also ready to take on other projects where they could have more influence. In spite of the conflict during this time, both artists maintained friendships and working relationships with other artists from Pilchuck who supported the changes, and both returned to Pilchuck to teach and make artwork in later years.

In addition to Bosworth's management style, his buildings became another focus of the artists' discontent. Although there was general agreement that the school needed more permanent studio buildings, some felt that the buildings were getting too much attention. "Among the artists at Pilchuck, there was a general perception that Bosworth was more concerned about his buildings than the glass program" (Oldknow, 1996, p. 155). Bosworth's designs quickly garnered local and national media attention and design awards. A 1981 issue of Progressive Architecture featured the bridge to the new Pilchuck 
Lodge on its cover, and included an article praising the integrated campus design and Bosworth's historic references through the design elements of the unpainted, wooden structures that referenced rural farm buildings and pioneer cabins (Murphy, 1981). Nearly every media reference to Pilchuck during the year the flat glass shop was finished (1975 and 1976) mentioned it as a significant feature of the school. Yet several artists singled out the flat shop (Figure 9.7) as being poorly designed for its function. The building was a studio for architectural glass and stained glass projects, and faculty who taught and worked with flat glass expressed their unhappiness with the design. Elskus and Vallien, two artists brought in to teach flat glass design were blunt in their assessment that the new studio just did not work at all for flat glass, although they did praise the architectural design (Elskus, 1983; Vallien, 1983). The building was originally designed with one open wall, which left the interior exposed to the elements. French doors were later added to provide shelter from the elements but the site, the lighting, and the walls of French doors that were made up of small windowpanes made viewing stained glass and other flat glass designs and colors difficult. At the time, flat glass was a fairly recent addition to Pilchuck's offerings and many considered it of lesser importance than the glassblowing that was Pilchuck's original focus. That, and Bosworth's perceived attitude that the buildings were more important than the educational program, may have helped fuel the artist's resentments toward the new flat glass studio. This attitude toward flat glass and other forms of glassmaking changed quickly, as artists took advantage of the new facilities and new specialties that faculty introduced. Pilchuck's offerings expanded and students and faculty used their time and the facilities at Pilchuck to experiment with and incorporate many different approaches into their work. 
Speaking of the flat glass building in 1990, Bosworth stated that one of the goals he attempted through his architectural design was to "encourage communication between the glassblowers and the flat glass artists" and he goes on to explain that "I placed their respective buildings close together... and kept the facing facades open for mutual viewing” (Bosworth, 1990, p. 7). The opening of Bosworth's newly-built architectural (flat) glass studio seemed to be an occasion of note, as three articles discussing the 1977 Pilchuck open house in August mention it, as does one from the school's official inaugural year as a nonprofit, 1976. The new flat glass studio represented an expansion of focus from glassblowing into other modes of glassmaking.

Adamson and other former staff, students and instructors from this time remember that Chihuly was tired of dealing with the administrative hassles of running the summer programs. This was no doubt part of the reason why he stepped down from his role as director to focus on teaching and producing his own artwork, and why he supported Bosworth as director for a time. However, Bosworth's tenure was marked by disagreements and conflict between him and the students and artists. In 1980, when enrollment dipped below expectations creating a budget deficit, conflicts increased. Some of the artists, including several longtime Pilchuck teachers, and even Chihuly, felt that Bosworth and the reorganized board of trustees had gone too far in taking the control of the school away from the artists and students when the board instituted an $\$ 800$ daily fee for working at Pilchuck after the school's annual session officially ended in the fall (Oldknow, 1996, p. 177). Because of the lack of available and affordable hot shops in the area and the limited time faculty had to do their own work while teaching during summer sessions, it had become a regular practice for the faculty to use the Pilchuck hot shop 
during the school's down time, typically paying only for the cost of fuel and keeping the buildings in operation. Chihuly in particular counted on this time to do his own work as he did not have a studio in Seattle, and his glassblowing team was made up of Pilchuck regulars. In response to the board's proposal, Chihuly put together a document titled “Some Thoughts on Pilchuck's Survival" (Chihuly, 1980). In it he briefly outlines his philosophy behind his initial founding of the school and details why the artists felt they needed to use the hot shop after the school session and why the board's reaction was a symptom of unresolved communication problems between the board and the faculty and staff of the school. Chihuly informed the board that he created his breakthrough Pilchuck Basket Series during one of these post-season sessions, and reminds them that he and his fellow artists actually created the facilities (although by then they were using several Bosworth-designed buildings). The tensions around administrative changes and a frustration about the loss of artist input into the process of running the school are evident in this document.

John Hauberg has now charged the Board of Trustees with making all Pilchuck decisions... but what disturbs me is that you are now making important educational policy decisions without having had the opportunity to meet with the staff members and without my ever meeting with the Board to explain the history and philosophy of the school. The lines of communication are almost nonexistent and the occasional cocktail party has not been adequate substitution (Chihuly, 1980, p.2).

Bosworth left Pilchuck for a fellowship at the American Academy in Rome, and was replaced by veteran arts administrator Alice Rooney in 1980. In a 1990 presentation 
at Seattle's Monday Club, Bosworth referred to his years at Pilchuck, from 1976 - 1980 as the "Golden Age" both because of his administrative and his architectural work there (Bosworth, 1990).

Rooney was hired as Pilchuck's first full-time director, and she remained in charge for the next decade. Rooney had a different management style than Bosworth, and she came to Pilchuck with extensive experience working with artists and funders as an arts administrator in Seattle. She had most recently been the executive director of an arts advocacy group in Seattle called Allied Arts, and had worked for the National Endowment for the Arts in Washington, D.C. Rooney had a reputation as a people person, who did not pull rank, but worked with people to resolve issues. According to Courtney, "Alice Rooney put Pilchuck on the map. She set it up as non-hierarchical" (Courtney, 2011 26). Under her leadership Pilchuck prospered. Pierce and Bosworth had overseen the administrative reorganization of the school. With a stable organization in place, Rooney's major task was to build up the school's long-term financial health. The Haubergs' connections to Seattle's cultural elites along helped facilitate that aspect of the school's administration in the past. A Northwest Arts article from 1976, the first year of the school's independent status, mentioned that half of the school's costs were supported through funding from various sources, including "Seattle-based Patrons of Northwest Civic, Cultural, and Charitable organizations (PONCHO), the Washington State Arts Commission, the Western States Arts Foundation and the National Endowment for the Arts. The Corning Foundation and the glass-art industry in Washington and Oregon also are helping this year" (Burley, 1976). The school's costs rose over the next few years. In

\footnotetext{
${ }^{26}$ Norman Courtney (artist), interview with the author, 2011.
} 
1977 the annual budget was approximately $\$ 100,000$ and tuition was $\$ 400$ to $\$ 500$ per three-week session of 30 students (Campbell, 1977). The budget in 1980 was $\$ 225,000$, and when the school experienced a budget shortfall, Rooney followed her predecessor's standard practice and sent the $\$ 6,000$ bill to Hauberg, who returned it unpaid (Oldknow, 1996, p. 179). From this time forward, the board and the school's director would be responsible for raising the money to support Pilchuck. During these years, Corning Glass Works provided some equipment, the Northwest Glass Company provided cullet, and money from other sources increased "as glass art became increasingly desirable to collect" (Lloyd, 1992, p. 27). Meanwhile, Rooney and the board worked to identify and recruit new donors and find new sources of funding. They created the Pilchuck Society in 1981 as part of the school's first annual drive; Pilchuck Society members donated specified amounts and in return received special privileges such as invitations to special events. Rooney presided over the school's first official capital campaign from 1984 to 1986. The capital campaign began due to a particularly rainy summer in 1983. After seeing that the students "spent miserable nights in wet tents and miserable days trying to dry wet jeans ... we decided to build a new dormitory" and raised $\$ 800,000$ (Rooney, 1990. p. 86). The money was used to expand the campus to add two new studio buildings and housing for students (Rooney, 1990; Hughbanks, 1992).

The annual Pilchuck auction, which started in 1978, moved from the Pilchuck campus to a central Seattle location. The auction featured works donated by Pilchuck artists with auction profits going to the school. This event increased in popularity and profitability as Seattle-based studio glass artists became more well known and glass collecting more popular. To ensure the school's long-term financial stability, an 
endowment fund was established under Rooney "with a \$100,000 grant from SteeleReese Foundation" (Hughbanks, 1992, p.3). The school continued to receive support from Washington state and Seattle area foundations and nonprofit throughout the next three decades.

New artists bring new techniques, Pilchuck regulars emerge

Artists who arrived at Pilchuck to teach or for residencies during the 1980s brought with them diverse approaches to working with glass and a willingness to collaborate and combine several techniques in a single work. The number of sessions increased and the processes and approaches to glass multiplied. In addition to glassblowing, the school invited artists to teach stained glass, mosaics, and glass painting. Classes offered during the 1980s included "painting, beveling, laminated glass, cold working, slumping, fusing” (Rooney, 1990, p.85). The German artist Ludwig Schaffrath taught stained glass at Pilchuck for the first time in the late 1970s and continued to teach through the 1980s. Bertil Vallien taught the first sandcasting glass in 1979 and he became one of the Pilchuck regulars.

Several women, including Ginny Ruffner, Sonja Blomdahl, Joey Kirkpatrick, Flora Mace, and Cappy Thompson, who worked at Pilchuck during this era became prominent artists, showing work at regional and national galleries and winning public art commissions during the 1980 s. According to Ruffner, "we had such a great time... group support of each other... And it was a lot of fun for us and the students" (Ruffner, 2006). Sonja Blomdahl arrived in 1978 as a teaching assistant at Pilchuck, and then settled in Seattle where she established her own studio and joined with Adamson as a partner in the Glass Eye. Joey Kirkpatrick and Flora Mace arrived as artists-in-residence for the 1980 
summer session and spent their first winter at Pilchuck, as they did not have a studio or living space in Seattle. Ginny Ruffner came to Pilchuck from Atlanta, Georgia, in 1984 to teach lampworking ${ }^{27}$ (Figure 9.8), typically used to produce small decorative figures. Ruffner employed this technique to produce large, complex, surrealist sculptures. She moved to Seattle in 1985, and continued teaching at Pilchuck regularly.

In addition to Kirkpatrick and Mace, Moore, Royal, Morris and some other Pilchuck regulars became members of Chihuly's team, spending summers at Pilchuck as faculty, visiting artists or artists in residence, and working on each other's projects at Pilchuck and in other locations during Pilchuck's off-season. Many traveled with Chihuly as he garnered commissions and public art projects and installations around the world. Collaboration continued as the standard practice at Pilchuck, and collaborative relationships helped build community bonds that lasted past the summer sessions. Other than Chihuly, studio glass artists did not make a lot of money during this time, and the cost of running a hot shop was prohibitive for most. It was common for artists who worked together at Pilchuck to call on one another for help with projects outside the school.

\section{$\underline{\text { Educating collectors and wooing patrons }}$}

One of the Pilchuck events that occurred under Rooney's directorship was the first “Collector's Seminar" organized by LaMar Harrington, a freelance curator and former associate director of the Henry Art Museum at the University of Washington. The seminar was offered during Pilchuck's 1982 summer session, from July 27 to July 31, 1982 (Hackett, 1982). There were 51 attendees, including the artists and Pilchuck staff

\footnotetext{
${ }^{27}$ In lampworking, a small torch is used to heat up glass rods until they are soft enough to form into new shapes and artwork.
} 
(mostly artists). Attendees came from California, Seattle, and New York, with a few from Michigan, Texas, and Chicago. Artists Klaus Moje from Australia and Jaroslava Brychtova and Stanislav Libensky from Czechoslovakia also attended (they were visiting artists at Pilchuck that summer). Also attending were Thomas Beuchner of Steuben Glass and William Warmus from the Corning Glass Museum. Prominent collectors included George and Dorothy Saxe from California. The list of attendees contained more artists and dealers than individual collectors. In a letter to Lloyd Herman, director of the National Museum of American Art at the Smithsonian, Harrington noted, "Did I tell you we were overrun with dealers" (Harrington, 1982a). Dealers included Heller of Heller Gallery in New York City, Aileen Kremin of Designs Recycled Art Gallery in Fullerton, CA, Ben Marks of the Rubin/Mardin Gallery of Seattle, and Bill Traver of the Traver/Sutton Gallery in Seattle.

This seminar brought Henry Halem, founder and first president of the Glass Art Society, to Pilchuck for the first time as a guest speaker, while the nationally known designer Jack Lenor Larsen provided the keynote address. Seminar topics included "glass artists and their support system" by Henry Halem, "Contemporary Glass and Contemporary Public Art Collections" by Davira Taragin, an assistant curator at the Detroit Institute of the Arts, while William Warmus, an assistant curator at Corning Museum of Glass presented a talk on "the Role of Criticism in Collecting." Day two presentations focused on "the meaning of art and connoisseurship" (Hackett, 1982).

The seminar was a targeted attempt not only to build up the patronage of studio glass art but to ensure that collectors looking to buy studio glass art would think of Pilchuck as the place that produced quality fine arts and quality studio glass art and 
artists. Pilchuck artists benefited from this association. Pilchuck regulars dominated the artist presentations. The seminar included artist demonstrations and a presentation on the school's history (Hackett, 1982). Not only did the seminar help build connections between Pilchuck artists and collectors, it accomplished its goal of turning some of these collectors and dealers into Pilchuck school supporters. Several dealers and collectors pledged scholarships (Harrington, 1982b). Harrington followed up with collectors to gauge their impressions of the seminar after the fact, and in a memo to the Pilchuck Board of Trustees reported that some of the attendees "pledged scholarships for the 1983 summer session" and that the seminar raised "about $\$ 6000$ " for the school, which she admits was "a small amount in consideration of the formidable time and effort that went into the planning and execution" of the seminar (Harrington 1982, p.1). Although the amount raised was perhaps small for the effort, it was the start of a long-term investment into Pilchuck's future, and it served its purpose in bringing Pilchuck to the notice of key influential people in the arts. Like most nonprofit arts organizations, Pilchuck continued to sponsor annual events to bring collectors and dealers to Pilchuck. It differed from many similar organizations in that the events were not only about Pilchuck, but encompassed Pilchuck's role in relation to the studio glass movement, studio glass art, and artists. Before the era of branding, Pilchuck took great care to ensure that its image and reputation was tied in with the promotion of glass as an artistic medium. At the same time they promoted Pilchuck and Pilchuck artists as representing the best that one could find when assessing the quality of work done in glass. 


\section{European Connections and Pilchuck}

In addition to promoting the school and its faculty among U.S. based dealers, curators and collectors, Pilchuck promoted itself worldwide. One result of these efforts was that Pilchuck became a preferred destination for many European studio glass artists. When Pilchuck began its formal visiting artist program and invited key European glassblowers and designers to the school, it helped spread the knowledge of traditional glassmaking techniques to nontraditional artists and artisans. As noted in the previous chapter, European masters in turn attracted other European artists, along with American artists who had worked in Europe and students who wanted to acquire skills that only the Europeans could impart. Artist David Huchthausen discussed the significance of the presence of international artists at Pilchuck during this time:

Harvey Littleton at the University of Wisconsin and Marvin Lipofsky at Berkeley and CCAC brought in a wide variety of international artists and designers starting in the mid 1960's, then Joel Myers at Illinois State from 1970 on. Pilchuck intensified its international programs in the late 1970's. The important thing about Pilchuck was that the artists got to stay for longer periods. Pilchuck added more sessions in the 1980s, and longer sessions. It was a more intensive experience. People could come and work with these artists for longer periods and really learn, and got to know them personally as well. ... Fame built up gradually. More people heard about it, then more artists came. The more artists came, the more people heard about it and wanted to come to Pilchuck. Once they got to Pilchuck 
or came out to take a workshop, many stayed in the region. Seattle became a big draw in the late 1980s through the 1990s (Huchthausen, $2011^{28}$ ).

Both the European and American artists shared critical information about processes and materials that helped grow the community's technical knowledge. One of the highlights of the early 1980s was the arrival at Pilchuck of two Czechoslovakian artists in1982, Stanislav Libensky and Jaroslava Brychtova. The sculptural works of this husband and wife team of artist-teachers were well known to many in the studio glass community, but because of limited opportunity for travel to or from Czechoslovakia under communist rule, the artists themselves were less known. Their work represented the model for the artistic approach to the medium that Pilchuck was interested in pursuing at that time. As Oldknow (1996) noted, the pair: "brought to Pilchuck a much needed intellectual, theoretical, and philosophical approach to making art with glass" (p. 191). If the arrival of the Venetians brought the knowledge of the craft of glassblowing to the region, the arrival of the Czechoslovakians enriched the intellectual and aesthetic approach to the medium, bringing the craft and art of glass together in one place.

\section{Pratt Fine Arts Center: A place to make art in the Central District}

For people who were just getting started in the studio glass world and for artists who did not make enough money to rent time in another artist's studio, Pratt Fine Arts Center provided a low-cost alternative to private commercial studios and more expensive academic arts programs. However, Pilchuck remained the regional draw for studio glass artists. While Pilchuck was undergoing growing pains during the mid to late 1970s, Pratt Fine Arts Center was being created. Pilchuck is connected to Seattle by reputation, but

\footnotetext{
${ }^{28}$ David Huchthausen (artist), interview with the author, 2011.
} 
Pratt is the place to go for anyone looking for the home of studio glass education within the city. While Bosworth was busy reorganizing Pilchuck, Pratt was preparing to offer its first classes.

Pratt was first envisioned as one small part of the Yesler-Atlantic Neighborhood Improvement Project (YANIP), a model cities program. YANIP was located in Seattle's Central District Neighborhood, a historically African-American community in one of the most diverse areas of the city. YANIP began in the late 1960s as part of an urban renewal program, and basically stalled after Richard Nixon was elected and federal funding for urban renewal was shifted into Community Development Block Grant programs in 1974. The project planned for the property and surrounding area included a business and cultural district to serve the needs and promote the economic future of the surrounding population. Before the project stalled, many buildings and properties were condemned, acquired and destroyed to make space for the ambitious redevelopment. Among the properties destroyed in 1975 was the Collins Recreation Center, a local recreation center with a popular pottery program among its offerings. A pottery program was included in the YANIP plans because of community demands to replace the Collins Recreation Center (Seattle Parks \& Recreation Dept., 1979). Early plans to revive the pottery program included it as part of a "fire arts program" in the proposed Langston Hughes Cultural Center, which was to be dedicated to promoting African American culture and history. The program was eliminated from the Langston Hughes Cultural Center plans due to lack of suitable space, but the idea remained alive because of community support.

Plans for the pottery program gradually evolved into a proposal for an independent arts center to be housed in its own building and offer classes in pottery, 
metalworking, jewelry making, and studio glass art. After learning that the Wonder Bread Company was planning to move out of its nearby garage at $19^{\text {th }}$ and Main Street, YANIP proposed purchasing this building for the art center (City of Seattle, 1977). The Wonder Bread garage was in the urban renewal district, next to the Yesler-Atlantic Park, and within a few blocks of the Langston Hughes Center, the pedestrian walkway and other facilities for the "cultural, social, and recreational complex" envisioned as part of the model cities neighborhood plan (Hudson, 1976). The budget for the art center was part of the block grant funding proposal for the adjacent park.

The art center's mission closely meshed with the community development goals of economic, social, and cultural advancement for neighborhood residents. The original 1976 program proposal named four fire arts to be offered: metal casting, lapidary, pottery, and glassblowing. A 1979 News Release published by Seattle Parks and Recreation identifies six goals for the center:

(1) to provide an outlet for the creative expression of rich and diverse cultural heritages that may not have had full access to the arts in the past; (2) to attract an influx of culturally oriented persons, and thus establish a 'connecting point' in the regional arts network; (3) to encourage a mix of people drawn together by a common interest in the arts, bringing about increased understanding and appreciation among persons of diverse backgrounds; (4) to assist interested persons in becoming self-sufficient in the arts; (5) to provide opportunities for minority artists outside the white establishment; and (6) to seek out and encourage new talent (Kirby \& Anderson, 1979). 
In March of 1976 the Yesler-Atlantic Project Area Committee submitted a letter in support of the budget allocation to the Seattle City Council. Representatives of several local community organizations including the Langston Hughes Cultural Arts Center Advisory Council, the Madison-Jackson Economic Development Council, the Rejected Community Council all wrote to voice their support for funding the art center (City of Seattle, 1976). The city approved the funding proposal, and acquired the building for $\$ 81,000$, using Housing and Urban Development (HUD) urban renewal funds. Woo and Park Associates were the architects responsible for redesigning the former garage into a 10,268 square foot arts center with fully equipped metalworking, glassmaking, and pottery studio spaces. A variety of funding sources were tapped for the final project development costs of \$532,012, including urban renewal funds, HUD community development block grants, and Seattle's 1968 Forward Thrust bond issue (Kirby \& Anderson, 1979).

YANIP director Bea Hudson and community development director Princess Jackson were actively involved in planning the project and recruited committee members to manage the project's planning and organization. One of the people Jackson called was Norman Courtney. Courtney was on the planning committee and was one of first four faculty members who helped plan Pratt's facilities and set up the various programs. In 1976 the city called me. I knew the Seward Center program; it was a city program and pottery center... The idea was to expand the program, and they asked if I was interested in designing a glass shop for the city, to be run by the city parks department. It was to include glass, ceramics, metal, jewelry, and fabrication. The city brought in four people, one from each area to design the 
workspaces. Nobody even knows their names now. Ben Woo was the architect (Courtney, 2011 29 ).

The project planning did not go smoothly, and Courtney remembered that there were many areas of contention, and some city representatives were not happy about the idea of the Parks and Recreation department running an arts center. In 1976 the city authorized a separate nonprofit organization, City Art Works, to plan and manage the art classes. Even the original name, Fire Arts Center, was contentious, and in 1976 it was changed to the Pratt Fine Arts Center, and the adjacent Yesler-Atlantic park was renamed Edwin G. Pratt Park in honor of Edwin Pratt, a former Seattle Urban League Executive Director and civil rights leader who was assassinated in 1969.

A 1976 report detailing the art center's mission, funding and program notes that some classes were expected to bring in local community members, while others, including glassblowing, were expected to draw people to the neighborhood from the surrounding neighborhoods and region. Reasons given for the popularity of glass included the growing interest in glass generally and the small number of glass studios in existence on the west coast (Smith, 1976). Another memo lists the programs in order of their potential citywide appeal, followed by a listing based on levels of community interest. Glassblowing was first on the list of programs most likely to attract a citywide following. Pottery was second on the list, followed by metal casting and jewelry making. On the list of programs of most interest to the local community, pottery was first, followed by jewelry, metal casting, and then glassblowing (Dinwiddie, 1976).

\footnotetext{
${ }^{29}$ Norman Courtney (artist), interview with the author, 2011.
} 
The Seattle Times carried a brief mention about the February 26, 1977 groundbreaking ceremonies for the new center, reporting that: "Renovation of a building at $19^{\text {th }}$ Avenue South and South Main Street will provide facilities for craft making and a gallery..." (Ceremonies for a new arts center, 1977, p. C10). It took several years of negotiation and planning in fits and starts before the center was ready to open to the general public. The facility was owned and administered by the Seattle Parks and Recreation Department, and City Art Works ran the arts programs. Staff salaries were paid through the federal Comprehensive Employment and Training Act (CETA) funding. Class costs were initially kept low, scholarships were provided for students with limited financial resources, and local residents could rent fully equipped studio spaces by the hour. Studio glass artists were among the earliest and most enthusiastic supporters of Pratt. One of the first workshops offered was in glassmaking techniques, and the school quickly became a sort of public studio space for local glass artists and students who could not afford to own or rent space in commercial glass studios.

Courtney's connections and the area's many glass artists quickly promoted Pratt as a key center for glassblowing activities in the city. The assumption that there was a large citywide interest in glass arts was reinforced by the predominance of glass artists from the region on Pratt's original mailing lists and the attendance at two glass workshops that were offered early in the school's history. The Pratt Fine Arts Center management plan (1977) noted that "the publicity in which we have been involved so far, has been on two glass workshops, therefore, our mailing list has leaned heavily towards glass artists. ... our greatest success has been by word of mouth between glass workshops. ... we bulk mail approximately 800 flyers to glass artists and distribute about 
200 flyers in the community and to glass manufacturers" (City of Seattle, 1977). A growing number of artists were attracted to Seattle as an affordable and welcoming place to live and work. Many of these artists, including glass artists, were seeking affordable studio spaces. However, it was unlikely that there were 800 glass artists in Seattle at that time, so the 800 flyers sent to glass artists either came from the membership list of the Glass Art Society, or from Pilchuck, or perhaps both. The glass artist community was a well-organized and communicative group, used to promoting its activities and supporting each other, and the Glass Art Society was the organization through which these activities were formalized. If that was the case, then Pratt had a potential following that extended far beyond the neighborhood and city boundaries.

Pratt's open-access studios provided low-cost access to equipment and tools and encouraged artists to pool their resources and work together to make the most of the space. The first classes were offered in the spring of 1979. When the center held its official opening ceremony on May $25^{\text {th }}, 1979$ in the refurbished former Wonder Bread garage, it offered programs in clay, glass, jewelry and metal casting, and included a gallery space. Barbara Bryant was the senior staff member from the Parks and Recreation department, and there were four "resident faculty" members: Lynn Fitzgerald (clay), Norman Courtney (glass), Walther White (jewelry), and Greg Skinner (metal). One additional instructor appeared in the 1979 opening announcement; Paul Marioni was listed as a guest instructor for "advanced stained glass" (Kirby \& Anderson, 3/28/1979, News Release, Seattle Parks and Recreation).

Financial support from the city proved precarious and short-lived. Over the next several years Pratt struggled to maintain its original utopian vision in the face of financial 
constraints. According to Courtney (2011), the city decided to fund staff salaries with federal CETA money because it was reluctant to take on the responsibility for running an art center. This decision was a key weakness for the organization's survival during this era of federal and city budget cuts that eliminated many programs ${ }^{30}$. By the winter of 1979 there were already signs of trouble. In November the Seattle Times reported that the city proposed to eliminate most of Seward Park's art offerings and transfer the staff to Pratt Fine Arts Center "to shore up a budget problem in the Parks department and in order to keep open a newer facility" (Tsutakawa, 1979a) and another article reported that both art centers were struggling (Tsutakawa, 1979b). By 1980 both Seward and Pratt had been reorganized and placed under City Art Works management. In spite of continuing budget issues, the center continued its programming, supported in part by raising fees for studio access and classes. City Art Works also received grants from the National Endowment for the Arts and from PONCHO to help offset some budget cutbacks. Pratt continued to provide support for local community members interested in the arts, regardless of age or experience. "The neighborhood kids aren't forgotten either. Children as young as 7 come to Pratt for glass fusing workshops, and nearby Summit Elementary School has 9-12 year olds who have learned to slump and now sport colorful glass pins of their own creation. Sometimes the artists go directly to the area schools; other times, art teachers bring their students to Pratt for instruction" (Bernstein \& Hansen, 1981).

When artist Therman Statom became the glass studio coordinator in 1980, his reputation helped cement the reputation of the center as a place to experiment with glassmaking for experienced and aspiring artists in the city. Seattle art critic Matthew

\footnotetext{
${ }^{30}$ Norman Courtney (artist), interview with the author, 2011.
} 
Kangas, writing in Artweek proclaimed: "Therman Statom is ... one reason that the center of innovative activity in glass has currently shifted to Seattle... His presence at the new city-owned Pratt Fine Arts center is exerting a magnetic force on other artists" (Artweek, 12, \#12, March 28, 1981—quoted by Oldknow 1996, p. 180). People were drawn to the center's public-access studios and excellent facilities for metal work, jewelry, glass, and ceramics and also for the chance to work with local and nationally known artists like Statom.

Statom was active in the local and national art scene, and well connected in the studio glass movement, especially with its Northwest practitioners. Like Courtney, Statom believed that Pratt could play an important role in furthering studio glass, and also provide an outlet for people interested in working with glass outside mainstream academic arts institutions. During his short tenure at Pratt he actively promoted the center as a possible national center for glass art. "There is an active interest within the glass department of the Pratt facility to promote the development and realization of new work and ideas within the glass art movement in art. I believe this facility may be of national significance in this respect" (Statom, letter, 1/17/1981).

Statom saw the upcoming Glass Art Society (GAS) conference as an opportunity to showcase Pratt. He tried to convince the Parks and Recreation Department to provide additional funding and support for conference activities at the school. Among the GAS events proposed for Pratt were a demonstration by the renowned Czechoslovakian artist Stanislav Libensky, a workshop by Richard Marquis, and tours of the facility. Statom and Pratt administrators proposed additional events scheduled to coincide with the GAS conference, including a week-long open house for the entire week of the conference, and 
even a fashion show for glassblowers (Bryant memo, 1/8/81 \& 2/5/1981; Statom letter, $1 / 17 / 81)$. Several of the proposed events took place, but it is unclear whether the Seattle Parks and Recreation department ever approved all of them and disputes between Statom and Pratt administration over expenses incurred for artist honorariums and other matters related to the GAS conference (Bryant, 5/22/81; 6/29/81) resulted in Statom's departure. In June of 1981 Statom resigned from Pratt.

Within six months the center was again suffering severe financial problems as city and federal funding disappeared. A December 1981 memo noted that the City Art Works, the nonprofit responsible for managing Pratt programs, was losing $\$ 50,000$ of city funding. In 1982, due to city budget shortfalls, Seattle ended funding for all city art programs, including Pratt. Pratt was allowed to stay in the city-owned building, but the programs and operational costs were no longer funded by the city. That same year the federal congress passed the Job Training Partnership Act, eliminating CETA. The loss of CETA funds meant in addition to losing the city's operational funding, Pratt could not pay its employees. Pratt now began a multi-year search for the means to stay afloat. Pratt wouldn't gain solid financial footing until the late 1980s, after an era of mismanagement and worsening financial crises. In the meantime, the center continued to offer arts programs, and they continued to rent studio time and facilities to local community members, including a large contingent of glass artists. One of the uses that local artist made of the facilities was to produce work destined for public locations, like parks, libraries, and government buildings. 
Glass Art Week: The 1981 Glass Art Society conference comes to Seattle

In the spring of 1981 the Glass Art Society (GAS) held its annual conference in Seattle for the first time. In honor of the event, Seattle Mayor Charles Royer declared the week of the GAS conference, April 6 to April $13^{\text {th, }}$ to be "Glass Art Week." The Glass Art Society was a professional organization founded in 1971 to promote glass as an art medium. Early in the organization's history, they established headquarters in Corning, New York, site of the Corning Museum of Glass, which was established in 1950, also to promote glass art. At the time of the GAS conference in 1981, Pilchuck Glass School was already well known and respected by studio glass artists internationally, and Pratt Fine Arts Center was a new, community-based arts organization and was unknown outside the city, and little known within the city. To help support the conference and promote their organizations, Pilchuck and the Pratt played host to workshops, demonstrations, tours, and other activities. It was the first time these three organizations had worked together and it would not be the last. Within ten years GAS would abandon its New York headquarters based at the Corning Museum of Glass and relocate to Seattle.

Many artists from the Puget Sound region were active members in this organization. Featured artists at the conference included names that were familiar on the Seattle arts scene and Pilchuck campus: Dale Chihuly, Richard Marquis, Susan Stinsmuehlen, and Dick Weiss. The keynote speaker was Italo Scanga, long-time Pilchuck faculty member and a close friend of Chihuly, and a session on Northwest glass was part of the conference proceedings. The fashion show that was proposed for the Pratt basketball court did not take place at Pratt, but was held instead at the Seattle Center pavilion, and was deemed worthy of a small mention in the local press: "You may wish 
to take some stones to the offbeat fashion show at 9 p.m. today in the Rainier Room at Seattle Center...Why stones? Because it's the Pratt Fine Arts Center Show for the "Best Dressed Glass Artists in the World" (Beers, 1981). The glass artist fashion show became a regular event at later conferences but as an event for the conference participants rather than the general public.

There were many events and several exhibitions staged as part of the conference activities. Oldknow (1996, p. 181) mentions three exhibitions: one that included 15 artists, called "Seattle Glass Artists" at the Seattle Center's Northwest Craft Center and Gallery (Tarzan, 1981; Oldknow, 1996, p. 181), and two others at downtown galleries. The Foster/White gallery showed art by Klaus Moje and Howard Ben Tre (Tarzan, 1981; Oldknow, 1996, p. 181), while the Traver/Sutton gallery featured "a major exhibition by three artists who work with nontraditional glass forms-Richard Cohen, Therman Statom and Susan Stinsmuehlen" at the Traver-Sutton Gallery (4 ${ }^{\text {th }}$ Ave) (Tarzan, 1981; Oldknow, 1996). Tarzan (1981) mentions an exhibit featuring Greg Englesby and Erik Brakken at the North Seattle Community College Art Gallery. In addition to the program demonstrations featuring Pratt students and faculty in glass, ceramics, metal, jewelry and metalsmithing, Tarzan also mentioned the open house at Pratt on Saturday, and noted that "Statom and Posner will collaborate in a performance project which will be one of the highlights..." (Tarzan, 1981, p. E1). The performance project took place, but it was Zynsky and Buster Simpson who collaborated in what was described as a reprise of "the early days at Pilchuck through their public 'kinetic and sound performance using molten and sheet glass"” (Oldknow, 1996, p. 181). 


\section{Chihuly's growing fame - The move to Seattle}

If Adamson was the godfather of Seattle's glass scene, Chihuly was its most famous icon. By the end of the 1970s Chihuly was well known in Seattle's art scene and his name was familiar in New York City (due to his RISD connections in part). Popular media outlets including Life magazine, Seattle TV stations, and others were paying attention to Pilchuck's founding artist, Dale Chihuly. Throughout the seventies Chihuly came to Pilchuck every summer to work and occasionally teach, but his career and multiple projects took him and his glassblowing team all over the world. His fame continued to spread, and sales from his artwork grew. He had his first show at the Seattle Art Museum in 1977. The Baskets that were featured at the Seattle Art Museum exhibition were the works Chihuly had completed at Pilchuck during and after the school's regular sessions in the summer of 1977, with Benjamin Moore as his gaffer ${ }^{31}$. The show was a popular success and helped Chihuly on his way to critical and commercial success. In 1977 he was selling his Basket series for \$1,000 each (Oldknow, 1996, p. 156). The world was beginning to take notice. "By 1980, my sales from exhibitions equaled my salary, which at that time was $\$ 18,000 \ldots$ And I quit teaching the year that my sales matched my salary" (Chihuly, quoted in Oldknow, 1996, p. 180). In 1982 he moved to Seattle, purchasing the Buffalo building in the Lake Union neighborhood as a studio. In 1983 he created Chihuly, Inc., and began producing work for the market, although he did not reach the height of his fame until the next decade.

During the 1980s Chihuly's work grew increasingly larger in scale, and he worked on a series of installations and commissions in Europe. Chihuly often stated that

\footnotetext{
${ }^{31}$ The gaffer is the lead artist/craftsperson on a glassblowing team. See Appendix D for additional descriptions of glassmaking techniques and terminology.
} 
one of the lessons he took away from his time in Venice was the importance of the teambased approach to glassblowing, and after he retired from RISD, he embraced this approach to art production. To produce his work, Chihuly typically created a design and engaged several artists to blow the glass, engrave it, paint it, and do whatever else was needed to produce the finished piece. At this time, Chihuly had a small team of Pilchuck regulars who worked with him over the summer and stayed on at Pilchuck through the fall after the workshops ended. This team often traveled with him to complete commissions around the world. Most of these artists were based in Seattle, and they worked on their own art, and artistic careers, when Pilchuck was not in session. They found that working with Chihuly was fun if unpredictable, was beneficial for their careers, and it provided income. Back in Seattle, it was Chihuly team members who tended to be the ones with the means to build their own studios and the social connections and skills to work together to produce their own work.

\section{Discussion}

Establishing a critical reputation and creating a market for glass art as a fine art were major goals for Pilchuck and for many, but not all studio glass artists. If the 1970s was the era of artistic experimentation and a willingness to try anything without worrying about the end result, the 1980s became the era of fragmentation, professionalization and hierarchy as artists focused more on how to establish a career and find a their place in the market. Establishing a critical reputation and creating a market for glass art as a fine art were major goals for Pilchuck and for many, but not all studio glass artists. As artists developed the technical skills that enabled them to produce quality objects, the emphasis 
shifted from the craft of production to the conceptual content of the art, creating friction between those who saw themselves as craftspeople, as craft artists, or as fine artists.

The drive to firmly establish Pilchuck's reputation as an academic arts institution required several changes to the school's organization and processes, which provoked conflict among artists who were happy with the school's original model, and new staff and board members focused on professionalization. Markusen and Johnson (2006) found that this process and the resulting conflicts between different groups of artists and between artists and new administrative staff or board members were typical of the "evolutionary process" (p. 14) of artist centers, especially when the changes resulted in artists having to give up some level of control over the organization.

The presence of European visiting artists helped establish Pilchuck as a destination for anyone wanting to learn from the best of those skilled in the craft of glass. In 1984 the school administration established the Artists-in-Residence program to extend the school's network beyond those artists identified as studio glass artists. The program's purpose was to invite established professional artists, including studio glass artists and artists who did not typically work in glass but were acknowledged among the New Yorkbased arts establishment as cutting edge contemporary artists to Pilchuck to work with glass (Herman, 1992, p. 37; Oldknow, 1996). Pilchuck provided the skilled teams and consulting experience for these artists, many of who had never worked with glass before. This was one strategy to move glass out of the craft world and into the realm of a contemporary fine arts material, and it had the effect of once again extending the artist network, bridging the studio glass networks with artists connected to the New York avant-garde. The program also brought these artists into the local network of the Puget 
Sound studio glass artists as they worked and socialized in the isolation of Pilchuck while they experimented with incorporating glass into the working methods of these artists.

By 1981, only ten years after it was founded, Pilchuck was one of the most famous art workshops in the U.S. It had an international reputation as the place to go to in the U.S. for anyone who wanted to experiment with innovative glassmaking techniques, and to work with renowned artists and teachers. Chihuly had not yet broken through to the sort of international fame that he gained by the 1990s, but he was well known in the art world, and was a tireless promoter of studio glass art. Promoting Chihuly, Pilchuck and Northwest studio glass as a single entity was an activity practiced by the Haubergs, Chihuly, and just about any one associated with the Seattle art scene at this time. Pilchuck artists most closely associated with Chihuly benefited the most from his growing fame. No other artist was seen as often, in as many places, or with as much media attention as the famed networker and maestro himself, Dale Chihuly.

In researching how smaller cities, including Seattle, were able to support thriving arts communities, Markusen and Johnson (2006) found that local nonprofit arts organizations that provided places for artists to "learn, network, get and give feedback, exhibit, share space and equipment" (p. 7) were key components. With the opening of Pratt Fine Arts Center in 1979, the Seattle region became home to two organizations that fit Markusen and Johnson's (2006) definition of an artist center, and both of these organizations were critically important for providing local studio glass artists with dedicated spaces for learning, working, and networking. However, as a 1981 presentation at the Glass Art Society (GAS) Conference held in Seattle noted, Pilchuck brought artists to the region, and also brought: "national attention to the Seattle glass movement. But 
Northwest glass is much more than Pilchuck alone. It is the Pratt Fine Art Center and the Glass Eye and a growing group of individual glass artists" (Bernstein \& Hansen, 1981). Markusen \& Johnson's (2006) research examined nonprofit organizations only; their study did not include for-profit enterprises like the Glass Eye and Benjamin Moore's studio, which employed artists, providing much-needed income, along with opportunities for artists to gain new skills and practice their craft. In Seattle, these for-profit organizations sometimes served as extensions of the nonprofit artist centers, being founded by artists who held positions at Pilchuck or Pratt as faculty or staff, and they drew from the same artist network. They also added to the artist support structure for studio glass artists who came to the region, as locations with opportunities for professional development, income, and access to information to further their careers (Jackson, 2004).

In addition to the artists and the organizations that included workspaces and offered educational experiences for local studio glass artists, a growing demand for studio glass art helped keep artists in the region. This was the era when new galleries and new markets emerged, mainly due to efforts by practitioners and collectors, as critical acceptance of glass art was still limited in the art world beyond the Pacific Northwest by the identification of glass as a craft medium.

Newly revitalized downtown spaces became sites of artistic production and markets, as tourism became more important to the downtown economy. Pike Street Market, saved by preservationists in the 1970s became a leading tourist destination in Seattle and a place for artists to sell. Pioneer Square became the central location for the growing number of art galleries in Seattle, catering to tourists at the mid and upper scale 
of the market (see map, Figure 9.2). Artists found low-cost studio space in the Pioneer Square area and nearby industrial and working-class neighborhoods just north of downtown Seattle including Belltown, Lake Union, Fremont and Ballard. Local galleries featured artists who were Pilchuck regulars, often due to the efforts of Chihuly and Pilchuck patrons Anne G. and John Hauberg. Glass artists also found outlets for showing and selling their work at local and regional craft fairs, at tourist venues, and at the two glass production shops with retail stores, the original Glass Eye at Pike Street Market and Glasshouse Studio at Pioneer Square. The growing number of spaces for artists to show and sell work, and the regular appearance of work by studio glass artists in local galleries, are evidence that Seattle was a viable place to be a studio glass artist, especially compared to the previous decade, when such opportunities to show and sell studio glass were limited. By the early 1980s, Seattle had at least some measure of all six of Jackson's (2004) place-based "dimensions" that her study found were needed to support artists over the course of their professional careers, as artists in the city including "validation, markets, material support, training and professional development, networks, information" (p. 45).

This period is marked by conflicting forces, which pulled the studio glass art community in different directions. The growing number of artists in the area attracted media attention, and studio glass artists met with a large share of that attention. Glass art is attractive to look at (a fact many artists saw as a weakness), and glassblowing production was a form of dramatic performance art with its synchronized teams and the dance of fire and glass and human skill. New options for selling work in the region, the segmented marketplace, and the differences between the artists about what it meant to be 
a glass artist all worked to create divisions in the group. At the same time, the small number of artists in the area, the limited number of glass studios, and a market that was still limited encouraged or artists to continue the teamwork approach they followed in the 1970s. The basic rule in the region was still the same: "Everybody knows everybody and everybody works with everybody" (Lieberman, quoted in Hackett, 1981). Continued shared work experiences and interactions helped keep the studio glass networks strong (Colemen, 1988). Pilchuck's growing international reputation and its connections with colleges and universities in the studio glass network brought a steady supply of new people into the mix, but the strongest bonds were between the groups who stayed on in the region after the Pilchuck program ended for the summer. People still worked together to help each other produce work for the fine arts marketplace and large public art projects, and people who identified themselves as fine artists whose goal was to see their work in a high-end New York gallery or a museum collection worked in production studios making tourist baubles alongside craft-oriented artists who saw glassmaking as a way to earn an independent living doing something they loved to do, and who were less interested in the climbing the ladder of the art world hierarchy. 


\section{Chapter 7: Seattle: Glass Mecca}

\section{Introduction}

In 1990, the Glass Art Society (GAS) returned to Seattle once again for its conference. This time, instead of a weeklong celebration of studio glass, the number of galleries, museums and local events featuring studio glass art and artists effectively extended the conference into a studio glass art month. With all the media attention that the city and its cultural scene received over the decade, the 1990s could be considered the Seattle decade. It was certainly a boom decade for Seattle's studio glass artists.

The decade opened with three significant events for the studio glass community: the Glass Art Society (GAS) conference in 1990, the celebration of Pilchuck's $20^{\text {th }}$ anniversary in 1991, and the opening of the new Seattle Art Museum building in 1992. By the mid-90s, the region seemed awash in new and expanded cultural institutions. Many of them featured studio glass in their opening exhibitions and became home to permanent studio glass collections. The presence of so many glass artists in Seattle and the quality of the work they produced was drawing comparisons between Venice and Western Washington. This comparison was literally illustrated through Chihuly's 1996 Chihuly Over Venice installation and the widespread distribution of the video documenting the installation and the artist's working processes, which also made him one of the most well known artists worldwide in the late 1990s.

\section{Seattle: The 1990s economy, demographics and cultural scene}

The transition from the 1980s to the 1990s was not all clear sailing economically for the city or the region. In the late 1980s, the downtown office construction boom had 
gone bust due to overexpansion, and from 1990-92 a national recession took its toll on the region. Threats of Boeing cutbacks and the closing of the longtime downtown department store Frederick \& Nelson in 1992 may have stirred memories of the 1982 recession (Groves, 1992), but Seattle's economy was no longer completely dependent upon Boeing. These economic setbacks "would prove nothing more than a speed bump in Seattle's Road Ahead. Boom times the likes of which no one in Seattle history had ever seen were coming" (Moody, 2003, p. 102). The region's economy had diversified since the 1982 recession. The high tech sector, led by Microsoft and its new operating system, Windows 3.0, dominated the personal computer market by the early 1990s. Microsoft's CEO Bill Gates was as famous as the company he founded, featured by Forbes magazine as the richest man in America. Starbucks completed its initial public offering (IPO) in 1992 and had grown from a small artisanal coffee shop next to Pike Place Market to a corporation with 165 locations in the United States and Canada. By the end of the decade Starbucks was global, with close to 2,500 locations. REI, a local cooperative founded in 1938 so local mountain climbing enthusiasts could access better quality mountaineering equipment, began a major expansion during the 1980s that continued through the 1990s. By 1995 the cooperative had sales of $\$ 432$ million, with 40 retail locations in 18 states (FundingUniverse.com, 2012). REI's new 100,000 square foot flagship store opened in the Lake Union neighborhood in 1996 and quickly became a tourist destination (Egan, 1998).

Companies like Microsoft and other high-end service industries made up a large part of the city's employer base, and the comparatively high wages their workers earned helped raise the median income of the city by 16 percent over the decade, while the 
national median income increased to about 10 percent during this time (Bernstein, 2008). Meanwhile, rental rates increased by 18 percent by the end of the decade, and homeownership in the city declined (Brookings Institute, 2000, p. 7). This was also the era when housing prices increased substantially, and gentrification throughout the region intensified. Conflicts around the rights of homeless people in the downtown streets were symbolic of the gentrification of Belltown, Lake Union, and other downtown neighborhoods that started in the 1980s and continued into the 1990s. Growth and rising housing costs meant that Seattle became increasingly unaffordable for many residents.

Throughout the 1990s, the city was a prime destination for young singles. Seattle's growth of 9 percent during the 1990s was more than double that of the 1980s, and the city gained 47,000 new residents during the decade. The population that made up the largest percentage of any age group in the city was young, childless people between ages of 25 and 34, comprising roughly 22 percent of the city's population in both 1990 and 2000 (City of Seattle, 1992. p. 4; Washington Office of Financial Management, 2000, p. 2). According to the 1990 and 2000 census figures, approximately 30 percent of the city's adult residents held bachelor's degrees. Over 20 percent of Seattle residents over the age of five had lived in other U.S. cities five years before moving to Seattle, and the city's immigrant population had increased by 40 percent during the decade (Brookings Institution, 2003, p. 39). The city's population became more diverse during these years, but even with the influx of new people, the city's population remained majority white. By the end of the decade, the city's population was up to 563,374 while the metropolitan area population reached 2,414,616. (Brookings Institute, 2000, p. 7). The increased migration from other parts of the U.S. to the West represented part of a continued 
demographic trend, while the influx of college-educated young people to the region reflected the growing presence of high-end service industries and the technology sector.

\section{Visual arts boom}

As the thriving music and visual arts scene indicated, artists were included among the population who flocked to the city during the 1990s, and the region, like the rest of the country, experienced an increase in the numbers of individual artists, art galleries, art dealers and museums. According to the National Endowment for the Arts (NEA), between 1980 and 1990 the artist population (people in the workforce who identified their job as one that fell into the artist category) increased from $1,085,693$ to $1,671,278$ nationally, a 54 percent increase. In 36 states artists comprised at least 1 percent of the civilian labor force. This increase was largest in the Western region of the United States, where the artist population showed a 60.4 percent increase, from 279,951 to 448,983 . Washington State experienced a 62.3 percent increase in the numbers of artists living there (from 22,974 to 37,296) between 1980 and 1990. In 1990, it ranked number seven in terms of percentage of artists in the labor force (1.54 percent). California and New York continued to be the top ranking states (National Endowment for the Arts, 1993a). See Table 7.1, below. 
Table 7.1: All artists in labor force by state of residence: 1970-1990. First five states by population, plus Washington State.

\begin{tabular}{|c|c|c|c|c|c|c|c|}
\hline \multirow[t]{2}{*}{ States } & \multicolumn{2}{|l|}{1990} & & \multirow{2}{*}{$\begin{array}{l}1980- \\
1990 \\
\text { Percent } \\
\text { Increas } \\
\text { e }\end{array}$} & \multicolumn{2}{|l|}{1980} & \\
\hline & Number artists & $\begin{array}{l}\text { Percent of } \\
\text { labor force }\end{array}$ & $\begin{array}{l}\text { Rank } \\
\text { by } \% \\
\text { in } \\
\text { labor } \\
\text { force }\end{array}$ & & $\begin{array}{l}\text { Number } \\
\text { artists }\end{array}$ & $\begin{array}{l}\text { Percent } \\
\text { of labor } \\
\text { force }\end{array}$ & $\begin{array}{l}\text { Rank } \\
\text { by } \% \\
\text { in } \\
\text { labor } \\
\text { force }\end{array}$ \\
\hline United States & $1,671,278$ & $1.365 \%$ & & $53.9 \%$ & $1,085,693$ & $1.050 \%$ & \\
\hline California & 285,633 & $1.924 \%$ & 2 & $62.0 \%$ & 176,321 & $1.559 \%$ & 3 \\
\hline New York & 183,360 & $2.061 \%$ & 1 & $32.5 \%$ & 138,424 & $1.746 \%$ & 1 \\
\hline Massachusetts & 51,412 & $1.593 \%$ & 4 & $59.6 \%$ & 32,223 & $1.150 \%$ & 11 \\
\hline Washington & 37,296 & $1.540 \%$ & 7 & $62.3 \%$ & 22,974 & $1.192 \%$ & 7 \\
\hline Colorado & 27,327 & $1.585 \%$ & 5 & $52.4 \%$ & 17,930 & $1.255 \%$ & 5 \\
\hline Hawaii & 10,223 & $1.872 \%$ & 3 & $51.4 \%$ & 6,753 & $1.559 \%$ & 2 \\
\hline
\end{tabular}

Note: In 1970 the percent of artists is calculated for the experienced civilian labor force. In 1980 and 1990 the percent of artists is calculated for the labor force presented in the Equal Employment Opportunity data file released by the Census Bureau. Source: National Endowment for the Arts (1993a)

The artist population continued to grow throughout the decade, and by 2000 , the total number of artists residing in the state reached 46,465 (1.56 percent of the labor force). These numbers do not specify what types of artists reside in the state, but they do indicate the growth in the artist population and provide some basis for comparison with the major arts regions of California and New York. Comparing cities, New York, with an artist population of 123,676 and Los Angeles, with an artist population of 119,044 together accounted for over 14 percent of the artist workforce in the U.S. As the largest city in its state, Seattle was home to the largest number of artists, and the artist population had continued to grow since the 1970s. By 1990 the Seattle Metropolitan Statistical Area (MSA) contained 22,115 artists in its work force. At 1.32 percent of the work force, the city's percentage of artists was nowhere close to New York where artists made up 7.40 percent of the workforce, or Los Angeles, with a percentage of 7.12 percent. At 1.32 
percent the city ranked $13^{\text {th }}$, falling behind Chicago, Washington, DC, Philadelphia, and Boston among other cities. These statistics include visual artists, performing artists and writers. (National Endowment for the Arts, 1993b).

$\underline{\text { Music, arts, and culture in Seattle }}$

The influx of young, single people with disposable income spurred a wide range of cultural activities, and the increased number of artists in the region helped nourish a vibrant cultural scene. There was a lively local music scene that started in the late 1980 s during the economic downturn, and produced what became known as grunge in the early 1990s. By 1989, Seattle-based bands Mudhoney, Soundgarden, and Nirvana, and local music label sub pop were being featured in music magazines like Melody Maker as the top grunge bands in the region. As products and people from Seattle became a part of the national culture, they began to receive national media attention. By 1991 Rolling Stone magazine and The New York Times had caught on to the idea that something worthy of note was happening in Seattle. Then in January 1992, Nirvana's album Nevermind reached number one on the charts, and suddenly it seemed that everyone knew about Seattle grunge. Even the New York fashion world took notice and several designers, including Marc Jacobs, introduced fashion lines based on their interpretations of the grunge look featuring lots of plaid flannel shirts, baggy dresses, and work boots.

Movie directors and television producers sought out Seattle locations. Director Cameron Crowe's movie Singles (1992) depicted the adventures and romance of a group of young single people living in an apartment building in Seattle's Capitol Hill neighborhood. Actor Matt Dillon played an aspiring grunge musician, and the movie included appearances by several local grunge band members. It had been filmed before 
grunge was an international brand, but by the time the movie was released, some of the music's early followers already considered the bands to be sellouts (Moody, 2003). The popular television show Frasier, which first aired in 1993, featured Kelsey Grammar as a radio-personality/psychiatrist who lived in a condominium in Seattle. The show makes a slight reference to studio art glass by including two studio glass art pieces, one by Chihuly, as part of the living room décor in Frasier's condo. The romantic comedy Sleepless in Seattle (1993) featured Tom Hanks as a widowed architect living on a houseboat on Seattle's Lake Union, a working class and industrial neighborhood, where gentrification had begun in the 1980s. The neighborhood was a prime location for Seattle's singles scene; the cluster of nightclubs along the shores of South Lake Union was so popular with singles that it was nicknamed "the herpes triangle" (Moody, 2003). The South Lake Union neighborhood was also the focus of the "Seattle Commons" plan, promoted by Microsoft's Paul Allen among others, that was first proposed in 1991 to redevelop the neighborhood "as a vast civic lawn framed by high-tech laboratories, condos, restaurants, and urban amenities" (Becker, 2007). The old industrial buildings around Lake Union provided studio spaces and homes for many artists, including the building Chihuly bought for his first studio in Seattle in 1985, and the building he purchased and remodeled into his showplace studio in 1990.

Chihuly was the only Seattle visual artist to attract attention from the national popular media at this time. Regardless of the lack of national media attention, visual arts activities in Seattle and the region were thriving and had expanded since the 1970s. By the early 1990s the city's cultural infrastructure including galleries, nonprofit arts organizations benefitted from the economic and demographic changes (Figure 7.1). 


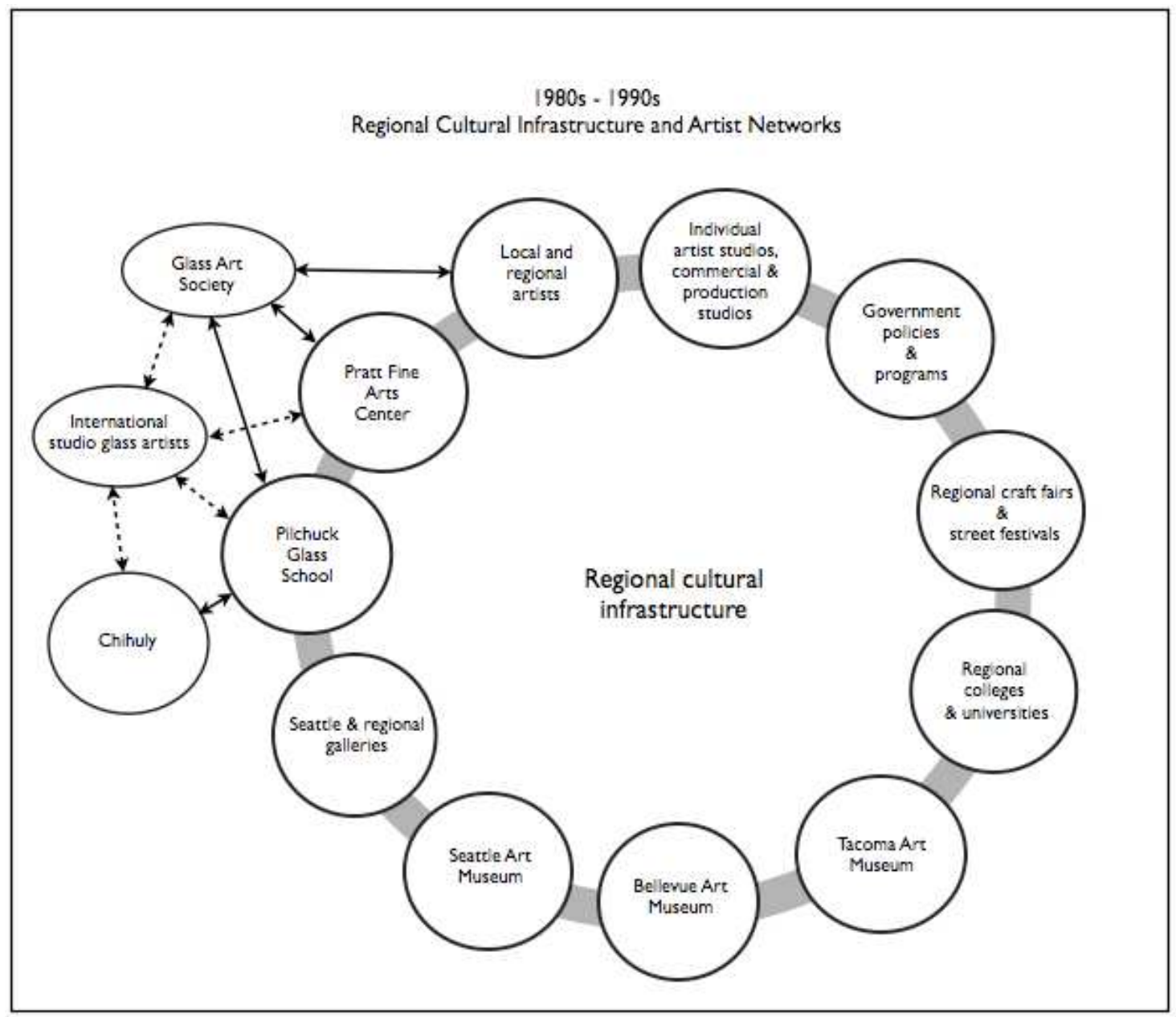

Figure 7.1. Cultural infrastructure of the Puget Sound region, 1980s - 1990s

Visual arts galleries were an integral part of the social scene for Seattle's young singles, along with local restaurants and bars. First Thursdays, a monthly event and "the first Art Walk in the nation," was started by a few Pioneer Square Galleries in 1981 to celebrate new shows and attract possible customers (Alliance for Pioneer Square, 2010). It had become incredibly popular and was "as much a social gathering as an art appreciation night. ... On warm nights, dining and drinking tables are set outside in front of the restaurants and brew pubs, giving the flavor of European-style café life" (Egan, Seattle: The art of living, 1991). In 1997 the Seattle Art Museum decided to take part in the monthly event, expanding its hours on First Thursdays and offering free admission, 
attracting more people downtown on at least one weeknight a month (Dames, 1999). Studio glass was a ubiquitous part of the culture, from the local crafts fairs and fine arts galleries, to the homes of wealthy collectors, regional museum collections, and public art on the region's streets and in parks, and public buildings, plus a few corporate buildings as well.

\section{Glass Art Society returns to Seattle, 1990}

The $20^{\text {th }}$ annual Glass Art Society conference opened in Seattle on March $29^{\text {th }}$, 1990, at the Seattle Sheraton Hotel in downtown Seattle. Ginny Ruffner, the conference coordinator, opened her GAS conference speech with the words "Welcome to Seattle: Glass Mecca” (Glass Art Society, 1990, p. 7). It had been nine years since the last GAS conference in Seattle, and the community had grown and matured in the interim. The 1981 conference showcased the region's educational facilities, a couple of studios, and a handful of artists working with glass as their medium. The 1990 conference demonstrated the successful development of art world components, from suppliers to educational organizations, collectors, museums and artists organizations that had supported the growth of studio glass art as a medium over the previous ten years.

Studio glass artists nationally had seen their medium move from crafts galleries into fine arts galleries in the 1980s, and several publications featuring studio glass art had appeared during that time. The 1980s was an era when higher prices became the norm for artwork sold in major art galleries, and prices for studio glass art increased during the same time. "In 1972 the average price for a studio glass piece was \$150. By 1990 an emerging artist's work might bring over a thousand dollars, while works by established artists would bring many thousands of dollars" (Lynn, 2004, p. 108). Glass had been 
exhibited in museum exhibitions and galleries since the late 1970s, and its presence was noted by artists, collectors and critics. Of the three groups, critics were the least enthusiastic. In the 1984 Americans in Glass exhibition he curated at the Leigh Yawkey Woodson Museum in Wausau, Wisconsin, studio glass artist David Huchthausen challenged artists and galleries in the studio glass movement to develop higher critical standards and "to develop a cohesive aesthetic philosophy beyond presentation of a specific material" (Huchthausen, 1984, p. 7). This critique continued to echo through the following decade. Critics dsimissed the studio glass art for appealing to viewers through its aesthetic qualities and physical beauty, qualities that the contemporary art world viewed with suspicion. Lynn (2004) notes that the article reviewing the Leigh Yawkey Woodson exhibition "did receive a notable, albeit stinging, critique from the high art press" (Lynn, 2004, p. 111). The lack of critical appreciation for studio glass by New York City's paper of record and its arts critics did not seem to slow the success of studio glass artists, or reduce public appreciation for their work. However, studio glass artists continued to strive for critical acceptance during this period. Susanne Frantz, a curator of contemporary glass at the Corning Museum of Glass in New York and the Glass Art Society President in 1990, authored the first catalog of the museum's contemporary collection, Contemporary Glass: A World Survey from the Corning Museum of Glass, published in 1989. The book was well-respected for providing a comprehensive and scholarly look at the history of contemporary glass, and "was also the first to present American studio glass with the rigor usually reserved for high-art media" (Lynn, 2004, p. 111). A number of books on contemporaroy studio glass followed in the 1990s, but none gained the reputation or status of Frantz's book had for its approach and content. 
The conference in 1990 drew 600 members, who included artists, students, arts administrators, collectors and art historians, with 20 percent of the members coming from international locations (Ruffner, 1990, p. 106). Opening night speakers included Frantz, Seattle artist Ginny Ruffner, a GAS board member from 1988 to 1990 and the conference coordinator, and Seattle Art Museum curator Patterson Sims. The other opening night speakers were Seattle artist Buster Simpson, and two internationally known conceptual artists Vitaly Komar and Alexander Melamid (Hackett, 1990). By 1990, Seattle was widely held to be the center of the Amercian contemporary studio glass art world, especially by Seattle artists, and events during the 1990s supported this belief. During Frantz's welcoming remarks, she noted that GAS was founded in Penland, North Carolina in 1971, the same year that Pilchuck was founded in Stanwood, Washington, and since that time, "Seattle has developed into the most important center of contemporary glassmaking in the United States" (Glass Art Society, 1990, p. 5). After the conference ended, the GAS leadership shifted to two prominent figures in the city's cultural scene, artist Ginny Ruffner and arts administrator Alice Rooney, Pilchchuck executive director. Ruffner was named GAS president. Alice Rooney accepted the position of executive director at the end of the year, after resigning her position as executive director of Pilchuck (Mathieson, 1990; Oldknow, 1996, p. 237-238). The organization's headquarters shifted from Corning, New York to Seattle, because Rooney would only accept the position if GAS moved its offices to Seattle. (Mathieson, 1990). Rooney's surprise resignation and the rumors that it was due to conflicts with Chihuly angered those in the studio glass community who supported Rooney (Oldknow, 1996). At the time of the GAS conference, Rooney was still at Pilchuck. 
The conference themes were embodied in its title: "Pacific Lip Rap: Public Art \& Private Studios" (Glass Art Society, 1990) (Figures 9.9 and 9.10) and the activities and presentations reinforced these themes and Seattle's prominence as a center for studio glass. The conference schedule contained some familiar elements. Just as in 1981, the schedule included glass workshops and glassblowing demonstrations at Pratt and at the new Glass Eye Studio, which had moved from its King Street location to a larger space in Ballard in the mid-1980s. Activities also included a post-conference trip to Pilchuck, and two pre-conference tours. One tour was to visit Anne G. Hauberg's glass art collection and the other was to Chihuly's new Seattle home and studio called the Boathouse, located in Seattle's North Lake Union neighborhood. By 1990, Chihuly owned several buildings in Seattle and Tacoma, including his first home and studio on Eastlake, and first hot shop not far from Lake Union. In 1990, the remodeling of the former boatbuilding studio had just been completed, and the Boathouse was already functioning as Chihuly's hot shop and production studio, employing many local artists "nearly as many artists as the Glass Eye, some of who move between one studio and the other" (Miller, 1991, p. 17). No doubt some of these artists also worked at Benjamin Moore's studio and were also students and instructors at Pilchuck and Pratt. Indeed, there were plenty of glass artists in the area by 1990 to staff all these venues and more. The Boathouse became the most famous artist's studio in the country after Chihuly used it as a location for videos documenting his work, including Chihuly Over Venice, filmed in collaboration with Seattle's public television station in 1995 and 1996.

One result of the GAS conference in Seattle was the discovery of the scale of the community in Seattle and surrounding area. Ruffner was confident in declaring Seattle a 
mecca for glass artists, but even the conference planners were surprised to discover how many glass artists called the region home. When conference volunteers decided to make a list of area artists and a map showing studio locations for conference participants the results were unexpected. "Although the artists know the community had been increasing, even they were surprised to find, when everything was tallied, that there were more than three-hundred people working in glass in the Pacific Northwest, over thirty individual hot shops, and more than fifty individual studios stretching from Portland, Oregon, to Bellingham, Washington” (Miller, 1991, p. 9).

Puget Sound area artists who spoke at the conference included Simpson, speaking about public art, Marvin Oliver who discussed Northwest Coast art, and Dick Weiss on the "Nuts and bolts of major stained glass commissions." Rob Adamson and Fritz Dreisbach discussed glass studios in the region. Artists Stephen Dale Edwards, Robert Carlson, Flora Mace and Joey Kirkpatrick discussed their latest work. Rooney provided a brief history of Pilchuck, and local independent curator Marjory Aronson gave a guided tour and lecture on the new Pacific First Centre building's collection of Pilchuck glass art, which she curated. Chihuly spoke about working with Lino Tagliapietra on his "Venetian" series. By this time Tagliapietra was spending a major part of every year living and working in the Seattle area. He was lead gaffer on Chihuly's team, and worked on several major projects, starting with the Venetian series in 1988. The artists featured at the conference represented the community's maturity and also featured artists who were in the mature phases of their careers. All of these artists had Pilchuck and Pratt connections in addition to their GAS memberships, and a few had been in the city since 
the 1970s, like Rob Adamson and Buster Simpson, while others, like Ruffner, Carlson, Mace and Kirkpatrick moved to Seattle in the 1980s.

The Pacific Lip Rap theme highlighted Seattle's geographic position as a Pacific Rim city and its international connections, and speakers discussed studio glass art in Japan, the Bay Area, Canada and Europe. The Niijima Glass Art Center, founded in 1987, and the Niijima International Glass Art Festival on the island of Niijima, Japan provided the focus of the discussion of Japanese studio glass art. The art festival began in 1988 with an international roster of studio glass artists. Seattle connections were underscored in the 1989 festival, which featured Seattle artists Benjamin Moore and Dante Marioni, and Dale Chihuly "with his Seattle staff” who produced work along with Moore and Marioni for an exhibition of his work in Tokyo (Noda, 1990, p. 69). International influences and collaborations were referenced and reinforced through speakers and artists incuding the Czech artists Stanislave Libensky and Jaroslava Brychtova who spoke about political revolution in their country, relationships between Czech and American glass artists, changes to the Czech arts education system under the new republic, and prominent Czech glass artists. Keynote speakers, Soviet artists Vitaly Komar and Alexander Melamid, spoke of retreating from the Manhattan art scene and its "art-crazed public" to the relative calm of Bayonne, New Jersey with its "gallery-free streets, reveling in their spare simplicity" (Komar \& Melamid, 1990, p. 65). Komar and Melamid were conceptual artists who did not work in glass. Their presence at the conference represented a Glass Art Society tradition of inviting artists and arts historians as conference speakers, reaching beyond the studio glass art community to connect with other members of the arts world. 
Conferences also provided learning opportunities for attendees through lectures, and this one also followed that tradition. In addition to Rooney's presentation on Pilchuck's history, the 1990 conference included presentations on the Blaschkas, a late $19^{\text {th }}$-early $20^{\text {th }}$ century Bohemian father and son glassmaking team. Another presentation: "The Glass Collections of Sigmund Freud and Robert Mapplethorpe" touched on the current culture wars about government support for the arts, and the National Endowment of the Arts funding.

The main agenda of the conference celebrated the region's artists and its support for art through its Public Arts Program. Seattle's Public Arts Program had achieved widespread notice as an early and successful example of a municipal percent for arts program, and studio glass artists were early and successful participants in this program. Buster Simpson provided the keynote address on public arts and Seattle. Although he was only briefly associated with the studio glass movement in the early 1970s, Simpson retained his ties to the glass artist community. Simpson, better known for his career working as an artist in the public realm with a focus on environmental art, represented many artists working in glass in the 1990s in that he used glass as one medium among many, as appropriate to the artwork's concept and location.

\section{Seattle galleries in the early 1990s}

By the early 1990s, artists who worked with glass spanned the range of artistic and craft arenas, and in the age of postmodernism, artists were comfortable mixing and appropriating various mediums and styles for their work. At the same time, the field was broad enough to include artists who specialized in other mediums, those who followed a traditional crafts-type career pattern, and those who saw themselves as fine artists with 
glass as their main medium. There were galleries in Seattle for all of these types of artists. There were also opportunities for artists interested doing large-scale public art.

The Seattle Times noted that galleries around the city were exhibiting the work of studio glass artists in conjunction with the GAS conference and called out two shows by the major galleries in town that exhibited glass artist's work, the Foster/White Gallery and the William Traver Gallery. The Foster/White Gallery show "Seattle Plus: An Invitational Exhibition of 100 Regional Artist Working in Glass" featured, as its title indicates, the work of 100 artists, all of whom had studios in the region, and the William Traver Gallery featured the work of two prominent and rising glass artists: Ginny Ruffner and Lino Tagliapietra (Hackett, 1990). Some nontraditional locations to experience regional studio glass included the lobby of the Pacific First Center, home of the Prescott collection of Pilchuck glass, which opened in 1989, and the Seattle Sheraton, which began a collection of Northwest regional art in 1982, including works by studio glass artists from Pilchuck (Aronson, 1990). The collections at Pacific First Center and at the Seattle Sheraton were both assembled by local independent curator and art advisor Margery Aronson. The SeaTac airport provided yet another venue for viewing regional studio glass through public art by numerous regional artists including a contingent of studio glass artists. SeaTac commissioned a special exhibition in honor of Pilchuck's $20^{\text {th }}$ anniversary which was on display from December of 1991 through November of 1992 (Godden, 1992). That exhibition of work by "by 55 Pilchuck teachers and students," described the school's history "and its role as a pioneer in both cold- and hot-glass working techniques" (Seattle Times, 1990). 
A December, 1990 New York Times article that appeared nine months after the GAS conference described the offerings and different character of the cluster of galleries exhibiting studio glass art in downtown Seattle that most tourists could easily visit on a stroll from the Pike Place Market to Occidental Park, just off Pioneer Square (Carmichael, 1990). Galleries listed in the article included Lynn McAllister, Toppers, William Traver, Foster/White, and Glasshouse Art Glass. Glasshouse Art Glass had been in the same location since the 1970s, and was noted as a place where people could watch the artists at work and purchase perfume bottles and paperweights for prices ranging from $\$ 66$ to $\$ 185$, while the Foster/White Gallery was the place to view and purchase works by some of Seattle's “internationally acclaimed artists” (Carmichael, 1990, p. 6) like Chihuly, David Schwarz, or William Morris, at prices ranging from $\$ 5,600$ to $\$ 20,000$. The William Traver Gallery was singled out as the place for works that demonstrated “wit, whimsy and technical mastery" (Carmichael, 1990, p. 6) with works by Ginny Ruffner, Sonja Blomdahl, or Danny Perkins, with prices ranging from $\$ 2,500$ to $\$ 3,600$. The article includes descriptions of the artwork on display at the gallery, but no critical analysis.

The article was seen as a slight to local artists by some in the community because of its emphasis on studio glass work as tourist souvenirs rather than fine art. The lack of critical recognition for studio glass in general was magnified by the lack of interest from the nation's art capital, New York City. Local art critic Regina Hackett responded to the article with a comment in a Seattle Post-Intelligencer:

Seattle glass artist Ginny Ruffner calls Seattle the "Manhattan of glass art." She has a point. Seattle is at the heart of the new glass art movement. What does the 
real Manhattan think, or at least how does its paper of record handle glass? I can't think of a Seattle glass artist who has ever received as much as a favorable nod in the arts pages of The New York Times. ... Glass art's 15 minutes of New York Times fame happened on Sunday Dec. 30, but not in the arts section. Under "Shopper's World" in the Travel section, the Times described glass in these parts, lumping art with trinkets" (Hackett, 1991, p. C9)

Ruffner, who was named as one of the artists whose work embodied "wit, whimsy and technical mastery" who first gained her reputation as an innovator in the lampwork ${ }^{32}$ technique, was equally at home making conceptually complex works for galleries or working with committees to create large-scale public art. Ruffner was a rising star in the local arts scene and a presence in the Seattle and even the national cultural scene at this time, with a solo show at the William Traver Gallery in Seattle in 1989 and another solo exhibition in a national venue at the Smithsonian's Renwick Gallery in Washington, D.C. the same year. Her work often contained humorous elements, and whimsical was an adjective that was often applied to it. Her humor and playfulness was expressed in her work and in every aspect of her career, but she also took her art and her career seriously: "Whimsy implies a lack of foresight, a whim. This is serious silly. The roles of the fool and the idiot were sacred roles. ... The artist's holy job is as the conscience of contemporary society" (Ruffner in Miller, 1995, p. 23).

In 1990 she was on the jury for the Corning Museum of Glass's New Glass Review 11 and in 1991 she curated the exhibition: "Glass: Material in the Service of Meaning," for the Tacoma Art Museum. She even had a presence in the literary world as

\footnotetext{
${ }^{32}$ In lampworking, a small torch is used to heat up glass rods until they are soft enough to form into new shapes and artwork.
} 
the inspiration for the leading character in Seattle writer Tom Robbins's 1990 novel, Skinny Legs and All. Ruffner's career was interrupted by an auto accident in 1991, when she suffered major injuries that resulted in brain damage and left the artist in a coma from which it was feared she would not recover. Ruffner's work always included elements of autobiography and as she underwent the lengthy and difficult recovery process, her work reflected her struggle to regain her life as an artist. Her work is an example of the expansion of techniques and approaches to work that marks the maturity of the movement.

Celebration of Northwest glass continued after the conference, as Pilchuck celebrated its $20^{\text {th }}$ anniversary with still more exhibitions and events. North of the city, the Whatcom Museum in Bellingham also sponsored an exhibition celebrating the $20^{\text {th }}$ anniversary in 1992. The exhibition traveled to eleven other locations throughout the United States, where it was scheduled to make its final appearance back in Washington at Washington State University and represented "the first time the accomplishments of Pilchuck artists will be seen in any organized way by the rest of the nation" (Tarzan Ament, 1992).

\section{The Rise of public art - Art in Washington's public buildings, streets, and parks}

When Berkson discussed Seattle's art scene in the 1986 Art in America article, he noted "the ubiquity of public sculpture" in the city (Berkson, 1986, p. 38). The article reinforced the idea that sculpture in the Pacific Northwest is the domain of artists working in glass and ceramics, and that public art is certainly a highly visible, if not critically important, part of the Seattle arts scene. If sculpture was everywhere in the city, the credit goes to public arts programs. In 1973, King County legislated a one percent for 
art ordinance. Seattle approved a similar program that same year, becoming one of the first cities in the United States to do so. The Seattle ordinance requires that "1 percent of eligible city capital improvement project funds be set aside for the commission, purchase and installation of artworks in a variety of settings" (City of Seattle, 1979; City of Seattle, 2011).

By the end of the 1970s, Washington's public arts programs were hailed nationally as models for other places. Over the decades these programs supported local and regional artists by commissioning and featuring their work in public spaces. As of 2011, Seattle owned “more than 350 permanently sited and integrated works and 2,600 portable works" (City of Seattle, 2011). Glass artists created many of these public art works. Public art commissions have been a major part of the careers of several glass artists, including Norman Courtney, Paul Marioni, Richard Posner, Ginny Ruffner, and Buster Simpson. Paul Marioni moved to Seattle from San Francisco in 1978 in part because of the public arts program.

I was aware, very aware of what Seattle had done and was starting in other places around the country... And the other thing was I felt like with the modernization, we were losing our landmarks. ... I felt like public art programs would address that issue; make something that people remember. ... So for that reason and several other reasons, I moved to Seattle, because Seattle had a great, established, well-supported public art program (Marioni, 2006).

The Office of Arts \& Cultural affairs manages Seattle's public art program. This office also produces and updates regular municipal arts plans that include status reports for works in progress and budgets for proposed projects. Committees comprising staff 
from city departments including the Department of Planning and Development and the Office of Arts \& Cultural Affairs work out the municipal plans, which are then used to formulate the details of the artist selection process. The Public Art Advisory Committee reviews the plan and the mayor approves it.

With few exceptions, the artist selection process is competitive, and requires that a minimum of 50 percent of the funds go to Pacific Northwest artists. "The competitive methods used for artist and artwork selections include 'open calls,' 'invitational calls,' and 'direct selection' of artists. Panels of qualified arts professionals, community members, design team members and city department representatives review applications of all competitors" (City of Seattle, 2009, p. 4). Sometimes the municipal plan spells out a detailed description of the proposed artworks to be commissioned, but often the artists submit their own detailed proposals or project plans based on community and sitespecific requirements. In some cases a department may request a particular artist, as in a 2009 request by the Seattle City Light's department to directly purchase works by Seattle artist Jacob Lawrence because of the artist's popularity and issues that his work addresses. Even in cases where it is a competitive, juried process, the presence of a friendly juror, especially a fellow artist, on the jury can affect the outcome, and studio glass artists who served on artist commission juries often had a role in persuading the rest of the committee that glass was a viable material for the work.

While it might seem surprising that a public sculpture would be constructed of glass, the fact that the funding was often tied to building programs produced a demand not only for outdoor sculptures but also for work that could serve as interior design elements. Public art works included windows, lighting elements, wall panels, doors, and 
ceiling panels along with traditional sculptural forms for interior and exterior spaces. Although the material shows up even in outdoor settings like urban parks and playgrounds, glass is frequently incorporated as one component of a mixed media piece. In his 1986 article on Seattle's art scene Berkson named Richard Posner as "the most engaged in public projects" (p. 38) and he described two of Posner's projects: Tunnel Garden, and The Veterans Lobby: The Glass Hearth (Berkson, p. 38). Tunnel Garden, a collaborative work by Posner and Ruffner, was designed for a University of Washington parking garage tunnel. Collaboration is typical and even a required component of public art projects. Given that studio glass processes typically require collaboration and teamwork, glass artists have an advantage over artists who work in media and processes where the artist works alone. It does not include glass although both Posner and Ruffner are glass artists. "People tend to pigeonhole you. Right now many people think I only do glass; I do these cutesy little glass sculptures. That's not even onetenth of what I do. I write, I make public art, I paint, I do bronzes, and I garden" (Ruffner, 2006).

Many artists who started their careers as studio glass artists, like Ruffner, produced a body of art works without including glass as a prominent part of the design, if at all. Public art commissions can have unique requirements that are based on many factors, and artists have to be flexible in their abilities to work with different materials and different constituencies. For her 1989 project The Unified Playing Field Theory, Ruffner's commission was to design an entry for the South Park Community Center in Seattle. The finished work includes a variety of materials and imagery drawn from community sources and designed to be attractive to children and local residents. 
According to the artist: "I did a demographic study prior to construction as to exactly who the public was ... I wanted to address the ethnic diversity and use appropriate imagery in the gate, sidewalk, and building. I found that the community center functioned as a living room for the community, and I wanted to create something which would help with that" (Ruffner, 2011). The exterior artwork includes a painted steel arch entryway, and a "game-board walkway" (Miller, 1995, p. 37). This type of public art commission connected the artists involved with various communities, and provided the complicated experience of designing art projects with input from many interested parties. Once the preliminary design was selected, artists had to be able to work throughout the process with local community members, planning departments, architects, construction workers, and other artists to bring the work to fruition.

In some cases studio glass artists cooperated with artists and specialists in other media, and in other cases public art commissions became the inspiration for artists to return to their original medium of glass to make it work in an urban, public context. Marioni was an early supporter of public art. He started out as a stained glass artist, and it was an easy transition to move from stained glass work to designing flat glass pieces for architectural settings. He did not stop there, but also took on commissions that required him to experiment and to push the medium in new directions, working with cast glass and water and light to create sculptures. Discussing his Reflection Fountain, a public art work from 2004, Marioni noted: "That's the primary reason I work with glass, is to capture and manipulate light. Color is also, therefore, for me content..." (Marioni, 2006 $6^{33}$ ).

\footnotetext{
${ }^{33}$ Paul Marioni, Oral history interview with Paul Marioni, 2006 Sept. 18-19, Archives of American Art, Smithsonian Institution. Interview conducted by Mija Riedel.
} 
Public arts commissions provided many artists with their first exposure to largescale design and production processes, and their first exposure to working with the public or with a committee. For most, it was difficult and for some the process was downright painful. However, the skills acquired and the connections artists made helped them win additional projects, expand their technical skills and gain skills as project managers if nothing else. The teamwork approach common to the working methods of glass artists and the natural connection between many glass forms and architecture, along with the existing strong network connections in the glass community gave glass artists an edge in many projects. Thanks to local percent-for-art ordinances and public art commissions, studio glass artists produced interior sculptures, wall sconces, lamps, glass wall panels, stained glass windows and other projects found in the region's schools, libraries, veterans hospitals, and in the SeaTac airport.

\section{Cultural Institutions and Patronage}

It was a decade of expansion for the region's cultural institutions. The demographic changes that produced customers for local restaurants, clubs, galleries and concerts also increased the museum-going audiences. As Seattle-based corporations increased their profits, local executives and stockholders, including a few "Microsoft millionaires" provided substantial funding and artwork to build and fill new wings and buildings.

The Seattle Art Museum moved most of its collection to a new building in downtown Seattle in 1992, where it was within walking distance of the gallery scene and major tourist attractions, including the Pike Place Market and Seattle Center. In addition to the art museum, other arts organizations that launched capital campaigns or opened 
new facilities during the 1990s included the Frye Art Museum (1994), Seattle Symphony Orchestra (Benaroya Hall, 1998), the Henry Gallery (1999), and the Seattle Opera (McCaw Hall, 2003). Regional museums followed the same pattern, including the Whatcom Museum in Bellingham (1992), the Museum of Northwest Art in LaConnor (1995), the Bellevue Art Museum (2001), and the Tacoma Art Museum (2003). Plans for two new museums, The Experience Music Project (2000) in Seattle and the Tacoma Museum of Glass in Tacoma (2002), were also initiated during the 1990s, and were completed in the next decade.

Museum building campaigns were financed in part and supported by local elites. Longstanding institutions like the Seattle Art Museum, the Opera and Pilchuck continued to receive support from Seattle's traditional leading families with connections to companies such as Weyerhaeuser, Boeing and Nordstrom. They were joined by some newcomers whose fortunes derived from real estate development, like Jack and Rebecca Benaroya, and from high technology companies including Microsoft. Many of these patrons collected the works of studio glass artists from the region.

Even casual observers of the regional art scene know that Seattle and glass art are synonymous. Walk into an upscale retail building, such as City Centre on Fifth Avenue, or a hotel, such as the Seattle Sheraton, and instead of seeing paintings on the walls you're likely to see glass sculpture in cases. Such individual tastemakers as Jeff and Susan Brotman (he co-founded Costco), Jon and Mary Shirley, and Jack and Rebecca Benaroya (he is one of the area's major real estate developers) all have sizable collections of Northwest glass (Updike, 1995) 
Although the software executives of Seattle and Redmond were not known for their cultural connections, by the mid 1990s local news reported that Microsoft top executives had begun collecting art. Bill and Melinda Gates, Paul Allen, and COO Jon Shirley were buying paintings and sculpture, and not a small amount of corporate art. Paul Allen put his money into creating his own museum for his favorite music and science fiction. Bill and Melinda Gates' tastes ran to paintings more than glass, but Microsoft's headquarters could boast of a Chihuly chandelier, and the company's corporate collection include more than one regionally known studio glass artist (Peterson, 2001).

The new Seattle Art Museum building, designed by architects Robert Venturi and Denise Scott Brown, opened in December of 1991 downtown, near Pike Place Market. Seattle voters had approved a levy of $\$ 29.6$ million to fund the new building in 1986 , and the museum augmented this, raising an additional $\$ 35$ million. The new building graced the cover of many architecture magazines when it opened, and the museum's opening day drew a crowd of 10,000 plus visitors (Egan, 1991). The museum also kept its original building in Volunteer Park, which reopened as the Seattle Asian Art Museum in 1994. Local collectors and museum patrons responded to the new museum not only by serving as board members but also with financial contributions.

Pilchuck co-founder and benefactor John H. Hauberg first became involved with the Seattle Art Museum as a board member in 1950. In 1973 he became museum president, serving in that position until 1979 . He was also a collector, with a deep and longstanding interest in Native American culture and in Northwest art and artists. In honor of the new museum, Hauberg donated his collection of works of Northwest Coast 
Native art to the museum in 1991, along with other artworks from his collection (Vinh, 2002). One notable name absent from museum donors at this time is Anne Gould Hauberg. According to Johns (2005), Anne was unhappy about the museum's expansion plans into the downtown area, essentially abandoning the museum designed by her father, although she later resumed her support of the art museum (Johns, 2005, p. 143). Microsoft's COO Jon Shirley and his wife, Mary, amassed a small collection of important studio glass art pieces that they donated to the Seattle Art Museum in 2005. Their studio glass collection, including pieces by Chihuly, Littleton, Marquis, Ruffner, Singletary, Tagliapietra and others, formed the basis of the museum's new studio glass gallery.

One museum proposal that didn't make it to the funding stage was a proposal from Chihuly to remodel the old Seattle City \& Light Steam Plant on Eastlake Avenue to create an international glass center. When the city held public meetings to solicit support for proposed new uses for the historic building, which had not been used since 1980, the proposed glass education center was promoted as an appropriate use that would preserve the building's architectural space. A glass center would also provide public access, something that the rival proposals to turn the building into office space or condominiums would not do (Smith, 1990, Lilly, 1990). The city rejected the glass center and other proposals in favor of developing the condominium project, which later fell through. Instead, the building became the headquarters of ZymoGenetics, a biotech startup founded by several UW professors.

Even without a new glass center, there was plenty of glass to be seen in Seattle's museums. One of the inaugural exhibitions in the new Seattle Art Museum was a 
retrospective of Chihuly's installation projects, Dale Chihuly: Installations 1964-1992. Included in the exhibition were two current works, an early version of some set designs he was working on for a Seattle Opera production of Pelleas et Melisande. The museum's oversized western windows were filled with a new Chihuly installation of large, flowerlike forms called the Venturi Window in honor of the architect (Ament, 1992).

About 90 miles north of Seattle, the Whatcom Museum in Bellingham opened in two remodeled buildings in May of 1992. One of their new buildings was dedicated to showing contemporary art, an area for which the museum had recently gained some fame. The opening exhibition in the new contemporary gallery was a survey of art and artists connected with Pilchuck, Clearly Art: Pilchuck's Glass Legacy, was organized by the Whatcom Museum Director John Olbrantz, and curated by Lloyd Herman who was the founding director of the National Museum of American Art's Renwick Gallery in Washington, D.C. (Hackett, 1992). Another museum located north of Seattle, the Museum of Northwest Art, was founded by photographer Art Hupy with support from Anne Gould Hauberg, who was a friend (Johns, 2005). The museum moved to a remodeled building in La Connor in 1995, which featured a gallery set aside for the work of regional studio glass artists, funded by the Benaroyas. The museum's first show featured works by "Pilchuck's big-name artists" (Updike, 1995).

The Bellevue Art Museum, which was an outgrowth of the Bellevue crafts fair, started in the 1960s, moved from its location in the Bellevue shopping mall to a new building at the center of downtown Bellevue in 2001. South of Seattle, planning was underway for a new museum of glass and international contemporary art, which opened 
in 2002 as the anchoring institution for Tacoma's waterfront redevelopment plan. The Tacoma Art Museum was raising money for a new building in downtown Tacoma, which opened in 2003. Anne Gould Hauberg was involved with both of these institutions. She became a member of the Tacoma Art Museum's board in 1994, helping to grow the museum's collection of Northwest artists both through her personal connections with artists in the region and by donating and promising future gifts of works from her personal collection, including studio art jewelry, paintings and more than 130 works by studio glass artists (Johns, 2005, p. 141, Tacoma Art Museum, 2012). She was also actively involved in planning the new glass museum in Tacoma, where she was noted for her "forceful voice" in support of architect Arthur Erickson's design, and against budget cutbacks that would be detrimental to the design (Johns, 2005, p. 141-142). Her unhappiness with the new Seattle Art Museum plans was probably a factor in her decision to become involved with other museums at the time, and perhaps even in her decision to promise her collection of studio glass to the Tacoma Art Museum instead of the museum in her home town.

\section{Chihuly in Seattle, Chihuly over Venice}

Chihuly officially moved to Seattle in 1983, but his commitments often kept him traveling and working in other places. However, in 1990 he purchased and remodeled an old building on Lake Union that he named "The Boathouse," which became his home, studio and hot shop. From then on Chihuly was a highly visible presence in the region. He actively promoted studio glass and his own work in Seattle and in Tacoma, where he became involved in plans for a new glass art center in the city. He continued his 
commitment to Pilchuck, moving from artistic director to a position on the board of trustees after Rooney, the school's director, resigned (Mathieson, 1990).

The decade also proved to be a productive one in the studio. Chihuly and his team kept busy designing and producing new installations, exhibitions, and private commissions for worldwide distribution. As his projects grew in scale and complexity, he hired additional staff, and by the mid-1990s he employed about 150 people to help produce and market his work (Graves, 2006). During the decade his work was exhibited at 27 different international art venues, including museums in Tokyo, Chile, Denmark, Sweden, The Czech Republic, Germany, Taiwan, and Australia. His exhibitions also traveled to arts centers and galleries throughout the United States, giving Chihuly's art and his name a wide geographic distribution. The number of Chihuly exhibitions in the Pacific Northwest also increased dramatically. During the 1980s there were two Chihuly exhibitions at Pacific Northwest museums. By comparison, during the 1990s there were 24 Chihuly exhibitions at Pacific Northwest venues ranging from the region's art museums to historical museums and university art galleries (Chihuly, 2012) as listed in Table 7.2 below. 
Table 7.2: Chihuly exhibitions in the Pacific Northwest, 1980 to 1999

\begin{tabular}{|c|c|c|}
\hline \multicolumn{3}{|c|}{ Chihuly Exhibitions in the Pacific Northwest, 1980 to 1999} \\
\hline $\begin{array}{l}\text { Exhibition } \\
\text { Date }\end{array}$ & Exhibition Title & Location \\
\hline \multicolumn{3}{|l|}{1980 - 1989} \\
\hline 1981 & Dale Chihuly Glass & Tacoma Art Museum, Tacoma, WA \\
\hline 1984 & Chihuly: A Decade of Glass & Bellevue Art Museum, Bellevue, WA \\
\hline \multicolumn{3}{|l|}{$1990-1999$} \\
\hline 1991 & Chihuly: Works on Paper & Tacoma Art Museum, Tacoma, WA \\
\hline 1992 & $\begin{array}{l}\text { Dale Chihuly: Installations } \\
\text { 1964-1992 }\end{array}$ & Seattle Art Museum, WA \\
\hline 1994 & Chihuly Baskets & $\begin{array}{l}\text { North Central Washington Museum, Wenatchee, } \\
\text { WA }\end{array}$ \\
\hline 1994 & & Port Angeles Fine Arts Center, Port Angeles, WA \\
\hline 1995 & Dale Chihuly: Installations & $\begin{array}{l}\text { Anchorage Museum of History and Art, } \\
\text { Anchorage, AK }\end{array}$ \\
\hline 1995 & Dale Chihuly & $\begin{array}{l}\text { Jundt Art Museum, Gonzaga University, Spokane, } \\
\text { WA }\end{array}$ \\
\hline 1995 & Chihuly Baskets & $\begin{array}{l}\text { Sheehan Gallery, Whitman College, Walla Walla, } \\
\text { WA }\end{array}$ \\
\hline 1995 & & Maryhill Museum of Art, Goldendale, WA \\
\hline 1995 & & $\begin{array}{l}\text { Washington State Historical Society Museum, } \\
\text { Tacoma, WA }\end{array}$ \\
\hline 1996 & & $\begin{array}{l}\text { Schneider Museum of Art, Southern Oregon State } \\
\text { College, Ashland, OR }\end{array}$ \\
\hline 1996 & Alaska Baskets & Sheldon Museum and Cultural Center, Haines, AK \\
\hline 1996 & & Sheldon Jackson Museum, Sitka, AK \\
\hline 1996 & & $\begin{array}{l}\text { Alutiiq Museum and Archaeological Repository, } \\
\text { Kodiak, AK }\end{array}$ \\
\hline 1997 & Chihuly Over Venice & Portland Art Museum, Portland, OR \\
\hline 1997 & $\begin{array}{l}\text { The George R. Stroemple } \\
\text { Collection }\end{array}$ & Portland Art Museum, Portland, OR \\
\hline 1997 & Chihuly Baskets & Prichard Gallery, University of Idaho, Moscow ID \\
\hline 1997 & & Allied Arts Association, Richland, WA \\
\hline 1997 & Alaska Baskets & Tongass Historical Museum, Ketchikan, AK \\
\hline 1997 & & $\begin{array}{l}\text { Valdez Museum and Historical Archive, Valdez, } \\
\text { AK }\end{array}$ \\
\hline 1997 & & Pratt Museum, Homer, AK \\
\hline 1997 & & Carrie M. McLain Memorial Museum, Nome, AK \\
\hline 1998 & Chihuly Baskets & Alaska State Museum, Juneau, AK \\
\hline 1998 & & West Sound Arts Council, Bremerton, WA \\
\hline 1998 & Alaska Baskets & Skagway Museum and Archives, Skagway, AK \\
\hline
\end{tabular}

Source: Chihuly website, http://www.chihuly.com/exhibition-history.aspx, accessed 6/19/2012.

In addition to exhibitions, there were installations, the largest being 100,000

Pounds of Ice and Neon at the Tacoma Dome in 1993. This was a reprise of a 1971

collaborative work that featured neon lights encased in giant ice blocks, called 20,000

Pounds of Ice, which he created with James Carpenter. The smaller version was also 
recreated at Chihuly's Seattle Art Museum retrospective, but the Tacoma version integrated the original concept with the artist's more recent interests in pushing the boundaries of size through ever larger-scale projects.

In 1992, the new Seattle Art Museum organized a Chihuly retrospective, Dale Chihuly: Installations 1964-1992. That exhibition attracted 163,600 people, a record for the museum up to that time (Hackett, 1993b). The Seattle Art Museum show included the artist's most recent work, designs for the Claude Debussy opera Pelleas et Melisande, commissioned by the Seattle Opera in 1992. During this decade, Chihuly's public identity transformed from artist and educator to artist as entrepreneur and marketing impresario as his marketing efforts intensified. Chihuly began renting shows of his work to arts organizations as traveling exhibitions, starting with the Seattle Art Museum show (Farr \& Kelleher, 2006), generating income and publicity at the same time. One year later Chihuly founded the Portland Press, which enabled him to control his image and produce his own catalogs documenting his work. Between the exhibitions, the promotional materials and publications that Portland Press generated, Chihuly's name and work were ubiquitous in the region. After Seattle magazine published an article praising Chihuly as "Seattle's own fiery fusion of Picasso and Warhol" (Hackett, 1993a), Seattle art critic Regina Hackett complained of "Chihuly bloat" due to the overload of Chihuly public relations. However, the region and the nation were soon to see a lot more of Chihuly. One of the early publications of the Portland Press was the exhibition catalog for Chihuly Over Venice, the project that carried the idea of Seattle as the new Venice into Venice itself. Chihuly had an idea to display his latest Chandelier series over water, over the canals of Venice (Chihuly \& Gibson, 1998). The project soon increased in scale and 
ambition. According to art historian William Warmus (1996), Chihuly planned to produce Chihuly Over Venice as a film project. Later, the Seattle Public Broadcasting station KCTS decided to film the project as one of its first high-definition videos. KCTS featured the Chihuly Over Venice video in its annual fundraising campaigns and sent the resulting documentary to other public broadcasting stations nationally, giving Chihuly's career yet another boost (Farr \& Kelleher, 2006).

The documentary depicted Chihuly's Seattle-based team at work creating components for glass chandeliers in the Boathouse studio and then journeying to glassmaking factories in Finland, Mexico, Ireland, and Venice to produce additional chandelier pieces at these locations. According to Chihuly, they decided to "pick five countries with glassmaking traditions and make chandeliers in each country, one in each of these fabulous countries" (Chihuly, 1998). Each chandelier featured techniques and skills for which the home country or the factory was known. At each location, Seattle artists took charge of the process, working with the factory glassblowers, while Chihuly supervised or detailed the process for the viewers.

For example, in Ireland, they worked at Waterford Crystal, creating 12 clear chandeliers with engraved surfaces, using processes for which Waterford was known. They also demonstrated to the factory glassmakers how to work with and how to blow glass without using molds, both techniques that were unknown to the factory glassmakers according to the video. The narrative at the other factories followed a similar pattern. At each factory, the documentary featured Chihuly and his team taking the lead roles working in teams of "artists and artisans" (Updike, 1995), with Chihuly's team clearly taking on the role of artists to the factory worker artisans. The video highlighted the 
ability of Chihuly's team to go anywhere in the world and work in whatever techniques they chose. It was a bit of Chihuly and team over Finland, over Ireland, over Mexico, and over Venice. The project itself could not have been accomplished without the 30 years of network-building activities that brought together professional, educational, and personal networks, plus the project management and marketing capacity of Chihuly, Inc.

According to Chihuly, he chose Venice for its beauty, not because of its history or his experience there. "People think it's about returning to my roots, to where I learned about glass, but it isn't. ... Had there been another city that was as beautiful as Venice, I might have considered it" (Chihuly, 1998). It is difficult to believe that there was no connection between Venice's history and the artist's decision to stage the installation there. There is a sense of competitiveness, even a touch of arrogance to the project, as the new glass champions broadcast their triumph on the site that was historically renowned as the center for artistry in glass. At one point in the video, Chihuly launched into a speech about Seattle as the new Mecca of Glass, and announced first that with 300 hot shops, Seattle is the new center of glassblowing, and that Seattle has overtaken Venice (Chihuly \& Gibson, 1998). The reactions from the Venetians were not documented, but they seem to have taken the event in stride. The video mentioned some difficulties getting permits to install sculptures at some of their preferred sites, but that could have been for many reasons. Warmus (1996) noted that the Italians required that Chihuly stage the installation to coincide with Venezia Aperto Vetro, the first biennial international exhibition of contemporary glass, and that this provided a "seal of approval" to the work (Warmus, p.2). Chihuly and several other Seattle artists exhibited work in the festival, including Ginny Ruffner, Richard Marquis, Flora Mace and Joey Kirkpatrick, providing a 
clear connection between the festival and the work of other Seattle area artists in addition to Chihuly. The Murano studio Chihuly's team worked at belonged to Lino Tagliapietra, who had collaborated with Chihuly since the late 1980s on the Venetian series, and taught at Pilchuck starting in the late 1970s, so the team did not work in the standard factory setting in Venice as they did in the other locations. There were only two issues mentioned by the Seattle media. One incident involved a chandelier that was dismantled after neighbors complained about the noise of the glass pieces hitting each other due to the water movement, and the second was that one piece of a chandelier was broken when a young boy threw a rock at it (Updike, 1996). Although the chandeliers were huge and were installed in both public and private settings throughout the city, Venetians were used to similar spectacles at the Venice Biennale, an international art exhibition that featured contemporary art, film and architecture. Perhaps they saw the Chihuly installation as more of the same, especially as its appearance coincided with the new international glass festival.

\section{Discussion}

Benjamin Moore, when asked about the secret to the success of glass artists in the region said, "We rode the wave" (Moore, 2011 $1^{34}$, Stern, 2011 35 ), and many aspects of the community's growth in the 1990s can be ascribed to the "right time, right place" aphorism. Puget Sound artists benefitted from the economic growth and demographic changes that supported leisure time activities and provided excess income that could be spent on luxury items. Studio glass artists in the region were well-prepared to provide

\footnotetext{
${ }^{34}$ Benjamin Moore, speaking at a Tacoma Art Museum panel discussion, with artists Joey Kirkpatrick, Flora Mace, Benjamin Moore, and Richard Royal, September, 2011 (author's notes).

${ }^{35}$ Ethan Stern, interview with the author, 2011.
} 
those items, whether the definition of a luxury item was a $\$ 20,000$ "Green Leaf Venetian" Chihuly sculpture from the Foster/White Gallery or a $\$ 65$ goblet or perfume bottle by one of the artists at commercial galleries that catered to tourists at the Pike Place Market.

Seattle-area studio glass artists were able to reap the benefits of changes in large part because they built upon mechanisms, institutions and networks that they initiated in the 1970s. The region had gained a robust cultural infrastructure, and studio glass arts organizations and artists were a major part of it. If in the 1980s the city had all the dimensions required for an artist support structure (Jackson, 2004), by the 1990s studio glass artists could successfully claim to have built an art world (Becker, 2008) to support regional artists who worked with glass as their medium. According to Becker (2006), the presence of a distribution system for the work that artists produce is one necessary part of an art world. Distribution systems connect the artist to the market and to an audience as they "integrate artists into their society's economy, bringing artworks to publics which appreciate them and will pay enough so that the work can proceed" (p. 93). Both galleries and museums played key roles in helping create a distribution system for studio glass art in the Puget Sound region. Galleries that started in the 1970s increased their audience and broadened their appeal through events like First Thursdays. Exhibitions of work by studio glass artists were frequent, and there were galleries, like the Traver Gallery, that were known for featuring regional studio glass artists, so the gallery-going public were exposed to studio glass art and artists on a regular basis, and saw the work as part of the local cultural scene. 
One of the notable changes in the cultural landscape was the museum building and expansion boom. New museums were springing up all over the world during the 1990s as more and more urban policymakers and economists became interested in building up a tourist economy and attracting the young, educated and single demographic that Seattle seemed to attract without trying (Eisinger, 2000; Florida, 2001; Strom, 2003; Miles \& Paddison, 2005). Neither Becker (2008), in his discussion of distribution systems, nor Jackson (2004) in her discussion of the market dimension included museums, perhaps because museums are not typically known for exhibiting the work of local artists or living artists. However, museums in Seattle, and in smaller regional cities like Tacoma and Bellevue were important links in bringing the work of contemporary regional studio glass artists to the notice of the public.

As existing museums expanded and new museums emerged, these institutions provided new opportunities for regional artists to exhibit their work. They also provided a stage for long-time patrons to display the fruits of their many years of supporting artist through collecting their work. New museums provided evidence of the history of collecting in the area, and were attractive to collectors as places to donate and display their collections, validating their own artistic choices and increasing the monetary value of the pieces that they owned. Artists whose current work was included in a temporary exhibition or in a well-known collection might see the value of their work increase in the market and could hope to see their artistic reputation enhanced, although neither was a given. When a museum exhibition featured objects made by artists whose work was also featured in a nearby art gallery exhibition, the market connection could be immediate. 
Artistic validation is one of the six elements that Jackson (2004) identified as critical to artists in sustaining their careers, and public art can be seen as one form validation, along with being a form of public sector, or state support for art, which serves to validate particular art forms in Becker's (2008) theory of art worlds. The awarding of a public art commission implies both peer recognition from fellow artists on the committee, and community recognition through the selection process as well. Percent for art programs in combination with the economic boom resulted in more commissions and more profitable commissions for work suitable for new corporate offices and public buildings such as libraries, community centers, and new government offices.

Again, the collaborative processes and technical skills of glass artists gave them a unique advantage working in this arena. The fact that their vocation spanned the nonfunctional arts arena and the functional craft/artisan profession meant that they were equipped to create studio glass sculpture for private and corporate art collections as well as functional work such as chandeliers, vases, and architectural elements for ostentatious homes for the newly wealthy. Moody (2003) recounted that after the dot.com bust he spent time finding people he had interviewed during the boom to see how they fared and how it affected them. Among the people he revisited were two glass artists, Sonja Blomdahl and her husband Dick Weiss. When he asked how they were affected by the boom Weiss replied "What happened was that all these technology people around here turned up with all this money for big new homes - they've been keeping me busy for years!" (Moody, 2003, p. 292). Many regional studio glass artists could have given the same answer. 
Pilchuck remained a central artist center in the community, providing education and teaching opportunities. Artists and art students continued to flock to Pilchuck and many remained in the region after their Pilchuck stint was completed. Pratt continued to provide low-cost studio space and additional teaching opportunities for artists in the region. As studies by Jackson (2004) Markusen and Johnson (2006) found, artist centers like Pilchuck and Pratt were important components of place-based support for artists and one of the reasons why some cities were able to "attract, and retain high concentrations of artists" while other cities weren’t able to do so (Markusen \& Johnson, 2006, p. 7).

Pilchuck and Pratt weren't the only attractions however; the city was known for the depth and breadth of opportunities to work in different studios and with artists who specialized in different glassmaking techniques. Art students who wanted to study or work with the masters of studio glass or just take a class or two knew that Seattle was the place to go. Production studios like the Glass Eye, Glasshouse Art Glass, and Seattle Glassblowing Studio (which opened in 1991 in Belltown) profited from the growing tourism market and provided additional places for studio glass artists to gain experience and earn income. Ethan Stern, who first came to Seattle to work at Pilchuck in 1999 while he was still a student at Alfred University in New York, moved to Seattle when he graduated in 2001. He echoed the idea of Seattle as glass Mecca:

Legend has it that when you graduate from Alfred, they give you a one-way ticket to Seattle. ...Because a lot of people-well, a lot of people in our school are in glass, and at some point they want to come out to Seattle and be part of the community ... it's so rich in resources ... Its sort of like there is some myth ... It's not necessarily a myth, but there's something that people are after, and there 
are so many people here that it's popular and people want to come and experience it (Stern, $\left.2011^{36}\right)$.

After he settled in Seattle, Stern continued to work at Pilchuck when he could, and worked for two years at various production studios, and in public access studios, including Pratt Fine Arts Center (Stern, 2011). His experience was typical of many young studio glass artists who arrived in the 1990s.

The GAS conference showed the depth and breadth of the glass art community in the Puget Sound region, and it was bigger than anyone thought it was. One result of the increasing number of artists in the city was a fracturing of the studio glass art community, which a few artists mentioned. Once in Seattle, the typical young art school graduate associated with other recent graduates; they did not socialize with the artists who arrived in the 1970s or 1980s, and knew members of Chihuly's original team as teachers, employers and occasionally as mentors rather than collaborators and friends.

Several artists emerged as stars in the regional glass art scene in the 1990s, including William Morris and Ginny Ruffner. A few "second-generation" studio glass artists mentored by older artists like Moore and Tagliapietra also gained critical notice, including Dante Marioni (Paul Marioni's son), and Preston Singletary. No single artist benefitted from the expanding economic context and arts sector to the extent that Dale Chihuly did. Indeed, he generated a fair amount the regional art production himself, through constant marketing of his own work, the promotional activities of his company, and multiple production facilities that produced the work featured in traveling exhibitions, installations and private commissions for worldwide consumption. Through

\footnotetext{
${ }^{36}$ Ethan Stern (artist), interview with the author, 2011.
} 
his media presence he helped brand the city of Seattle as an international center for studio glass art. As he broke through to worldwide fame in the 1990s, he always represented himself as a Seattle artist, and continued to link his name to Pilchuck and reinforce the school's identity as a place that existed to support excellence in making fine art objects that incorporated glass. The Chihuly Over Venice installation and video celebrated Puget Sound artists and Chihuly as the ultimate masters of glassmaking, comfortable working in every style and at any location they select. At the same time, the scale of the work, the number of people involved in its production, the use of interchangeable parts, and factory-like processes raise questions about whether the artist has indeed returned glassblowing to its earlier origins, not in Venice but in the industrial-era factory. 


\section{Chapter 8: Tacoma: From City of Destiny to City of Glass}

\section{Introduction}

“Tacoma is not just your destiny, it's also your destination” (City of Tacoma, 2010).

On July 6, 2002, the Tacoma Museum of Glass: International Center for

Contemporary Art and the Chihuly Bridge of Glass opened along the western edge of the Thea Foss Waterway, at the edge downtown Tacoma. The museum's most prominent feature was the 90 -foot tall tilted cone clad in stainless steel (Figure 9.4) which served as

a reminder of the cone-shaped sawdust burners once common in the region, as an echo of nearby Mt. Rainier, and as an icon of the new Tacoma (Cheek, 2002, p. 81; Boddy, 2002, p. 33). Architect Arthur Erickson's building design attracted enthusiastic reviews from local and national media, and expectations for the museum were high.

Erickson's museum, in concert with a bridge extravagantly endowed with Dale Chihuly glass art, has suddenly tilted metropolitan Puget Sound's cultural center of gravity toward Tacoma, away from Seattle. The Museum of Glass is more evocative, more memorable, decidedly more disciplined, and finally, more worthy of contemplation than Frank Gehry's Experience Music Project in the big city that lies 30 miles north (Cheek, 2002, p. 81).

Tacoma's plans to “increase the city's symbolic capital and catalyze other unsubsidized commercial activities" (Strom, 2002, p. 6) did not start with a glass museum, which was a relatively late entry. Before anyone proposed a Glass Museum, the city's revitalization plans already included two new museums: the Washington State History Museum and the Tacoma Art Museum. The decision to build three new museums 
in a city whose previous claim to art world fame was a citizen referendum passed in 1984, giving Tacoma the "dubious distinction as the only city ever to repeal percent-forarts legislation" (Wagonfeld, 2005, p. 20) represented a complete turnaround in the city's attitude toward cultural development, and it did not happen without sustained effort and careful planning.

This chapter examines how the city business interests and political leaders used the new museums and waterfront development to reframe Tacoma's reputation as a working-class city and create a more upscale image to appeal to the investors, developers, tourists, and the creative class.

\section{Putting culture at the heart of Tacoma's economy}

In the 1990s, Tacoma was a blue-collar town, and the second largest city in the state of Washington with a population of just under 180,000. "Between 1980 and 1990, the city grew by 11.5 percent, more than double the rate of any other city in the state" (Moody, 1991). Nearly half of the households fell into the low-income category (incomes less than $80 \%$ of Pierce County averages) according to the 2000 census and "more than 11 percent of families" fell into the poverty range (Dunphy, 2002). Although the Foss Waterway was no longer in use, the Port of Tacoma in the 1990s was very much alive. The port had expanded throughout the 1980s and was handling so many container ships that it was ranked as the $6^{\text {th }}$ in the nation by the mid-1980s. In 1991 the port had "seven times the amount of cargo it handled in 1984" and was "the $20^{\text {th }}$-largest port in the world—right behind no. 19, Seattle (Moody, 1991). The Port formed the base of Tacoma's economy. The city also supported significant manufacturing industries, in addition to the Port. The Simpson Paper mill, which was the source of the infamous 
"aroma from Tacoma" (they closed the furnace that was the major culprit in the aroma in 1999) and the Kaiser company copper smelters put the city's economy into the manufacturing realm. Military personnel from the nearby military joint base LewisMcChord supported the city's retail industry, although they did their shopping in the suburban malls, avoiding the city's traditional downtown commercial districts.

After the Port of Tacoma, the major employer in the city was Frank Russell Investments, a financial services company headed by local businessman George Russell. Russell was one of the forces behind the Foss Waterway Cleanup and became a major patron and funder of the Museum of Glass. Russell Investments represented the type of company that policymakers thought Tacoma needed to be competitive in the $21^{\text {st }}$ century.

The decision to place culture at the heart of the city's revitalization strategy symbolized Tacoma's attempt to leave behind the its industrial economy in favor of the new financial services economy. The attempt to rebrand Tacoma began with the old warehouse district just north of the downtown neighborhood. Efforts expanded into the waterfront district at the foot of downtown Tacoma due to events that were at first seen as a hindrance to the city's economic development: EPA designation of the Commencement Bay Tide flats as a Superfund site in 1983.

\section{A chance to reconnect the waterfront and downtown Tacoma}

The City of Tacoma is located about 30 miles south of Seattle, and was established and expanded along the shoreline of Commencement Bay in the South Puget Sound. Tacoma overlooks Commencement Bay, and the tide flats along the waterways are home to Tacoma's traditional industries and port activities, from copper smelters and paper mills to container shipping docks and related businesses. The unlikely origin of 
Tacoma's waterfront revitalization plans began when the Environmental Protection Agency (EPA) designated the Commencement Bay, the bay at the Southern part of the Puget Sound as a superfund site:

The Commencement Bay Nearshore/Tideflats Site covers 12 square miles in Tacoma, Washington, and includes more than 300 active businesses and nearly 500 identified point and non-point sources of contamination. The site is divided into a number of separate Project Areas being managed as distinct sites. ... Commencement Bay Nearshore/Tideflats (CB/NT) consists of 10-12 square miles of shallow water, shoreline and adjacent land, most of which is developed and industrialized. Marine sediments are contaminated from diverse industrial activities including shipbuilding, oil refining, chemical manufacturing and storage, and pulp and paper mills, dating from the turn of the century." (EPA, 2010)

The Nearshore/Tideflats site included the Thea Foss Waterway, which lies just below and to the east of downtown Tacoma, which sits at the top of a bluff. The Waterway had been the destination for runoff from the city and the location of many of the city's toxic industries since the $19^{\text {th }}$ century, and these activities had leached toxic contaminants, including arsenic, into soils and the water for over a century. "Between 1983 and 1989, EPA and the state Department of Ecology investigated the contamination and identified cleanup remedies for contaminated sediments... During this time, EPA identified parties it believed were potentially liable for cleanup, ... The challenge was deciding how much of the cleanup bill — over $\$ 55$ million — would be paid by each 
party" (Serie \& Adams, 2003, p.1). The process of assigning responsibility, negotiating cleanup costs and paying for the cleanup was expected to be lengthy and complicated.

\section{The Executive Council for a Greater Tacoma and the "Pierce County Mafia"}

The superfund designation was only one of Tacoma's problems in the early 1980s. Like many cities, Tacoma suffered economic decline during the 1970s, and in spite of the port's economic health, downtown Tacoma had not recovered economically in the 1980s. "Pulp mills choked the air, drug dealers marketed openly on street corners, and gangs and prostitution rounded out the scene. Most investment went north to Seattle and retail left downtown for the mall. Foot traffic downtown was virtually nonexistent" (Wilkerson, p. 8). In addition, plans were complicated by the Puyallup Tribe's claims on land along the Tacoma waterfront and other areas in the city. The cost and complexity of cleaning up the waterfront seemed like the final blow to the city's future.

However, Tacoma's business and political elites had not yet given up on the city, and beginning in the late 1980s, a coalition of wealthy business executives and politicians pooled their resources and used their influence to spur economic development in the city's downtown. Two groups represented this coalition: the Executive Council for a Greater Tacoma and a group of politicians nicknamed the "Pierce County Mafia." Together they launched the economic development projects that remade the former warehouse district and industrial waterfront in the 1990s and spurred the widely praised “Tacoma Renaissance." The Executive Council for a Greater Tacoma was a private nonprofit organization of Tacoma business and political elites with business and personal stakes in the city's future and believed they had a mission to help make things better. Members included the "bosses of Weyerhaeuser, the Frank Russell Co., Columbia Bank, 
The News Tribune, Simpson, the City of Tacoma, Pierce County and the Port of Tacoma" (Callaghan, 2009). In addition to the executive council, the Washington legislature in the 1980s and 1990s was home to a highly influential group of state legislators from Pierce County that the press labeled the "Pierce County Mafia." This group included two speakers of the House, Wayne Ehlers (1983-1987), and Brian Ebersole (speaker from 1993-94, Mayor of Tacoma 1996-2000), and a Senate majority leader, Ted Bottiger (later Commissioner of the Port of Tacoma). "In addition, Dan Grimm and George Walk, both legislators from Puyallup, had top budget posts. During those years, tens of millions of state dollars flowed into the county, much of it to help revitalize downtown Tacoma" (Edwards, 2005).

These two groups had the financial and political resources to bring money to city projects, and they used their influence to do so at every opportunity. Projects designed to spur economic development in Tacoma benefitted from the group's ability to direct funding into the city, raise funds for projects that did not have public funding, and influencing urban policies to promote favored projects and real estate development. Projects included the historic Pantages Theater renovation in 1983 and the later Theater District development; the decision to build the Tacoma Dome, which opened in 1984; settlement of the Puyallup tribe's land claims in 1990; restoring Union Station and leasing it to the federal government as a federal courthouse (1988-92); securing resources ranging from cash to real estate to help construct a new Tacoma Art Museum, the Washington State History museum, and the Museum of Glass; securing land and funding for the Thea Foss Waterway redevelopment and for a new University of Washington (UW) Campus along Pacific Avenue. 
These projects generated new downtown investment and cleared the way for additional development, but the project that is often credited with helping start Tacoma's downtown renewal was the opening of the Tacoma campus of the University of Washington in downtown Tacoma in 1990. The force behind this project and subsequent urban makeover came from two influential executive council members: George Russell, former head of Russell Investment Group, and Bill Philip, who founded Columbia Bank in Tacoma. "In the late 1980s, Russell and Philip looked out of their office buildings and saw a city calling for help. 'We figured Tacoma needed some guidance,' Russell said. 'We started talking about what we could do' (Edwards, 2008). Russell's involvement was especially critical for the plan to develop the glass museum on the Thea Foss Waterway, but that came later. First, Russell and Philip worked to ensure that the University of Washington would choose to locate their planned branch campus on Pacific Avenue in downtown Tacoma by raising \$1 million dollars toward the cost of the new campus (Edwards, 2008). The university was housed in a group of remodeled warehouse buildings in the Union Depot Warehouse Historic District, a stretch of downtown listed on the National Register of Historic places in 1980. The UW Tacoma campus opened in 1990, bringing new life to downtown, and from that point on, downtown projects funded by similar private-public partnerships multiplied. The renaissance continued with the 1992 opening of a the federal courthouse in the historic Union Station, a $19^{\text {th }}$ century railroad station also located on Pacific Ave. The General Services Administration leased the building in 1988. After the city spent $\$ 57$ million to remodel it (Wilkerson, 2004), Union Station reopened to the public in 1992, housing federal courtrooms. 


\section{"Make a Place for Yourself on the Foss"}

Chihuly and his work are connected with Seattle, but he was born and raised in

Tacoma, and in the 1990s he seemed to be spending a lot of time there. In 1992, Chihuly

owned four buildings in Tacoma, at least two of them located in the historic warehouse

district along Pacific Avenue, and he also conducted some of his business activities in the city, employing 24 people full-time "crating and shipping glass" (Farr, 2002). His

mother, Viola, was still living in Tacoma during this time, and thus Chihuly had personal as well as business connections to the city. Chihuly joined with the rest of the Tacoma boosters to add his own flair to the city's changing landscape through his sculptures, installations, and more ambitious projects. It was about this time that Chihuly approached Phillip Phibbs, president of the University of Puget Sound, where Chihuly had briefly attended classes as an undergraduate, to discuss an idea he had to create "a hotshop studio and glass center in the city where he grew up" (Farr, 2002). Phibbs was excited about the idea, but rather than a hot shop, he proposed the idea of building a glass museum to the Executive Council (Farr, 2002; Museum of Glass, 2012):

He fully expected to be politely dismissed. Instead, he was invited to stay for the next presentation. It was a plan for the redevelopment of the Thea Foss Waterway, which at the time was an empty industrial wasteland along a narrow channel of water so polluted that it qualified as a federal Superfund clean-up site. The Chairman of the Council, George Russell, concluded that the idea of a glass museum coincided quite beautifully with the need for a dynamic anchor tenant on the restored waterway (Museum of Glass, 2012). 
The proposal for a glass museum was well timed. From this point on, the glass museum becomes merged with the ongoing plans to redevelop the waterfront, and George Russell, along with his wife, Jane, become the strongest supporters and patrons of the proposed museum. By 1992, the Thea Foss waterway development was considered vital to the next phase of the city's economic development.

Plans to redevelop the waterway along the festival waterfront model typified by Baltimore's Harborplace and Boston's Quincy Market were credited to the third influential actor in Tacoma's comprehensive remake of the city, Tacoma city manager Ray Corpuz. The waterfront cleanup required cooperation and financial support from multiple private landowners along the waterway, and Corpuz developed a strategy to bypass the process of EPA negotiations with individual landowners. Rather than working with individual property owners, Corpuz proposed that the city buy the land and take on responsibility for cleanup costs. "In the early 1990s, the city had taken a careful look at this Superfund site and determined no private sector developer was going to take on this site - and the liability that went with it. So the city had purchased the 26-acre tract of land with the long-range goal of cleaning it up and seeking private investment" (Wilkerson, 2004). Once the city owned the land, they could more easily manage the redevelopment. Owning the land resulted in more flexibility to coordinate cleanup with the EPA and an ability to control how the land was used, leading to an ambitious development plan for the waterway.

According to Edwards (2008), Corpuz presented his plan to the Executive Council in 1990, 18 months before he presented it to the City Council. "Members were convinced the plan was economically viable and good for the city. ... Corpuz, parks 
district officials and city staff members negotiated in private meetings to buy property from private landowners" (Edward, 2008). The Executive Council hired Canadian architect Bruno Freschi, best known for designing the Expo 86 fairgrounds in Vancouver, B.C. to produce the original development plans. Freschi illustrated his Vision Plan with watercolors showing an esplanade populated with people shopping, sitting in sidewalk cafes, and strolling alongside high-rise condominiums and office buildings on the west side of the Thea Foss Waterway, which at the time was still an industrial site and an unreclaimed brownfield.

In 1991, the City Council approved the plan and the Metropolitan Park District and the city paid $\$ 6.8$ million for 27 acres of land purchased from private landowners on the Waterway. "The City, in the unfamiliar role of property developer, hoped to eventually turn the barren land into a residential, commercial and recreational area linking downtown Tacoma and the Ruston Way shoreline to the north of downtown" (City of Tacoma, 2010). Within five years the city created the Foss Waterway Development Authority Board, which was responsible for parceling out land to favored developers, managing the marketing and development of the Waterway property the city acquired from private owners.

By 1992 the city produced its own development plan for the Waterway, which incorporated details from council's vision of the west side of the Waterway. The News Tribune published a special section on the proposed redevelopment of the Thea Foss Waterway using the Executive Council's plans (Figure 9.11). Freschi's watercolors helped bring the vision to life and garnered public support for the project (Edwards, 2008, Callaghan, 2009). In 1994, the city solicited public comments and suggestions about the 
redevelopment plan at public workshops and focus group discussions. Over 900 people attended the 40-plus meetings where they could "view photos, maps and a model of the waterfront and add their ideas to a comment wall" (Washington State Department of Community Development, 2000, p. 29).

The public workshop slogan "Make a place for yourself on the Foss" and the plan's language emphasized public access and public benefits to the cleanup along with economic benefits, as this quote from the City of Tacoma's website indicates. "The City's plans for this former industrial area have one overriding thing in mind - public access. Picture this: 1.5 miles of waterfront walkway, public event plazas, marinas, shops and cultural centers stretching along the Thea Foss Waterway's western shore" (City of Tacoma, 2010). Of course, the Executive Council had commissioned the original redevelopment plans and the city had already acted to secure the necessary real estate before the public was invited to have their say. Despite the language emphasizing public benefits, it was clear that the city council and local business interests were placing their bets on the economic returns of the project. In addition to the west side development that was featured in the first phase of the project, the redevelopment would also replace businesses on the east side, most of which depended on the working waterfront and industrial Port activities for their livelihood. The Thea Foss Waterway plans dismayed several landowners along the east side of the waterway who worried about the future of their businesses, but for the time being the city reassured east-side property owners by focusing their efforts on the west-side. 


\section{Plans for a Chihuly Glass Museum get underway}

The west side of the Waterway required the full focus of Tacoma's growth coalition and city leaders to make the vision a reality. To start, they needed to establish a strong anchor organization to draw people to the waterfront, and they believed that they had their anchor in the proposed Chihuly Glass Museum. Along with the condos and office buildings, Freschi's 1990 plan “came up with the museum precinct... with a "bridge of glass" providing pedestrian access to a museum in which the glass art and archives of Tacoma native Dale Chihuly were intended to play a central role" (Boddy, 2002). A Chihuly Glass Museum fit quite well into the economic development focus of the Foss redevelopment plan, as the Chihuly name was expected to bring in tourists from around the world to spend money in the city. Between Freschi's 1990 vision and the opening of the Chihuly Bridge of Glass and the Museum of Glass in 2002, the vision met with several challenges, including those caused by the artist's plans, and other people with other visions for the city.

The Chihuly Glass Museum got off to a promising start, with George Russell and his wife Jane taking on the roles of co-chairs for the museum's board of trustees. The city helped out by providing two acres along the southern end of the Waterway, and provided additional support totaling $\$ 8.2$ million (Voelpel, 2005). Museum trustees and supporters began an international fundraising campaign to finance the building, collections, and exhibitions, and hired Canadian architect Arthur Erickson to design the museum. Erickson was well known and admired for his modernist designs, including the Simon Fraser University and the Museum of Anthropology in Vancouver, B.C. Erickson was already known in Tacoma as one of the architects who competed to design the 
Washington State History building, losing in that case to the team of Charles Moore and Arthur Andersson. The architect for the Chihuly Glass Museum would have to face several design challenges because of the site.

The planned museum was situated almost directly below the other components of a cultural corridor along Pacific Avenue that included the Theater District, UW Tacoma campus, the remodeled Union Station, and the Washington State History Museum. The proposed "museum district" included the parts of the cultural corridor from Hood Avenue on the north to S. $21^{\text {st }}$ Street on the south end of downtown, and included the new Tacoma Art Museum building (opening in 2003) at the northern end, and the Washington State History Museum and the Chihuly Glass Museum at its southern end. Moore's design for the State History museum echoed the design and material of the $19^{\text {th }}$-century red-brick, domed classical form of the Union Station. The UW buildings, housed in restored $19^{\text {th }}$ century red brick warehouses, added to the unity and consistency of the southern end of the Pacific Avenue streetscape. The Glass Museum had to connect visually and physically with the Pacific Avenue streetscape above, and also act as the anchor to the planned esplanade, retail shops, condominiums and offices to create a second neighborhood on the waterfront below. Because the glass museum was also expected to attract tourism dollars, expectations for some sort of striking and memorable iconic structure were built in to the project.

The biggest challenges to be addressed were not visual but physical, especially for pedestrians and bicyclists. Thea Foss Waterway lies within easy walking and commuting distance from the UW Tacoma campus, the History Museum, other downtown Tacoma attractions, but it sits below Pacific Avenue at the bottom of a 60-75 foot bluff. 
“Topography, I-705 and the railroad mainline tracks all restrict, in various degrees, access to the Waterway" (Tacoma Planning Commission, 2006, p. 11). It would take more than a dramatic structure bearing the name of the city's local celebrity artist to draw visitors from downtown Tacoma across a freeway and multiple active railroad lines, which visually and physically blocked access to the site from downtown.

\section{$\underline{\text { Two Visions, Two Bridges, No Museum? }}$}

The obvious solution to the problem of site access was a bridge, and Freschi's plan included a glass bridge for pedestrians and bicyclists going from Pacific Avenue to the waterfront, in keeping the waterfront museum's glass theme. However, at the time, plans for another bridge were also underway. In 1990, Michael Sullivan, head of Tacoma's Cultural Resources Division met Russian artists, Alexander Brodsky and Ilya Utkin, who were visiting the area. The artists were known for their surrealist-style architectural visions, none of which had been built at the time. Sullivan was impressed by their work, and recruited them to develop a bridge design that would also become an iconic architectural statement for the city. After spending some time in Tacoma researching the city's history and architecture, the artists proposed a design for a new pedestrian bridge that began on $12^{\text {th }}$ street (which came to a dead end on the bluffs overlooking the freeway and the railroad tracks) and extended the street to the waterfront.

The structure resembled a timber railroad trestle, a vernacular form that referenced Tacoma's history as a railroad terminal (Smallwood, 1991; Updike, 1995). The artists started with the basic railroad trestle bridge form, but modified it with modern materials and playful, even odd, details. The bridge deck measured 30 feet wide by 320 feet long, "supported by five timber columns, reaching 70 feet up from the level of the 
waterfront and connected to one another by timberwork arches" (Moody, 1991). A glassenclosed ramp structure zigzagged down between the timber frame trestles to the waterfront. An arcade of "potted firs" lined the bridge deck, and the downtown entrance to the bridge sported "a pair of stone guardian figures" that resembled "two wise dogs in fezzes" (Smallwood, 1991). Seafirst Columbia Center in Seattle displayed the model and sketches to the public in its gallery, and the design generated much public enthusiasm and media interest.

The city approved the work and the initial funding, and the project seemed to be proceeding toward construction, but it was never realized. The design was dramatic and unique, and would certainly have brought attention to that part of downtown Tacoma. However, $12^{\text {th }}$ Street was at the opposite end of Pacific Avenue from the museum district, and was not close to the core of the new Waterway development or the Glass Museum, and this may have contributed to its fate. As late as 1995, the bridge was still under discussion and was "a cause celebre in Tacoma, particularly within the arts community" (Updike, 1995).

According to Farr (2002), the Brodsky and Utkin project was abruptly cancelled when the Museum of Glass commissioned Chihuly to create the artwork for a second city-funded pedestrian bridge. The Chihuly Bridge of Glass connected to Pacific Avenue between Union Station and the Washington State History Museum at $19^{\text {th }}$ Street, and terminated at the Museum of Glass on the Waterway. After the Glass Museum agreed to pay for Chihuly's art installation on the bridge, "the city dropped the Brodsky and Utkin plan like a hot brick" (Farr, 2002a) and shifted funding from the other bridge to Chihuly's Bridge. Although Chihuly expressed his support for constructing both bridges, it was 
clear that Chihuly was not going to be upstaged in his own hometown, and it was difficult for the $12^{\text {th }}$ street bridge designers to compete with an artist who could marshal substantial private funding to sweeten the deal for the city. The idea for the $12^{\text {th }}$ Street pedestrian bridge disappeared from the landscape.

After receiving the commission from the Glass Museum to add his work to the pedestrian bridge, Chihuly's attention shifted away from the Chihuly Glass Museum to the Chihuly Bridge of Glass. The Chihuly Glass Museum supporters had to contend with questions about funding and mission fueled by the museum's namesake whose actions raised questions about his own ambitions regarding the museum. Chihuly seemed to lose interest in the glass museum, or at least in attaching his name to it. While the plans for the Chihuly Glass Museum moved into the funding and design stages, Chihuly and his managers were moving forward with their own plans for making the Chihuly name a part of Tacoma's downtown identity:

They worked out a deal for a dramatic installation at the renovated train station near the Thea Foss Waterway, just across from the site under consideration for the glass museum. Chihuly says glass museum officials weren't too happy about that project: 'They thought it would detract from what they were doing,' he said. 'Then I got involved with the bridge - at a certain point the city asked me to design a bridge (which later became the Chihuly Bridge of Glass). At that point I said I don't want a museum' (Farr, 2002).

Even as Chihuly's ambitions became increasingly intertwined with the rebuilt Tacoma, his actions sometimes ran counter to the city booster's plans for the new Tacoma and the plans for building a monument to his artistic career. Chihuly's decision 
to withdraw his name from the museum caused a crisis for the museum's supporters and raised doubts about the museum's purpose and role in Tacoma's redevelopment, but Chihuly seems to have continued along his own path without too much concern. It is not clear what his reasons were for abandoning the idea of a Chihuly Glass Museum. It may have been personal disputes, or a conflict over the museum's mission, or something else entirely. However, there is no doubt that with or without a museum to himself, Chihuly had plenty of options for displaying his work and his name in Tacoma, and he was not shy about doing just that.

Chihuly's Tacoma-“Chihulyland"

Chihuly owned properties and conducted business out of several old warehouses in and near downtown Tacoma, and throughout the 1990s he expanded the range activities there, from his business activities to supporting a nonprofit arts program, providing glassmaking classes for the city's at-risk youth, and, most visibly, creating installations throughout the city. All of these activities prompted one Seattle art critic to remark: "If he keeps up his largess, Tacoma's cultural center will end up looking like Chihulyland" (Farr, 2002). While some saw the Tacoma becoming Chihulyland, others saw Chihuly as a vital force in the city's economic future. As one city council member put it when asked about Chihuly: "He's put the economic in economic development down there... Because of him, it's going to be an art center. It's going to enhance the economics of the whole area" (Bil Moss, quoted by Porterfield, 2001).

When the Chihuly Bridge of Glass opened in 2002, it made a significant contribution to Tacoma's Chihulyland status and to the city's attractiveness to tourists, 
but it was not the first of the artist's installations to mark the city, although it was the largest, seen by the most people, and the only permanent outdoor installation by the artist.

In 1993 Chihuly recreated his and James Carpenter's 1971 RISD Installation “20,000 Pounds of Ice and Neon" at the Tacoma Dome, reincarnated on a much larger scale, as "100,000 Pounds of Ice and Neon." According to the artist's website, this installation drew 35,000 attendees over the course of four days (Graves, 2007; Chihuly.com, 2011), and surely must have soothed the arts community's embarrassing memories of the 1984 "neon war" controversy centered on public funding for a neon sculpture by Stephen Antonakos that was installed as part of the dome's construction.

The 1984 referendum resulted from reaction to the winning artist proposal selected for the Tacoma Dome, an earlier urban redevelopment project also designed to spur economic development in the city. The Tacoma Dome’s budget was \$28 million, with a percent-for-art budget of $\$ 280,000$. The call for artists brought in proposals from several well-known artists, including Andy Warhol, in addition to local artists. Jurors included "architect Michael Graves and art curators from Miami and Denver (Callahan, 2011). New York artist Antonakos proposed a rooftop orange neon sculpture that was the winning idea, but it was controversial from the start. The builders claimed that it could not be safely installed on the dome as planned, and the city then requested a new design from the artist for inside the dome (Zielenziger, 1984; UPI, 1984; Graves, 2011). By the time the Dome opened, the project had attracted a lot of publicity. The reactions to the abstract neon sculpture, the project's price, even the fact that the money went to a New York artist, and anger at what were seen as elitist attitudes on the part of the local arts administrators all combined to produce a groundswell of opposition to the work and to 
public art, leading to a referendum that repealed the percent for art ordinance and removed the sculpture (Wagonfeld, 2005). It took years for local arts administrators to win back support for public arts projects, and the $1 \%$ for arts program was not reinstated until 2000. Chihuly's 1993 neon and ice installation at the Tacoma Dome evoked memories of that earlier neon sculpture controversy and replaced them with one of the triumphal return of public art to Tacoma. If the 1984 neon war was seen as a sign of Tacoma's cultural backwardness, then Chihuly's neon installation could be seen as a general triumph of a local artist over the earlier failure of an elite New York artist to win the hearts and minds of the local population, and also demonstrated that Tacoma's citizens would welcome abstract, conceptual artworks if they were created by a local favorite.

The Tacoma Dome installation was a temporary spectacle, and the artist followed up with multiple, permanent installations in the 1990s. The next publicly accessible Chihuly installation was installed in 1994 at Union Station. It is not one but actually a set of five Chihuly installations that adorn the large lobby under the renovated dome including drawings, a Monarch Window, Lackawanna Ikebana, Water Reeds, and the End of Day Chandelier. The Chandelier and the Monarch Window dominate the viewer's attention upon entering the lobby because of their scale and bright colors. The Monarch Window fills the immense dome window that faces the waterfront with large yelloworange ruffled shapes, as if a flock of butterflies had made their way into the building and were perched on the window. Chandeliers and windows seem to be the artist's favorite forms in Tacoma. Anyone interested in seeing more Chihuly chandeliers in Tacoma at this time could visit the lobby of The News Tribune, or University of Washington at 
Tacoma Library. Pacific Lutheran University and the University of Puget Sound commissioned Chihuly window installations. On a smaller scale, a local downtown bar, the Swiss Tavern, displayed eight works from the Venetian series.

\section{Chihuly's Bridge}

The installations at the Tacoma Dome and Union Station, and commissions at other sites in Tacoma provide evidence of the artist's desire to make his mark on the city of his birth. This desire is nowhere more evident than on the Chihuly Bridge of Glass. Architect Arthur Andersson, whose firm also worked on the Washington State History Museum, designed the 500-foot long concrete and painted steel bridge. The bridge cost a total of $\$ 6.7$ million (some sources put a higher price tag on it). The Museum of Glass paid Chihuly $\$ 3$ million to design the art installations, and the city contributed $\$ 3.7$ million for constructing the bridge. The bridge itself is a nondescript concrete form that runs from the courtyard of the Washington State History Museum to the roof of the Tacoma Museum of Glass, and supports three installations of Chihuly's work along its length.

Each installation featured a different theme drawn from the artist's past work. The installations included: the Seaform Pavilion, Crystal Towers, and the Venetian Wall. The Seaform Pavilion forms the bridge's colorful ceiling, and is made up of 2,364 objects from Chihuly's Seaform and Persian series. "Placed on top of a fifty-by-twenty-foot plate-glass ceiling, the forms are suspended in midair and make dramatic use of natural light. As visitors walk under this pavilion, they experience a seemingly underwater world of glass shapes and forms a few feet above their heads" (Museum of Glass, 2002). The Venetian Wall displays work from the Venetians, Ikebana, and Putti series in what looks like a set of oversized, glass-walled cabinets (Figure 9.4). The outdoor location and 
expected human interactions posed some problems with the large display of glass objects, and the artist responded with both design elements and choice of materials. The Crystal Towers section is the only part of the installation that is exposed to the elements. The towers are supported by concrete bases, from which rises a 40 -foot tall cluster of rough, blue shapes reminiscent of ice cubes or rock candy. The blue shapes are not crystal, or even glass. They are made of a form of polyurethane that Chihuly studios developed for his large-scale works, called polyvitro. Polyvitro weighs less than glass, withstands outdoor exposure better than glass, and does not shatter like glass. The ceiling and walls that form the other two bridge "pavilions" are constructed of bulletproof glass that protects the glass sculptures contained within. The bridge raises questions about the practicality of glass as a medium for public art, questions that the Museum of Glass confronted after both structures opened in 2002. However, the museum had other issues to resolve, including questions about its independent status.

\section{A Museum emerges}

Even as the planners were envisioning a new Chihuly Glass Museum on the Waterway, Tacoma's long-standing art museum was planning a new space. The Tacoma Art Museum collection included many Chihulys, and some questioned whether there was even a need for an entirely new museum dedicated to the artist, given that the city already had an art museum with a Chihuly collection. The Art Museum had a long history of showing Chihuly's work, beginning in 1968 when it included Chihuly's work in a sculpture exhibition, followed in 1971 by another exhibition that included a Chihuly piece. The museum also presented solo exhibitions of Chihuly's work in 1981 and 1991 
and installed a permanent display of the artist's work in 1987, which the artist donated to the museum in 1990 .

The Tacoma Art Museum had been a part of Tacoma's cultural scene since 1935, when it started as the Tacoma Art Association, and later changed its name to the Tacoma Art Museum. Since 1971, the museum had been located in the former National Bank of Washington building on Pacific Avenue. By 1993, when the museum board hired Chase Rynd as curator, they were considering a move to a new building, including a wing dedicated to glass. It made sense that discussions of a Chihuly Glass Center would include the Tacoma Art Museum in some way. According to Rynd, they had years of discussions about making the new Tacoma Art Museum and the new Chihuly Glass Center a "joint effort" before they decided to pursue separate paths (Farr, 2002a). Questions about sharing resources were raised again after Rynd left in 1999, but "after extensive talks, the two sets of trustees still couldn't see eye to eye" (Farr, 2002), and it appears that the idea was not raised again, even though there was a strong likelihood that the two organizations would be competing for the same funding, in a city with a limited pool of potential funders. They were both already competing for work by the same artist, although Chihuly settled that conflict in the Tacoma Art Museum's favor when he donated a collection of his work to the art museum in 1990 and then withdrew his name from the waterfront glass museum.

Despite questions about what the new glass museum was going to be named and what it would contain, museum fundraising and construction moved ahead. In 1997 Erickson revealed his first designs for the Museum of Glass, with the iconic tilted cone housing the hot shop. Construction began in June of 2000, and by March the frame of 90- 
foot tall cone was completed. Erickson's design met the challenges of the site admirably, and was widely praised in the architectural press; feature articles appeared in Architecture magazine and Canadian Architect, and the museum received widespread mainstream media when it opened in 2002. The diamond-patterned, stainless steel cone is the most dramatic element in a building that is striking in its modesty of form and structure. Although the cone barely rises above the level of Pacific Avenue, its full form is clearly visible from the freeway, passing trains, and from the higher levels of the downtown area. The rest of the building is markedly less dramatic than the cone. From Dock Street at the waterfront level, the stainless steel cone dominates, while the rest of the street-side structure displays a nondescript, pale concrete wall topped by several rows of translucent windows. What looks like a set of oversized curved metal smoke stacks connotes the dock's industrial shipping and railroad activities. Visitors approaching from Dock Street must find their way around the giant cone to find the museum's entrance, which faces the Thea Foss Waterway. The cone also dominates the museum's waterfront façade, marking the southern edge of the building. A long, low, sloped roof overhangs the glass-front entrance. A box containing a glass elevator to the parking garage below rises from the front courtyard. The roof slope is shallow because it also serves as a pedestrian ramp and a multilevel viewing platform for waterfront events, and a space for outdoor art installations. The museum's collection of ramps, stairs and reflecting pools highlight the most dramatic approach to the museum, the passage from downtown Tacoma, over the Chihuly Bridge of Glass; "offering a promenade architecturale from the city to its waterfront" (Boddy, 2002). This route to the museum rewards visitors with dramatic views of the cone and the waterfront as they pass through the Chihuly Bridge of Glass 
and descend down the museum's roof which comprises three sloping terraces, each level with its own reflecting pool. Visitors can travel along the terraces to reach the waterfront, or descend the wide, curving ceremonial stair that wraps around the cone.

The cone dominates the interior of the 79,000 square foot museum, just as it does on the outside. As museum visitors enter the spacious lobby, their attention is drawn to the metal base of the cone, just behind and to the left of the reception area. The base of the cone houses a 9,200 square foot hot shop amphitheater that includes space for 200 people in tiered seating and a wraparound balcony. Visitors can watch an in-house team of artists work with a changing group of visiting artists to demonstrate different glassmaking techniques. A webcam broadcasts the hot shop activities worldwide.

The hot shop amphitheater is the heart of the museum, and is the site of nearconstant artist production, sometimes with multiple teams of artists at work on different projects. The glassmaking setup and equipment includes four glory holes ${ }^{37}$ for heating and reheating glass (at 2,100 to 2,300 degrees Fahrenheit) while it is being formed. Two furnaces, each of which can accommodate about 1,000 pounds of glass, keeps the glass in molten state by operating constantly, 24 hours a day. The hot shop also includes hot and cold glass studios and five annealers ${ }^{38}$ to control the temperature at which the glass objects cool after they've been made, to prevent cracking or shattering. The hot shop amphitheater is the main attraction of the museum, and highlights the performative aspects of glassblowing and glass art production. An in-house team works with a changing array of visiting artists who work represents the wide range of artistic possibilities of glass in contemporary art. However, given the complexity and time

\footnotetext{
${ }^{37}$ The part of the glass furnace used for keeping the glass hot and reheating glass as it is being worked.

${ }^{38}$ An oven used to cool hot glass at a controlled temperature.
} 
required for many glassmaking processes, it's the glassblowing and the production processes that can occur rapidly that take center stage.

The rest of the museum structure contains 11,000 square feet of exhibition galleries, a theater, a grand hall lobby area, café, museum shop, and administrative offices. Although Erickson complained about the limited budget that constrained his ability to realize the full design concepts as he scaled back design elements or substituted cheaper materials in a process Erickson labeled "De-Value Engineering” (Boddy, 2002, p. 30), the building met or exceeded expectations for its exterior design and hot shop spaces in particular. The small, low-ceilinged galleries were less admired, but adequate for a museum that had no collection, and whose major purpose was still in question at the time of its opening.

The board quickly took action to resolve the question about the museum's mission by hiring Josi Callen as the museum's director in 2000. Callen was the former director of the San Jose Museum of Art and she was credited with making that museum a major cultural organization in the region. She immediately began working with the architect to refine the museum designs and worked with the trustees to shape the organization's vision. Her response to the situation was to rename the museum to the Tacoma Museum of Glass: International Center for Contemporary Art, and expand its mission beyond glass to become a showcase for contemporary art, "to place artists who work in glass in the context of international art trends, not to ghettoize them" (Farr, 2002b). During the first year after the museum's opening it had an audience of 300,000 visitors; 90,000 people stopped by during the first two months. According to city sources, the museum opening also "generated 20 million media impressions worldwide" (City of Tacoma 
Storybook, 2010b); the media frequently included a mention of Tacoma's renaissance and revitalization efforts:

This museum is a landmark for downtown Tacoma, one in an increasingly ambitious succession. First came the adaptive rebirth of the curvaceous, Romanesque Union Station into a federal courthouse, then the renovation of a row of workaday warehouses into a University of Washington branch campus. Next May, Antoine Predock's new Tacoma Museum of Art is set to open, and then, not far off, come two museums of American cars and motorcycles (Cheek, 2002, p. 81).

The museum's opening exhibitions included some of studio glass art's international and regional stars, and included a show featuring Northwest painters from the past. Chihuly appeared in person as the first visiting artist in the Hot Shop Amphitheater. Three exhibitions were part of the opening celebrations: The Inner Light: Sculpture by Stanislav Libensky and Jaroslava Brychtova, and Sounds of the Inner Eye: John Cage, Mark Tobey, and Morris Graves filled the interior gallery spaces. The outside courtyard and rooftop terraces displayed work by Gregory Barsamian, Patrick Dougherty, Gronk, Mildred Howard, and one of the original Pilchuck participants, Seattle artist Buster Simpson. In addition to the museum's exhibition, Chihuly's permanent installations on the Chihuly Bridge of Glass were indistinguishable from the museum's temporary installations, thanks to the architectural merger of the bridge with the museum's rooftop terraces.

The museum's combination of art forms and artists included in its opening exhibitions confused some in the art world who did not see the connection between 
Studio Glass, the Northwest Mystic painters, and modern composers. Whether the exhibitions were explicitly linked or not, the combination did fit the historical context of the studio glass movement in the Pacific Northwest, especially when paired with Tacoma Art Museum's opening exhibition lineup the following year. The Tacoma Art Museum's opening exhibitions featured a Chihuly installation and an exhibition of the Northwest Mystic School of painters. This combination of artists and art forms in both museums connected the movement back to its beginnings, reiterating the role of Chihuly, and the importance of international influences. The inclusion of exhibitions featuring Mark Tobey and Morris Graves at both museum openings emphasized the regional connections and lineage of the Northwest Studio Glass movement. Perhaps unconsciously, the two Tacoma curators revisited the PNAC strategy from the 1972 exhibition in the organization's Seattle gallery, which paired work by artists from Pilchuck's first year with the work of Tobey, Morris, and the Northwest Mystic School. Studio glass as a movement did not start in the Pacific Northwest, but its development was shaped and strengthened by northwest artists, patrons, and organizations.

Tacoma's emergence as a cultural center to rival Seattle was reinforced in 2003 when the new Tacoma Art Museum opened in May, featuring a Chihuly installation as one of its inaugural exhibitions. On the waterfront, Seattle gallery owner William Traver opened a satellite Traver Gallery in November of 2003, next to the Glass Museum in the restored $19^{\text {th }}$ century Albers Mill building. By 2005, visitors wanting a totally glassthemed vacation could book rooms at the Hotel Murano, which featured a glass collection in the lobby. Within a few years of opening, in 2005, the museum changed directors and changed its name once again to the Museum of Glass, dropping the reference to 
international contemporary art, and focusing on glass. After the original interest, attendance settled down to an average of about 160,000 visitors per year.

\section{Discussion}

The opening of the Tacoma Museum of Glass proclaimed, and literally institutionalized glass as a regional art form. The museum and related developments in Tacoma represented the city's attempts to promote itself as the city most closely associated with this medium through its connection to Dale Chihuly, the artist most closely associated with the medium.

Competition between Tacoma and Seattle has long been part of both cities' history. The story of Tacoma's revitalization represents the efforts of city officials to transform the city's economic identity from blue-collar roots to a smaller, less expensive version of its larger and more economically successful neighbor to the north. Tacoma's business elites saw opportunities to advance Tacoma's cause using the strategies that had gained popularity in other cities-waterfront redevelopment and cultural development. Tacoma's urban museum cluster gained a glass museum because of the efforts of two prominent people connected to Tacoma: George Russell, former head of Russell Investments, and a former resident, Dale Chihuly.

Tacoma leaders' decision to create a cultural district and to market the city as a home for the creative class combines two strains of cultural development policies: the emphasis on cultural districts and mega-projects to generate media attention, bring in tourists and attract corporate headquarters, and a more recent focus on attracting the "creative class" of new industry professionals who prefer lively urban neighborhoods with multiple cultural amenities (Florida, 2002, 2005; Markusen \& King, 2003, 2004; Markusen, 
2005).

During the 1990s, it was common for cities to create new cultural institutions in a bid to attract tourists, media attention, and redevelopment investment in declining postindustrial downtowns (Eisinger, 2000; Strom 2002, 2003; Miles \& Paddison, 2005, Diaz-Orueta \& Fainstein, 2009, Lehrer \& Laidley, 2009). However, Tacoma's efforts went beyond most other cities in their enthusiasm for museums and public art in their rebuilding plans, and the outpouring of money and planning that went into these projects seems at odds with the city's economy and demographics.

Urban scholars Diaz-Orueta and Fainstein (p. 761) list several development categories in their definition of the new mega-projects, including:

- "Regeneration of waterfronts

- Recovery of old manufacturing and warehousing zones

- Construction of new transport infrastructure or the extension of existing ones

- Renovation of historic city districts, usually to meet the special consumer demands of middle- and upper-class sectors" (Zukin, 1998, Loures, 2001).

The history of Tacoma's revitalization includes every one of these strategies, put into place over two decades, beginning in the 1980s and accelerating throughout the 1990s (Table 8.1). 
Table 8.1: Revitalization projects and strategies in Tacoma, 1985 - 2005.

\begin{tabular}{|l|l|l|}
\hline Project & Strategy & Year \\
\hline $\begin{array}{l}\text { Union Depot Warehouse } \\
\text { Historic District designation }\end{array}$ & Historic preservation & 1980 \\
\hline Tacoma Dome & $\begin{array}{l}\text { Mega-project of an earlier } \\
\text { model/era }\end{array}$ & 1983 \\
\hline Pantages Theater Restoration & Renovation of historic city district & 1983 \\
\hline $\begin{array}{l}\text { University of Washington, } \\
\text { Tacoma Branch }\end{array}$ & $\begin{array}{l}\text { Recovery of old manufacturing and } \\
\text { warehousing zones }\end{array}$ & 1990 \\
\hline $\begin{array}{l}\text { Thea Foss Waterway property } \\
\text { purchase }\end{array}$ & $\begin{array}{l}\text { Waterfront regeneration/ Recovery } \\
\text { of old manufacturing and } \\
\text { warehousing zones }\end{array}$ & 1991 \\
\hline Union Station remodel & Renovation of historic city district & 1992 \\
\hline $\begin{array}{l}\text { Foss Waterway Public } \\
\text { Development Authority created }\end{array}$ & $\begin{array}{l}\text { Encourage public/private } \\
\text { partnership to reclaim waterfront }\end{array}$ & 1996 \\
\hline $\begin{array}{l}\text { Washington State History } \\
\text { Museum }\end{array}$ & Renovation of historic city district & 1996 \\
\hline "Wired Tacoma" & New infrastructure construction & 1999 \\
\hline Chihuly Bridge of Glass & $\begin{array}{l}\text { Waterfront regeneration/ Recovery } \\
\text { of old manufacturing and } \\
\text { warehousing zones }\end{array}$ & 2002 \\
\hline $\begin{array}{l}\text { Museum of Glass: International } \\
\text { Center for Contemporary Art }\end{array}$ & $\begin{array}{l}\text { Waterfront regeneration/ Recovery } \\
\text { of old manufacturing and } \\
\text { warehousing zones }\end{array}$ & 2002 \\
\hline Tacoma Art Museum & Renovation of historic city district & 2003 \\
\hline LINK Light Rail & $\begin{array}{l}\text { New infrastructure in historic city } \\
\text { district }\end{array}$ & 2003 \\
\hline $\begin{array}{l}\text { Tall Ships festival in Thea Foss } \\
\text { Waterway }\end{array}$ & Festivals & 2005 \\
\hline New Convention Center & 2005 \\
\hline
\end{tabular}

Tacoma's elites did not start with or confine their efforts to museums, but included projects across the spectrum of revitalization strategies. Between 1985 and 2003, Tacoma was an enthusiastic participant in the national urban "cultural building boom" that Strom (2002) attributed in large part to economic changes that made cities more economically dependent on consumption activities and a lessening of "cultural hierarchies" that expanded the definition of cultural forms and activities considered 
suitable for museums. Both factors resulted in an increase in museum building and expansion campaigns undertaken as part of an economic development strategy.

Did these strategies work to re-energize Tacoma's economy? For a time, the strategies seemed to succeed. Tacoma's renaissance story received lots of attention as an example of the success of cultural development throughout the early 2000s, especially when Tacoma seemed to weather the dot.com recession of the era in better shape than Seattle, although at least one writer noted that this was because Tacoma did not have enough dot.com companies to affect their economy, and the city's economy in general was less subject to the boom and bust variations that are a trademark of Seattle. Tacoma has not fared any better than any other Northwest city in the most recent economic recession. The Washington State History Museum nearly closed its doors because of state funding cuts, although it was reprieved at the last minute, and the Museum of Glass suffered serious economic setbacks due to the economic slump and the high cost of operations.

After the period of initial enthusiasm ended, questions arose about the city's role as an urban real estate developer. A 2005 article in The News Tribune (Voelpel, 2005) questioned the city's activities in the sale of city-owned properties and noted that the city donated land in some cases or sold land at below-market prices to several developers and museums. According to Voelpel (2005), developers and nonprofit managers who made a good case that their project would spur economic development got a good deal from the City. Beneficiaries included the Museum of Glass, the Tacoma Art Museum, the LeMay Automobile Museum, and even the Federal Courthouse, which got Union Station for its use after the city financed the renovation. Commercial developers who benefited by the 
city's desire to establish public-private partnerships included those who developed hotels and office buildings.

The most popular part of the Museum of Glass was the hot shop, which was part of Chihuly's original vision of a glass center and hot shop, where people could watch artists at work with red-hot molten glass in front of the flames of the glory holes and furnaces. In its own way, the museum could be seen as one possible direction for museums as they rethink their institutional roles. The Museum of Glass is not just a museum that displays work, it is a museum where people make art, and do so in a way that invites local people, along with tourists, to take part, as audience members through the hot shop demonstrations, and as participants through weekly workshops in glassmaking techniques.

The hot shop also served as an artist center and educational resource. As museum management strove to keep the hot shop active, local, regional, and international studio glass artists from were invited to work with the in-house team, or to bring their own teams with them, providing opportunities for artists to work together and trade ideas and techniques. The presence of the Museum of Glass (specifically its hot shop) helped support at least one small group of local artists working with glass outside the museum's walls, and helped spur additional hot shop construction in the area. Chihuly also ensured that studio glass would become a Tacoma tradition when he supported the establishment of Hilltop Artists in 1994, a tuition-free educational program in teaching glassmaking to the city's youth from a range of backgrounds. Throughout the 1990s Chihuly's activities ensured that anyone traveling in or through Tacoma would see his artwork if not his name, and at the same time, through the actions of the Museum of Glass and the artists 
associated with that institution, Tacoma has indeed become a city with a growing population of artists who work with glass, if not a city of glass. 


\section{Chapter 9: Findings and Discussion}

\section{Introduction}

The studio glass movement emerged fifty years ago with the expressed aim of promoting glass as an artistic medium, and took root in academic arts programs due to the efforts of its early practitioners. The movement's innovative approach to the medium, which required artists to develop new processes, materials, and conventions, also defines the movement as an artistic revolution according to Becker's (2008) theory of art worlds. As representatives of a new artistic movement, the first group of studio glass artists who worked in the Puget Sound region during the 1960s and early 1970s were challenged to create the cultural support systems they needed, or to work within the existing cultural framework to create the environment necessary to thrive. Over the next 30 years, the group succeeded beyond anyone's expectations. The major factors in their success included Seattle's emerging cultural infrastructure; the social capital that the artists developed through artist networks created by working relationships; ties to educational and professional organizations; and the group's ability to strategically access existing cultural resources while building new support systems that supported individual careers and promoted their chosen medium.

\section{Findings}

This section briefly lists and describes the major research findings. These are discussed in detail in the following section.

1. The Puget Sound studio glass artist movement represents a regional manifestation of a national studio glass movement. The studio glass movement in the 
United States traces its roots to two glass workshops held in Toledo, Ohio in 1962. It spread from there to several university arts programs, which became hubs in a national studio glass artist network. Faculty and graduates of these programs expanded the movement through recruitment activities, learning networks, and professional associations.

2. Two categories of support systems developed in the Puget Sound region. These support systems were instrumental in furthering the growth of studio glass art in the region. The first category was place-based, and comprised artist centers, regional patronage, institutions, and market support. The second was network based, centered on formal and informal educational programs, professional networks developed through the Glass Art Society, and international artist networks. Both systems interacted and overlapped. Pilchuck Glass School, for example, falls into both categories, as it was a locally based artist center that connected a wide network of artists. Artists participated in the systems to different degrees at stages of their careers. Both systems fostered collaborative activities and shared learning experiences that were instrumental in building social capital and expanding the network of artists who worked with the medium of glass.

3. Studio glass artists, acting as a group and as individuals, engaged in activities to strategically access the existing cultural infrastructure of people, place, policy, cultural institutions, and the arts market to promote the medium and the interests of the group. Once those connections were established, institutional activities and marketing efforts on behalf of regional artists helped develop the market for the work of regional studio glass artists. These institutional activities were carried out by a variety of actors, including artists, local museum curators, arts patrons, gallery owners, and art critics. 
4. As the Puget Sound region gained a reputation as a center for studio glass, a regional studio glass art cluster developed. More artists came to the area, attracted by the learning opportunities and vocational experiences available only in the region. By the 1990s, the Puget Sound area was home to a large pool of artistic talent, which provided labor for larger scale projects. Galleries that specialized in selling studio glass art opened, new businesses formed to manufacture and supply specialized materials, and professional production studios emerged. Division of labor became more formal and hierarchical. Cooperative arrangements were still common, but commercially successful artists shifted production from a reliance on trading labor to a mix of labor exchanges and paid labor. How and why did this community of artists emerge and thrive in the Puget Sound region?

The interactions that sustained studio glass artists regionally were varied and emanated from different sources. Local cultural infrastructure, educational programs, cultural policies, market support, artist social networks, and the region's changing social and economic context all played a role. This community was a regional manifestation of the national studio glass movement, which began in 1962 and was originally spread through academic programs at several universities. According to Becker's (1982/2008) theory of change in art worlds, artistic revolutions that are not successful in building or accessing the necessary support required to become an art world will not grow beyond the original artists who initiated them.

The Puget Sound artists were undeniably successful in marshaling the resources they needed to build an art world that supported their medium. The Puget Sound region provided overlapping place-based and network-based support systems for Puget Sound artists. The place-based system included local arts networks, patrons, arts administrators, 
galleries, and artist centers, represented by Pilchuck, Pratt, and some for-profit production studios. The network-based system comprised international artist networks and organizations, including university arts programs, the Glass Art Society and informal learning institutions like Pilchuck. Artist networks facilitated knowledge sharing and community expansion through social gatherings, workshops held at annual meetings, and informal gatherings. Place-based support systems also facilitated knowledge sharing and network expansion through shared production, and created location-specific opportunities for face-to-face interactions between artists, patrons, gallery owners, arts administrators and other members of the arts community. Group competition and conflict periodically reshaped the boundaries of the community and the support system over time.

Seattle in the early 1970s lacked an economic support system for studio glass art, but the city was home to a vibrant cultural and civic life that included a growing number and range of cultural activities and venues, and cheap housing and studio space also provided a form of support for arts-related activities. From the mid-1950s, when business elites first began planning the world's fair for downtown Seattle, business, civic, and cultural coalitions, working sometimes cooperatively and sometimes at odds, initiated processes that were to reshape the city's culture along with its civic, economic, and built environment over the next 50 years. By 1970, Seattle's cultural infrastructure included several elements necessary to support artistic production (Becker, 2008; Jackson, 2004). Key pieces in this framework were several academic programs in the arts at regional colleges and universities, a few local funding organizations, a municipal arts commission, regional arts crafts fairs, and a few nonprofit and for-profit galleries. The city was also home to a core group of civic, business and cultural elites who supported the city's 
cultural expansion and local cultural institutions, and a growing middle-class population with an interest in cultural activities and urban amenities.

The Haubergs used their influence to promote Pilchuck and the work of artists connected to the school. This connection was established at the end of Pilchuck's first summer program in 1971 when Anne Hauberg arranged to exhibit artwork created by Pilchuck students and faculty at the nonprofit Friends of the Crafts Gallery in Seattle. Artists who came to Pilchuck and decided to stay in the region found that their connection to the school helped them in furthering their artistic careers in Seattle. Chihuly and the Haubergs promoted Pilchuck through their educational and social networks. Regional studio glass artists also promoted each other and their medium through the national Glass Art Society, which was a national professional association founded in 1971, modeled on the national Council on Education and the Ceramic Arts (NCECA), an organization to promote ceramics and education that emerged as part of the American studio craft movement.

By the 1980s, a steady flow of artists passed through a small group of institutions, learning and sharing knowledge, and Pilchuck was an important node in this institutional network. Pratt Fine Arts Center, which started as a community arts center in the late 1970s, was another center for artist production, connected to Pilchuck and the Glass Art Society through the artists who were involved with both organizations. Pratt, located in Seattle's Central District, provided the city with an open access studios and glassmaking equipment that supported low-cost educational opportunities for local artists to learn glassmaking processes. Pratt's glass studios provided affordable facilities for experienced and emerging artists to work together to carry out projects at a larger scale than they 
could accomplish in individual studios. Both Pilchuck and Pratt served as workspaces to produce artistic commissions for public art projects or private commissions. As a community center in the middle of the city, Pratt was accessible to a much broader range of people in the community than Pilchuck. It did not have the academic or financial requirements of Pilchuck, nor did it require the skills, money, or artist connections that were needed to work in private artist production and commercial studios. Unlike Pilchuck, Pratt was open year-round, and artists could supplement their income through teaching at Pratt.

Along with the proliferation of local schools and production sites, local artists were also finding career success. Most news articles about Chihuly also included a reference to Pilchuck Glass School, and its location near Seattle. Chihuly was the most well-known of the glass artists at this time, and he purchased a home in Seattle in 1982. However, he continued to spend much of his time traveling to execute large-scale commissions, and conduct workshops, and he primarily worked at Pilchuck during the summer. Artists who came to the region to study at Pilchuck and stayed in the city included Benjamin Moore, Paul Marioni, Sonja Blomdahl, Therman Statom, Joey Kirkpatrick, and Flora Mace. Their work was a major presence in the city's galleries. Some of them traded expertise or shared labor with other artists to produce that artwork. A few, including Moore, Rob Adamson, and Blomdahl ran for-profit studios that employed artists for production work, or leased their studios to other artists. Production studios like the Glass Eye, Glasshouse Studio, and Seattle Glassblowing Studio profited from the growing tourism market, provided additional places for glass artists to gain experience and earn income, and became another resource for artists in need of 
workspace. During the 1980s corporations nationally began investing in the arts and accruing corporate art collections. Studio glass was a centerpiece of several Seattle corporate collections, most notably the Sheraton Hotel and the U.S. Bank Centre in downtown Seattle. Work by Chihuly and other Pilchuck artists formed the core of these collections.

The 1990s opened with three significant events for the region's studio glass artists: the Glass Art Society (GAS) conference in 1990, the celebration of Pilchuck's $20^{\text {th }}$ anniversary in 1991, and the opening of the new Seattle Art Museum building in 1992. Studio glass could be seen in the region's corporate headquarters, public buildings, parks, and public spaces. One of the reasons that this art form was so much a part the region's built environment was because of King county's percent for art program, which stipulated that public capital construction projects dedicate one percent of their budget to project-related art. With their strong cooperative networks including people with skills in many artistic production processes, and the presence of workspaces like Pratt, Pilchuck and local production studios, the region's studio glass artists were well-positioned to work at an architectural scale and on group projects in the private and public sphere.

Artists continued to come to Seattle throughout the decade, attracted to the area by Pilchuck, by the growing numbers of studio glass artists in the region, and by the city itself. Support systems provided by community resources and social networks are important factors for artists in choosing to move to a particular city (Markusen, 2004). Students who wanted to study with the masters or just take a class or two knew that Seattle was the place to go to work with the leaders in the field of studio glass. There was a momentum to the process that echoed these effects. As artists arrived in the region 
during the 1980s and 1990s, they found the resources, fellow artists, opportunities for work and for learning, and a market for what they produced. These artists established careers through a variety of approaches to their work, from applying to public arts commissions, creating sculptural work for the fine arts market, teaching, opening galleries, starting production studios, and selling their work in craft fairs to supplement their artistic income. Many also enlisted other artists with complementary skills as part of their team. As artists learned about the opportunities in the region, more artists arrived to further their careers and work with the recognized masters. Artists who arrived in the later decades found or formed their own social and working groups; if they knew artists from the first or second generations, it was likely as teachers or employers rather than collaborators and friends.

The market for art was not the only part of the regional cultural infrastructure that grew. During the 1990s, many cities promoted or developed cultural projects, including new visual arts museums, as part of their economic strategy to attract tourists and middle class residents to urban downtowns (Eisinger, 2000; Strom, 2002, 2003; Miles \& Paddison, 2005). By the mid-90s, the many new and expanded cultural institutions in the region featured studio glass in their opening exhibitions, and became home to permanent studio glass collections. New museums included the Seattle Art Museum, which opened in 1992 in downtown Seattle, with an inaugural exhibition featuring a Chihuly retrospective. Regional museums that began expansion campaigns during this decade included the Whatcom Museum in Bellingham, the Museum of Northwest Art in LaConnor, the Bellevue Art Museum in Bellevue, and the Tacoma Art Museum. All of these museums provided additional exhibition opportunities to regional artists, including 
studio glass artists. Planning for a new museum in Tacoma began in the 1990s, based on the assumption that studio glass was a major arts form in the region and that a museum of glass would draw enough visitors to provide an economic boost to the city.

In 1990, the Glass Art Society noted that the region could claim over 300 glass artists, 30 hot shops, and over 50 glass studios "from Portland, Oregon, to Bellingham, Washington" (Miller, 1991, p. 9). These numbers that drew comparisons between Venice and the Puget Sound region, and Chihuly's 1996 Chihuly Over Venice installation highlighted this comparison. The widespread distribution of the high definition film documenting the installation, produced by Seattle Public Broadcasting, also made Chihuly one of the most well known artists worldwide by the late 1990s. The Chihuly Over Venice film linked Seattle, Chihuly, and studio glass art as an art form in which Seattle artists were dominant. When people visited Seattle, they expected to see studio glass art, and they were not disappointed.

What roles did social capital, cultural capital, social networks, and cultural policy play in the community's formation and growth?

\section{$\underline{\text { Cultural Capital }}$}

Formal and informal educational facilities, fellowships, and academic networks were critical at the start of the studio glass movement to spread information and establish the social capital that helped the group solidify. The first generation of studio glass artists benefitted from what Bourdieu (1986) identified as the institutional form of cultural capital provided by academia. Formal educational facilities provided creative freedom, professional validation, material support and workspaces during a time when there was a need for basic skill development, experimentation, and innovation that the market would 
not support. During this initial incubation phase, university faculty recruited collaborators and students who went on to establish new glass programs or accepted faculty positions in existing art programs, which expanded the network of artists active in the field. Several artists who were influential in the early Puget Sound studio glass community, including Chihuly, Fritz Dreisbach, and Michael Whitley, studied with Harvey Littleton, one of the movement's founders, at University of Wisconsin Madison, which was home to the first university program in glass. Whitley went on to teach glassmaking at several colleges in Washington during the early 1970s. After receiving graduate degrees from both the University of Wisconsin and the Rhode Island School of Design, Chihuly became a faculty member at the Rhode Island School of Design and established the glass program there. Through his position as a RISD professor, he was able to secure the funding to hold the first glass workshops at Pilchuck in Stanwood, Washington in 1971. Dreisbach graduated from the University of Wisconsin in 1967. He cofounded the Glass Art Society at Penland, North Carolina in 1971 to promote information sharing among glass artists, and taught at Pilchuck during its first summer workshop. Academic connections brought Chihuly and the Haubergs together. Chihuly had attended the University of Washington and met the well-known Seattle textile designer Jack Lenor Larsen, who later provided him with an introduction to the Haubergs. This was the meeting that led to the first glass workshop being held on Hauberg's land in Stanwood, from which developed the subsequent symbiotic relationship between Chihuly, the Haubergs, and the Pilchuck Glass School, and which linked the school and its artist population to Seattle's elites and its cultural institutions. 
Academic credentials and academic networks proved useful to Puget Sound artists who sought to learn traditional European glassmaking techniques. Artists were able to travel and study at European studios through their academic credentials. Chihuly, Marquis, and Huchthausen were all awarded Fulbright scholarships that funded study trips to Europe, spending time at different European glass studios and factories where they studied traditional glassmaking methods and established connections to European artists that proved fruitful for both European and American artists.

\section{$\underline{\text { Social Capital }}$}

According to Florida (2005), members of the creative class preferred weak ties and looser social networks, which promoted innovation and creativity. The artists profiled in this research sought out and benefitted from both strong and weak ties. Weak ties and bridging social capital were important to artists at the start of their careers and for connecting to new sources of knowledge, as in the initial relationships established between and various American and European artists through Pilchuck. The initial connections were established through academic sources. As artists spent time with their European counterparts, working and social relationships developed, and several European artists became a regular part of the American academic visiting artist circuit, including stints at Pilchuck and occasionally at Pratt. Bonding ties and social capital were created and strengthened as the artists worked together and socialized over the decades.

Lloyd's (2004) study of artists in Wicker Park, Chicago provides an example of bonding social capital and its role in artist community formation. The community building process required not only the presence of the artist residents but also local semipublic gathering places, and spaces for performing and showing work (Lloyd, 2004; 
Markusen \& Johnson, 2006). Puget Sound artist centers generated both bonding and bridging social capital among artists, as local artists socialized and collaborated with each other and with visiting artists from outside the region. Events and workshops also connected with new artists, art students, audience members and patrons, creating bridging social capital among these groups. Regional artist centers like Pilchuck Glass School and Pratt Fine Arts Center, and for-profit spaces like the Glass Eye Studio, the Glasshouse Studio, and Benjamin Moore's Studio, served as institutional actors in the networks through which other group relationships were formed (Coleman 1988). Social capital and strong artist networks were reinforced from artists trading labor and sharing workspaces to complete commissions, producing work for sale in galleries or to show in museums, from informal gatherings where artists socialized and worked together, and through the professional development activities of the Glass Art Society.

Participants in Jackson's 2004 study of the support structures for U.S. Artists "emphasized affiliations with training institutions, such as universities, art schools, companies, and studios, and with individual master teachers that 'brand' artists and associate them with the characteristics ascribed to those entities" (p. 46). Artists came to the Puget Sound region because they wanted to study with specific artists like Chihuly, Tagliapietra, Moore, and others, or more generally, to study at Pilchuck or to be in an environment where they could be surrounded by a community of artists whose skills encompassed the range of knowledge about working with the medium of glass, and where there was a range of career opportunities. Over time, artists trained at local institutions provided large pool of artistic talent and labor for larger scale projects, division of labor became more formal. The local glass art networks grew to incorporate 
people producing new materials, supplies, new galleries to exhibit and sell work, and new production facilities.

All these factors contributed to building artist networks, and increased social capital, and in 1996, Chihuly and his team of Seattle-based artists demonstrated the strength and breadth of their networks in staging Chihuly Over Venice. This installation entailed Chihuly and his team starting from their home base in Seattle, and traveling to glassblowing factories in Finland, Mexico, Ireland, and Murano to create components for large scale Chihuly chandeliers to be installed in the streets, courtyards and over the canals in Venice. This event trumpeted the supremacy of Seattle in the international studio glass art world, and the persona of Chihuly as the face of Seattle studio art glass. At the same time, it also highlighted the broad international network of studio glass artists and the movement's genealogy as both art and craft, turning glass factories into sites of artistic creations, as artists and factory workers labored together to fabricate the glass components to be shipped and assembled in Venice, in celebration of Seattle and Chihuly and the international studio glass art network.

\section{$\underline{\text { Cultural Policy }}$}

A wide variety of cultural policies were initiated over the thirty years covered by this study. This section highlights a few policies that were key to supporting a particular event or the careers of several artists portrayed here. These include historic preservation policies, percent for arts programs, CETA, and cultural districts created as an economic development strategy.

The one percent for art ordinance in Seattle originated in 1973 and required that " $1 \%$ of eligible city capital improvement project funds" be earmarked for works of art 
(City of Seattle, 1979). As a result, Seattle's urban spaces, public buildings, and transportation infrastructure became sites for art installations and displays. Studio glass artists were commissioned to create windows, sculptures, and mixed media installations for a variety of settings, and also served as jurors and community panel members during arts selection processes. These projects, many of them large-scale, provided commissions and also opportunities to establish relationships with community members, city officials, architects, and other artists working on mixed-media installations. Not all artists sought out this experience, but for several of the artists discussed in this research, public art comprised a significant part of their career.

The 1973 Comprehensive Employment and Training Act (CETA) and the Model Cities program of 1966 to 1975 are two short-lived but significant policies in this narrative. The Model Cities program provided the original vision and demonstrated community support for a local community arts center which eventually became the Pratt Fine Arts Center, and CETA funding paid for the center's first employees, including the artists who worked there. Without the backing of these two programs, it is unlikely that Pratt, with its open studios for glass production, would have gotten off the ground.

The museum building boom of the 1990s was spurred by a combination of factors and was less an outcome of cultural policy than of growth coalitions and economic developers combining forces with local arts patrons during a time of unprecedented economic growth in the region. The outcome of what Strom (2003) labeled "cultural policy as economic policy" was that new regional museums provided new spaces for regional artists to exhibit their work, and new opportunities for patrons and collectors to show and sell the work they owned. 
Other cultural policies that provided more general support and were important elements of the cultural infrastructure included the Seattle Arts Commission, the Washington State Arts Commission and the support they offered artist careers through grants, arts education programs, and administration of percent for arts programs. Historic preservation policies designated certain urban areas as historic districts, validating the range of cultural activities that were already taking place in neighborhoods like Pike Place Market and Pioneer Square, and incidentally making these destinations easy for tourists to locate, generating additional economic activity along with the cultural activities.

How were these processes affected by the region's larger cultural, social, and economic $\underline{\text { context? }}$

The initial group of studio glass artists arrived in Seattle in the early 1970s, during an era when the city was undergoing economic and demographic changes that would set the stage to regional changes over the next three decades. Many of these artists were themselves representative of the new demographics: college-educated, middle-class, white, and young. Some of them came to the region to escape from the pressures of big city life and later found themselves in Seattle for work or educational opportunities, while others were attracted to the city from the start. Seattle's economy shifted from its dependence on Boeing as the major industry to become the center of the new hightechnology and lifestyle industries sector and home to the headquarters for global corporations like Microsoft, Starbucks, Amazon, REI and others. Economic growth supported a prosperous middle class that counted an interest in all forms of cultural activities, including art viewing and collecting. During the 1980s the market for artwork 
increased nationally, and regional artists experienced the benefits. Higher art prices and a growing audience for art generated new galleries, and provided even moderately successful artists with the possibility of supporting themselves through their art during the boom periods.

Regional economic prosperity during the 1990s expanded the market for art once again. Revitalized downtown spaces became sites of artistic production and markets, and tourism contributed to the downtown economy of cities throughout the region. Pike Street Market and Pioneer Square, both saved by historic preservation campaigns in the 1970s, became leading tourist destinations in Seattle and provided places to show and sell art. The more prosperous cities commissioned new public buildings and remodeled public plazas and parks. Percent for art programs guaranteed that artists would gain commissions every time this occurred. In addition, the success of Microsoft spawned new millionaires who commissioned artwork that was suitable for corporate offices and suburban mansions. The regional museum building boom provided new spaces for artists to show work, and for patrons to display their art collections, many of which featured the work of regional artists.

These factors combined to provide artists with a variety of opportunities for pursuing careers. And, once again, every time the social or economic context changed, the region's studio glass artists were well poised to quickly adapt to the changes, through their network connections that enabled them to learn new skills and processes, or assemble a team with the necessary skills to work in the new environment. 
How can this case provide examples for other cities?

This study detailed how the combined effects of activities by local actors helped an emerging artist community take root and grow, and illustrated how a group of artists organized at an early stage to create the networks needed to support themselves and their art form. There is certainly no guarantee that any city will have the economic growth of Seattle in the 1990s, but economic growth was not the primary factor that created this community during the 1970s and 1980s when studio glass artists became a noticeable presence in the region. Although the economic boom of the 1990s produced the largest expansion of the studio glass movement in the region, the movement grew over several decades of boom and bust cycles. The network and cultural infrastructure development activities that supported the growth of studio glass movement in the Puget Sound region could provide a model for artist communities in other regions with local variations taken into account.

There is nothing new in the notion that artists seek out cities and neighborhoods that have abundant, affordable spaces for working and living, and this study provides yet another instance in support of this idea. The findings also reinforce the importance of artist centers to artist careers. In addition to the informal artist spaces, academic institutions were also important to the formation of this artist community. Universities and colleges provided spaces for experimentation for student artists and their professors. They also fostered the learning networks that spread new ideas and new ways of working. Finally, they offered artists the possibility of long-term careers in a field where instability and financial insecurity are common. 
Local arts supporters helped establish this art form in the region. Local patrons supported local arts centers, provided exhibition spaces or encouraged galleries to exhibit studio glass art made in the region, and purchased early works before the artist makers became well known. Cultural policies and local arts commissions provided opportunities for local artists to create work for public spaces, making studio glass art a part of the local landscape. These are strategies that local communities and policymakers can adopt to create their own cultural infrastructure from which an artistic community can form.

One example that this study provides that is not found in the lexicon of urban cultural development strategies is the benefits of artists organizing to support each other. Artists have a reputation as individualists who prefer to make their own way in the world. The artists in this study went against that stereotype and worked as a group, not always in peace and harmony, but still together. In part this was due to the nature of the medium they worked with, and in part due to strategic decisions by several early leaders that organizing would help them learn the medium and promote their work more effectively. In doing so, they strengthened their own and their communities abilities and careers, and built a foundation of knowledge that helped other artists to innovate and develop the art form in new directions over the years. This is a strategy that artists residing in a city without the cultural infrastructure of recognized arts capitals could follow to strengthen their position.

\section{Possibilities for Future Research}

This study ranges over thirty years and covers multiple actors in a changing cultural and economic context. By its nature and design it touches only lightly on many important issues and themes that could be developed further. For example, a social 
network approach would be useful for providing a more complete picture of how artist networks functioned to support artist careers, and delineate some of the different cliques/cohorts and hierarchies that developed over the years as the community grew. Most of the artists mentioned in this research had successful careers. As a group they have generated economic outcomes locally and regionally. Aside from the Glass Art Society's count of studio glass artists in 1990, there have been no studies that looked into the size and economic impact of this cluster. The regional growth of studio glass art could be developed as a case study of economic cluster development. Another area that is barely touched upon in this study is the role of nonprofit funding in supporting regional arts centers such as Pilchuck and Pratt. For those interested in cultural policy to support artists and community development, the story of Pratt offers some intriguing possibilities. The role of CETA as an artist employer and the effects of this program on communities and on artists who worked on community projects during the late 1970s has not been explored, although some scholars are beginning to do some work in this area. An investigation into the effects of the prolonged recession on artist's career paths provides another possible area for research. My interest in this research is in the processes that shape artist communities, how artists negotiate careers across a changing spectrum of cultural policies and the larger economic and social contexts. The narratives of the artists and careers that are briefly touched upon here hint at the roles that artists have played in reshaping urban culture over the past thirty years, and this is a particularly rich area for research to explore in future work. 


\section{Conclusions}

This research used an analytical framework based on Jackson's (2004) study of the support structure for U.S. artists, and Becker's (2008) theory of art worlds, with a focus on change in art worlds. Both approaches proved useful in helping to answer the "why here?" and "why at this particular time?" questions posed by the research.

Jackson's theory provided useful criteria for identifying and examining the cultural dimensions that helped make artistic careers possible in a particular place, and Becker's theory provided a framework for identifying and analyzing how the collective activities of the people involved with cultural production contribute to different culturally-specific art forms that arise at certain times and places. This section brings in these approaches to illuminate the processes that shaped the successes of the studio glass artist community in the Puget Sound region.

\section{Changes in art worlds}

In Becker's (2008) discussion of changes in art worlds, one of the first points he makes is that change is a constant, and art worlds routinely come and go over time (p. 300). Change can be subtle and slow, or can be drastic and fast-moving, overturning established forms of creative expressions. A new cultural development can be classified as an art world revolution if it eliminates "one or more important groups of participants" (Becker, 2008, p. 307). The birth of the studio glass movement can be considered an art world revolution, as the original group of artists, by introducing the innovation of working with glass as an artistic medium, effectively removed themselves from the established networks of artistic production. The path from innovative experimentation to a new art world requires practitioners of a new art to engage with an existing art world 
when it can, and to attract new supporters to build new networks that provide the "conventions," "aesthetic criteria," "material resources," "personnel," "distribution systems," and criteria for aesthetic judgment of a particular artwork (Becker, 2008).

One of the existing resources that the founders of the studio glass movement were immediately able to access and mobilize to their advantage was the network of university and college programs in the arts, which were a result of the expanded support for higher education that began after World War II and continued through the end of the twentieth century. Because the original group of artists who initiated the studio glass movement at the workshop in Toledo, Ohio, comprised university professors and graduate students who subsequently created new programs at their home institutions, there were graduate level programs in studio glass art even before most studio glass artists really knew how to work with the medium or could produce any identifiable objects or processes that critics or the market could identify as art.

As with many other art forms of the post World-War II era, academic institutions acted as incubators, supporting early experimentation and innovation while artists worked out the technical issues and developed a conceptual framework for the art form. This was the beginning of the era of the traveling visiting professor in arts programs, as Singerman (1999) documented. The connection to academic institutions allowed studio glass artists to begin their careers from a privileged position. The academic system provided a national network through which visiting artists and graduate students traveled and exchanged information and tried out new ideas, without worrying about how their work would be received in the market. Grants and fellowships also promoted interaction between students and faculty at geographically distant academic institutions, extending 
professional and social networks beyond the local and into the international sphere. Sites for formal and informal training are critical to artists who are new to the field and to established artists, not only for the training they provide but also because they are recognized as important for network building (Jackson, 2004; Markusen and Johnson, 2006; Becker, 2008). This case study illustrates how academic institutions and helped build artist networks that served as a foundation for this new art form, and how the artists were able to deploy these network connections outside of academia in support of individual careers and field-building activities.

Another existing support system that the emerging studio glass movement used as model for bringing building a new art world originated in the studio craft movement. Many of the first group of studio glass artists had a background in ceramics, and continued to participate in the activities of the National Council on Education for the Ceramic Arts (NCECA) even after they began working in glass (Dreisbach, 2010). The NCECA was an organization that "promotes and improves the ceramic arts through education, community-building, research and creative inspiration" (NCECA website, 2013). The organization provided a model for the Glass Art Society (GAS), which was founded in 1971 with a similar mission to promote glass and share knowledge (Dreisbach, 2010). GAS provided another dimension of support to the studio glass movement as it acted to provide the same functions as dedicated artist centers (Markusen \& Johnson, 2006) and became part of the support structure that helped promote and support studio glass in the Puget Sound region through its educational and networking activities (Jackson, 2004; Becker, 2008). However, it was distinct from artist centers and place-based artist support structures in that it was not connected to a specific art-making 
organization and was independent of place. GAS emphasized the personal connections and networking activities that bridge place-based networks and foster knowledge-sharing outside of academic institutions, being open to artists from all backgrounds and locations who have an interest in studio art glass or glassmaking activities.

Among the key characteristics of the studio glass movement at its inception were the emphasis on education, information sharing, and networking that originated with this first generation and continued throughout the group's history. These characteristics, combined with local, place-based cultural factors in the Puget Sound region, were critical to the long-term success of the studio glass artist community in the Puget Sound region. Creating a new art world in the Puget Sound region

When the early group of studio glass artists came to Seattle and to Pilchuck in the 1970s, neither the city nor the region had a fully developed system of support that could sustain artistic careers over the long-term. In addition, because studio glass was a new art movement, still in its formative stages, there was no art world dedicated to supporting its production. The artists who arrived in the Puget Sound region in the 1970s found what artists in many other cities have sought over the last part of the twentieth century: an abundant supply of old buildings adaptable for use as artist studios, low-priced housing, and a supportive local community. They brought with them their connections to academic and professional artist networks, and a desire to share information and make contacts with others who were interested in supporting this new art movement. To create a sustainable art world in the Puget Sound region, studio glass artists needed to develop new methods of working and educate others in these methods, make or find sources for 
designing and manufacturing new equipment, find patrons, develop an audience, and access the available support structures for art in the region.

Many artists took part in these activities, but Dale Chihuly emerged as an important leader and a key actor in establishing artist networks in the region. Becker (2008) emphasized that artists who could not identify and mobilize allies and supporters would not succeed in moving beyond the experimental phase of a new form of artistic production, but he does not discuss the activities or qualities required of artists who are among the leading innovators. Chihuly played an important role in the growth of the Puget Sound studio glass movement through his ability to connect with people and mobilize resources necessary to complete projects ranging from arts installations to new educational programs, especially during the early phase of the studio glass in the Seattle area. Although he has been criticized for his nonstop promotional activities, Chihuly's ability to garner media attention brought attention and financial rewards to the studio glass artists in the region. This talent was first displayed through his success at convincing the Haubergs to host the first Pilchuck glass workshop, and to continue funding the organization beyond its first summer. This connection between Pilchuck and prominent Seattle cultural patrons brought the studio glass artists at Pilchuck into Seattle's cultural infrastructure. It also demonstrates one pathway for emerging art forms to mobilize resources from an existing art world in support of an emerging art world, a critical activity for long-term survival of a new art form (Becker, 2008).

Pilchuck was founded to create a place for artists to work together, experiment and share knowledge in an environment where there would be few distractions. The search for knowledge and the artists' shared interests in promoting a specific medium 
provided incentives for them to work together in places where they could interact in person. Becker discussed the benefits and limits of face-to-face interaction during the early innovative phases of new forms of artistic production. He noted that as artists working together, or within a limited area, experimented with new processes and techniques, face-to-face interactions with other artists and the local audience produced locally-specific versions of an art form; and a search for raw materials and opportunities to market the work can produce at least the beginnings of a place-bounded art world (Becker, 2008). As the art world develops, local artists stay in the area because of available resources, and may even establish local arts organizations that support their activities (Markusen \& Johnson, 2006; Becker, 2008). However, studio glass artists at Pilchuck, in Seattle, and elsewhere soon discovered the limits of what they could learn through experimentation and collaboration with other local artists. This realization prompted studio glass artists to seek out sources of expert knowledge, which required access to international studios, factories and networks. After making those links to new networks, they worked to bring the knowledge and the international artists to local artist centers including Pilchuck and Pratt, essentially turning a local art world and local artist centers into gateways to international knowledge. Pilchuck's rural location required artists to work in close quarters and as a result, many close personal and work relationships formed among artists there. These relationships formed the basis for the collaborative processes and tightly knit networks that became a trademark of the artists in the region. Collaboration in the classroom and the art studio did not mean that the community functioned without conflict, or that all participants benefitted equally. 
Conflict shaped the boundaries of the field of studio glass art, as different artists contested its existence, definition, and practices.

This study explored the idea of art worlds (Becker, 2008) and place-based support structures for artists (Jackson, 2004) as complementary approaches to understanding the factors that can help sustain new art forms and artist communities and how artists sustain careers while negotiating a changing landscape of support over time. It enriches the previous studies by placing a special focus on the role of artist networks. In particular, this study sheds light on how artist networks develop, and how place-based cultural infrastructures develop to support locally specific forms of art. It also highlights the complex, interwoven nature of institutional, commercial, community, and individual activities in shaping a cultural form with strong associations to place.

\section{The Seattle Connection}

In examining the trajectory of the studio glass movement in the region and its ability to sustain itself over time, three factors become key to understanding the success of this group of artists in Seattle and the Puget Sound region. One is the importance of formal and informal learning institutions as incubators for the new art form, the second is the role of artist networks and artist centers, and the third is the importance of community support.

Pilchuck's initial mission to remain aloof from “the usual distractions and restrictions of our overcrowded and confusing cities" (Chihuly, 1972) was a successful strategy for building artist networks and fostering intensive learning experiences at the summer workshops. However, many students and faculty who arrived for a brief workshop extended their stay, becoming permanent residents in both rural and urban 
locations, especially Seattle. The landscape and mild climate of the Pacific Northwest was an attraction for many artists, and although Pilchuck seemed remote from any urban connection, the circumstances of the school's founding demonstrated the historic links between Seattle's economy and culture, and the surrounding landscape. The City of Seattle, nestled in a spectacular setting of forests, mountains, and bays, provided a constant reminder of the closeness of nature and offered an easy escape to a more rural experience for those who sought that lifestyle. As mentioned previously, the city also offered hospitable living and working possibilities, and it had a small but supportive base of cultural patrons, including members of the traditional business elite and the new cultural elite. Both groups shared an interest in promoting local culture and new cultural expressions in the city. This interest in promoting local culture was manifested in several ways, including individual patronage, percent for arts legislation, corporate collections, and community supported arts programs. All of these provided new opportunities for local and regional artists.

Beyond the fact that the studio glass artists used glass in their artwork, the group did not have a shared conceptual or underpinnings that defined them as a movement or a school of art. They did not all share the same aesthetics and did not all follow the same career paths. Over time, the lack of a shared style or aesthetic philosophy was a criticism leveled against the works produced by the studio glass movement. However, the lack of rigorous philosophical boundaries was also a factor in its success in the Puget Sound region. The openness of the studio glass movement to anyone with an interest in glass fit with the attitudes of a city and a region that was in the midst of change. When Chihuly and the first group of studio glass artists arrived in search of a place to make art and 
patrons to support art, they found that Seattle's cultural patrons and business elites were actively looking for new cultural forms to reflect the city's changing demographics and culture.

As artists participated in local and regional festivals and craft fairs, they connected with local residents, and built up a local following. Studio glass artists literally took their art to the streets, doing demonstrations and "road shows" at arts and crafts fairs throughout the region. Glassmaking, especially glassblowing processes, was inherently theatrical, and the resulting beautiful objects made glassmaking an art form with broad popular appeal. In addition, the presence of studio glass art at local fairs and festivals, and in public buildings and parks, helped make the form a part of the cultural landscape. As the city's economy grew in the 1980s and 1990s, a population of new cultural consumers with disposable income began looking for objects to collect. Glass art objects were aesthetically appealing, demonstrated technical expertise, and because studio glass established itself as a local art form, it had a strong following among all levels of collectors, from individuals with limited funds for art, to patrons who commissioned works for mansions, and corporations who commissioned work for new corporate headquarters.

The artists who settled in the Puget Sound region were already looking for opportunities to promote their work. They took advantage of the opportunities that were available to them, and collaborated to create new opportunities. Within thirty years they had succeeded in accessing the support structures provided through the existing regional cultural infrastructure, and creating what Becker (2008) described as the "patterns of collective activity we can call an art world" (p. 1). The art world they created made the 
region a hub for studio glass production. For their part, studio glass artists accomplished this by building and expanding cooperative networks, taking advantage of the available support for cultural production, developing new support structures or making use of the region's existing cultural infrastructure, including artist centers, cultural institutions, galleries, fairs and festivals, and patronage. They were supported in along the way by a combination of cultural policies, an increased taste for diverse forms of cultural consumption among the region's residents, and regional, social, and economic changes that supported a growing art market and expanding regional cultural infrastructure. 


\section{Images}

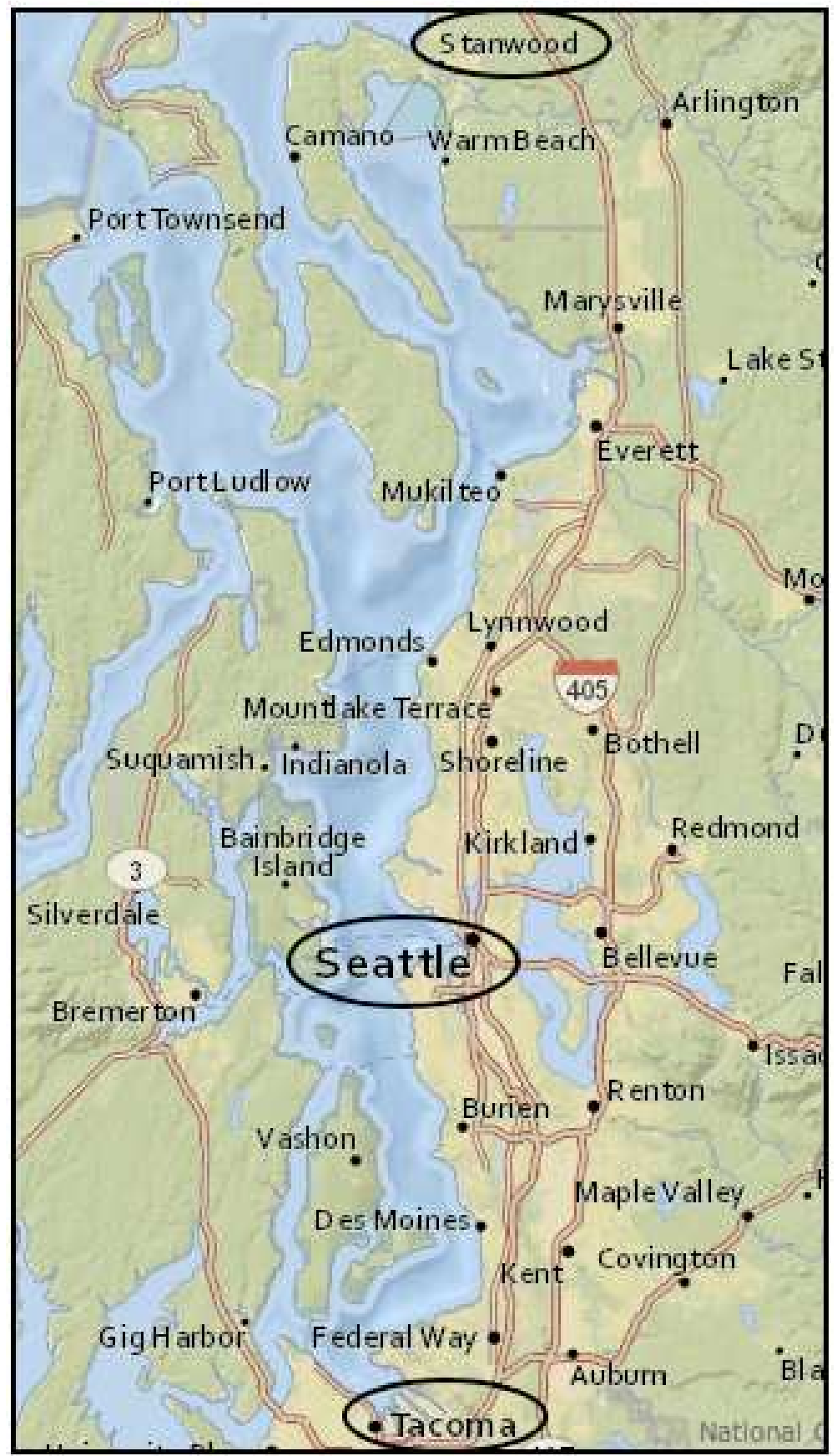

Figure 9.1. Map of the Puget Sound Region Study Area (Source: ArcGis.com) 


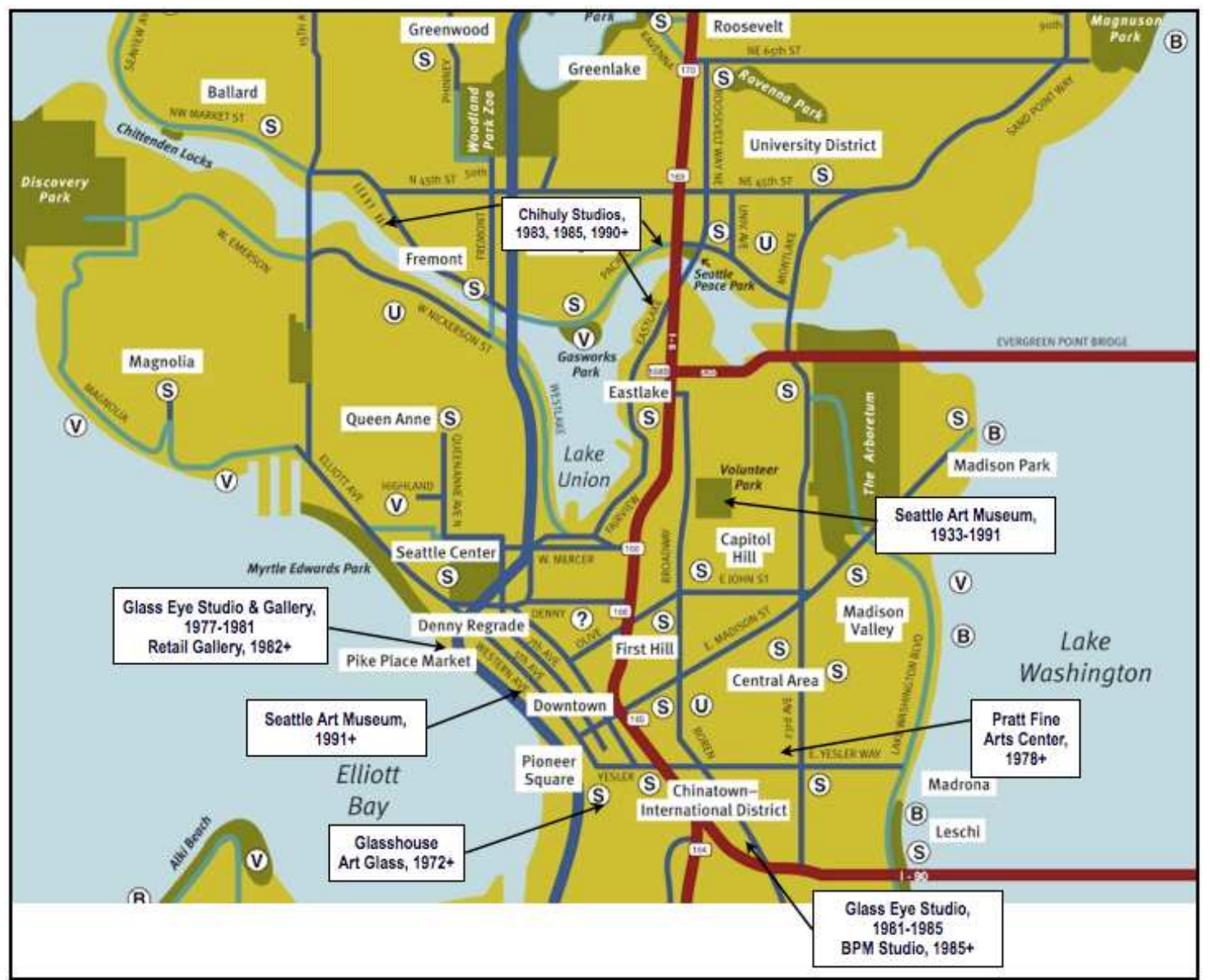

Figure 9.2. Downtown Seattle with selected glass studio locations Source: Downtown Seattle map (modified by the author) accessed from http://www.visitseattle.org/Essentials/Seattle-Maps.aspx 


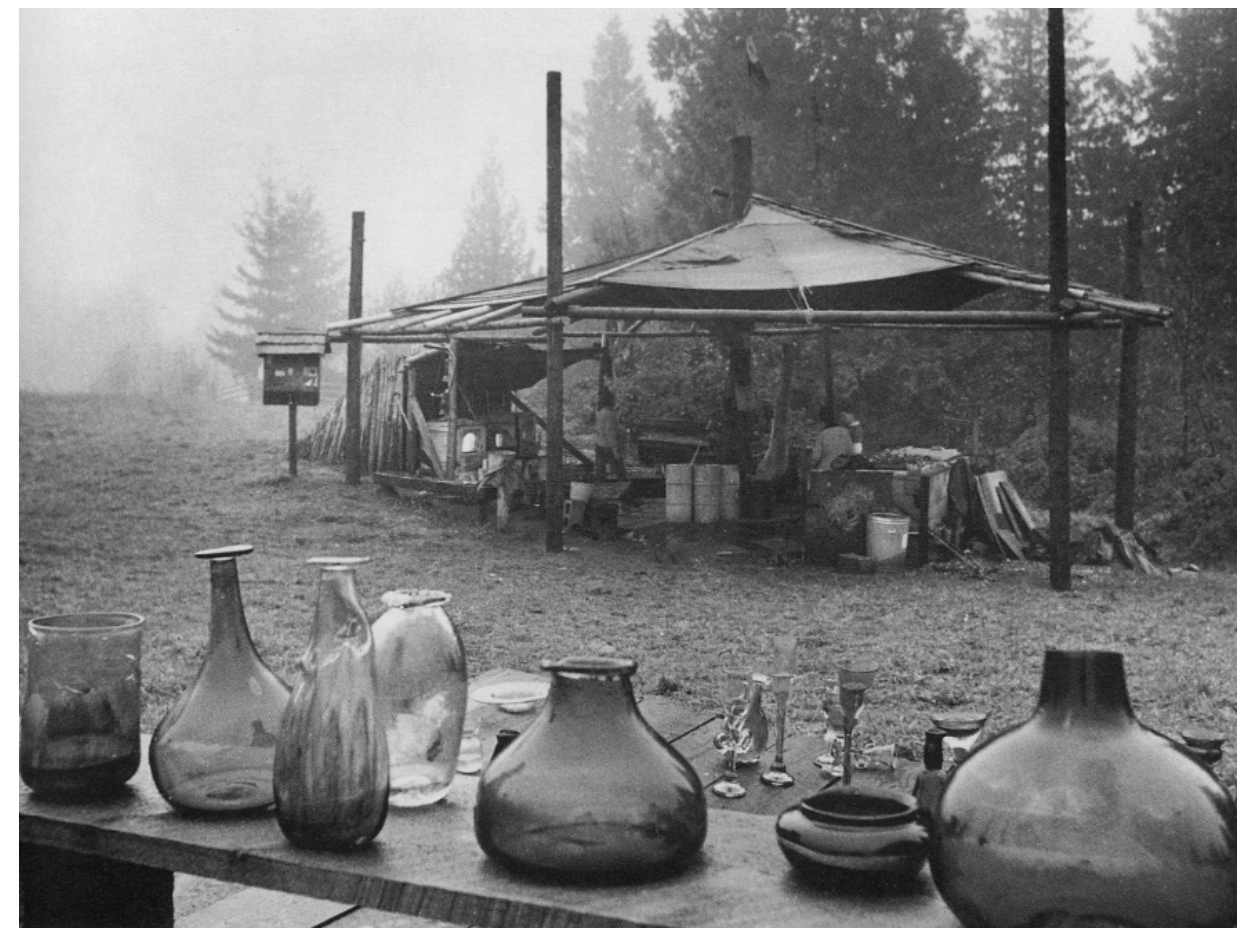

Figure 9.3. Pilchuck hot shop, 1971

(Source: Oldknow, 1996, p.77; photographer, Art Hupy)

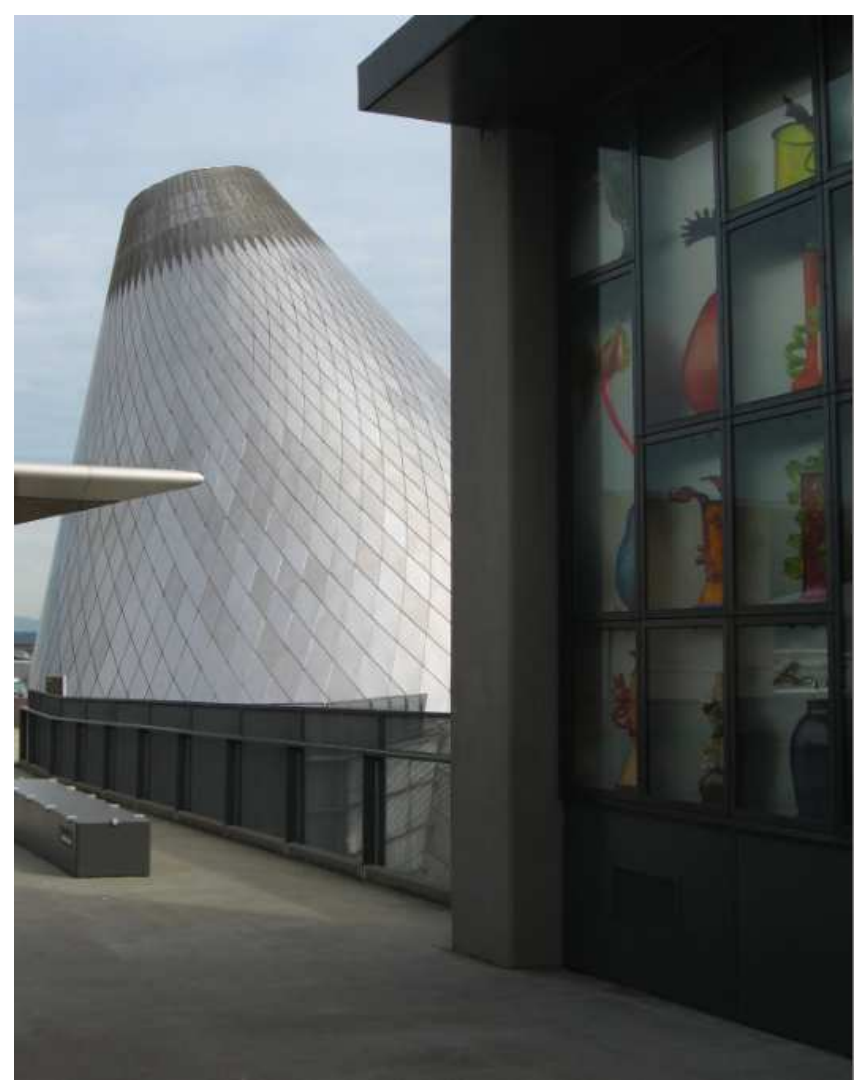

Figure 9.4. Tacoma Museum of Glass \& Chihuly Bridge of Glass, 2009 (Photographer, Marianne Ryder) 


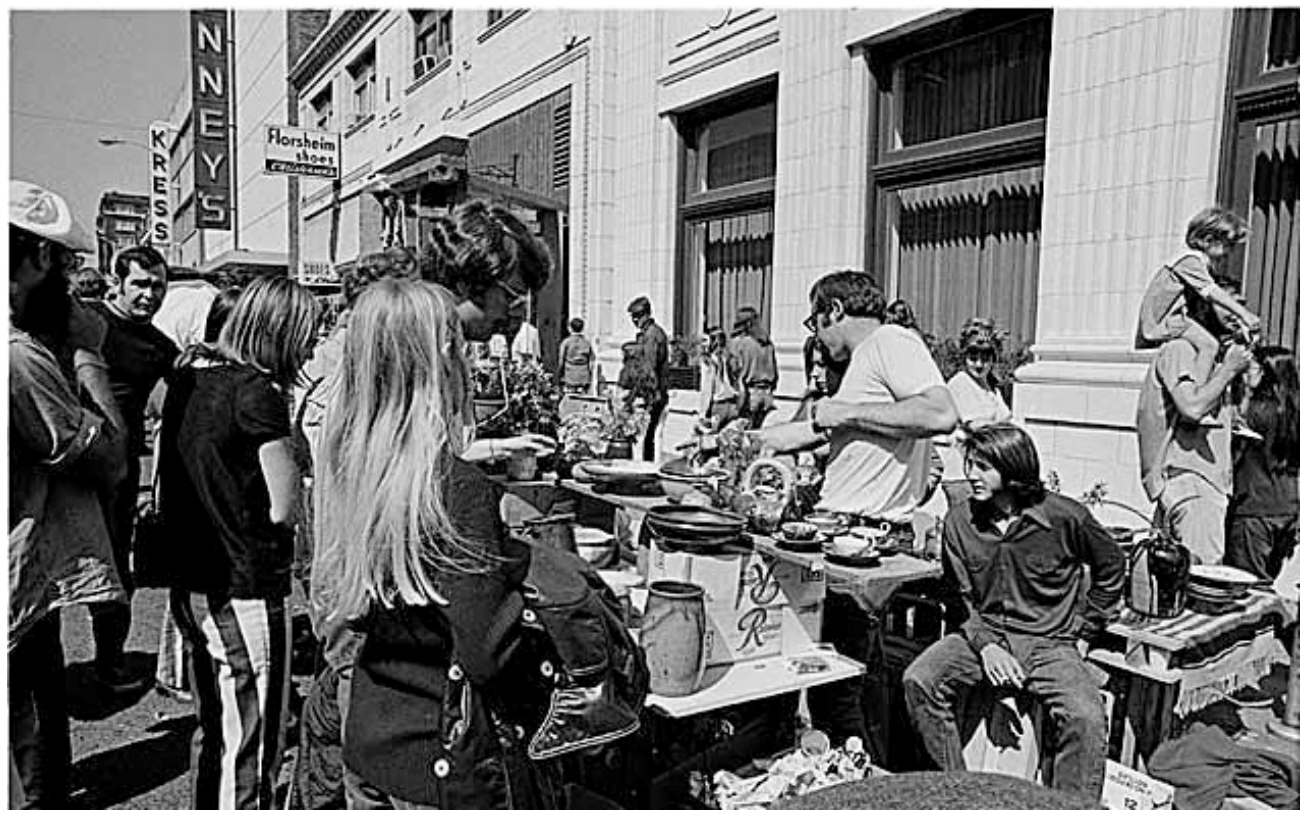

Figure 9.5. Pottery Booth at University District street fair, Seattle, 1971

(Source: MOHAI, Seattle; photographer Bob Miller)

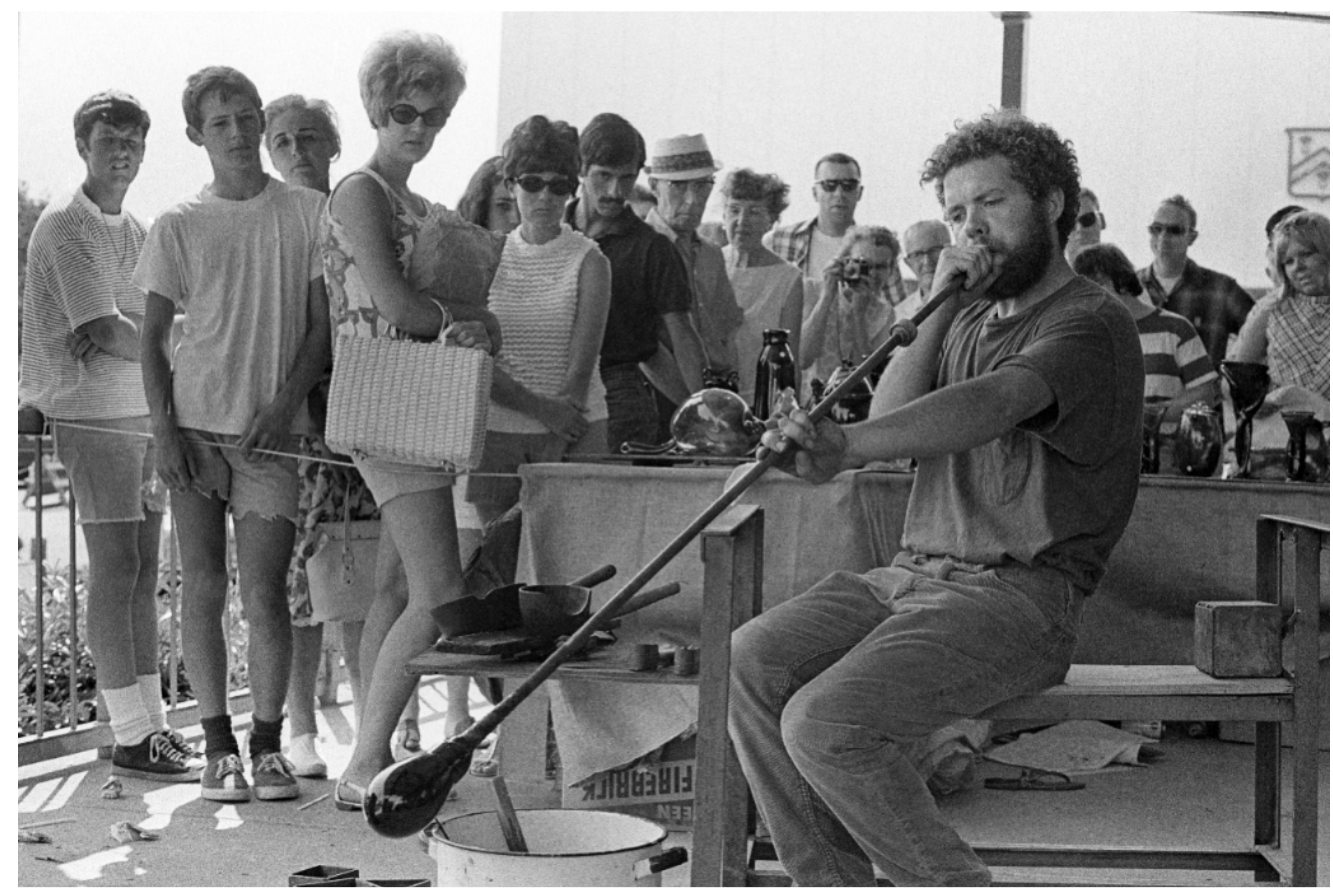

Figure 9.6. Glassblower Dale Chihuly blowing glass at Bellevue Arts Festival, 1968 (Source: MOHAI; photographer Dave Potts) 


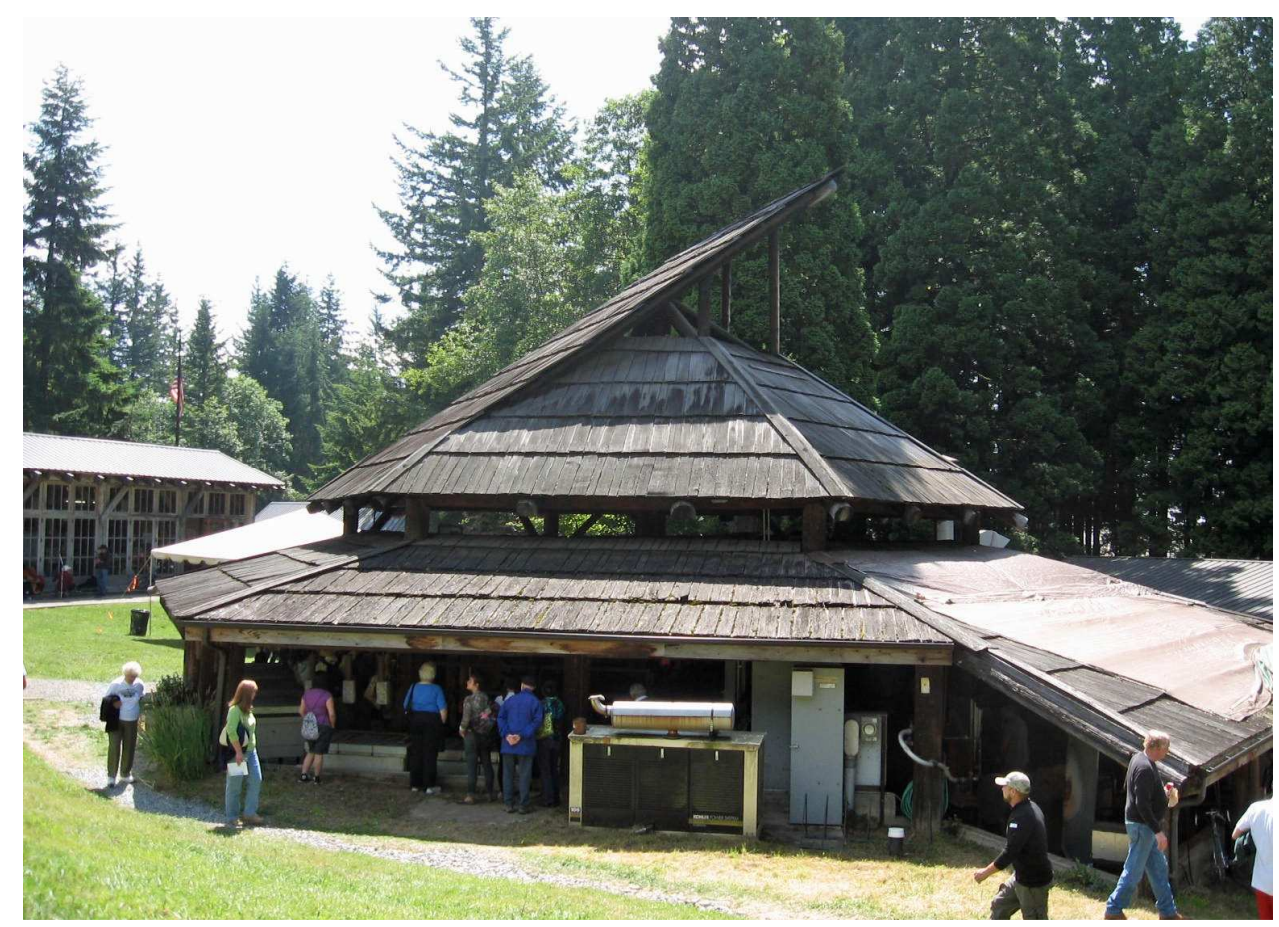

Figure 9.7. Pilchuck buildings by Bosworth: Hot shop with flat glass studio building in background (Photographer, M. Ryder, 2010)

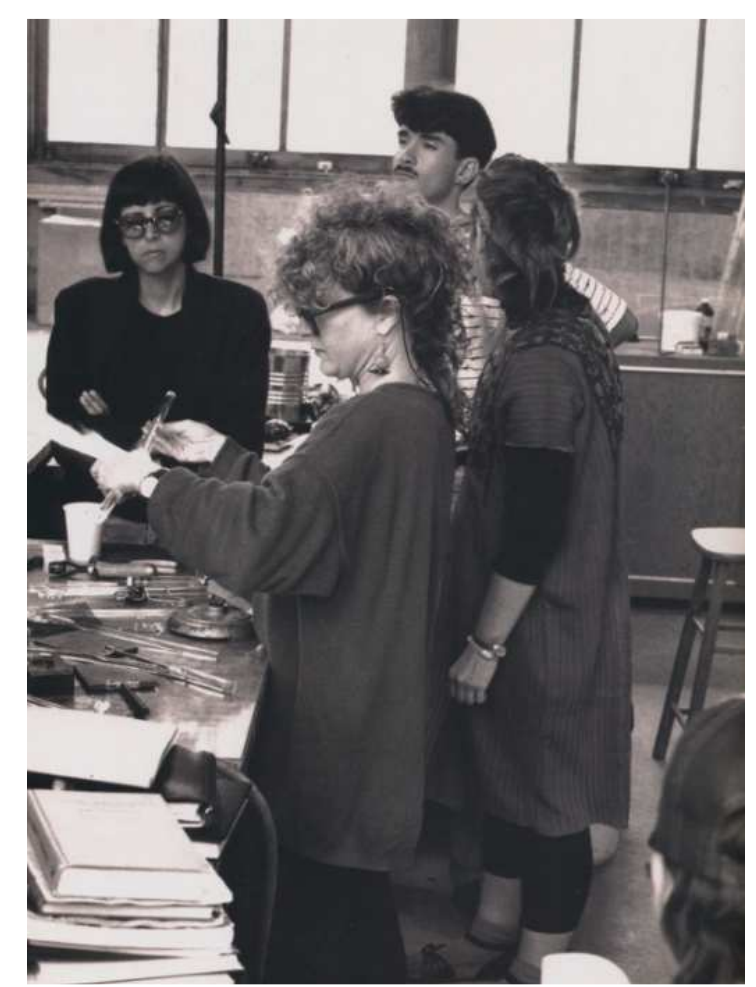

Figure 9.8. Ginny Ruffner teaching at Pilchuck, 1980s (Source: Herman, 1992.) 


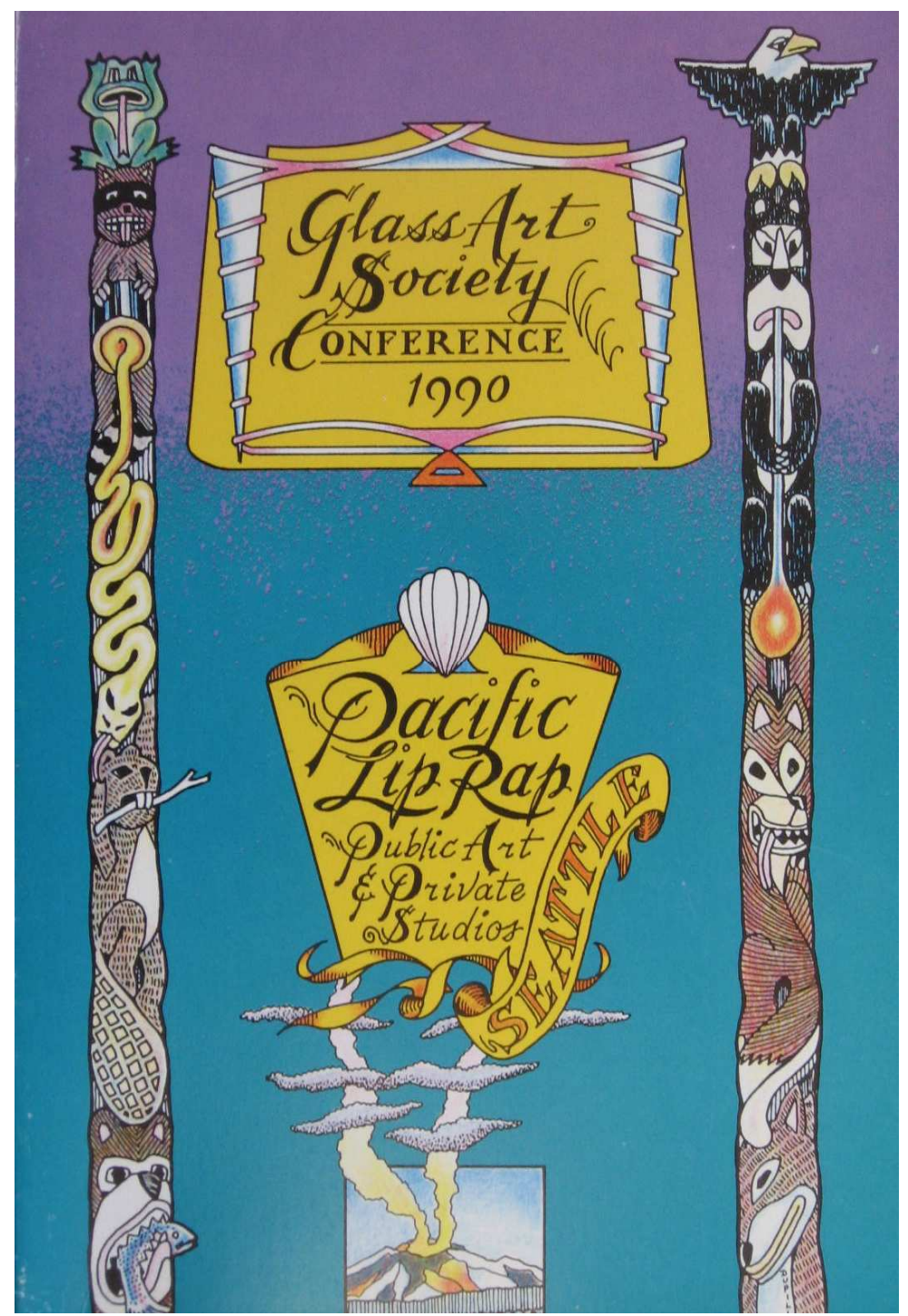

Figure 9.9. 1990 Glass Art Society conference brochure cover, "Pacific Lip Rap" (Source: Glass Art Society, 1990) 


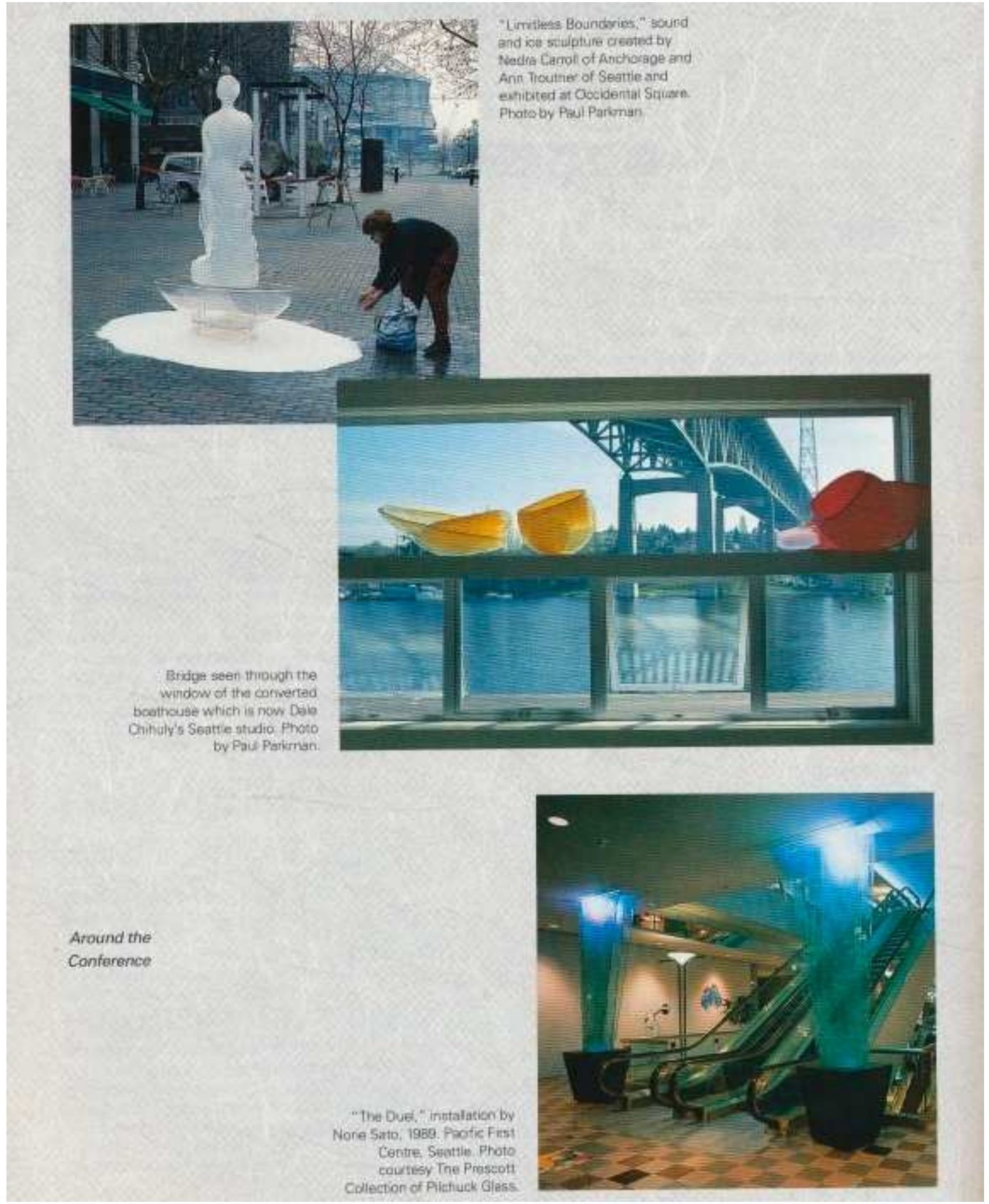

Figure 9.10. 1990 Glass Art Society conference photos (Source: Glass Art Society Journal, 1990) 


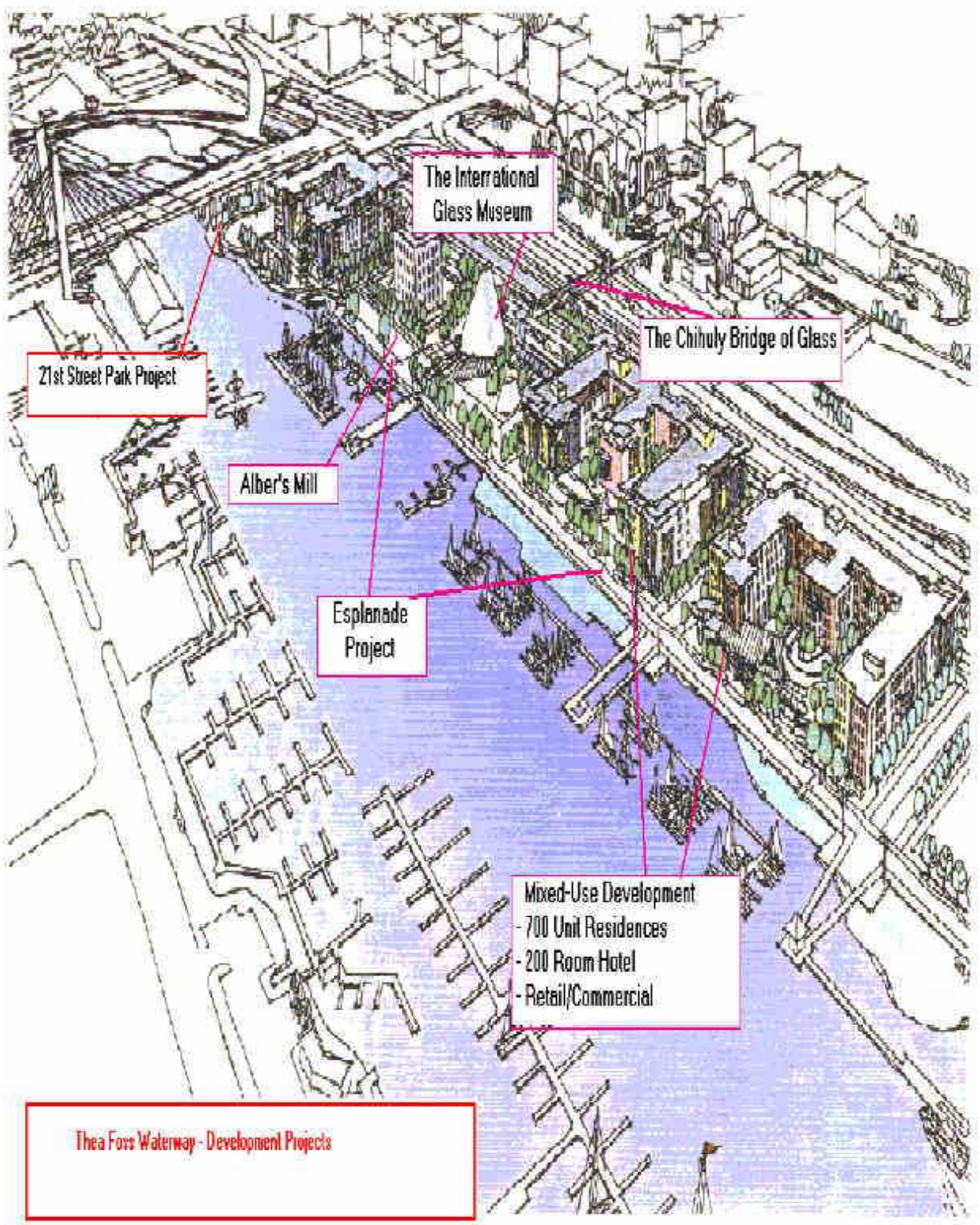

Figure 9.11. Foss Waterway development plan, 1990s (Source: City of Tacoma) 


\section{References}

---Team Chihuly at S.A.M. (1993). Seattle: Seattle Art Museum.

Abbott, C. (1993). The metropolitan frontier: cities in the modern American West. Tucson: University of Arizona Press.

Abbott, C. (1992). Regional city and network city: Portland and Seattle in the twentieth century. The Western Historical Quarterly, 23:3, August 1992, (293-322).

Adamson, G. (2009). Modern craft: Directions and displacements. Museum of Contemporary Craft lecture, Portland, OR. 2/21/2009.

Airport exhibit for Pilchuck's 20th (1990, November 18). Seattle Times.

Alliance for Pioneer Square. (2010). About the 1T art walk. (Alliance for Pioneer Square, Producer) Retrieved June 7, 2012, from First Thursday Seattle Art Walk in Pioneer Square: http://www.firstthursdayseattle.com/about.php

Ament, D. T. (1992, June 17). World Glass -- Sam looks at the works of the man who changed art history. The Seattle Times.

Ament, D.T. (2003, February 16). Tobey, Mark (1890-1976): The Old Master of the Young American Painting. HistoryLink.org Essay 5217, February 16, 2003. Accessed February, 2012, from Historylink.org.

Americans for the Arts. (2002). Arts and Economic Prosperity. Washington, DC. Accessed from: http://ww3.artsusa.org/information_resources/online_publications/.

Aronson, M. (1990). Glorious glass: A salute to The Pilchuck Glass School. Glass Art Society Journal, Corning, NY, 1990, (33-34).

Bain, A.L. (2003). Constructing contemporary artistic identities in Toronto neighbourhoods. The Canadian Geographer, 47:3 (303-317).

Bannard, W.D., \& H. Geldzahler (1993). Chihuly: Form from fire. Daytona Beach: Portland Press and The Museum of Arts and Sciences, Inc.

Baumol, W. \& Bowen (1966). Performing Arts - the Economic Dilemma: A Study of Problems Common to Theater, Opera, Music and Dance. New York: The Twentieth Century Fund.

Becker, H. (1982/2008). Art worlds. Berkeley and Los Angeles: University of California Press.

Becker, P. (2007, August 8). Seattle voters reject the Seattle commons levy on September 19, 1995 (HistoryLink.org Essay 8252). Retrieved June 14, 2012, from Historylink.org. 
Beers, C. (1981, April 8). Today's delights, Seattle Times, p. C2.

Berkson, B. (1986, September). Seattle's Art Scene, part II: In the studios. Art in America, (29, 38).

Bernstein, R. \& Hansen, C. (1981). Northwest Glass. Glass Art Society Journal, Corning, NY, 1981. Accessed from: http://www.glassart.org/1981-NorthwestGlassBernstein-Hansen.html

Bernstien, J. (2008). Compared to 1990s, middle-class working families lose ground in the 2000s. Economic Snapshot. Washington, DC: Economic Policy Institute. (August 27, 2008). Accessed from http://www.epi.org/publication/webfeatures_snapshots_20080827/ November 1, 2012.

Blecha, P. (2012, April 4). Foster, Donald Isle (1925-2012). HistoryLink.org Essay 9618, April 4, 2012. Accessed 8/12/2012 from http://www.historylink.org/index.cfm?DisplayPage=output.cfm\&file_id=9618 .

BMA Research Corp. (1999). An Economic Impact Study of Arts and Cultural Organizations in King County: 1997.

Borer, M.I. (2006) The Location of Culture: The Urban Culturalist Perspective. City \& Community; 5:2 (June), (173-197).

Boddy, Trevor (2002). "Landscape of Ideas." Canadian Architect (30-36).

Boss, K. (1988, April 4). Fund times return to arts center. The Seattle Times, p. E1. Accessed from Newsbank.

Boswell, S. \& McConaghy, L. (1991, December 1). A Silicon Forest Grows. Seattle Times. Accessed from Newsbank on 9/19/2011.

Bosworth, T. (1990). A Pilchuck Retrospective. Unpublished manuscript: presentation. John H. Hauberg papers. Special Collections, University of Washington Libraries, Seattle, Washington.

Bourdieu, P. (1986). The forms of capital. In Handbook of theory and research for the sociology of education. New York: Greenwood Press, (241-258). John G. Richardson, editor.

Bourdieu, P. (1993). The field of cultural production, or: The economic world reversed. In The field of cultural production: Essays on art and literature. Columbia University Press, (29-73).

Breitbart, M.M. \& Stanton, C. (2007). Touring templates: Cultural workers and regeneration in small New England cities. In Tourism, Culture and Regeneration. Cambridge: CABI, (111-122). M.K. Smith, editor. 
Brookings Institute. (2003). Seattle in focus: A profile from census 2000. Brookings Institution Center on Urban and Metropolitan Policy. Washington, DC: Brookings Institution.

Brown, M. \& Morrill, R. (2010). Seattle Geographies. Seattle: University of Washington Press.

Bulick, B., Coletta, C., Jackson, C., Taylor, A., \& Wolff, S. (November 2003). Cultural Development in Creative Communities. Monograph, (1-11). Accessed from http://www.AmericansForTheArts.org.

Burley, G. (1976, August 20). Unique glass center grows on Hauberg tree farm. Northwest Arts, 2, p.15.

Callaghan, Peter (2009). “There's no room for 'dirty', 'polluting' industry in their elitist vision of Tacoma. The News Tribune, Tacoma, WA. September 24, 2009. Accessed from Lexis-Nexis Academic database.

Callaghan, Peter (2011). "Hope springs eternal that design by Andy Warhol for Tacoma Dome's roof might be used someday." The News Tribune, Tacoma, WA. (October 23, 2011). Accessed online on March 16, 2012.

Callaghan, Peter (2011b). "Dream for Foss abandoned by current City Council with ease." The News Tribune, Tacoma, WA. (December, 4, 2011).

Campbell, R.M. (1977, October 9). The extraordinary Pilchuck Center. Seattle PostIntelligencer, (G6).

Carmichael, S. (1990, December 30). Shopper's World: the art of glass in the Northwest. The New York Times, Section 5, (6). Accessed from Lexis-Nexis Academic database.

Ceremonies for a new arts center (1977, February 24). Seattle Times, p. C10.

Chambers, K. S. \& T. Oldknow (1999). Clearly inspired: contemporary glass and its origins. San Francisco: Tampa Museum of Art; Pomegranate.

Cheek, Lawrence W. (2002). A new cultural landmark celebrates the Pacific Northwest's native glass artistry. Architecture, August, 2002, 91:8, (81-87).

Chihuly.com (2011). "Dale Chihuly - Artist - Crystal Towers Description." Accessed from http://www.chihuly.com/crystal-towers-description.aspx on May 13, 2013.

Chihuly, D. (1972) Pilchuck Proposal. LaMar Harrington papers. Special Collections, University of Washington Libraries, Seattle, Washington.

Chihuly, D. (1980, August 22). Some Thoughts on Pilchuck's Survival (unpublished, ms). John H. Hauberg papers. Special Collections, University of Washington Libraries, Seattle, Washington.

Chihuly, D. (1996). Chihuly over Venice. Seattle: Portland Press. 
Chihuly, D., \& Gibson, G. (1998). Chihuly over Venice. (Produced by KCTS, Seattle). Chicago: Home Vision Arts (DVD).

Chihuly, D., West, P., McDonnell, M. \& Museum of Glass (2007). Chihuly in the hotshop. Seattle: Portland Press.

Christen, R.S. (2008). Julia Hoffman and the Arts and crafts Society of Portland: An aesthetic response to industrialization. Oregon Historical Quarterly; 109:4, (510$535)$.

City in Despair (1971, May 22). The Economist, May 22, 1971, (57-58).

City of Seattle (1976). Letters to the Seattle City Council in support of the Central Area Fire Arts Center, 1976. Box 4, Folder 10. Department of Parks and Recreation, Pratt Fine Arts Center Records. Record Series 5810-01, Seattle Municipal Archives.

City of Seattle (1977) Pratt Fine Arts Center Management Plan, 1977-78, Box 4, Folder 11. Department of Parks and Recreation, Pratt Fine Arts Center Records. Record Series 5810-01, Seattle Municipal Archives.

City of Seattle, Seattle Parks \& Recreation Department (1979). Fact Sheet, 1979. Seattle Parks \& Recreation Department. Seattle City Archives.

City of Seattle (1992). Census 90: Seattle 1990. Who we are. Current planning research bulletin Number 52. City of Seattle, Seattle Planning Department. December 1, 1992. Accessed from the City of Seattle website on November 1, 2012.

City of Seattle (2001). Decennial Population, City of Seattle, 1900 - 2000. Accessed from the Seattle Department of Planning and Development website February 5, 2012.

City of Seattle (2009). 2009 Municipal Art Plan. Accessed from the City of Seattle Office of Arts \& Cultural Affairs website on 9/19/2011

City of Seattle (2011). Public Art Ordinance details, 2011. Accessed from the City of Seattle Office of Arts \& Cultural Affairs website on 9/19/2011.

City of Tacoma (2000). Thea Foss Waterway: City of Tacoma, p. 28-29, in Achieving Growth management goals: Local success stories. Washington State Office of Community development, Busse Nutley, Director. (December, 2000.)

City of Tacoma (2007) Tacoma Culture. Accessed from the Tacoma-Pierce County Public Art Tour website http://wspdsmap.ci.tacoma.wa.us/website/art/

City of Tacoma. (2010) City of Tacoma. Reclaiming and redeveloping the Tacoma Waterfront accessed from http://www.cityoftacoma.org/Page.aspx?hid=1935

City of Tacoma (2010a) City of Tacoma. The Tacoma Advantage. Accessed from http://www.cityoftacoma.org/Page.aspx?nid=565 
City of Tacoma, (2010b) City of Tacoma, Community and Economic Development Department. Downtown Tacoma, 2000-2010: A storybook from the City of Destiny. Accessed from www.cityoftacoma.org.

Clemans, G. (2012, April 7). Obituary: Longtime Seattle gallery owner Don Foster nurtured fine art in region. Seattle Times, April 7, 2012. Accessed from the Seattle Times website on 8/20/2012.

Coleman, J.S. (1988). Social capital in the creation of human capital. American Journal of Sociology, Vol. 94. Supplement, p. S95-S120 (1988).

Currid, E. (2007). The Warhol economy: How fashion, art, and music drive New York City. Princeton, NJ: Princeton University Press.

Dames, J. (1999, December 18). Seattle art world meets on gallery walk. The Japan Times.

Danto, A. C. (1995). Introduction: Glassy essences. In B. J. Miller, Why not? The art of Ginny Ruffner (pp. 8-11). Tacoma, Seattle: Tacoma Art Museum/University of Washington Press.

De Santillana, Anna Venini Diaz, 2000. Venini. Catalogue Raisonne, 1921 - 1986. Milano: Skira Editore.

Diaz Orueta, F. \& Fainstein, S. (2009). The new mega-projects: genesis and impacts. International Journal of Urban and Regional Research, p. 759-767.

DiMaggio, P. J. (1986). Cultural entrepreneurship in nineteenth-century Boston. Nonprofit Enterprise in the Arts: Studies in Mission and Constraint: p. 41-61.

Dinwiddie, T. (1976, February 17). Memo from Theresa Dinwiddie to Bud Girtch regarding the Wonder Bread Garage. Seattle Parks \& Recreation, February 6, 1976. Box 4, Folder 10. Department of Parks and Recreation, Pratt Fine Arts Center Records. Record Series 5810-01, Seattle Municipal Archives.

Dreisbach, F., Adamson, R., Courtney, N., Englesby, G., Marquis, R. (2003). Glass in the Pacific Northwest B.C. (Before Chihuly). Glass Art Society Journal, Seattle.

Dreisbach, F. (2010). The roots of the Glass Art Society: The first decade. GAS Journal. Seattle.

Dubb, S. \& Howard, T. (2007). Linking colleges to communities: Engaging the university for community development. College Park, MD: The Democracy Collaborative. Accessed from http://community-wealth.org/content/linking-collegescommunities-engaging-university-community-development.

Dunphy, S.H. (2002). Local economy, development on the rise for Tacoma, Wash. Seattle Times. (August 12). Seattle, WA. 
Edwards, G. (1995). Klaus Moje: Glass, a retrospective exhibition. Melbourne, Victoria: National Gallery of Victoria.

Edwards, M. (2008). New leaders, new directions in Tacoma: City looks toward a more livable core after two years without its once-strong alliances. News Tribune (Tacoma). Originally published September 20, 2005; revised May 20, 2008. Accessed from the News Tribune website March 21, 2012.

Egan, T. (1991, August 25). Seattle: The art of living. The New York Times, (15). Accessed from Lexis-Nexis Academic database.

Egan, T. (1991, December 10). Museum by Venturi opens in Seattle. The New York Times. Accessed from Lexis-Nexis Academic database.

Egan, T. (1998, May 27). Seattle is abloom with sports, culture: With a fresh skyline and a rejuvenated waterfront, the city has turned its attention to auditoriums, arenas and shining new venues for the fine arts. The Globe and Mail, (D6).

Eisinger, P. (2000). The politics of bread and circuses. In The Politics of Urban America: A Reader. Dennis R. Judd, Paul Kantor, editors (2002). New York: Longman, (252-266).

Etulain, R.W. (1996). Re-Imagining the modern American West: A century of fiction, history, and art. Tucson: University of Arizona Press.

Evans, G. (2005). Measure for measure: evaluating the evidence of culture's contribution to regeneration. Urban Studies, 42:5/6 (959-983).

Farr, S. \& Kelleher, S. (2006). Chihuly, Inc. Part 1: Building an empire. Seattle: Seattle Times, August 6, 2006. Accessed online from the Seattle Times website on September 14, 2011.

Findlay, J.M. (1992). Magic Lands: Western Cityscapes and American Culture after 1940. Berkeley: University of California Press.

Florida, R. (2002). The rise of the creative class. New York: Basic Books.

Florida, R. (2005). Cities and the creative class. New York: Routledge.

Frantz, S.K. (1989). Contemporary glass: a world survey from the Corning Museum of Glass. New York: Harry N. Abrams.

Frantz, S. (2007). The Italian Connection: Americans at Venini (p. 20-33) Viva Vetro! Glass Alive! Venice and America. Pittsburgh, PA: Carnegie Museum of Art.

Frantz, S.K. (2008). Lino Tagliapietra in retrospect: A modern Renaissance in Italian glass. Tacoma: Museum of Glass, in association with University of Washington Press, Seattle.

Fulbright U.S. student program (2013). History. Retrieved from the Fulbright website: http://us.fulbrightonline.org/about/history on April 29, 2013. 
FundingUniverse.com. (2012). Recreational Equipment, Inc. History. Retrieved June 9, 2012, from FundingUniverse.com: http://www.fundinguniverse.com/companyhistories/recreational-equipment-inc-history/

Galligan, A.M., \& Alper, N.O. (2000). The career matrix: The pipeline for artists in the United States. In The public life of the arts in America. Cherbo, J.M. \& Wyszomirski, M.J. New Brunswick: Rutgers University Press (171-201).

Galligan, A.M. (2008). The evolution of arts and cultural districts. In Understanding the arts and creative sector in the United States, Cherbo, J.M., Stewart, J.M, \& Wyszomirski, M.J., eds. New Brunswick, New Jersey \& London: Rutgers University Press (129-142).

Gibson, T.A. (2004). Securing the spectacular city: the politics of revitalization and homelessness in downtown Seattle. Lanham, MD: Lexington Press.

Glass Art Society. (1990). 20th Anniversary Symposium on Glass Art: Pacific Lip Rap: Public Art \& Private Studios. In G. Ruffner (Ed.), GAS Conference Program Book (p. 55). Corning: Glass Art Society.

Gluck, M. (2005). Popular bohemia: modernism and urban culture in nineteenth-century Paris. Cambridge: Harvard University Press.

Godden, J. (1992, May 17). Where to see glass before the Pilchuck open house. The Seattle Times.

Goldbard, A. (2006). New creative community: The art of cultural development. Oakland: New Village Press.

Granovetter, M. (1973). The strength of weak ties. American Journal of Sociology, 78 (1360-1380).

Graves, J. (2006, February 22). Glass Houses: Dale Chihuly files a lawsuit that raises big questions... about Dale Chihuly. The Stranger.

Graves, J. (2007, June 29). Prince of glass: As sovereign of his hometown's cultural scene, glass artist Dale Chihuly draws world to Tacoma. The News Tribune.

Grindeland, S (2005, March 26). Museum director, 87, was "spark plug" for local art. Seattle Times, March 26, 2005, Entertainment \& the Arts section (accessed from Newsbank database on 9/13/2010).

Groves, M. (1992, March 1). Boeing Runs Into Some Turbulence: Economy. Los Angeles Times.

Guenther, B. \& Klein, D. (2007). Klaus Moje. Portland: Portland Art Museum.

Hackett, R. (1981, August 2). Artists mirror the growing interest in glass. Seattle PostIntelligencer (no page number). 
Hackett, R. (1982, June 25). Pilchuck to hold glass collectors seminar. Seattle PostIntelligencer (no page number). LaMar Harrington papers. Special Collections, University of Washington Libraries, Seattle, Washington.

Hackett, R. (1986, July 24). Art report gives Seattle some long-awaited recognition. Seattle Post-Intelligencer. Art Notes section, p. C7. Accessed from the Newsbank database.

Hackett, R. (1990, March 29). City of Glass: Glass Art Society opens 20th annual conference. Seattle Post-Intelligencer, p. C8. Accessed from Newsbank database.

Hackett, R. (1991, January 9). Mitchell show finally opens - and encloses - at SAM. Seattle Post-Intelligencer, p. C9. Accessed from Newsbank database.

Hackett, R. (1992, May 16). Celebrating with glass -- New and old team up at museum. Seattle Post-Intelligencer, p. C1. Accessed from Newsbank database.

Hackett, R. (1992b, September 3). Sonja Blomdahl in color - artist moves from the edges to the center of glass world. Seattle Post-Intelligencer, p. C1.

Hackett, R. (1993a, November 23, 1993). Six-city exhibit to examine work by video artist. Seattle Post-Intelligencer, p. C7. Accessed from Newsbank database on $8 / 25 / 2011$.

Hackett, R. (1993b, December 9). Downtown move takes museum up - new building has allowed SAM to show its strengths. Seattle Post-Intelligencer, p. C3. Accessed from Newsbank database on 8/25/2011.

Hackett, R. (2005, April 1). Happy days are here again for Pioneer Square galleries. Seattle Post-Intelligencer. Accessed 3/16/2009 from http://seattlepi.nwsource.com/visualart/218310_pioneerart.html.

Hanover, D. (2010). House beautiful. Vibrant design [DVD]. A\&E Network. New York.

Harrington, L. (1970). Letter from LaMar Harrington to John Hauberg, 10/19/1970. Unpublished manuscript. LaMar Harrington papers. Special Collections, University of Washington Libraries, Seattle, Washington.

Harrington, L. (1971, June 19). Letter from LaMar Harrington to Mr. \& Mrs. Alexander Girard of Santa Fe, NM, 6/19/1971. Unpublished manuscript. LaMar Harrington papers. Special Collections, University of Washington Libraries, Seattle, Washington.

Harrington, L. (1979). Ceramics in the Pacific Northwest: A history. Seattle: University of Washington Press.

Harrington, L. (1982a, January 2). Correspondence to Lloyd Herman, Renwick Gallery, National Museum of American Art. LaMar Harrington papers. Special Collections, University of Washington Libraries, Seattle, Washington. 
Harrington, L. (1982b, September 14). Memo. LaMar Harrington papers. Special Collections, University of Washington Libraries, Seattle, Washington.

Hauberg, J. H. (2003). Recollections of a civic errand boy: The autobiography of John Henry Hauberg, Junior. Seattle: Pacific Denkmann Co.; distributed by University of Washington Press.

Heckathorn, D.D. \& Jeffri, J. (2003). Social networks of jazz musicians. In Changing the Beat: A Study of the Worklife of Jazz Musicians, Volume III: Respondent-Driven Sampling: Survey Results by the Research Center for Arts and Culture, National Endowment for the Arts Research Division Report \#43, Washington DC, 2003; (p. 48-61).

Heilbrun, J. (1992). Art and culture as central place functions. Urban Studies, 29:2 (205215).

Herman, L.E. (1992). Clearly art: Pilchuck's Glass Legacy. Bellingham, WA: Whatcom Museum of History and Art.

Heying, C. (1995). Civic elites, civic institutions, and the urban growth dynamic (Doctoral dissertation, University of North Carolina at Chapel Hill).

Huchthausen, D. (1984). Introduction to the Exhibition. In Americans in glass: An exhibition. By the Leigh Yawkey Woodson Art Museum. Wausau, WI: Leigh Yawkey Woodson Art Museum.

Hudson, B. (1976, February 4). Memo from Beatrice Hudson, Project Director to Ruth Smith, District Manager, Parks \& Recreation department, February 4, 1976. Box 4, Folder 10. Department of Parks and Recreation, Pratt Fine Arts Center Records. Record Series 5810-01, Seattle Municipal Archives.

Hughbanks, C. D. (1992). History: Pilchuck Glass School. Unpublished manuscript. John H. Hauberg papers. Special Collections, University of Washington Libraries, Seattle, Washington.

Jackson, J., \& Oliver, T. (2003). Personal networks theory and the arts: a literature review with special reference to entrepreneurial popular musicians. Journal of arts management, law \& society, 33:3 (240-256).

Jackson, M. (2004). Investing in creativity: a study of the support structure for U.S. artists. Journal of arts management, law \& society, 34:1(43-56).

Jeffri, J. (2002). Changing the beat: A study of the work life of jazz musicians. NEA Research Division Report \#43. Washington, DC: National Endowment for the Arts.

Johns, B. (2005). Anne Gould Hauberg: Fired by beauty. Seattle: University of Washington Press. 
Kangas, M. (1991). Doubt, delirium, and delight: Experimental glass in Seattle in the early 1980s. Glass Art Society Journal, Seatle, WA, 1991, p. 58-59.

Kangas, M. (2002). The big six: Seattle's longest lasting art dealers. Art Guide, Seattle. Accessed February 13, 20012 from http://www.artguidenw.com/BigSix.htm .

Kangas, M. (2005). The Translator: Benjamin Moore is the bridge between Italian design and the American studio glass. Glass Quarterly (Issue 97, Winter 2004, p. 95-97).

Kangas, M. (2006). Craft and concept: The rematerialization of the art object. New York City: Midmarch Arts Press.

Kangas, M. (2007). Venice and America: Cultural Exchanges in Glass (p. 8-19) in Viva Vetro! Glass Alive: Venice and America; curator Sarah Nichols, Pittsburgh: Carnegie Museum of Art.

Kirby, L.A. \& Anderson, C. (1979, March 28). News Release/Fact Sheet from Lou Anne Kirby \& Cheryl Anderson Seattle Parks \& Recreation, March 28, 1979. Seattle City Archives. Box 43, Folder 25. Department of Parks and Recreation, Planning, Construction and Maintenance Records. Record Series 5804-05, Seattle Municipal Archives.

Kirkpatrick, J. (2011, September). Panel discussion at the Tacoma Art Museum, September. (author's notes).

Klein, D. (1989). Glass: a contemporary art. New York: Rizzoli.

Komar, V., \& Melamid, A. (1990). Beyond Manhatten: Bayonne Manifesto. (C. Hansen, Ed.) Glass Art Society Journal, 1990 , 64-66.

Landry, C. (2000). The creative city: A toolkit for urban innovators. London, Earthscan Publications Ltd.

Lasking, David (2006). "The mystic artists: A Puget Sound quest," The New York Times, March 12, 2006, section: Cultured Traveler. Accessed from Lexis-Nexis Academic database.

Lehrer, U. \& Laidley, J. (2009). Old mega-projects newly packaged? Waterfront redevelopment in Toronto. International Journal of Urban and Regional Research. (786-803).

Lee, V. (2002). Dale Chihuly, Seattle. In V. Lee, Innovative interiors. New York, NY: Watson-Guptill.

Ley, D. (2003). Artists, aestheticisation and the field of gentrification. Urban Studies, 40:12 (2527-2544).

Lilly, D. (1990, July 10). Council Oks Condos For Steam Plant -- Sale To Be Negotiated. The Seattle Times .

Lindquist, G. (1990). Bertil Vallien. Stockholm: Carlsson Bokforlag. 
Lloyd, R. (2004). The neighborhood in cultural production: material and symbolic resources in the new Bohemia. City and Community. December, 3:4. (343-372).

Lynn, M. D. (2004). American Studio Glass, 1960 - 1990: An interpretive study. New York and Manchester: Hudson Hills Press.

MacColl, E.K. (1988). Merchants, money and power: the Portland establishment, 18431913. The Georgian Press.

Markusen, A. \& King, D. (2003). The artistic dividend: the arts' hidden contributions to regional development. Minneapolis: Humphrey Institute, University of Minnesota.

Markusen, A., Schrock, G., \& Cameron, M. (2004). The artistic dividend revisited. Minneapolis: University of Minnesota.

Markusen, A. (2004b). Targeting occupations in regional and community economic development." Journal of the American Planning Association. Summer, 70:3.

Markusen, A. (2005). Artists as Community Developers. ProgressivePlanning. Vol. 70:3. (Fall).

Markusen, A. \& Johnson, A. (2006). Artists' Centers: Evolution and impact on careers, neighborhoods and economies. Minneapolis: Project on Regional and Industrial Economics; Humphrey Institute of Public Affairs, University of Minnesota.

Markusen, A. (2006b). Urban development and the politics of the creative class: evidence from a study of artists. Environment and Planning A, vol. 38 (1921-1940).

Mathieson, K. (1990, November 18). Like any family, Pilchuck's has its differences. The Seattle Times .

Miles, M. (1997). Art, space and the city: Public art and urban futures. London: Routledge.

Miles \& Paddison. (2005). Introduction: The rise and rise of culture-led urban regeneration, Urban Studies, 42:5/6 (833-839).

Miller, B. (1991) Out of the fire: Contemporary glass artists and their work. San Francisco: Chronicle Books.

Miller, B. J. (1995). Why not? The art of Ginny Ruffner. Tacoma, Seattle, WA: Tacoma Art Museum/University of Washington Press.

Milne, V. (2000). In De Santillana, Anna Venini Diaz, 2000. Venini. Catalogue Raisonne, 1921 - 1986. Milano: Skira Editore.

Moody, Fred (1991). Bridge to the future: Can Tacoma really pull off its inspired civic and cultural agenda? Seattle Weekly 16, No. 16 (April 17, 1991); (cover \& 40-49). Accessed from 
http://www.feldmangallery.com/media/brodskyutkin/general\%20press/1991_bnu_ seattleweekly_moody.pdf on April 5, 2012.

Moody, F. (2003). Seattle and the demons of ambition: From boom to bust in the number one city of the future. New York: St. Martin's Griffin.

Moor, A. (1997). Architectural glass art: Form and technique in contemporary glass. New York: Rizzoli.

Moore, B. (2011, September). Panel discussion at the Tacoma Art Museum (author's notes).

Morley, J.M. (2011). Seattle's Pike Place Market (p. 218-241) In City Dreams, Country Schemes: Community and Identity in the American West. Brosnan, Kathleen A. \& Scott, Amy L., eds. Reno and Las Vegas: University of Nevada Press.

Murphy, J. (1981, June). Timber and glass. Progressive Architecture 62 (98).

Museum of Glass opens its doors (2002). Artweek, 33:6 (2), (July August 2002).

National Endowment for the Arts. (1993a). Regional and state trends for artists: 19701990. NEA. Washington, DC: NEA.

National Endowment for the Arts. (1993b). Artists in Metropolitan Areas - 1990. NEA. Washington, DC: NEA.

Netzer, D. (1978). The Subsidized Muse: Public Support for the Arts in the United States. Cambridge; New York: Cambridge University Press.

The New England Council (2000). The creative initiative: The role of the arts and culture in New England Economic competitiveness. A New England Council Report (June).

Nichols, S., Curator, (2007). Viva Vetro! Glass Alive! Venice and America. Pittsburgh, PA: Carnegie Museum of Art.

Noda, O. (1990). Niijima Glass Art Center, Japan. (C. Hansen, Ed.) Glass Art Society Journal, 1990 (68-69).

Northwest Designer Craftsmen (2012). History. Northwest Designer Craftsmen website, accessed August 8, 2012 from http://www.nwdc-online.org/history.html .

Office of Financial Management (2000). Profile of general demographic characteristics: 2000 (2000). Seattle's Population \& Demographics. Washington: Office of Financial Management. Accessed from http://www.ofm.wa.gov/pop/census2000/profiles/place/1605363000.pdf on November 1, 2012.

Oldknow, T. (1996). Pilchuck: A glass school. Seattle: Pilchuck Glass School in association with the University of Washington Press. 
Oldknow, T. (2005). 25 Years of New Glass Review. Corning, NY: Corning Museum of Glass.

O’Neil, P. (1970, October 2). The mood back home: five reports from American Hometowns. Seattle. LIFE Magazine, 69: 14, (31-32), (Oct. 2, 1970).

Parkman, P. \& Parkman, E. (1991). The rise of glass art: A personal view. Glass Art Society Journal, Seattle, WA (44-48).

Peck, J. (1985). Arts activists and Seattle's cultural expansion, 1954-65: Increasing in beauty as it increases in size. Pacific Northwest Quarterly, Portland, OR, July 1985 (82-94).

Peterson, T. (2001, August 14). Moveable feast: The art of being Bill Gates. Bloomberg Business Week.

Porter, Elaine (2001, June 14). City of destiny is Dale Chihuly's Seattle PostIntelligencer. Accessed from the Seattle PI website on April 5, 2012.

Porterfield, E. (10/23/2002). Artistic renaissance transforms Tacoma. Seattle PostIntelligencer. Accessed from the Seattle Post-Intelligencer website.

Pottinger (2008). The time of Lino (2008). DVD included with Frantz, Susanne K. (2008). Lino Tagliapietra in retrospect: A modern Renaissance in Italian glass. Tacoma: Museum of Glass, in association with University of Washington Press, Seattle.

Putnam, R.D. (2000) Bowling alone: The collapse and revival of American community. New York: Simon \& Schuster.

Quist, M. (1973). Looking ahead on Sunset's $75^{\text {th }}$ anniversary. Sunset Magazine, May 1973 (104 - 111): Menlo Park.

Ricke, H. \& Schmitt, E. (1997). Italian Glass: Murano-Milan, 1930 - 1970. Munich: Prestel.

Robinson, J.P. (1989). Assessing the artist's condition: some quantitative issues. In The Modern Muse: the Support and Condition of Artists. Swaim, R.C., editor. New York, N.Y.: ACA Books, American Council for the Arts.

Rooney, A. (1990). Two Decades of The Pilchuck Glass School. Glass Art Society Journal, Corning, NY (85-87).

Royal, R. (2011, September). Panel discussion at theTacoma Art Museum, September (author's notes).

Ruffner, G. (1990). President's Letter. Glass Art Society Journal, 1990 (106).

Ruffner, G. (2011). Quoted on the City of Seattle Office of Arts \& Cultural Affairs website, n.d. Accessed from http://www.seattle.gov/arts/publicart/permanent.asp?cat=2\&view=2\&item $=28 \& \mathrm{i}$ $\underline{\mathrm{mg}=0}$ on $9 / 27 / 11$. 
Rupp, J.M. (1992). Art in Seattle's public places: An illustrated guide. Unpublished manuscript. Seattle: University of Washington Press. Special Collections, University of Washington Libraries, Seattle, Washington.

Sale, R. (1976). Seattle past to present. Seattle: University of Washington Press.

Schuster, J.M. (2003). Mapping state cultural policy: the state of Washington. Chicago: University of Chicago Cultural Policy Center.

Seattle Parks \& Recreation Department (1979). Fact Sheet, 1979. Seattle: Seattle City Archives.

Public Art Ordinance details, 2011.

Serie, Patricia \& Adams, Diane (2003). Foss waterway cleanup kicks into high gear: Attention shifts to cleaning up below the waterline. Environmental Outlook 2003. Special Section, Seattle Daily Journal of Commerce, July 17, 2003. Accessed from http://www.djc.com/news/en/11146961.html March 26, 2012.

Simpson, Buster (1990). Water, vinegar, newspaper, and the public works. Glass Art Society Journal, 1990, p. 13-15.

Singerman, H. (1999). Art subjects: Making artists in the American University. Berkeley, CA: University of California Press.

Smallwood, Lyn (1991). Trestle: Ancient. A monument to impossible dreams. Seattle Weekly, April 17, 1991 (46-48). Accessed from http://www.feldmangallery.com/media/brodskyutkin/general\%20press/1991_bnu_ seattle\%20weekly_moody.pdf April 4, 2012.

Smith, R.L. (1976, February 6). Memo from Ruth L. Smith to C.M. Girtch regarding the Fire Arts Center. Seattle Parks \& Recreation, February 6, 1976. Seattle City Archives. Box 4, Folder 10. Department of Parks and Recreation, Pratt Fine Arts Center Records. Record Series 5810-01, Seattle Municipal Archives.

Smith, D. (1990, June 28). International Glass Art Center Proposed At Old Steam Plant -Council Panel Reviews Ideas. The Seattle Times.

Smithsonian Institution. Harvey Littleton's bio. Accessed from the Smithsonian website http://americanart.si.edu/search/artist_bio.cfm?ID=2961 11/28/10.

Sommer, C. (1998). Ballard's retail renaissance: Artists fleeing high rents bring hope for a neighborhood revival. Seattle Post-Intelligencer, February 4, 1998; Business, E1.

Spectrum Glass Company, Inc. (n.d.). A brief history of Spectrum. THE SCORE 0049, Spectrum Glass Company, Inc. Knowledgebase. Accessed from http://www.spectrumglass.com/stained-glass/archives/brief-history-ofspectrum.asp in February, 2012. 
Stansell, C. (2000). American moderns: Bohemian New York and the creation of a new century. New York: Metropolitan Books.

Statom, T. (1997). Artist Presentations. Glass Art Society Journal, Seattle (62).

Stevenson, D. (2003). Culture and the reimaging of cities. From Cities and Urban Cultures. Philadelphia: Open University Press.

Strom, E. (2000). Let's put on a show! Performing arts and urban revitalization in Newark, New Jersey. Journal of Urban Affairs, 21:4 (423-435).

Strom, E. (2001). Strengthening communities through culture. Art, Culture and the National Agenda, Center for Arts and Culture Issue Paper.

Strom, E. (2002). Converting pork into porcelain: Cultural institutions and downtown development. Urban Affairs Review, 38:1 (3-21), (September).

Strom, E. (2003). Cultural policy as development policy: Evidence from the United States. International Journal of Cultural Policy, 9:3 (247-263).

Sullivan, C.C. (2002). Specifications: Hearth and cone. Architecture, August, 2002, 91:8 (89-91).

Tacoma Planning Commission (2006). The Foss Waterway design and development plan: A comphrehensive plan element (amended Nov. 15, 2005). Tacoma: Community and Economic Development Department.

Tarzan, D. (1981, April 9). Glass artists don’t do windows. Seattle Times (E1).

Tepper, S.J. (2002). Creative assets and the changing economy. Journal of Arts Management, Law, and Society, 32:2 (159-168).

Thea Foss Development Authority (2010) Thea Foss Development Authority Website, http://www.theafoss.com/web2011/about.html )

Toso, G. (2000). Murano: A History of Glass. Verona: Arsenale Editrice.

Tsutakawa, M. (1979a, November 14). Arts notes, Seattle Times (C19).

Tsutakawa, M. (1979b, December 23). Arts notes (or Around Town?), Seattle Times (E7).

United States Environmental Protection Agency (2010) U.S. Environmental Protection Agency. "Region 10: The Pacific Northwest: Site description and cleanup process. Commencement Bay, Nearshore/Tideflats, Washington.” EPA ID\# WAD980726368. Accessed 3/31 from http://yosemite.epa.gov/r10/nplpad.nsf/88d393e4946e3c478825631200672c95/06 e1c0cda0d11fc285256594007559fd?OpenDocument

Updike, R. (1995, August 27). Capital of glass -- Pilchuck puts Seattle on the map. The New York Times. 
Updike, Robin (1995, March 9). Bridging Fantasy - Russian architects' vision for Tacoma is a work of art, whether or not it's built. Seattle Times, March 9, 1995. Accessed from the Seattle Times website on April 6, 2012.

Updike, R. (1995b, December 3). Man of glass - Dale Chihuly gains fame and fortune and then dreamed up a project that has him hanging chandeliers all over Europe. Seattle: Seattle Times, Sunday, December 3, 1995.

Updike, Robin (1997, March 16). Making a place for art to grow. Seattle Times.

UPI (1984). Tacoma Dome neon sculpture draws mixed reviews. Anchorage Daily News, August 1, 1984, p. 129. Anchorage, Alaska.

Vinh, T. (2002, April 6). Northwest art world loses benefactor. The Seattle Times.

Voelpel, D. (2005). Dan Voelpel Column. The News Tribune, (March 30). Tacoma, WA. (3/30/2005). Accessed from the EbscoHost database on April 16, 2009.

Voorhees, J. (1972, July 11). Let's hear it for the P.N.A.C. Seattle Times, July 11, 1972 (A15).

Waggoner, S. (2000, March/April). Sonja Blomdahl: Queen of Symmetry. Glass Art.

Wagonfeld, Judy (2005). 4 Tacoma: the dynamics of temporary. Public Art Review, Spring-Summer 2005, issue 32 (20-22). (Accessed from www.PublicArtReview.Org).

Warmus, W. (1996). Chihuly in Venice: Prologue. In Chihuly, D. Chihuly over Venice (1-16). Seattle: Portland Press.

Warmus, W. (1998). A fire in the studio: Harvey Littleton. Glass. Autumn, 1998. Article accessed from http://www.warmus.org/newpage2.htm on 6/13/11.

Wilkerson, Juli (2004), "From superfund site to wired city," Economic Development Journal, Winter, 2004, (8-15). Accessed 4/1/2012 from: http://www.iedconline.org/EDJournal/Winter_04/Wired_City.pdf .

Wojan, T.R. (2006). The emergence of rural artistic havens: A first look. Economic Research Service/USDA: Washington, DC.

Woronkowicz, J., Joynes, D.C., Frumkin, P., Kolendo, A., Seaman, B., Gertner, R., Bradburn, N. (2012). Set in Stone: Building America's New Generation of Arts Facilities, 1994 - 2008. Chicago: University of Chicago Cultural Policy Center.

Zielenziger, Michael (1984). In Tacoma, age-old question still persists: 'What's Art?' The Day, October 21, 1984, p. 11. New London, CT. Accessed from news.google.com/newspaper?nid=1915\&dat=19841021\&id= (get rest from bookmark.)

Zukin, S. (1982). Loft living: Culture and capital in urban change. Baltimore: Johns Hopkins University Press. 
Zukin, S. (1995). The cultures of cities. Cambridge: Blackwell Publishers.

\section{Interviews and oral histories}

Interviews with the author

Canlis, Leigh, 2011. Personal interview with the author, Seattle, Washington, August 23, 2011.

Courtney, Norman, 2011. Personal interview with the author, Seattle, Washington, August 9, 2011.

Huchthausen, David, 2011. Personal interview with the author, Seattle, Washington, July 23, 2011.

Moore, Benjamin P., 2010. Personal interview with the author, Seattle, Washington, February 11, 2010.

Stern, Ethan, 2011. Personal interview with the author, Seattle, Washington, 2011, July 20, 2011.

Traver, Willam, 2010. Personal interview with the author, Seattle, Washington, February, 2010.

$\underline{\text { Smithsonian Institution Oral Histories }}$

Littleton, Harvey (2001). Oral history interview with Harvey K. Littleton, 2001, Mar. 15, Archives of American Art, Smithsonian Institution. Interview conducted by Joan Falconer Byrd, in Spruce Pine, North Carolina.

Marioni, Paul. (2006) Oral history interview with Paul Marioni, 2006 Sept.18-19, Archives of American Art, Smithsonian Institution. Interview conducted by Mija Riedel, in Seattle, Washington.

Roberts, M.H. (1984). Oral history interview with Maurine Hiatt Roberts, 1984 Aug. 2931. Archives of American Art, Smithsonian Institution. Interview conducted by Ken Shores, in Portland, Oregon.

Ruffner, G. (2006). Oral history interview with Ginny Ruffner, 2006 Sept. 13-14, Archives of American Art, Smithsonian Institution. Conducted by Mija Riedel, at the Artist's home in Seattle, Washington. 
$\underline{\text { Interviews from archival sources }}$

Adamson, R. (1984, February 29). Interview with LaMar Harrington, Seattle. LaMar Harrington papers. Special Collections, University of Washington Libraries, Seattle, Washington.

Borris, M. (1984, September 14, 1984). Interview with LaMar Harrington, Parsons School of Design, New York City. LaMar Harrington papers. Special Collections, University of Washington Libraries, Seattle, Washington.

Elskus, A. (1983, September 14). Interview with LaMar Harrington, New York City. LaMar Harrington papers. Special Collections, University of Washington Libraries, Seattle, Washington.

Hauberg, John H. (1978, January 9). "John Hauberg, interviewed by Sue Ragan, Seattle, Washington, January 9, 1978. Archives of Northwest Art." John H. Hauberg papers. Special Collections, University of Washington Libraries, Seattle, Washington.

Vallien, B. (1983, July 15). Interview with LaMar Harrington. Stanwood. LaMar Harrington papers. Special Collections, University of Washington Libraries, Seattle, Washington. 


\section{Appendix A: Systems of Support}

$\underline{\text { Arts policies, educational programs, galleries and studios, 1960s-1980s }}$

Table A.1: Arts policies, programs and agencies

\begin{tabular}{|c|c|c|}
\hline Name & Date(s) & Notes \\
\hline $\begin{array}{l}\text { Washington State Arts } \\
\text { Commission (WSAC) }\end{array}$ & 1961 & Founded by or through efforts of Allied Arts \\
\hline Artists in Residence Program & $\begin{array}{l}\text { Early } \\
1970 \mathrm{~s}\end{array}$ & \\
\hline Art in Public Places Program & 1974 & $\begin{array}{l}\text { Washington State Arts Commission allocates } 1 / 2 \\
\text { of one percent of construction costs for state } \\
\text { buildings to art purchases }\end{array}$ \\
\hline ARTSPLAN & 1978 & $\begin{array}{l}\text { State arts plan, developed by the Arts Alliance of } \\
\text { Washington State }\end{array}$ \\
\hline Artist Trust & 1987 & $\begin{array}{l}\text { Provides technical assistance, information } \\
\text { resources, and advocacy services for artists; in } \\
\text { charge of WSAC fellowship awards and grants } \\
\text { for artist projects }\end{array}$ \\
\hline Arts Network of Washington State & & $\begin{array}{l}\text { Organization of arts organizations--provides } \\
\text { workshops and technical assistance to arts } \\
\text { organizations }\end{array}$ \\
\hline Arts Northwest & & $\begin{array}{l}\text { Supports performing artists; regional multi-state } \\
\text { organization--Washington, Oregon, Idaho }\end{array}$ \\
\hline Building for the Arts Program & & $\begin{array}{l}\text { Program in the Office of Community } \\
\text { development in the State Department of } \\
\text { Community, Trade and Economic Development; } \\
\text { promoted by Corporate Council for the Arts }\end{array}$ \\
\hline $\begin{array}{l}\text { Community Arts Development } \\
\text { Program }\end{array}$ & & $\begin{array}{l}\text { Provides technical assistance, information } \\
\text { resources (to arts organizations) }\end{array}$ \\
\hline Folk Arts Program & & $\begin{array}{l}\text { Provides artist fellowships, residencies and } \\
\text { heritage tours }\end{array}$ \\
\hline $\begin{array}{l}\text { King County Commission for the } \\
\text { Arts }\end{array}$ & & \\
\hline
\end{tabular}

Source: Schuster, J.M. (2003). Mapping state cultural policy: The state of Washington. 
Table A.2: Regional educational institutions with programs in glass, 1970s

\begin{tabular}{|l|l|l|l|}
\hline Name & Date(s) & Notes & Location \\
\hline Pilchuck Glass School & 1971 & $\begin{array}{l}\text { Dale Chihuly, Ruth Tamura, Anne } \\
\text { Gould Hauberg and John Hauberg; } \\
\text { Open house, last Sunday in July; Early } \\
\text { May=spring tour week; }\end{array}$ & Stanwood \\
\hline Pratt Fine Arts Center & 1978 & $\begin{array}{l}\text { Seattle Parks Dept., taught } \\
\text { "metalworking, ceramics, jewelry } \\
\text { making, and glassblowing" Miller, p. } \\
\text { 16; became a nonprofit }\end{array}$ & Settle \\
\hline $\begin{array}{l}\text { Central Washington } \\
\text { University }\end{array}$ & $1970 \mathrm{~s}$ & & Ellensburg \\
\hline $\begin{array}{l}\text { Everett Community } \\
\text { College }\end{array}$ & $1970 \mathrm{~s}$ & & Everett \\
\hline $\begin{array}{l}\text { University of Washington, } \\
\text { Seattle }\end{array}$ & $1970 \mathrm{~s}$ & Richard Marquis taught here briefly & Pullman \\
\hline $\begin{array}{l}\text { Pacific Lutheran } \\
\text { University }\end{array}$ & & & Tacoma \\
\hline $\begin{array}{l}\text { Western Washington } \\
\text { University }\end{array}$ & & & Bellingham \\
\hline
\end{tabular}

Table A.3: Artist studios, cooperatives, production studios, commercial studios ,1970s

\begin{tabular}{|c|c|c|c|}
\hline Name & Date(s) & Notes & Location \\
\hline Arts \& Crafts Cooperative & $\begin{array}{l}\text { 1971- } \\
\text { mid- } \\
1970 s\end{array}$ & $\begin{array}{l}\text { Steve Beasley, Roger Vines, Rob } \\
\text { Adamson }\end{array}$ & Seattle, WA \\
\hline Bullseye Glass Co. & 1974 & $\begin{array}{l}\text { Ray Ahlgren, Dan Schwoerer, Boyse } \\
\text { Lundstrom }\end{array}$ & Portland, OR \\
\hline The Glass Eye & 1977 & Rob Adamson, Sheila Blomdahl... & Seattle, WA \\
\hline Glasshouse Studio & 1972 & $\begin{array}{l}\text { Eric Brakken, Greg Englesby, Tom } \\
\text { Andre, Dave Stone }\end{array}$ & Seattle, WA \\
\hline Penberthy Electromelt & $\begin{array}{l}\text { 1960s- } \\
1970\end{array}$ & Roger Ek \& Spectrum Glass founders & Seattle, WA \\
\hline San Juan Art Glass & $1970 \mathrm{~s}$ & Rob Adamson & Seattle, WA \\
\hline Spectrum Glass & 1974 & $\begin{array}{l}\text { Jerry Rhodes, Don Hanson, Ron } \\
\text { Smids. }\end{array}$ & $\begin{array}{l}\text { Woodinville, } \\
\text { WA }\end{array}$ \\
\hline Uroboros Glass Studio & 1973 & Eric Lovell & Portland, OR \\
\hline
\end{tabular}




\section{Appendix B: Interviews}

Interview Questions

Themes and possible questions

\section{Studio Glass Community Research Project}

I. Biographical/demographic information

a. What is your full name?

b. Tell me about your work, title, collection, gallery, organization.

c. What year did you arrive in the Pacific Northwest? What brought you here?

d. Arts background? Education, dates of attendance, major fields of study?

\section{Training and Professional Development—conventional and lifelong learning} opportunities

a. Where/when did you first become involved in the arts?

b. Where/when did you first become interested in collecting/buying/selling studio glass?

c. Why did you become interested in studio glass?

d. Who encouraged/supported you in this endeavor/pursuit?

e. Where do you find information about artists that interest you?

f. How do you learn about new arts and media practices?

g. Can you name a person, institution or organization that you frequent or turn to for technical, business, or other advice/information about arts practices?

III. Communities/Networks - inward connections to other artists and the cultural sector; outward connections to non-artists and realms beyond the cultural sector

a. In what ways are you connected to the arts community? For example, do you socialize with other artists or take part in community arts activities? (Locally, regionally online, etc.)

b. What arts-related community or volunteer activities have you been involved with (i.e., cooperative gallery or arts workspace, informal or formal artist groups, nonprofit or for-profit cultural or community organizations, etc.)?

c. What local community organizations or volunteer activities are you involved with or have you been involved with in the past?

IV. Geographies of Art-Places/neighborhoods, cities regions, where artists congregate

a. Do you work at home primarily or have a separate studio/workspace

b. If yes, where is your studio/primary workspace and how long have you lived/worked there?

c. What places in or near the community are important to you now? When you first began your career?

d. Where else have you lived and worked in the region?

e. Why did you choose to locate your home/studio in these places? 
V. Validation/Demand/Markets

a. Where and when was your first show? How did it happen?

b. What organizations/galleries currently show your work?

c. Who is the audience for your work? How do they find out about it?

d. What are the local/regional/national media sources for reviews/publicity for your work?

e. What changes have you noted in media support over time?

f. Which media report/review/article brought you the most response from nonartists? From fellow artists?

g. How has the knowledge of and audience for your work changed over the past 10 years? Twenty years? Thirty years?

h. What do you think is needed to increase the appreciation of and audience for your work? Why?

VI. Material Support and Informational resources

a. Who do you turn to/have you turned to in the past for financial support? (Nonprofit, government, patrons, family, friends, other sources.)

b. What are your current major sources of funding for developing your arts practice? In 2000/1990s/1980s/1970s (if relevant)?

c. What organizations/funding sources have you applied to or have been awarded funding by in the past? Which of these was most important to your career?

VII. Future outlook, vision

a. What role do you think place (this community, neighborhood, city, region) has played in your success as an artist?

b. What are the biggest challenges to being an artist in the region now? Ten years ago? Twenty years ago?

c. What role do you think the arts/artists should play in the community?

d. What do you think has been the major contribution of artists to Seattle/Tacoma/Portland, the region?

e. What do you see as the future of studio glass in the region?

Thank you very much for taking the time to speak with me today. If you have any other comments please let me know.

\section{Additional Comments:}


Table B.1: Interviews conducted

\begin{tabular}{|l|l|l|}
\hline Name & Interview Date & Title or position \\
\hline Ray Ahlgren & 2010 & $\begin{array}{l}\text { Fireart Glass, Inc., owner, } \\
\text { Portland }\end{array}$ \\
\hline Leigh Canlis & August 23, 2011. & $\begin{array}{l}\text { Canlis Glass Co-owner, } \\
\text { Seattle }\end{array}$ \\
\hline Ed Carpenter & October 9, 2009 & Artist, Portland \\
\hline Norman Courtney & August 9, 2011 & Artist, Seattle \\
\hline Linda Ethier & October 6, 2009 & Artist, Portland \\
\hline David Huchthausen & July 23, 2011 & Artist, Seattle \\
\hline Benjamin P. Moore & February 11, 2010 & Artist, Seattle \\
\hline Ethan Stern & July 20, 2011 & Artist, Seattle \\
\hline William Traver & February, 2010 & $\begin{array}{l}\text { Gallery owner, Traver } \\
\text { Gallery }\end{array}$ \\
\hline
\end{tabular}




\section{Appendix C: Technical Appendix}

This appendix lists and describes the different glassmaking techniques discussed in this document. The definitions on this page were derived from the glossary available on the Tacoma Museum of glass website and the online dictionary on the Corning Museum of Glass website. ${ }^{39}$

Anneal

To cool glass slowly, typically in an annealing oven. If hot glass cools down too quickly, it can break.

$\underline{\text { Annealer }}$

An oven used to cool hot glass at a controlled temperature.

$\underline{\text { Batch }}$

Batch is the raw material used for making glass. It is mixed from silica, soda ash, and lime (or potash) and then melted, which produces glass.

Blowpipe

A hollow metal rod that is used to blow glass.

$\underline{\text { Cane }}$

A rod of glass made by melting glass, sometimes using multiple colors and clear glass to create patterns, and then stretching the glass at both ends while it is still hot.

\section{Cold working}

The name for a group of glassmaking techniques that are used on glass that is not heated. Cold working techniques include engraving, etching, grinding, polishing and cutting glass.

\section{Engraving}

A process of creating a surface design in glass by scratching the surface or using a grinding wheel.

\footnotetext{
${ }^{39}$ For a comprehensive list of glass terminology, refer to the online dictionary on the by the Corning Museum of Glass website at: http://www.cmog.org/research/glass-dictionary/all or the glossary on the Tacoma Museum of Glass webpage "Learn about glass" at: http://museumofglass.org.
} 
Etching

A process of cutting into glass using a chemical process, or with a tool, to create a surface design. ${ }^{40}$

\section{Facon de Venise}

A glass object made outside of Venice in the $16^{\text {th }}$ or $17^{\text {th }}$ century, in a style that looked like Venetian glass.

$\underline{\text { Frit }}$

A glass powder that is made up of "batch ingredients such as sand and alkali, which have been partly reacted by heating but not completely melted." ${ }^{41}$

Fusing

A process of heating glass pieces until they bond, or fuse, creating a single glass piece.

\section{$\underline{\text { Gaffer }}$}

The lead artist or artisan on a glassblowing team.

\section{Glassblowing}

A technique for producing hollow vessel shapes and forming glass objects by starting with a small clump of molten glass on one end of a hollow rod (a blowpipe), then blowing through the blowpipe to create a glass bubble, and using a variety of glassmaking techniques to add color, and pattern, and to produce the final shape.

\section{Glory hole}

The part of the glass furnace used for keeping the glass hot and reheating glass as it is being worked. The temperature in the glory hole is kept at a range between $2100^{\circ} \mathrm{F}$ and $2300^{\circ} \mathrm{F}$.

\section{Incalmo}

Incalmo is an Italian technique of joining two glass bubbles of the same diameter together to create an object.

${ }^{40}$ Glossary, Tacoma Museum of Glass, (http://museumofglass.org).

${ }^{41}$ Corning Museum of Glass dictionary (http://www.cmog.org/research/glass-dictionary/f ). 
Laminated glass

Laminated glass is created by joining two layers of glass by heating them or by applying adhesive between the layers.

\section{Lampworking}

Lampworking, also called flameworking, is a technique the uses a small torch to heat up glass rods until they are soft enough to form into new shapes and artwork.

Lip wrap

A decorative technique where a glass thread is applied around the rim of a glass vessel shape to create a contrasting line of color.

\section{$\underline{\text { Marver }}$}

A flat surface that is used to roll hot glass as it is being shaped, to keep it smooth or to pick up decorative elements.

$\underline{\text { Mold }}$

A hollow form that is used to shape or to create textures on molten glass, which can be poured into the mold, or blown into the mold.

$\underline{\text { Murano }}$

A group of islands that are part of Venice, Italy. Murano is known for its glassmaking tradition since the $13^{\text {th }}$ century, when glassmakers on the island of Venice were relocated to Murano to reduce the risk of fires caused by the glass furnaces.

\section{$\underline{\text { Murrine }}$}

The murrine technique involves creating long glass rods (canes) composed of different glass colors, and then slicing the canes to reveal flat disks with complex patterns.

\section{$\underline{\text { Polyvitro }}$}

A "polyurethane material developed to withstand the elements" that Chihuly sometimes used in place of glass for large-scale projects, including the Crystal Towers on the Chihuly Bridge of Glass in Tacoma (Chihuly.com, 2011). 
Punty/ Pontil

A metal rod that is used to hold a blown glass object as it is being created.

\section{$\underline{\text { Sandcasting }}$}

The process of creating cast glass objects by pouring molten glass using a mold made of sand.

\section{Slumping}

A fused glass (or kilnforming) technique where glass pieces are put into a kiln on top of a curved mold, and heated until the glass melts or "slumps" over the mold. 